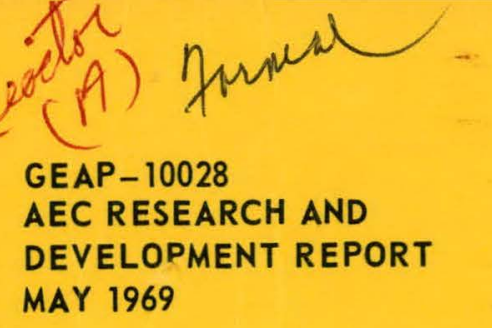

\title{
SODIUM-COOLED REACTORS
} FAST CERAMIC REACTOR DEVELOPMENT PROGRAM THIRTIETH QUARTERLY REPORT FEBRUARY-APRIL 1969

\author{
U.S. ATOMIC ENERGY COMMISSION \\ CONTRACT AT (04-3)-189 \\ PROJECT AGREEMENT 10
}

BREEDER REACTOR DEVELOPMENT OPERATION

\section{GENERAL ELECTRIC SUNNYVALE, CALIFORNIA}




\section{DISCLAIMER}

This report was prepared as an account of work sponsored by an agency of the United States Government. Neither the United States Government nor any agency Thereof, nor any of their employees, makes any warranty, express or implied, or assumes any legal liability or responsibility for the accuracy, completeness, or usefulness of any information, apparatus, product, or process disclosed, or represents that its use would not infringe privately owned rights. Reference herein to any specific commercial product, process, or service by trade name, trademark, manufacturer, or otherwise does not necessarily constitute or imply its endorsement, recommendation, or favoring by the United States Government or any agency thereof. The views and opinions of authors expressed herein do not necessarily state or reflect those of the United States Government or any agency thereof. 


\section{DISCLAIMER}

Portions of this document may be illegible in electronic image products. Images are produced from the best available original document. 


\section{SODIUM-COOLED REACTORS \\ FAST CERAMIC REACTOR DEVELOPMENT PROGRAM}

Thirtieth Quarterly Report

February - April 1969

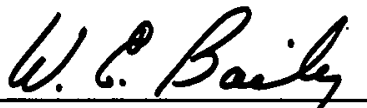

W. E. Baily, Project Engineer

Fast Ceramic Reactor Development Program

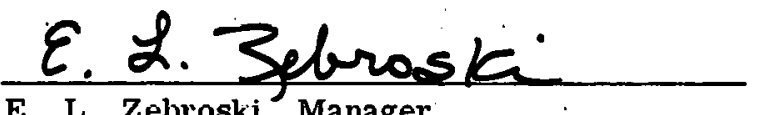

E. L. Zebroski, Manager

Sodium Reactor Technology

Prepared for the

United States Atomic Energy Commission

Under Contract No. AT(04-3)-189

Project Agreement No. 10

Printed in U.S.A. Available from the

Clearing House for Federal Scientific and Tecbnical Information

National Bureau of Standards, U.S. Department of Commerce

Springfield, Virginia

Price: $\$ 3.00$ per copy

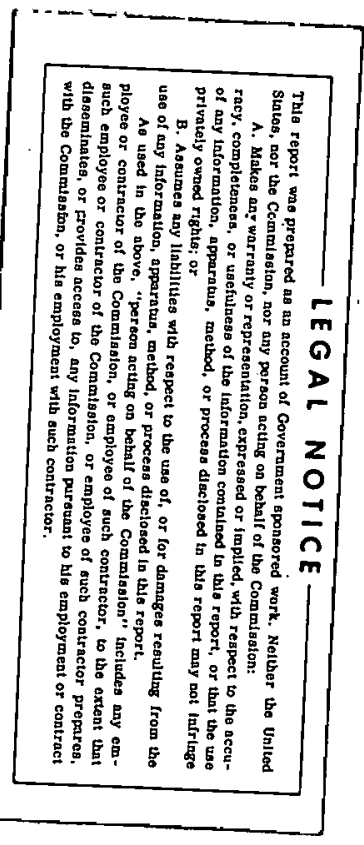




\section{LEGAL NOTICE}

This report was prepared as an account of Government sponsored work. Neitber the United States, nor the Commission, nor any person acting on bebalf of the Commission:

A. Makès any warranty or representation, expressed or implied, with respect to the accuracy, completeness, or usefulness of the information contained in this report, or that the use of any information, apparatus, metbod, or process disclosed in this report may not infringe privately owned rights; or

B. Assumes any liabilities witb respect to the use of, or for damages resulting from the use of any information, apparatus, method, or process disclosed in this report.

As used in the above, "person acting on bebalf of the Commission" includes any employee or contractor of the Commission, or employee of such contractor, to the extent that sucb employee or contractor of the Cammission, or employee of such contractor prepares, disseminates, or provides access to, any information pursuant to bis employment or contract with the Commission, or bis employment with such contractor. 


\section{TABLE OF CONTENTS}

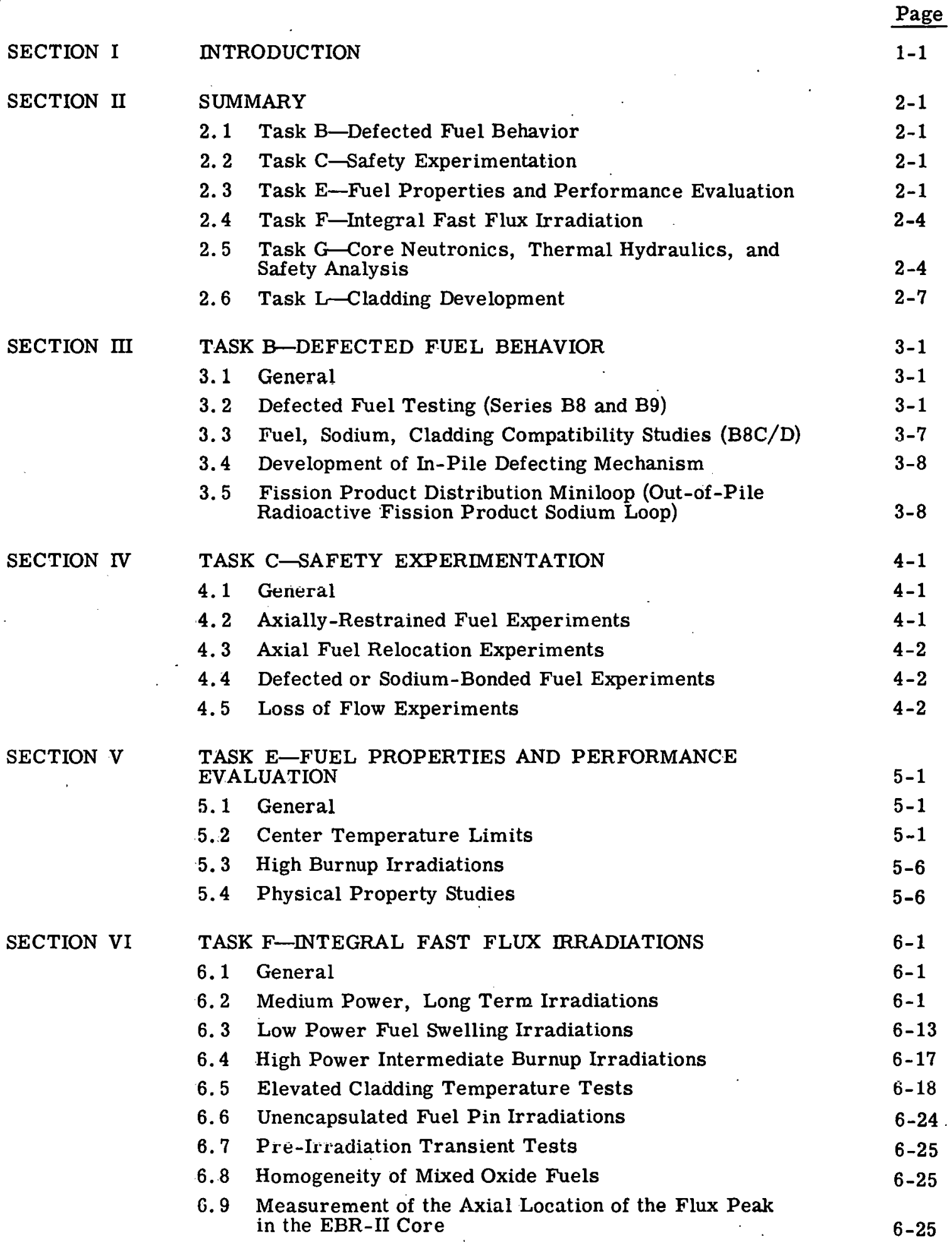


TABLE OF CONTENTS (Continued)

Page

SECTION VII TASK G-CORE NEUTRONICS, THERMAL HYDRAULICS AND SAFETY ANALYSIS

$7-1$

7. 1 General

$7-1$

7.2 Nuclear Data and Group Constants

$7-1$

7.3 Core Analysis

$7-5$

7.4 Transient and Safety Analysis

$7-7$

7.5 Fuel Analysis and Thermal Hydraulics

$7-15$

SECTION VIII

TASK L-CLADDING DEVELOPMENT

$8-1$

8. 1 General

$8-1$

8.2 Materials Irradiation Performance

$8-1$

8. 3 Materials Management and Specification Program

8-10

REFERENCES

$-1-$

APPENDIX

PRIOR REPORTS

$-3-$

CONTRIBUTORS

$-7-$ 


\section{LIST OF ILLUSTRATIONS}

Figure

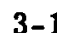

3-2

3-3

$3-4$

$3-5$

3-6

4-1

4-2

4-3

4-4

5-1

5-2

5-3

$5-4$

5-5

5-6

6-1

6-2

$6-3$

$6-4$

6-5

6-6

6-7

$6-8$

6-9

6-10

6-11

6-12

6-13

6-14

6-15

6-16

$6-17$

6-18

6-19
Title

Page

$\mathrm{X}$-ray Showing Sodium Level in B9A

3-2

3-3

3-4

3-6

3-9

$3-10$

Miniloop Prior to Insertion of Fuel Specimen

$4-3$ Specimen C4A)

FORE-II Rod Ejection and Accident

4-4

Comparison of FORE-II Calculations for a Rod-Ejection Accident versus THTD Calculations for Fuel Specimen C4A in TREAT

$\mathrm{Na}-\mathrm{Fill}$ System

$4-5$

4-6

Calibration Data of Irradiated W5Re/W26Re Thermocouples

$5-2$

Photomicrograph and Beta-Gamma Autoradiograph from Capsule E1J-7

$\int_{900}^{\mathrm{T}} \mathrm{kd} \theta$ As a Function of Temperature

$5-3$

Profilometer Traces of Pins E2F and E2Q at First Interim

$5-5$

Examination at 8900 and $9400 \mathrm{MWd} / \mathrm{Te}$, Respectively

$5-7$

Gamma Scan of Capsule E2P (8900 MWd/Te) and E2Q (9400 MWd/Te)

$5-8$

Creep Rate versus Stress for Stoichiometric $\mathrm{UO}_{2}$

$5-10$

Gross Gamma Scan of Fuel Pin F2H

6-3

$6-4$

$6-5$

$6-6$

$6-7$

$6-8$

Profilometer Traces of Fuel Pin F2T

$6-9$

Traces of Fuel Pin F2C

Relationship between Pellet o. d. and the Fuel Pin Profilometer Traces of Fuel Pin F2H

$6-10$

$6-11$

Traces of Fuel Pin F2R

$6-12$

Traces of Fuel Pin F2T

$6-14$

$6-15$

$6-16$

$6-20$

Diametral Gap

Group F4, Fuel Axial Expansion versus the Minimum As-Fabricated Diametral Gap in Top Inch of Fuel Column

$6-20$

$6-22$ Capsule (Solid-Pellet-Fueled Pins F4A, F4E, F4G, F4H, and F4J)

$6-23$

$6-27$

$6-27$ 


\section{LIST OF ILLUSTRATIONS (Continued)}

\begin{tabular}{|c|c|c|}
\hline Figure & Title & Page \\
\hline $7-1$ & $\mathrm{Pu}-239$ Fission Cross Sections between 0.25 and $20 \mathrm{keV}$ & $7-3$ \\
\hline $7-2$ & $\mathrm{Pu}-239 \alpha(E)$ between 0.25 and $20 \mathrm{keV}$ & $7-4$ \\
\hline $7-3$ & Effectiveness of FREADM Time Step Control & $7-10$ \\
\hline $7-4$ & $\begin{array}{l}\text { System Diagram for a Specified Heat Input to the Coolant in an } \\
\text { Axial Section }\end{array}$ & $7-12$ \\
\hline $7-5$ & Step Decrease in Flow at Constant Power & $7-13$ \\
\hline $7-6$ & Step Increase to Coolant Inlet Temperature & $7-14$ \\
\hline $7-7$ & Step Flow Loss to $50 \%$ Flow, Average Coolant Temperature & $7-16$ \\
\hline $7-8$ & Step Flow Loss to $5 \%$ Flow, Coolant Average Temperature & $7-17$ \\
\hline $7-9$ & Nusselt Number Variation & $7-18$ \\
\hline $7-10$ & $\begin{array}{l}\text { Outside Cladding Wall Temperature Profiles, Variation with } \\
\text { Pitch-to-Diameter Ratio }\end{array}$ & $7-19$ \\
\hline $7-11$ & $\begin{array}{l}\text { Outside Cladding Wall Temperature Profiles, Variation with } \\
\text { Peclet Number }\end{array}$ & $7-20$ \\
\hline $7-12$ & $\begin{array}{l}\text { Clad Swelling Normalized Against Fluence Effect versus Reciprocal } \\
\text { Temperature. Equation Fits to Data Assuming }\end{array}$ & \\
\hline & $\ln \left(\frac{-\Delta \rho}{\rho}\right)$ Dependent Variable & $7-23$ \\
\hline $7-13$ & $\begin{array}{l}\text { Clad Swelling Normalized Against Fluence Effect versus Reciprocal } \\
\text { Temperature. Equation Fits to Data Assuming in F Dependent Variable }\end{array}$ & $7-24$ \\
\hline $7-14$ & $\begin{array}{l}\text { Clad Swelling Normalized Against Temperature Effect versus Fluence. } \\
\text { Equation Fits to Data Assuming } \ln \left(\frac{\Delta \rho}{\rho}\right) \text { Dependent Variable }\end{array}$ & $7-26$ \\
\hline $7-15$ & $\begin{array}{l}\text { Clad Swelling Normalized Against Temperature Effect versus Fluence. } \\
\text { Equation Fits to Data Assuming In F Dependent Variable }\end{array}$ & $7-27$ \\
\hline $7-16$ & Correlation Data Bank & $7-29$ \\
\hline $7-17$ & Fuel Pin Diametral Deformation & $7-30$ \\
\hline $7-18$ & Trial Correlation Functions & $7-32$ \\
\hline $7-19$ & Final Correlation Compared with F2T Data & $7-33$ \\
\hline $7-20$ & $\begin{array}{l}\text { Change in Center Temperature with Change in Temperature, } \\
\text { Defining Three Fuel Density Regions }\end{array}$ & $7-34$ \\
\hline $7-21$ & $\begin{array}{l}\text { Change in Central Void Radius with Change in Temperature, } \\
\text { Defining Three Density Regions }\end{array}$ & $7-34$ \\
\hline $7-22$ & $\begin{array}{l}\text { Representation of Fuel Microstructure for a Pin at } 16 \mathrm{~kW} / \mathrm{ft} \text { at a } \\
\text { Low and High Burnup }\end{array}$ & $7-35$ \\
\hline $7-23$ & $\begin{array}{l}\text { Predicted Magnitude and Location of Gaseous Fuel Swelling as a } \\
\text { Function of Linear Power Level }\end{array}$ & $7-36$ \\
\hline $7-24$ & $\begin{array}{l}\text { Effect of Fuel Plasticity on the Predicted Total Fuel Swelling of a } \\
\text { Pin Operating at } 8 \mathrm{~kW} / \mathrm{ft}\end{array}$ & $7-37$ \\
\hline $7-25$ & $\begin{array}{l}\text { Comparison of Total Predicted Swelling from Gaseous and Solid } \\
\text { Fission Products to that Predicted for Solid Fission Products Alone }\end{array}$ & $7-37$ \\
\hline $8-1$ & L-10 Capsule Specimens & $8-3$ \\
\hline $8-2$ & The L-10 Capsules Photographed Through Hot Cell Window & $8-5$ \\
\hline $8-3$ & High Resolution Gamma Scan of Capsule L10-C Sentinels & $8-7$ \\
\hline $8-4$ & Description of L-10 Temperature Sentinels & $8-9$ \\
\hline $8-5$ & $\begin{array}{l}\text { Comparative Metallography on Type-304H Stainless Steel: } \\
\text { Assessment-of-Vendor Tubing }\end{array}$ & $8-11$ \\
\hline $8-6$ & $\begin{array}{l}\text { Comparative Metallography on Type-316H Stainless Steel: } \\
\text { Assessment-of-Vendor Tubing }\end{array}$ & $8-12$ \\
\hline
\end{tabular}




\section{LIST OF ILLUSTRATIONS (Continued)}

Figure

Title

$\underline{\text { Page }}$

$8-7$

$1300^{\circ} \mathrm{F}$ Creep Curves for Type-304 Capsule Tubes

$8-16$

$8-8$

$1300^{\circ} \mathrm{F}$ Constant Strain Curves for Type-304 Capsule Tubes

$8-18$

$8-9$

Isochronal Biaxial Stress-Strain Curves for Type-304 Capsule Tubes

$8-19$

8-10

Simplified Calculation Flow Diagram

8-21

vii/viii 


\section{LIST OF TABLES}

Table

Title

Page

2-1

$2-2$

2-3

2-4

2-5

$3-1$

3-2

3-3

3-4

3-5

5-1

6-1

6-2

6-3

$6-4$

7-1

7-2

7-3

$7-4$

8-1

8-2

8-3

$8-4$

8-5

$8-6$

Task B-Summary of Current Mixed Oxide Capsule Irradiations

Comparison of Design and Operating Conditions of Forced Convection Capsule B9A

Values of $\left\langle\Gamma_{\mathrm{f}}\right\rangle_{\mathrm{J}=1}^{\ell=0}(\mathrm{eV})$ Derived from Total and Fission Cross Section and Alplia Measurements

Tubular Test Section Swelling in L-10 Capsules

$8-8$

Dimensional and Ultrasonic Assessment of Tubing-Comparison of Vendors 


\section{SECTION I}

\section{INTRODUCTION}

The Fast Ceramic Reactor Development Program is an integrated analytical and experimental program directed toward the development of fast reactors employing ceramic fuels, with particular attention to mixed plutoniumuranium oxide. Its major objectives are:

a. Development of a reliable, high perform-

- ance fast reactor having nuclear characteristics which provide stable and safe operation, and

b. Demonstration of low fuel cycle cost capability for such a reactor, primarily through achieving high burnup of ceramic fuels operating at high specific power.

Progress during the period February 1 through April 1969 on the currently active tasks of this program is described in subsequent sections.

This is the thirtieth in a series of quarterly progress reports written in partial fulfillment of Contract AT(04-3)-189, Project Agreement No. 10, between the United States Atomic Energy Commission and the General Electric Company. Prior progress reports to the Commission are listed in the Appendix. 
SECTION II

\section{SUMMARY}

\subsection{TASK B-DEFECTED FUEL BEHAVIOR}

The first operation of an integral sodium loop in GETR (GE Test Reactor) was completed and fully met all of its test objectives. The B9A test was a coaxial, pumped-sodium loop ("forced convection capsule") which carried two predefected mixed-oxide pins to a scheduled burnup of over $7000 \mathrm{MWd} / \mathrm{Te}$. Operation was sustained at a peak power of $20 \mathrm{~kW} / \mathrm{ft}$ (12 fps velocity, $1040^{\circ} \mathrm{F}$ outlet temperature) for over $85 \%$ of the operating cycle. An apparent voltage anomoly in a flowmeter (previously reported) has been traced to a magnet calibration error; actual flow, temperatures, and power level were as specified. The successful development and operation of the initial forced circulation capsule is regarded as an important milestone with benefits to both the fuel and safety areas of the LMFBR (Liquid Metal Fast Breeder Reactor) development. It provides a capability for timely and relatively low-cost testing of the behavior of failed fuel and of the propagation of failure along a single pin and to adjacent pins. Extension of this capability to cover a wide variety of casualty condition tests appears feasible.

The miniloop (fission product distribution loop) successfully completed its operation exposing irradiated mixed-oxide fuel to flowing sodium at $1100^{\circ} \mathrm{F}$ for 22 hours.

Current Task B irradiation experiments are summaried in Table 2-1.

\subsection{TASK C-SAFETY EXPERIMENTATION}

Axially restrained fuel specimens $\mathrm{C4G}$ and $\mathrm{C} 4 \mathrm{H}$ have completed irradiation in EBR-II and are awaiting return shipment for interim nondestructive examination.
Installation of the high pressure sodium fill system was begun and initial operation is scheduled for early next quarter.

Table 2-2 summarizes the current status of the inpile experimental program for Task C.

A comparison of recent TREAT (Transient Reactor Test Facility) experiments with a simulated reactor accident (rod-ejection followed by scram) has been made using THTD (Transient Heat Transfer Model D) to analyze the test, and FORE- $\Pi$ for the reactor. Excellent agreement is found between the instantaneous temperatures of fuel, cladding, and sodium for the two systems. It is concluded that the TREAT experiments in Task $C$ provide adequate simulation of a large class of severe reactor accidents.

\subsection{TASK E-FUEL PROPERTIES AND PERFORMANCE EVALUATION}

Calibration of an irradiated thermocouple (W-5 Re/W-26 Re) exposed in GETR along with instrumented capsule E1AA showed an irradiation-induced change in emf readings, implying that the actual temperatures were $1350^{\circ} \mathrm{C}$ when the indicated valve was $1275^{\circ} \mathrm{C}$. This change in calibration will require a reevaluation of data on E1AA.

A determination of $\int_{1100^{\circ} \mathrm{C}}^{\mathrm{Tm}} \mathrm{kd} \theta$, for stoichiometric mixed oxide fuel in pin E1J-7 gave a value of about $37 \mathrm{~W} / \mathrm{cm}$, which is consistent with previous values.

Definite increases in diameter were observed at low burnups on capsules E2P and E2Q. The capsules were clad with 15- and 
TABLE 2-1

TASK B-SUMMARY OF CURRENT MIXED OXIDE CAPSULE IRRADIATIONS

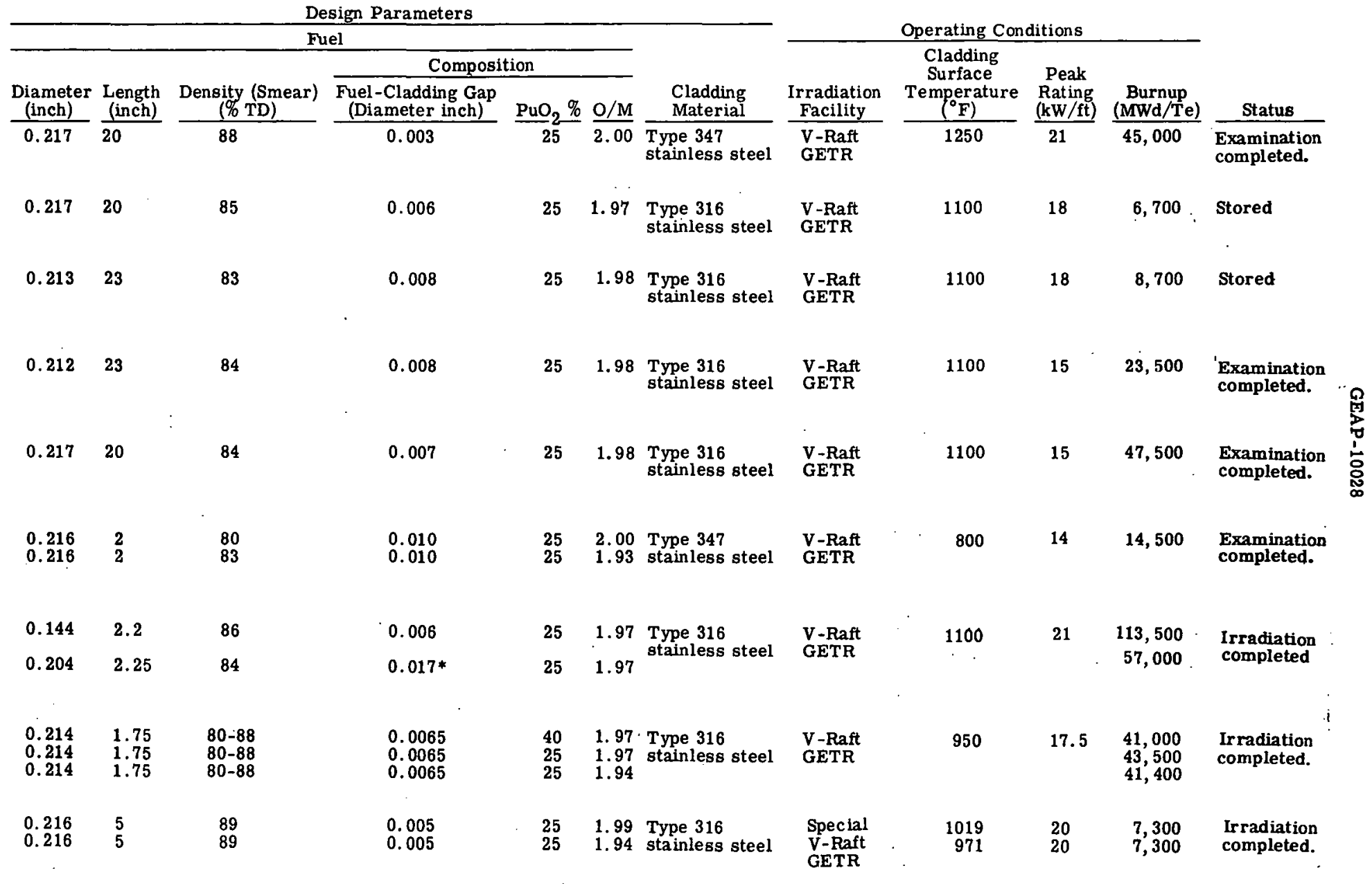


- GEAP-10028

TABLE 2-2

TASK C-CURRENT EXPERIMENTAL TEST SERIES

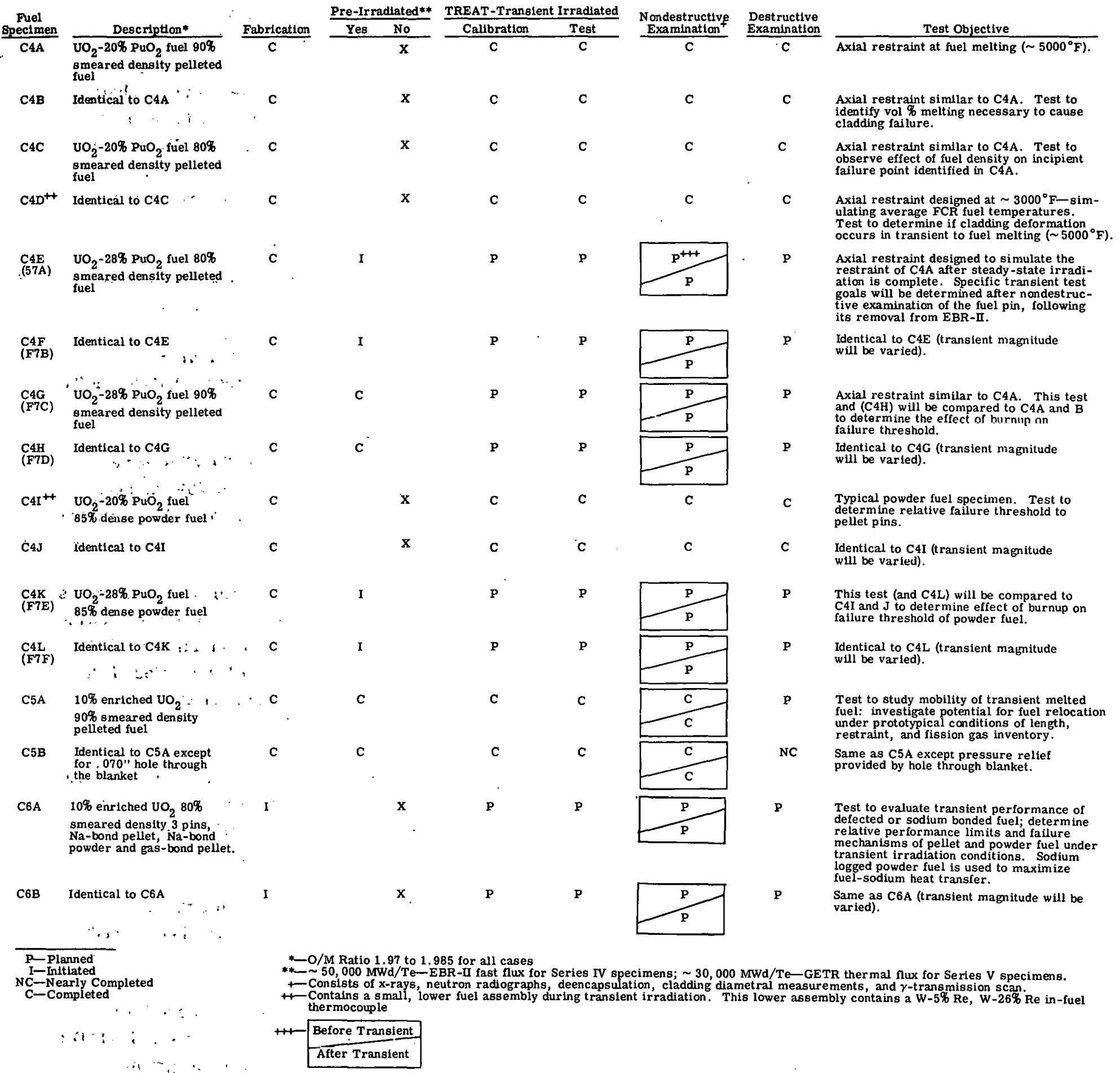


10-mil Type-316 stainless-steel tubing, respectively, and were assembled with a $1 \pm 0.5$ mil fuel-cladding gap. The fuel reached burnups of 8900 (E2P) and 9400 (E2Q) MWd/Te. Ridging was also noted in the cladding of both pins, corresponding to pellet interfaces.

The irradiation of samples to compare solid, annular, and powder fuels was terminated after attaining 130,000 MWd/Te. These capsules, E5C, E5D, and E5E, contain 16-inch fuel lengths.

An improved expression describing the creep of $\mathrm{UO}_{2}$ as a function of temperature, stress, grain size, and density has been developed.

A summary of Task E's current inpile test program is shown in Table 2-3.

\section{4 TASK F-INTEGRAL FAST FLUX IRRADIATION}

Three subassemblies of unencapsulated fuel pins (37 pins each, designated Group F9A, Group F9C, and Group F9D) were inserted into the EBR-II core. These are the first unencapsulated fuel pins of 0.250 -inch diameter to be irradiated under this program.

The 16 unencapsulated pins of $0.290-$ inch diamcter fuel pins continued to be irradiated in the EBR-II (Group F3A). Peak burnup for these pins was 23,300 MWd/Te as of April 30, 1969.

The 37 pins of Group F9B (0.250-inch diameter, unencapsulated) and the 19 pins of Group F5 (0.250-inch diameter, encapsulated) were shipped to the EBR-II site and are undergoing pre-insertion inspection.

An interim examination of the seven capsules in Group 4 was successfully completed at $57,000 \mathrm{MWd} / \mathrm{Te}$. A request to continue irradiation of all seven capsules to $80,000 \mathrm{MWd} / \mathrm{Te}$ was granted.

Microprobe and $\alpha$-autoradiograph examination of three samples of unirradiated mixed oxide fuel were performed and minor inhomogeneities were observed. High resolution $\alpha$-autoradiography was used which is capable of resolving alpha-rich regions as small as 30 microns.

Table 2-4 notes the current status of the Task F irradiation test program.

\subsection{TASK G-CORE NEUTRONICS, THERMAL HYDRAULICS, AND SAFETY ANALYSIS}

A set of statistically "best" s-wave resonance parameters for $\mathrm{Pu}-239$ has been fitted using independent sets of high-resolution experimental data.

Interface data for computational modules in the areas of reactor kinetics, fluid mechanics, solid mechanics, and shielding are being specified in conjunction with activities of the ad hoc committee on Computer Code Coordination.

A comparison of cross section adjusting methods was done in cooperation with Pacific Northwest Laboratories (PNL)' and Argonne National Laboratory (ANL).

The principle routine for the fuel management code FUMBLE has been coded and is being checked out.

Test cases for both small and large problems were successfuly run using DOT2DB, which is a two dimensional multi group transport diffusion code.

Conversion of the BISYN code to FORTRAN-IV has been completed as requested. 
Design Parameters

Fue

$\begin{aligned} \frac{\text { Capsule }}{\text { E1AA }} & \begin{array}{l}\text { Description } \\ \text { Continuous in-pile thermal } \\ \text { conductivity. }\end{array} \\ \vdots & \\ \text { E1B-1: } & \text { Gap conductivity. Four pins } \\ 2 & \text { with diametral gaps ranging } \\ 3: & \text { from } 2 \text { to } 10 \text { mils. } \\ 4: & \end{aligned}$

$\begin{array}{lll}\text { E1E } & \text { Relative smeared conductivity } 0.218 \\ \text { E1F } & \text { at high burnup irradiation to } & 0.218\end{array}$ high burnup and rabbit test E1F.

E1J-1 Effect of restructuring on smeared thermal

0.217

Effect of restructuring

smeared thermal

conductivity

E1J-3 Effect of restructuring on smeared thermal conductivity.

E1J-4 Effect of restructuring on smeared thermal conductivity.

E1J-5 Effect of restucturing on smeared thermal conductivity.

E1J-6 Effect of restructuring on smeared thermal conductivity.

E1J-7 Effect of restructuring on smeared thermal smeared the

E1J-8 Effect of restructuring on smeared thermal conductivity. E1J-9:- Effect of restructuring on conductivitv.

E2C-1 High burnup. Reference fuel 0.218 2 irradiated at near reference 0.218 thermal conductivity.

E2D-1 High burnup. Reference fuel 0.150 irradialed al mear reference 0.150 thermal conditions. Two pins in each capsule

E2E : : Fuel swelling. Four separate 0.100 $\begin{array}{lll}\text { F } & \text { pins at three power levels. } & 0.100 \\ \text { G } & 0.100 \\ \text { H } & 0.100\end{array}$

$\begin{aligned} \text { E2J-1 High burnup. Annular versus } & 0.218 \\ 2 & \text { solid pellet. }\end{aligned}$

E2P - Effect of radial restraint 0.219 on fuel swelling. (15 mil tubing)

E2Q Effect of radial restraint 0.229 on fuel swelling. (10 mil tubing)

E5A-1 Powder and pellet fuel

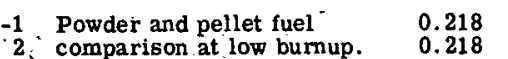

$\therefore \quad \therefore \quad \therefore$

E5B-1 Powder and pellet fuel $\quad 0.218$

2 comparison at high buimup. 0.218

-1 Powdér, pellet, and annular 0.215

1. fuel rnmparison at high burnup.

$\therefore$. : :

E5D-1 Powder, pellet, and annular Powder fuel comparison at high burnup.

E5E-1 Powder, pellet, and annular 0.215 Powder, pellet, and annular (Annular)
fuel comparison at high

$\therefore$ burnup. versus burnup.

16.090 .5
5.092 .0

Fuel Density, \% TD Composition $\frac{\text { (inch) }}{6.0} \frac{\text { Pellet }}{92.0} \frac{\text { Smeared }}{91.0} \frac{\mathrm{PuO}_{2} \%}{20} \frac{\mathrm{O} / \mathrm{M}}{1.97}$

.97

1.2595 .8

$1.25 \quad 94.2$

1.25
1.25

92.5
94.2
85.0

$\begin{array}{llll}1.9 & 94.7 & 94.5 & 20\end{array}$

1.98
1.98

1.98
1.98
1.98

$\begin{array}{ll}2.00 & \text { Type } 347 \\ 2.00 & \text { stainless }\end{array}$ stainless
steel

1.93 Type 316 stainless
steel

$\begin{array}{llll}5.0 & 92.0 & 92 & 25\end{array}$

1. 93 Type 316 stainless steel

$\begin{array}{llll}5.0 & 92.0 & 92 & 25\end{array}$

1.93 Type 316 stainless steel

$\begin{array}{llll}5.0 & 92.0 & 92 & 25\end{array}$

1.97 Type 316 stainless

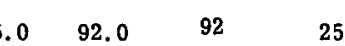

1.97 Type 316 stainless steel

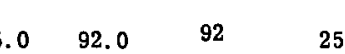

2.00 Type 316 stainless stainles
steel

$\begin{array}{llll}.0 & 92.0 & 92 & 25\end{array}$

2. 00 Type 316 stainless stainless
steel

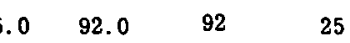

$2.00 \quad \begin{aligned} & \text { Type } 316 \\ & \text { stainless }\end{aligned}$ stainless
steel

$\begin{array}{llll}5.0 & 92.0 & 92 & 25\end{array}$

2.00 Type 316

stainless
steel

$5 \quad 84$

$\begin{array}{llll}5 & 84.5 & 82.2 & 25 \\ 5 & 94.3 & 91.4 & 25\end{array}$

$\begin{array}{ll}2.00 & \text { Type } 347 \\ 2.00 & \text { stainless }\end{array}$ steel

$\begin{array}{llll}5 & 90.1 & 87.5 & 25 \\ 5 & 91.6 & 88.3 & 25\end{array}$

2.00 Type 316A statnless steel

$2.00 \quad$ Type 304

2.00 stainless

2.00 steel

$\begin{array}{ll}5 & 90.4 \\ 5 & 96.0\end{array}$

89.5

$1.98 \quad$ Type 316 $1.98 \substack{\text { stainless } \\ \text { stepl }}^{1.98}$

$\begin{array}{rrrrrr}2.0 & 92.0 & 91.0 & 25 & 1.98 & \text { Type } 316\end{array}$

stainless steel

$\begin{array}{llllll}2.0 & 92.0 & 91.0 & 25 & 1.98 & \text { Type } 316\end{array}$ stainless steel

$\begin{array}{lllllll}4.9 & 86.8 & 84.3 & 25 & 2.00 & \text { Type } 347\end{array}$

$\begin{array}{llll}4.9 & 86.8 & 84.3 & 25 \\ 4.9 & 84.1 & 84.1 & 25\end{array}$

$\begin{array}{ll}2.00 & \text { Type } 347 \\ 2.00 & \text { stainless }\end{array}$ steel

$\begin{array}{llll}4.9 & 85.8 & 84.1 & 25 \\ 4.9 & 84.1 & 84.1 & 25\end{array}$

2.00. Type 347

2.00 stainless

steel

$\begin{array}{llll}16.0 & 87.5 & 82.9 & 25\end{array}$

1.96 Type 316 stainless

$\begin{array}{llll}16.0 & 81.8 & 81.8 & 25\end{array}$

83.3 25

1.97

Type 316 stainless
steel

$\begin{array}{lll}10.0 & 92.0 \quad 87.1 & 25\end{array}$

$1.96 \quad \begin{gathered}\text { Type } 316 \\ \text { stainless }\end{gathered}$ steel

1. 97 Type 316 stainless steel

GETR

GETR

GETR

GETR
GETR

MTR

MT

GETR

- GETR

GETR

GETR

GETR

GETR

GETR

GETR

(1)

GETR

GETR

GETR

GETR

MTR

MTR

MTR

GETR

GETR

GETR

GETR

GETR

GETR

GETR

GE'rR

GETR

GETR

Operating Conditions

Cladding

$\begin{array}{llll}\text { Irradiation } & \begin{array}{c}\text { Surface } \\ \text { Facility }\end{array} & \begin{array}{c}\text { Peak } \\ \text { Temperature }\end{array} & \begin{array}{c}\text { Power } \\ (\mathrm{kW} / \mathrm{ft})\end{array}\end{array} \quad \begin{gathered}\text { Burnup } \\ \text { (MWd/Te }\end{gathered}$

( F

$\frac{(\mathrm{kW} / \mathrm{ft})}{15}$

$\frac{(\mathrm{MWd} / \mathrm{Te})}{0}$

Statu

Examination in progress.

$\overline{974}$

20
20
20
20

500
500
500

Report in publication.

$\begin{array}{cccc}875 & 20 & 85,000 & \text { Data analysis } \\ 654 / 875 & 20 / 28 & 77,000 & \text { in progress. }\end{array}$

$1100 \quad 23 \sim 2000 \quad$ Irradiated

1100

$1100 \quad 23$

$1100 \quad 23$

1100

1100

1100

1100

1060

1060

20

1040

$\begin{array}{ll}17 & 120,000 \\ 17 & 120,000\end{array}$

Report in
publication

\begin{tabular}{|c|c|c|c|}
\hline $\begin{array}{l}785 \\
655 \\
560 \\
785\end{array}$ & $\begin{array}{r}11.6 \\
9.4 \\
7.9 \\
11.6\end{array}$ & $\begin{array}{l}199,000 \\
172,000 \\
255,000 \\
330,000\end{array}$ & $\begin{array}{l}\text { Report in } \\
\text { process. }\end{array}$ \\
\hline $\begin{array}{l}1100 \\
1100\end{array}$ & $\begin{array}{l}22 \\
22\end{array}$ & $\begin{array}{l}120,000 \\
120,000\end{array}$ & $\begin{array}{l}\text { Report in } \\
\text { process. }\end{array}$ \\
\hline 1160 & 15 & $8,900\}$ & Irradiation \\
\hline 1160 & 15 & $9,400)$ & \\
\hline $\begin{array}{l}1100 \\
1100\end{array}$ & $\begin{array}{l}27 \\
27\end{array}$ & $\begin{array}{l}2,000 \\
2,000\end{array}$ & $\begin{array}{l}\text { Report in } \\
\text { review. }\end{array}$ \\
\hline $\begin{array}{l}1100 \\
1100\end{array}$ & $\begin{array}{l}20 \\
20\end{array}$ & $\begin{array}{l}100,000 \\
100,000\end{array}$ & $\begin{array}{l}\text { Report in } \\
\text { review. }\end{array}$ \\
\hline 1050 & $19.5^{\circ}$ & 130,000 & $\begin{array}{l}\text { Awaiting } \\
\text { examination. }\end{array}$ \\
\hline 1050 & 19.5 & 130,000 & $\begin{array}{l}\text { Awaiting } \\
\text { examination. }\end{array}$ \\
\hline 1050 & 19.5 & 130,000 & $\begin{array}{l}\text { Awaiting } \\
\text { examination. } \\
.\end{array}$ \\
\hline 850 & 15 & 44,000 & $\begin{array}{l}\text { Awaiting } \\
\text { examination. }\end{array}$ \\
\hline
\end{tabular}

Fabrication

Fabrication in progress.

Fabrication in progress.

Irradiated

Fabrication In progress.

Irradiated an examined.

Fabrication in progress.

Fabrication in progress.

Report in process. 
TABLE $2-4$

SUMMARY OF TASK F FAST FLUX FUEL TESTING PROGRAM IN EBR-II

April 15, 1969

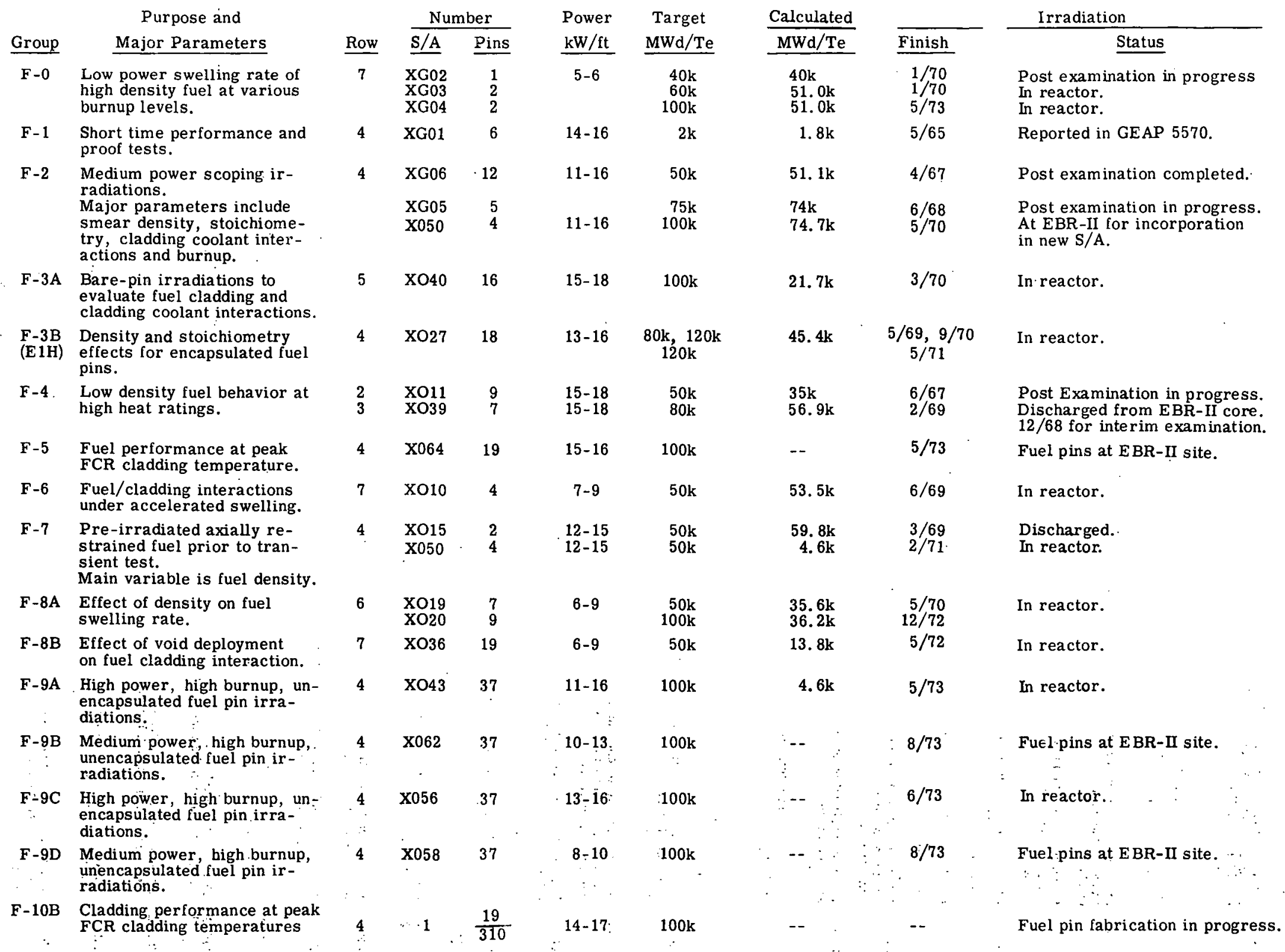


Running cost for a typical problem rose by a factor of three because of lower efficiency of read-and-write functions of FORTRAN-IV.

The time step control in the FREADM (Fast Reactor Excursion and Accident Dynamics Model) code has been checked out and is expected to give substantial cost savings in transient calculations.

An explicit numerical method, having unlimited stability, for solving the transient conduction and convection equations has been developed and published.

The revised VELVET code has been used to analyze the temperature distributions and heat transfer coefficients in fast reactor fuel bundles.

Statistical correlation of the available data was developed for the volumetric swelling of stainless steel after exposure to a fast flux.

The diameter changes for eight pins, irradiated in Task $F$, has been statistically correlated with some of the factors which influence swelling.

A parametric study of fuel swelling due to gaseous fission products has been completed.

\section{6 TASK L - CLADDING DE VELOPMENT}

Irradiation of four materials capsules in the L- 2 series is continuing. The L-6 series of capsules were discharged and reassembled in S/A X018A for further irradiation. The L-15 series $A$ capsules are awaiting reinsertion into a new subassembly. The total fluences, as of April 15, 1968, are $5 \times 10^{22}, 5 \times 10^{22}$, and $1.4 \times 10^{22} \mathrm{n} / \mathrm{cm}^{2}$ for the L-2, L-6, and L-15 series, respectively.

The post-irradiation examination of the L-10 capsules was initiated. High resolution gamma scans show movement of markers in temperature sentinels, indicating that the highest melting temperature, $1185^{\circ} \mathrm{F}\left(640^{\circ} \mathrm{C}\right)$, for the A1-Ni eutectic was attained or exceeded during the $\mathrm{L}-10$ irradiation.

Micrometer measurements taken along L-10 capsules indicate that negligible clad swelling had occurred at peak fluence of $2 \times 10^{22} \mathrm{n} / \mathrm{cm}^{2}$.

Quality characterization, vendor assessment, and evaluation of tube defects are continuing. The majority of the characterization work was performed on lots of cladding which are being used for current tests. The assessment of vendors is completed. Evaluation of the effect of surface defects on long-term mechanical properties of tubes has been initiated.

A facility for performing biaxial creep tests on irradiated tubular materials has been built. Initial tests of control samples are in progress on Type-304 tubing used for capsules.

The current status of the inpile test program of Task $L$ is summarized in Table 2-5. 
SUMMARY OF TASK L MATERIALS IRRADIATED IN EBR-II

\begin{tabular}{|c|c|c|}
\hline Series & Row-S/A & Capsule: \\
\hline \multicolumn{3}{|c|}{$\underline{\text { Irradiation Completed }}$} \\
\hline $\mathrm{L}-2$ & $4-X G 06$ & 5 \\
\hline $\mathrm{L}-4$ & $4-X 009$ & 2 \\
\hline$L-4^{\prime}$ & $2-\mathrm{XO14}$ & 5 \\
\hline$\cdot$ & & \\
\hline L-10 & $4-X 016$ & 10 \\
\hline $\mathrm{L}-14$ & $4-X 025$ & 19 \\
\hline
\end{tabular}

\section{L-2I 4-XG05 \&}

Irradiation in Progress

$\begin{array}{lll}\text { L-2 } & \begin{array}{l}\text { 4-XG05 } \\ \text { 4-X050 }\end{array} & 4 \\ \text { L-6 } & \begin{array}{l}\text { 2-X018 } \\ \text { 4-X018A }\end{array} & 9 \\ & & \\ & & \\ \text { L-15 } & 4-X 039 & 4 \\ \operatorname{MT-3}_{\text {and 4 }}^{(5)} & 4-X A 08 & 2\end{array}$

Capsule Materials One each of Types $304,316,321$
and 347 stainless steels, and Incoloy -800 .

Type 316 stainless steel.

One each of Types 304, 321, and 347 stainless steels; and two of Incoloy -800 .

One each of Types 321 and 347 stainless steels; two of Type 304 stainless steel; three each of Incoloy-800.

Five each of Type 316 stainless steel and Incolos -800; four of Type stainless steel.

Type 321

One each of Types 304, 316, and

347 stainless steels, and

Incoloy -800 .

One each of Types 321 and 347 stainless steels; two each of Type 304 stainless steel and stainless steel.

All five alloys.

32 Incoloy $-800,32$ Inconel-625 and 32 Hastelloy-X Tensile
Samples.

$133^{\cdot} \quad 114^{(1)}$

\begin{tabular}{|c|c|c|c|c|c|}
\hline 3 & 16 & 0.76 & 0.61 & 0.45 & December 1968 \\
\hline 12 & 64 & 0.76 & 0.50 & 0.37 & September, 1969 \\
\hline 63 & $126^{(1)}$ & 1.30 & 0.50 & 0.29 & September : 1970 \\
\hline None & 288 & 0.30 & 0.14 & 0.10 & September, 1969 \\
\hline None & 96 & 1.00 & 0.59 & 0.43 & December 1970 \\
\hline
\end{tabular}

Total Fluence

$\frac{\text { Number of Specimens }}{\text { Biaxial Tensile }}$

Target,
$10^{23} \mathrm{nvt}$

April 1969

$10^{23} \mathrm{nvt}^{(3)} \quad 10^{23} \mathrm{nvt}^{(4)}$

Projected

Completion

Date ${ }^{(2)}$

$\begin{array}{llllll}15 & 80 & 0.38 & 0.34 & 0.25 & \text { February } 1967 \\ 10 & 20 & 0.20 & 0.19 & 0.15 & \text { December } 1966 \\ 25 & 50 & 0.20 & 0.17 & 0.10 & \text { April } 1967\end{array}$

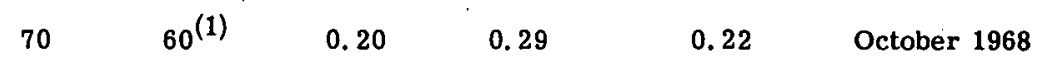

0.20

0.31

0.23

December 1968

1. Includes specimens of experimental alloy of base compositions $\mathrm{Fe},(9-14) \mathrm{Ni},(9-14) \mathrm{Cr},(0.0004-0.05) \mathrm{C}$.

2. Assuming EBR-II continues to operate at $45 \mathrm{MW}$ with $50 \%$ load factor.

3. Fluence based on EBR-II core physics conversion factors.

5. Fluence based on flux wire analysis conversion factors. 


\section{SECTION III}

\section{TASK B-DEFECTED FUEL BEHAVIOR}

\section{1 GENERAL}

The purpose of Task B is to determine analytically and experimentally the manner and consequences of propagation of fuel defects, the behavior and performance of the fuel cladding interface in intimate contact with sodium, the distribution and rate of release of fission products from high performance mixed oxide fuel, and the identity of the fission product species which can escape to the primary coolant and cover gas.

The technical feasibility of fast reactors depends on quantitative knowledge of such release and on designs to limit the consequences of such release. It appears attainable to limit long-term activity release from vented fuel to essentially $\mathrm{Kr}-85$ so that primary system maintenance conditions are equivalent to (or possibly better than) nonvented designs.

The technologies of defected, vented, and sodium-bonded fuels are closely related. Although directed primarily at studying the behavior of defected fuel, Task $B$ also has included development of vented and sodiumbonded fuels. Although vented pins are a prospective reference design for $300 \mathrm{MW}$ and $1000 \mathrm{MW}$ plants, funding limitations have made it necessary to terminate this aspect in future work on Task B.

\section{2 DEFECTED FUEL TESTING} (Series B8 and B9)

\subsubsection{Forced Convection Capsule (B9A)}

The fabrication, sodium filling, and irradiation of forced convection capsule (FCC) B9A was successfully completed. The capsule tested the effect of oxygen component of mixed oxide on defected fuel operated at about $20 \mathrm{~kW} / \mathrm{ft}$ to a burnup of about $7300 \mathrm{MWd} / \mathrm{Te}$. This experiment is the first in a series designed to establish the performance of defected mixedoxide fuel pins in flowing sodium.

Installation of the sodium cleanup and fill system used to charge the FCC with high purity sodium was completed. A checkout of the system was made by filling a dummy capsule. The dummy fill also provided a checkout of the fill procedure and the capsule sealing operation. The B9A capsule was then filled and the sodium level verified by eddy current detectors and $\mathrm{x}$-rays as shown in Figure 3-1.

After filling, the capsule was transported to the GETR (GE Test Reactor) in a portable heater can. The heated can maintained molten sodium in the capsule during the handling and transfer operations from the sodium cleanup and fill loop to GETR. Figure 3-2 shows B9A in the heater can after filling the capsule with sodium.

During handling operations in the GETR, the internal heaters in the capsule failed. To maintain molten sodium, the capsule was reinserted into the heater can and the binary gas annulus was filled with xenon to reduce the heat transfer through the capsule wall. With the insulating xenon in the gas gap, the capsule was rapidly transferred from the heater can to the special V-RAFT in the GETR pool. The electromagnetic (EM) pump was capable of putting enough heat into the sodium to maintain molten sodium at $500^{\circ} \mathrm{F}$.

During capsule startup the xenon was purged from the capsule and replaced with a helium-nitrogen mixture. The composition of this binary gas mixture was adjusted to 


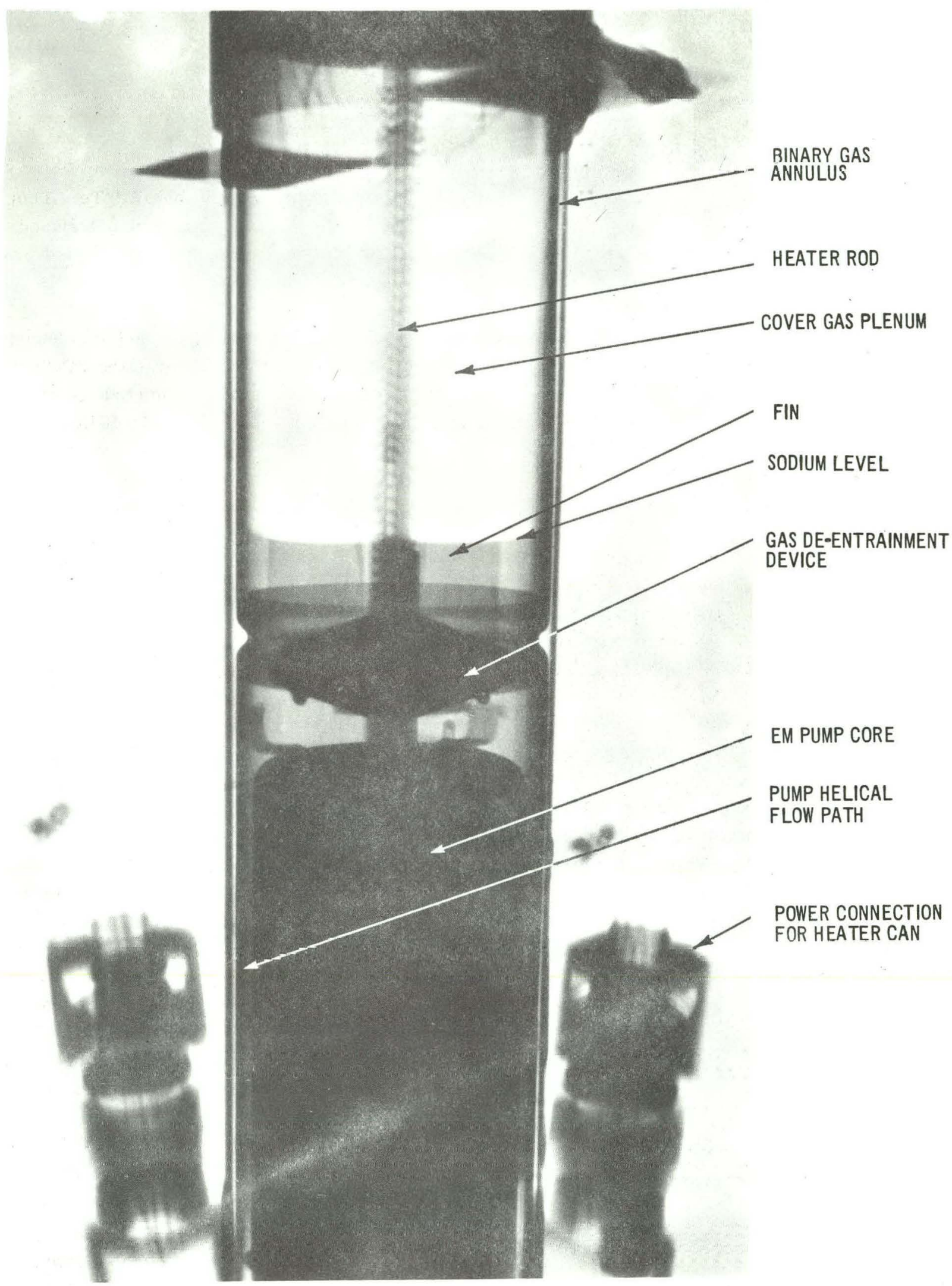

FIGURE 3-1. X-RAY SHOWING SODIUM LEVEL IN B9A 


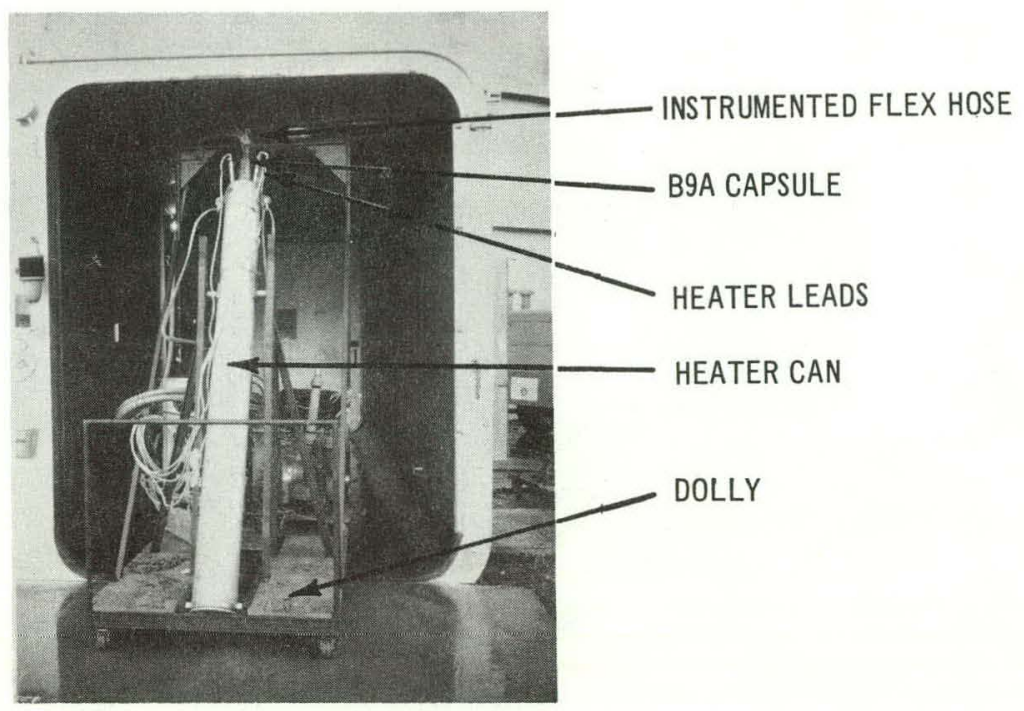

FIGURE 3-2. FORCED CONVECTION CAPSULE B9A IN HEATER CAN

maintain the desired sodium inlet temperature of $950^{\circ} \mathrm{F}$ during operation.

During startup, flowmeter voltages were only approximately $10 \%$ of the predicted value. The cause of this discrepancy was traced to the flowmeter magnet. As shown in "a" of Figure 3-3, the proper orientation for the probe guides is 90 degrees to the flux lines of the magnet. Checks made on the original magnet drawings and two spare magnets indicate that the probe guides were approximately 80 degrees out of orientation as shown in "b" of Figure 3-3. In addition, a map was made of the magnetic flux of the actual region of the flowmeter magnet in capsule B9A after irradiation. Correlation with $\mathrm{x}$-rays of the came region also show the probe guides to be approximately 80 degrees out of orientation. Thus misorientation of the magnet has been confirmed to be the cause of the reduced voltage. Allowing for the actual magnet position, the nominal voltage design flow as attained.
Capsule operation was quite close to predicted design values. Table $3-1$, for example, shows measured sodium temperatures and power as determined by detailed thermal analysis compared to power calculated from GETR fluxes.

The capsule operated smoothly throughout the cycle including the two scheduled GETR refueling outages. During those periods the binary gas annulus was again filled with xenon and the pump voltage increased to supply the necessary heat. A summary of the capsule operation is given in Table 3-2.

Thermal noise measurements (rapid fluctuations in temperature at a fixed point) were made on the inlet and outlet thermocouples of the forced convection capsule. These measurements were made to help determine the potential for using thermal noise analysis to monitor the condition of fuel. Figure 3-4 shows the location of the monitored thermocouple and measured 


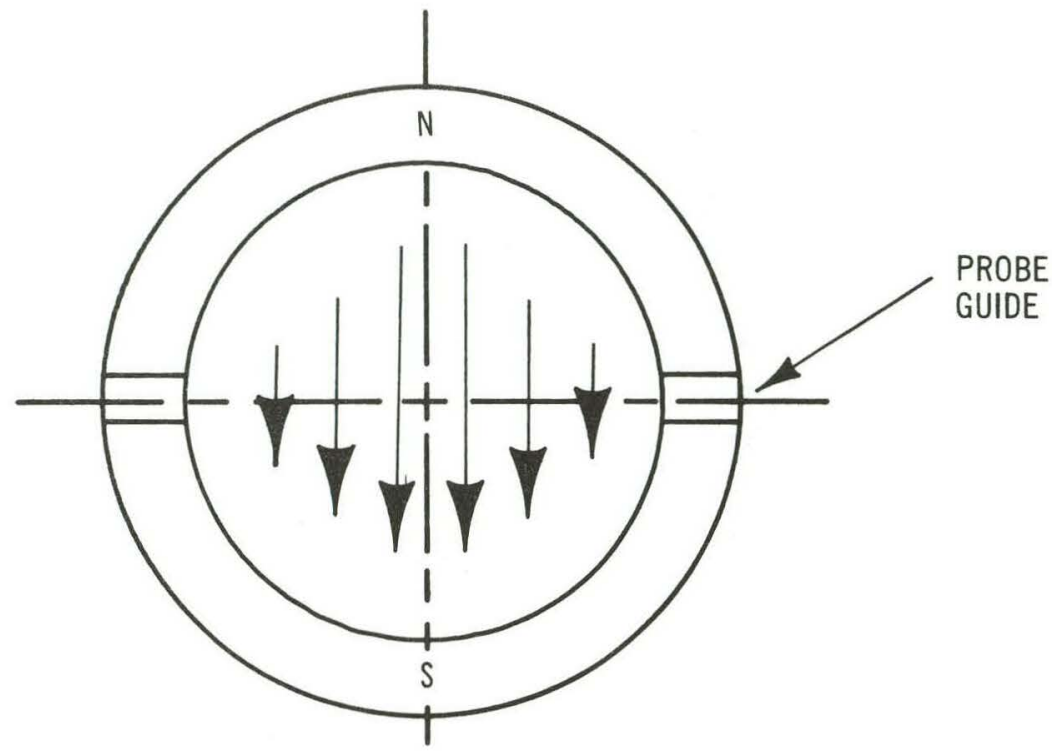

(A) PROPER ORIENTATION OF PROBE GUIDES

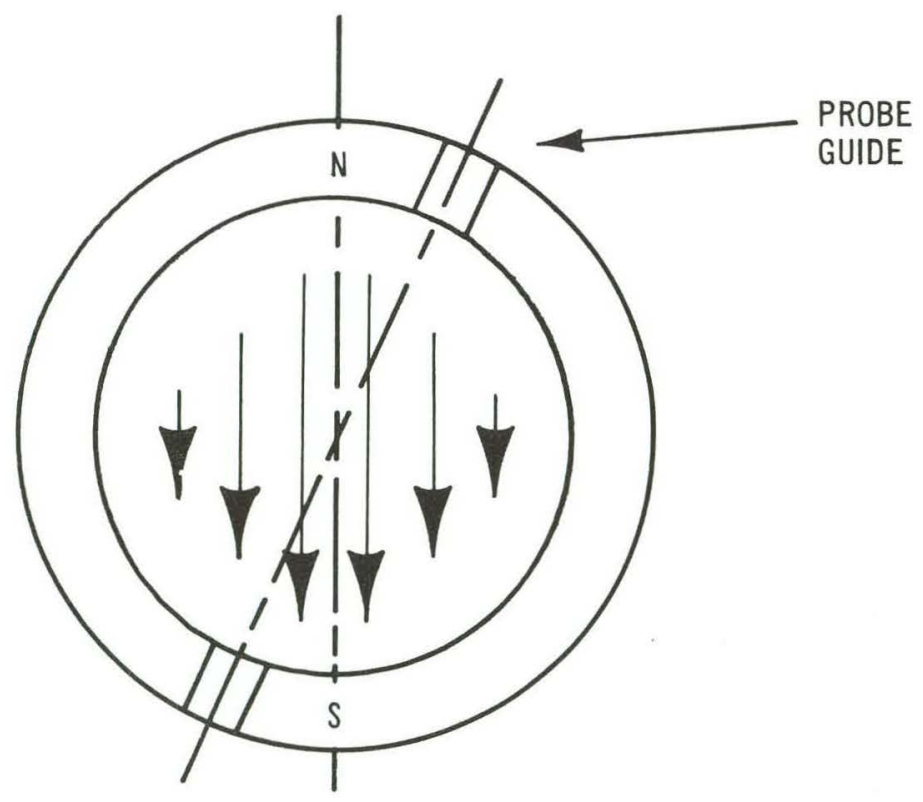

(B) ACTUAL ORIENTATION OF PROBE GUIDES 
TABLE 3-1

\section{COMPARISON OF DESIGN AND OPERATING CONDITIONS OF}

FORCED CONVECTION CAPSULE B9A

\begin{tabular}{|c|c|c|c|}
\hline & $\begin{array}{l}\text { Thermal } \\
\text { Analysis }\end{array}$ & $\begin{array}{c}\text { Measured } \\
\text { Data } \\
\end{array}$ & $\begin{array}{c}\text { GETR } \\
\text { Physics } \\
\text { Calculation } \\
\end{array}$ \\
\hline \multicolumn{4}{|l|}{ Power } \\
\hline fission & $20 \mathrm{~kW} / \mathrm{ft}$ & $20.6 \mathrm{~kW} / \mathrm{ft}$ & $19 \mathrm{~kW} / \mathrm{ft}$ \\
\hline gamma & $3.3 \mathrm{~kW} / \mathrm{ft}$ & $3.3 \mathrm{~kW} / \mathrm{ft}$ & $3.3 \mathrm{~kW} / \mathrm{ft}$ \\
\hline Total & $23.3 \mathrm{~kW} / \mathrm{ft}$ & $23.9 \mathrm{~kW} / \mathrm{ft}$ & $22.3 \mathrm{~kW} / \mathrm{ft}$ \\
\hline Flowrate & $6 \mathrm{gpm}$ & $6.6 \mathrm{gpm} *$ & \\
\hline Inlet Temperature** & $607^{\circ} \mathrm{F}$ & $625^{\circ} \mathrm{F}$ & \\
\hline Outlet Temperature** & $695^{\circ} \mathrm{F}$ & $705^{\circ} \mathrm{F}$ & \\
\hline$\Delta \mathrm{T}$ & $88^{\circ} \mathrm{F}$ & $80^{\circ} \mathrm{F}$ & \\
\hline
\end{tabular}

*Calculated from voltages based on actual position of magnet

**Based on operation with $100 \% \mathrm{He}$ gas in annulus of capsule

TABLE 3-2

SUMMARY OF B9A OPERATION

Power

Fission

Gamma

Total

Coolant (sodium)

Flowrate

Inlet Temperature

Outlet Temperature

Operating Days

Number of Power Cycles

Total Burnup
$20.6 \mathrm{~kW} / \mathrm{ft}$

$3.3 \mathrm{~kW} / \mathrm{ft}$

$23.9 \mathrm{~kW} / \mathrm{ft}$

$6.6 \mathrm{gpm}$

$950^{\circ} \mathrm{F}$

$1040^{\circ} \mathrm{F}$

25

3

$7300 \mathrm{MWd} / \mathrm{Te}$ 


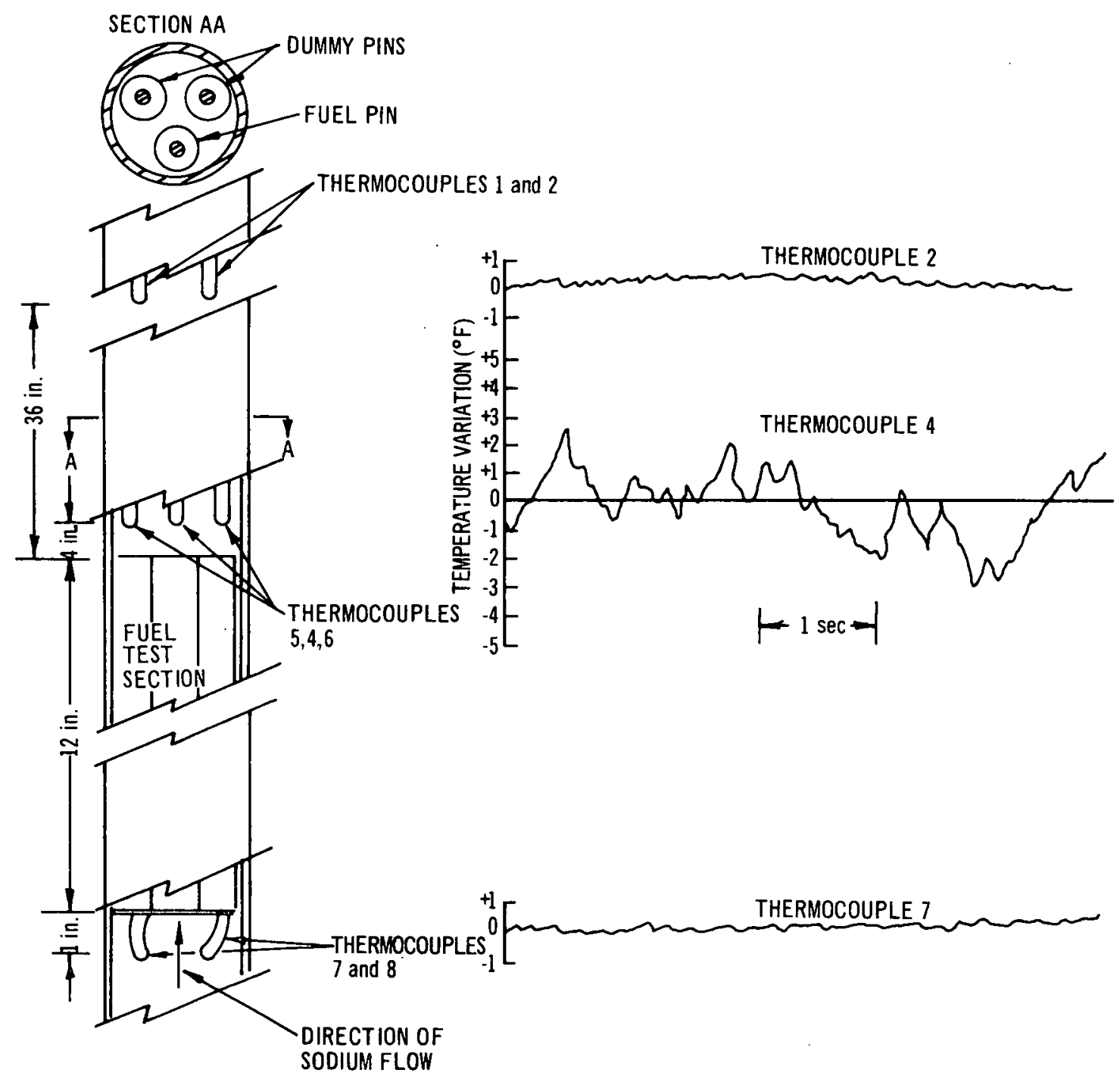

EIGURE 3-4 THERMAL NOISE MEASUREMENT IN THE FORCED CIRCULATION TEST 
temperature variations. The figure shows that local flowing sodium temperature measurements made within 4 inches of the top of operating fuel specimens exhibit substantially larger temperature variations in time than those measured 36 inches farther downstream in the same flow channel. This attenuation indicates that the fluctuations are not primarily caused by flow or reactor power variations. Rather, downstream attenuation of temperature fluctuations is characteristic of the thermal noise resulting from the eddying and downstream mixing of hot and cold streamers of sodium.

The capsule is presently stored in the GETR and awaiting completion of modifications to the shielded transfer cask required to transfer B9A from the reactor to neutrography and to Radioactive Handling Operation [ (RHL) formerly RML], for destructive examination. (An existing cask must be lengthened about 3 feet to accommodate the B9A.)

\section{3 FUEL, SODIUM, CLADDING COMPATIBILITY STUDIES (B8C/D)}

No work was done on capsule B8C containing sodium-bonded mixed-oxide fuel in this reporting period.
A second capsule (B8D) conta ining sodiumbonded mixed-oxide fuel completed its scheduled irradiation. Accumulated burnup on the three pins in this capsule was approximately 42, $000 \mathrm{MWd} / \mathrm{Te}$.

Fuel pin B8D-1a containing sodium bonded fuel pellets (U-25\% Pu) with an oxygento-metal ratio of 2.04 (initially fabricated for irradiation in capsule $\mathrm{B} 8 \mathrm{D}$ ) was destructively examined after a 5 mil increase in diameter was observed after heat treatment. Maximum swelling occurred in the plane of the low density fuel pellets after $3-1 / 2$ hours at $730^{\circ} \mathrm{F}$. Fuel pin examination and initial results were described in the 27th Quarterly Report. ${ }^{(1)}$

A leach analysis was performed on selected pellets from B8D-1a for sodium monouranate. The cold and boiling water technique of Pechurova, Ippolitova, and Kovba ${ }^{(2)}$ was used. As can be seen in Table 3-3, each of the cold leach samples contained sodium in the range of 200 to $1000 \mathrm{ppm}$ suggesting the presence of $\mathrm{Na}_{2} \mathrm{O}$. (If all the excess oxygen in each pellet were reacted with the sodium to form $\mathrm{Na}_{2} \mathrm{O}$, the sodium concentration in the cold leach solutions would have been $\sim 400 \mathrm{ppm}$, in reasonable agreement with this data. )

The uranium and plutonium concentrations in both the cold and hot water leach solutions

TABLE 3-3

FUEL PIN B8D-1a SODIUM-FUEL LEACH TESTS

$\mathrm{ppm}$ of Indicated Elements

\begin{tabular}{|c|c|c|c|c|c|c|c|}
\hline Sample & Density & $\underline{\mathrm{O} / \mathrm{M}}$ & Conditions & $\underline{\mathrm{Na}}$ & $\underline{\mathrm{U}}$ & $\underline{\mathrm{Pu}}$ & $\underline{\mathrm{Pu} / \mathrm{U}+\mathrm{Pu}}$ \\
\hline 248 & 94.8 & 2.037 & Cold & 230 & 5.1 & 0.80 & 15.7 \\
\hline 248 & 94.8 & 2.037 & Hot & $"<10$ & 11.3 & 0.64 & 5.7 \\
\hline 251 & 94.9 & 2.037 & Cold & 460 & 8.3 & 0.65 & 7.8 \\
\hline 251 & 94.9 & 2.037 & Hot & $<10$ & 32.9 & 0.30 & 0.91 \\
\hline 266 & 85.4 & 2.045 & Cold & 920 & 6.3 & 0.053 & 0.84 \\
\hline 266 & 85.4 & 2.045 & Hot & $<10$ & 14.0 & 0.79 & 5.6 \\
\hline 271 & 85.6 & 2.044 & Cold & 560 & 4.5 & 0.097 & 2.2 \\
\hline 271 & 85.6 & 2.044 & Hot & $<10$ & 14.0 & 0.28 & 2.0 \\
\hline Blank & & & Cold & $<10$ & trace & N.D. & \\
\hline Blank & & & Hot & $<10$ & trace & N.D. & \\
\hline
\end{tabular}


were very low and similar to concentrations observed in interim waste solutions following co-precipitation of mixed oxides. This suggests that no sodium monouranate was present since the presence of a soluable uranate in the fuel would have provided a uranium ion concentration of at least $200 \mathrm{ppm}$. Hydrolysis of sodium monouranate to the diuranate in boiling water would also have resulted in a sodium concentration in the hot water leach solutions of about $200 \mathrm{ppm}$.

The erratic nature of the plutonium concentration data is probably caused by polymerization of $\mathrm{Pu}$ ions to colloidal state during the leaching. (High acidity is necessary to prevent this polymerization, but addition of nitric acid to the leach solution would have led to dissolution of much of the fuel.)

The leaching analysis was not adequate to detect uranates other than sodium monouranate. From the above data, it would appear that the fuel pin swelling was probably caused by the formation of sodium oxide within the fuel pin.

\subsection{DEVELOPMENT OF IN-PILE DEFECTING MECHANISM}

Development of an on-demand defecting mechanism continued. During this reporting period, analytical work was done to guide further experimental testing of the torsional defecting method.

The reference method of loading the torsional defecting mechanism is shown in
Figure 3-5. The slotted cap is pulled vertically, applying both an axial and torsional load on the fuel rod through the pin attached to the top of the fuel rod. Analysis indicates that a small slot angle is preferable since the coefficient of friction in the slot has less of an effect on the orientation of the notch angle and smaller loads are required to cause rupture of the cladding.

\section{5 FISSION PRODUCT DISTRIBUTION MINILOOP (Out-of-Pile Radioactive Fission Product Sodium Loop)}

Installation, check-out, and experimental operation of the miniloop was completed. Final loop installation required the addition of heating tape and insulation to the loop piping, the connection of gas, electrical, and instrument leads, and set-up within the RHL hot cell. Figure 3-6 shows the assembled loop during check-out prior to insertion of the irradiated fuel specimen and sodium fill. After set-up the loop was sodium filled and flow established. The loop sodium was then cleaned for 20 hours using $\mathrm{Zr}$ chips and a static (cold finger) cold trap after cleanup. The $\mathrm{Zr}$ chips were removed from the flowing sodium, and a stoichiometric mixed-oxide fuel pin F2U (irradiated in EBR-II to 56, $700 \mathrm{MWd} / \mathrm{Te}$ ), was inserted into the test chamber. The loop plugged, stopping flow 18 hours after the fuel sample was lowered into the loop sodium. The fuel and loop test parameters are shown in Tables 3-4 and 3-5. Destructive examination of the loop has been initiated. 


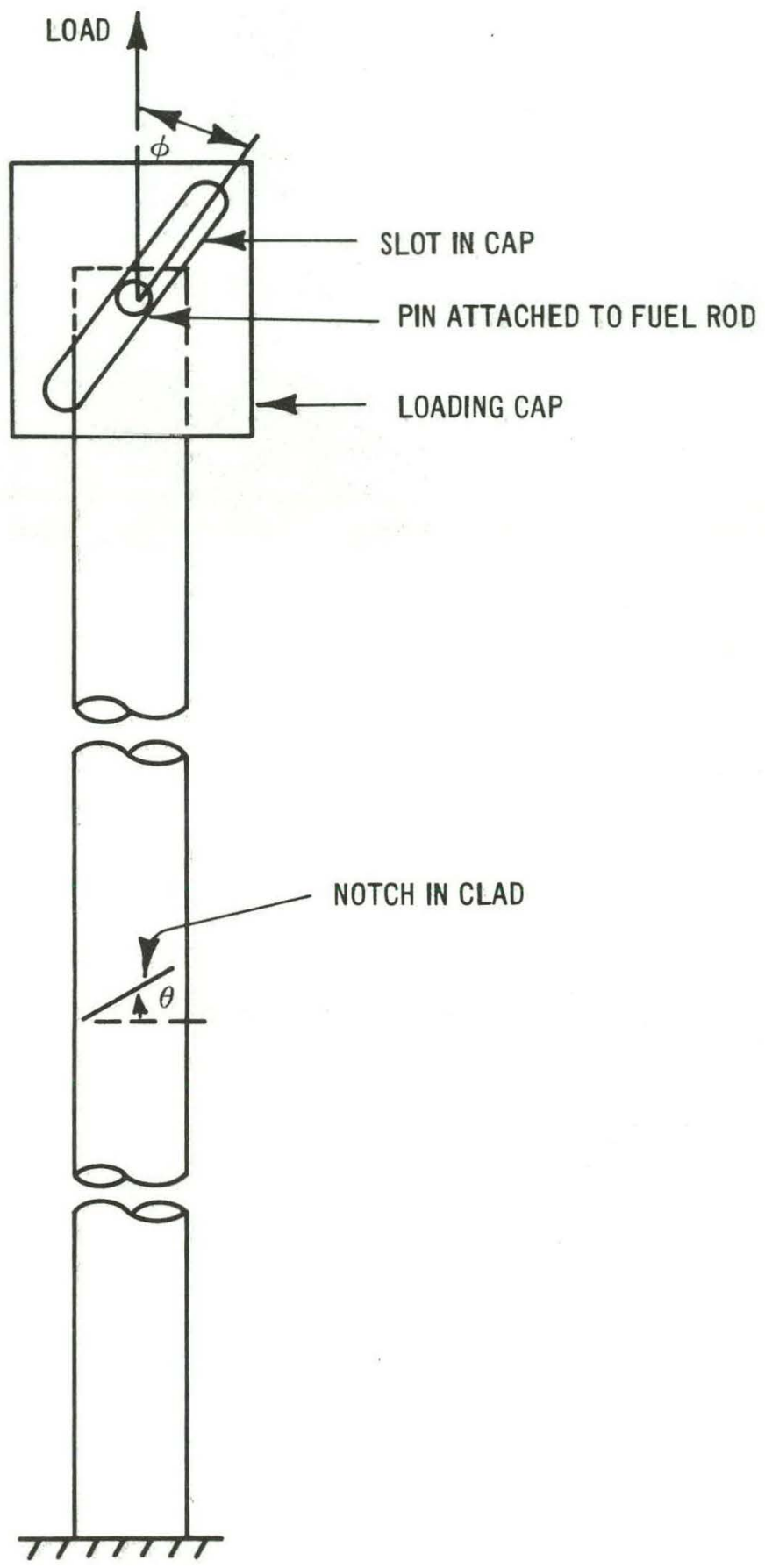

FIGURE 3-5. TORSIONAL DEFECT MECHANISM 


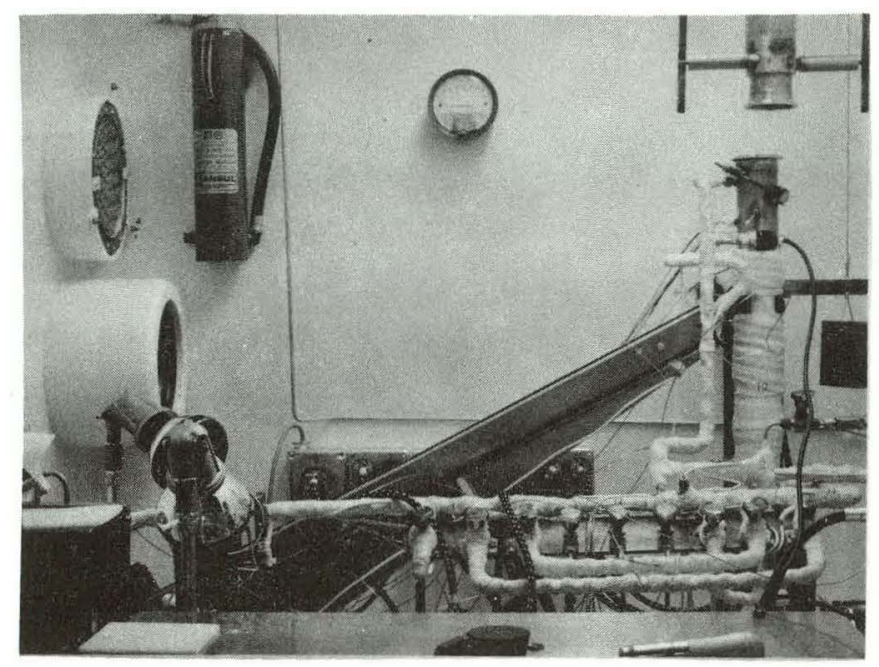

FIGURE 3-6. MINILOOP PRIOR TO INSERTION OF FUEL SPECIMEN

TABLE $3-4$

\section{MINILOOP FUEL PARAMETERS}

Fuel Rod

Original $\mathrm{O} / \mathrm{M}$

Original Density (\% TD)

Burnup (MWd/Te)

Center Void (mils)

Sample Length (inches)
F2U

1.99

89.6

56,700

47

3
TABLE 3-5

\section{MINILOOP TEST PARAMETERS}

Na Maximum Temperature

$\sim 1125^{\circ} \mathrm{F}$

Na Minimum Temperature

$\sim 475^{\circ} \mathrm{F}$

Na Flow

Na Purity (estimated)

Weight $\mathrm{Na}$ in Loop

Initial Velocity of $\mathrm{Na}$
$0.1 \mathrm{gpm}$

5 to $10 \mathrm{ppm} \mathrm{O}_{2}$ 860 grams

$\sim 7 \mathrm{ft} / \mathrm{sec}$ 


\section{SECTION IV}

\section{TASK C $\longrightarrow$ SAFETY EXPERIMENTATION}

\section{1 GENERAL}

The purpose of Task $C$ is to establish the behavior of fuel and cladding under various casualty and accident situations. Both analytical techniques and an experimental program of testing the response of fuel to serve transients are used. These investigations include a study of the performance of fuel and cladding under transient conditions as a function of axial restraint, density, performance of fuel in the presence of a defect, and comparison of the behavior of power and pelleted fuel. Additional tests are conducted to determine the potential for molten fuel movement and to observe the effect of the prototypical range of fuel and blanket lengths on movement. Future experiments involve multiple-pin assemblies to study reduced flow conditions and energy partition data needed for the analysis of large terminal accidents.

During the current contract period, a final report will be issued on transient irradiation of zero-burnup, axially-restrained fuel as a function of density and fuel form (pellet and powder). Experiments will be conducted on pre-irradiated long pins to study relocation of molten fuel during transients. Tests of defected or sodium-bonded fuel pins will be initiated. Out-of-pile scoping studies on flow blockage experiments will be performed, and conceptual design of workenergy experiments will continue.

\subsection{AXIALLY-RESTRAINED FUEL EXPERIMENTS}

\subsubsection{EBR-II Irradiations Preceding Transient Tests}

EBR-II irradiation has been completed for fuel specimens $C 4 G$ and $C 4 H$, which have accumulated a maximum burnup of $\sim 61,000$ $\mathrm{MWd} / \mathrm{Te}$. Irradiation of the remaining four specimens ( $\mathrm{C} 4 \mathrm{E}, \mathrm{F}, \mathrm{K}$, and $\mathrm{L}$ ) is continuing with the present peak burnup at $4,700 \mathrm{MWd} / \mathrm{Te}$.

\subsubsection{Treat Capsule for Pre-Irradiated Fuel Specimens}

Final design of the TREAT capsule for transient irradiation of pre-irradiated fuel specimens is nearly complete, and acquisition of long lead items has been initiated.

\subsubsection{Comparative Study of FORE-II} Calculated Fast Reactor Overpower Accidents and THTD Calculated Analyses of Treat Experimental Transient Irradiations

There have been repeated questions in the past as to the applicability of TREAT reactor data to fast reactor systems. This concern stems mainly from consideration of a) the order-of-magnitude differences in the periods of fast reactor transients compared to the TREAT reactor and b) the fact that TREAT is a thermal reactor, resulting in a severe flux depression in mixed oxide test specimens $\left(P_{S} / P_{G} \sim 2\right.$ to 4$)$, and c) the TREAT design, which has required initiation of transients from zero power.

In an attempt to provide a quantitative response to such questions, a study has been initiated to review the actual thermodynamic relationship between the expected reactions of fast reactor fuel, in response to transient overpower, and the physical results of the Task C TREAT transient irradiation experiments. As an initial phase of this study, the THTD code was used to calculate the timetemperature history ${ }^{(3)}$ of the transient irradiation of the Task $\mathrm{C}$ specimen $\mathrm{C} 4 \mathrm{~A}$ (90.4\% smeared density, zero burnup, 
pelleted fuel). ${ }^{(4,5)}$ This result was compared to the time-temperature history calculated for a control rod ejection accident using the FORE-II code. ${ }^{(6)}$ In order to establish a meaningful comparison, the FORE-II analysis was made for a severe hypothetical accident which is scrammed realistically (the chosen accident was in the hypothetical range in order to match the high fraction of fuel melting, 60 vol $\%$ measured for the actual $\mathrm{C} 4 \mathrm{~A}$ experiment).

The specific accident chosen for the FORE-II analysis was a control rod-ejection accident resulting in a $15 \$ / \mathrm{sec}$ reactivity insertion for 0.1 second (or $1.50 \$$ total). The programmed scram system was signal actuated on $110 \%$ overpower, and a 0.25 second inertial delay was imposed in initiating the movement of the scram rods.

The THTD representation of the actual C4A results closely matched the measured sodium annuli temperatures, fuel melting radius, and total energy input (all within $\sim \pm 3 \%$ ). As expected, the calculated radial temperature profiles within the fuel, as a function of time, differ radically between the TREAT and THTD results and the FORE-II results (see Figures 4-1 and 4-2). The effect of the large radial flux depression in the thermal spectrum of the TREAT reactor is visible in the form of the humping of the radial temperature profile calculated by THTD (Figure 4-1). If, however, a time scale is defined such that $t=0$ at the time the first fuel reaches the fuel melt temperature, a more meaningful correlation is obtained. A comparison of the development of the volume of fuel melted (both the volume entering the heat of fusion and the volume exceeding the heat of fusion) as a function of this newly defined time scale indicates a remarkable similarity in the time-energy histories of the moltenfuel region for the two cases (Figure 4-3). In addition, a comparison of the temperatures in the annular region of solid fuel, adjacent to the cladding (Figures 4-1 and 4-2) also shows great similarity. Therefore, the results of this initial comparison between TREAT results and a severe fast reactor accident indicates that TREAT adequately simulates, in both time and magnitude, the distribution of accident-released energy in a fast reactor accident.

\subsection{AXIAL FUEL RELOCATION EXPERIMENTS}

Destructive examination of failed specimen C5A and completion of $\mathrm{C} 5 \mathrm{~B}$ is scheduled during the next quarter.

\subsection{DEFECTED OR SODIUM-BONDED FUEL EXPERIMENTS}

The high pressure sodium fill system components have been installed and electrical and water connections for the control console completed. The sodium lines are being installed. The system is presently scheduled for operation early next quarter. Figure 4-4 shows the control console and glove box.

A study was initiated to determine the feasibility of using the Series- 6 multiple-pin capsule for TREAT irradiation of EBR-II specimens. Aside from the mechanical features of reencapsulation, the primary questions involve reducing power and minimizing shadowing with fully enriched pins. Physics calculations are in progress.

\subsection{LOSS OF FLOW EXPERIMENTS}

Work has been temporarily halted on Mockup 1A. All components have been fabricated and are being stored for assembly later this year.

A study was initiated to determine what conditions can be expected during a flow coast-down accident. The information obtained from this study will be used in defining the final design and operating parameters of the capsule. 

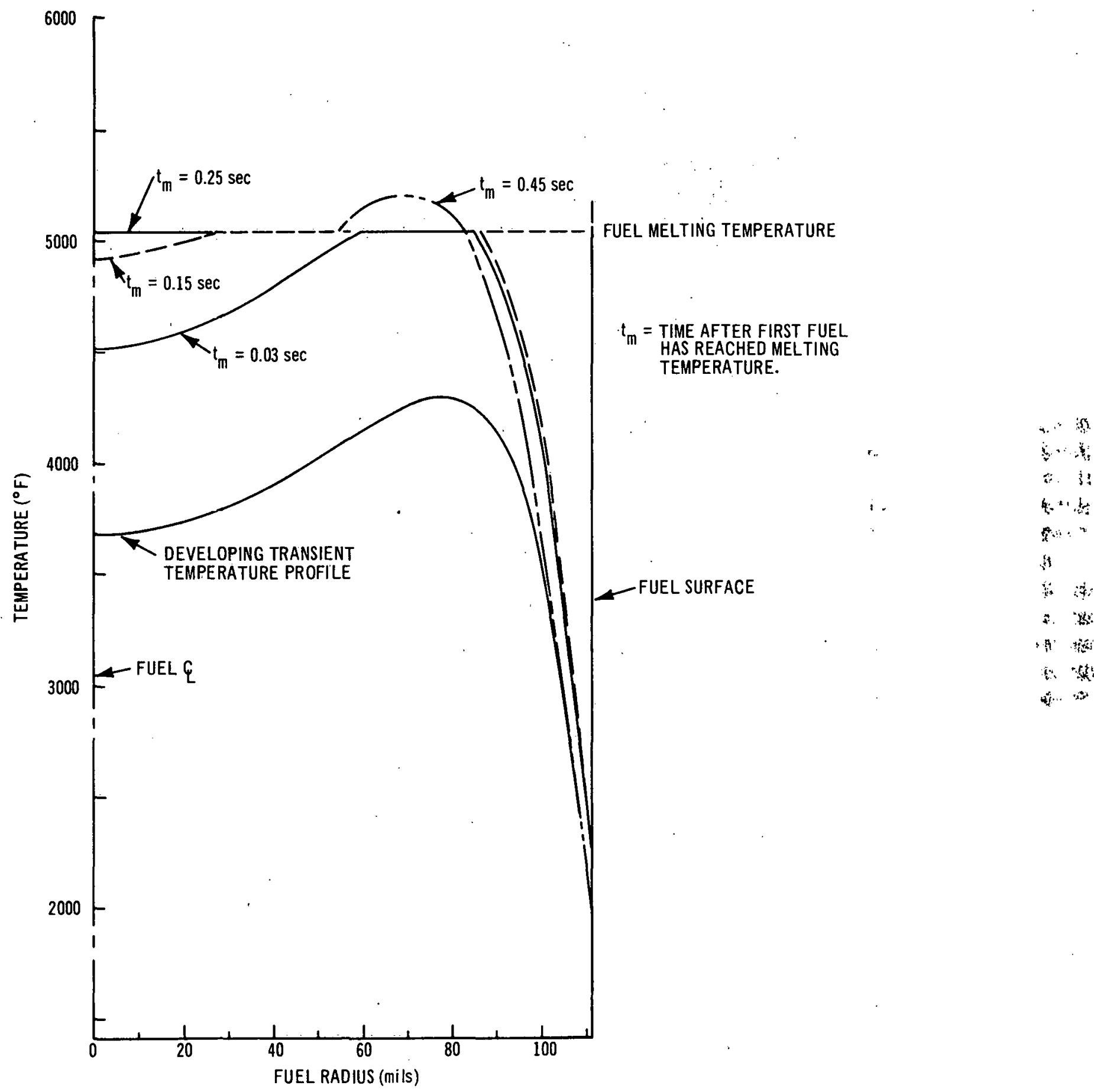

FIGURE 4-1. THTD TREAT IRRADIATION TRANSIENT ANALYSIS (Tosk C Fuel Specimen C4A) 


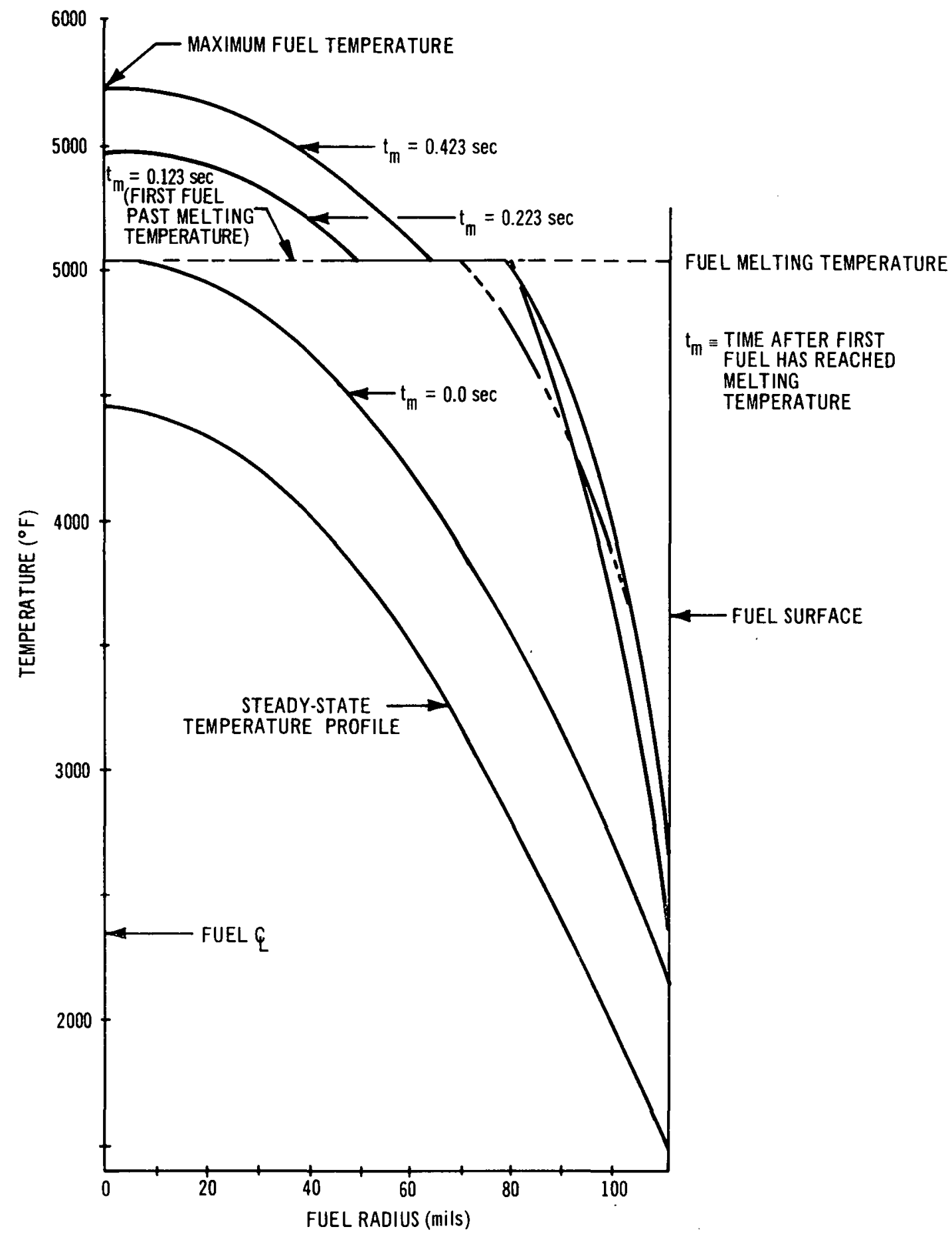

FIGURE 4-2. FORE-II ROD EJECTION ACCIDENT 


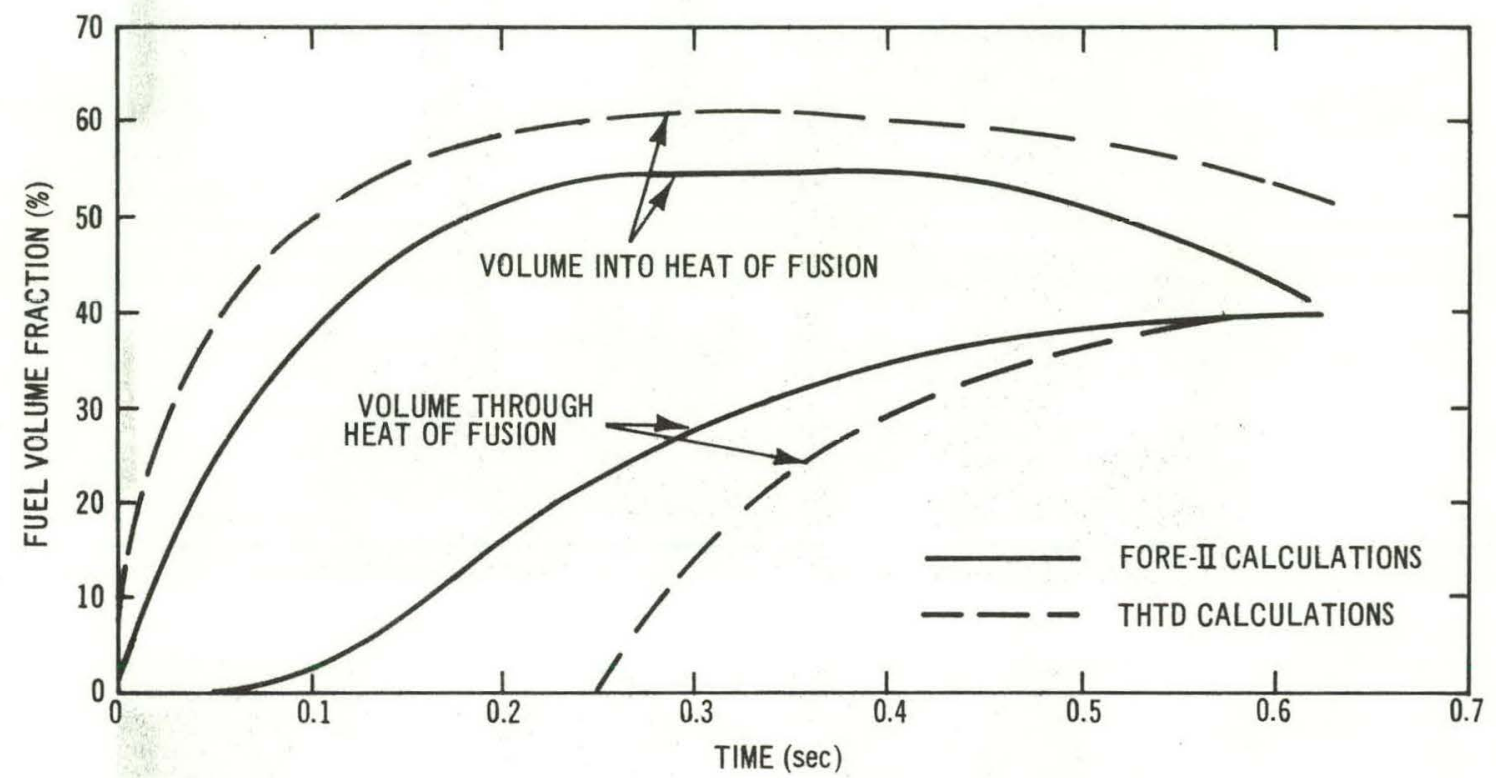

NOTE: TIME ZERO IS DEFINED AS TIME WHEN FIRST FUEL REACHES MELTING TEMPERATURE 


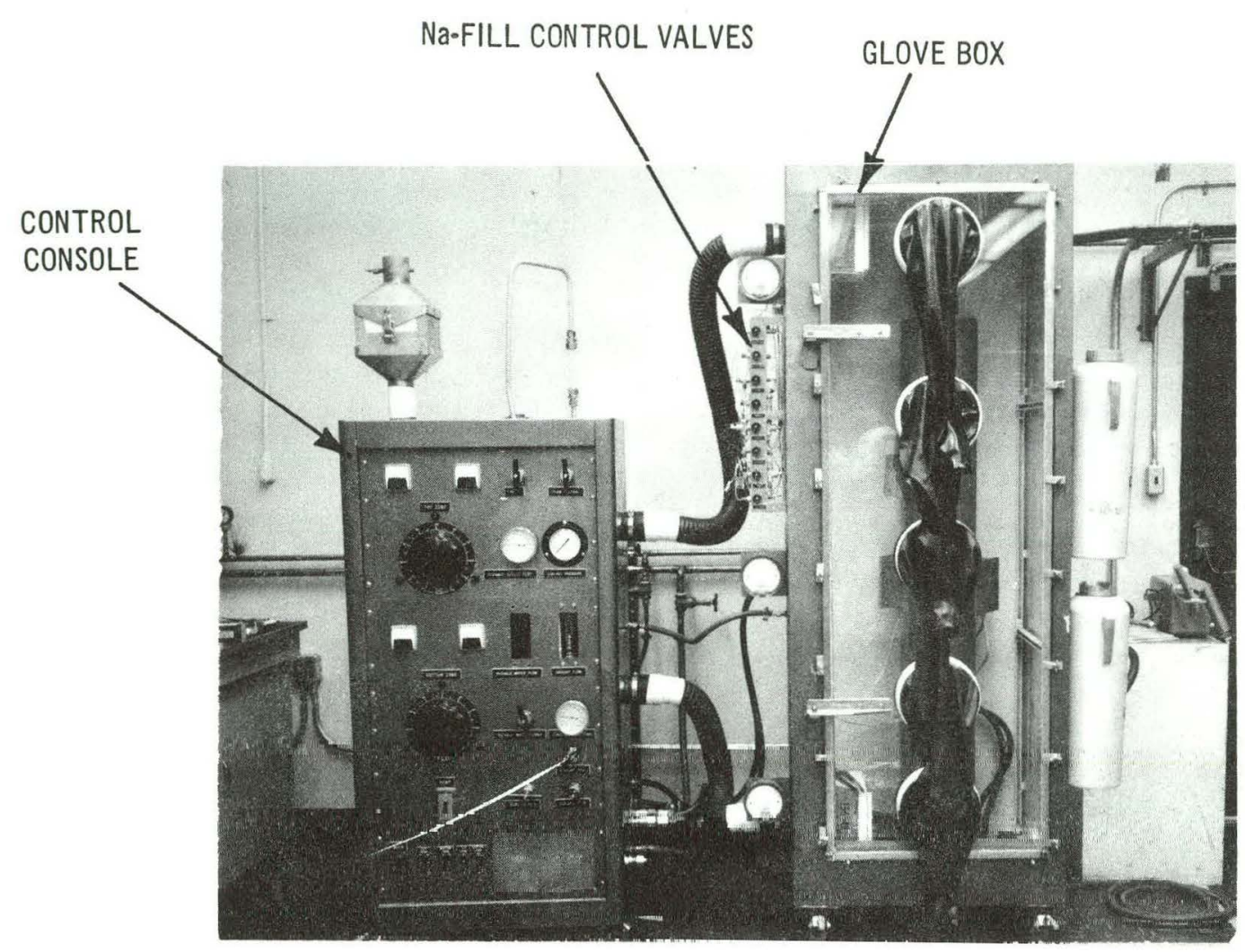

FURNACE

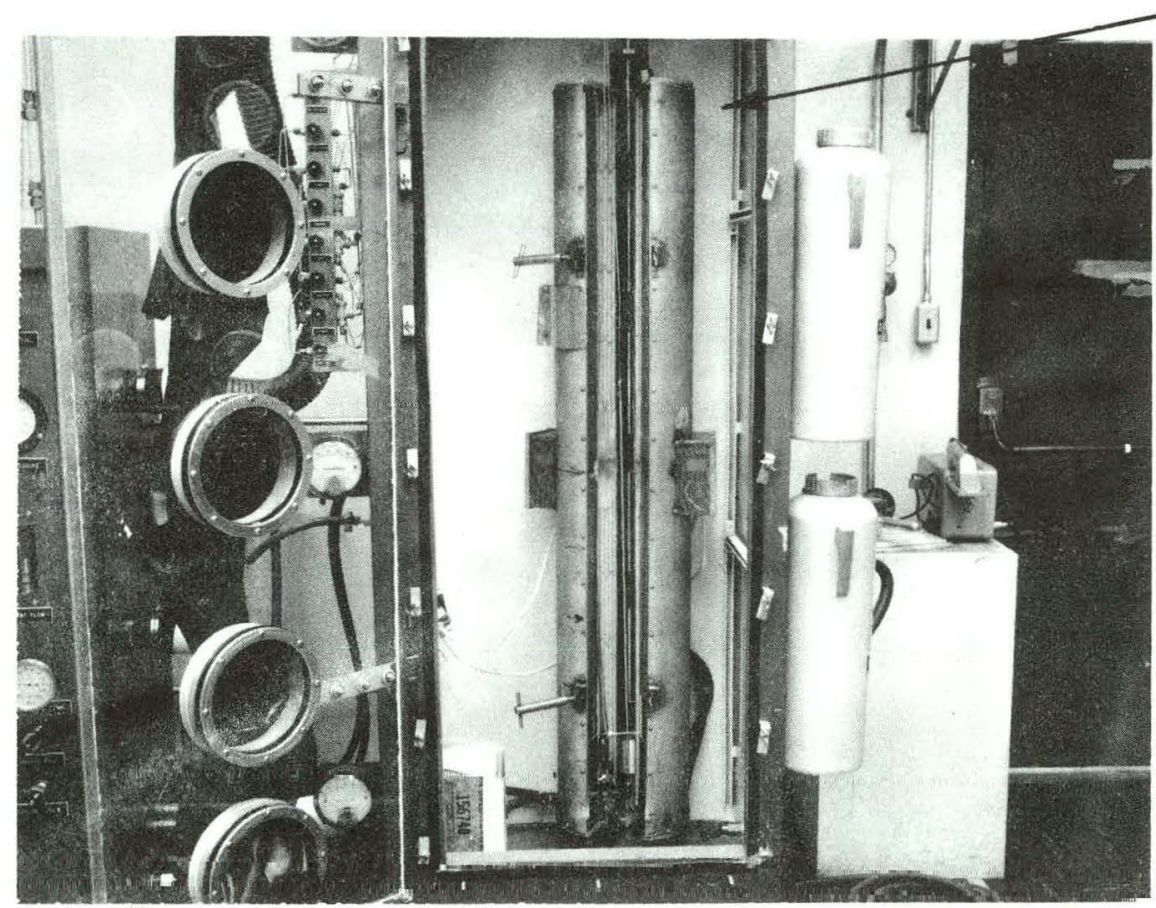

FIGURE 4-4. SYSTEM FOR FILLING CAPSULES WITH SODIUM 


\section{SECTION V}

\section{TASK E-FUEL PROPERTIES AND PERFORMANCE EVALUATION}

\subsection{GENERAL}

The purpose of this task is to establish physical, mechanical, and thermal properties of ceramic fuels which are needed for design of fast reactor fuel elements and which are used in fuel behavior calculations under both steady-state and casualty conditions. Exreactor experiments are conducted (as well as in-reactor) to provide property measurements or metallographic observations which can aid in the interpretation of the behavior of irradiated specimens.

\subsection{CENTER TEMPERATURE LIMITS}

\subsubsection{Instrumented Thermal Conductivity Capsule E1AA}

The irradiation test conditions for this capsule have been reported previously. (7) To better interpret the in-fuel thermocouple readings, two of the 20-mil diameter $\mathrm{W}-5$ $\mathrm{Re} / \mathrm{W}-26 \mathrm{Re}$ thermocouples that had been irradiated with the capsule were recalibrated to temperatures of $1275^{\circ} \mathrm{C}$. These two thermocouples were located outside of the capsule and exposed to temperatures of $\sim 100^{\circ} \mathrm{C}$ during irradiation. The total neutron flux on the thermocouple wires was assumed to be similar to that calculated for the capsule wall as follows:

- Thermal $1.9 \times 10^{20}$ neutrons $/ \mathrm{cm}^{2}$

- Epithermal $2.1 \times 10^{20}$ neutrons $/ \mathrm{cm}^{2}$

- Fast $5.3 \times 10^{19}$ neutrons $/ \mathrm{cm}^{2}$

These two thermoelements were removed from their housing and prepared for recalibration. New hot junctions were fabricated by crimping molybdenumrhenium tubing around the wire. The irradiated thermocouples were enclosed in a tantalum tube and inserted into a calibration furnace where emf readings were taken at temperatures up to $1275^{\circ} \mathrm{C}$. Similar readings were taken with a standard unirradiated thermocouple of the same W-5 Re/W-26 Re composition.

A comparison of the readings from the two thermocouples is shown in Figure 5-1. The data show a negative decalibration, signifying low readings in-pile, varying from about $-55^{\circ} \mathrm{C}$ at $800^{\circ} \mathrm{C}$ to $-75^{\circ} \mathrm{C}$ at $1275^{\circ} \mathrm{C}$. The bulk of this decalibration is attributed to the irradiation-induced transmutation of the alloying elements to osmium and had previously been noted by Novak and Asamoto. ${ }^{(8)}$ In the latter case, however, the negative deviations did not persist and were eliminated at $1300^{\circ} \mathrm{C}$. This difference in behavior has not yet been accounted for. Factors such as temperature, composition gradients, condition of the irradiated thermocouple, and neutron fluence will be evaluated so that proper adjustment of the in-pile thermocouple readings may be made. The implication is that a portion of the change in center temperature that occurred late in the irradiation cycle ${ }^{(7)}$ was caused by a change in thermocouple emf readings.

\subsubsection{Capsule Series E1J (Effect of Stoichiometry on Effective Thermal Conductivity of Restructured Fuel)}

Capsule E1J-7, containing stoichiometric fuel was irradiated in GETR following the 88-hour irradiation cycle as previously 


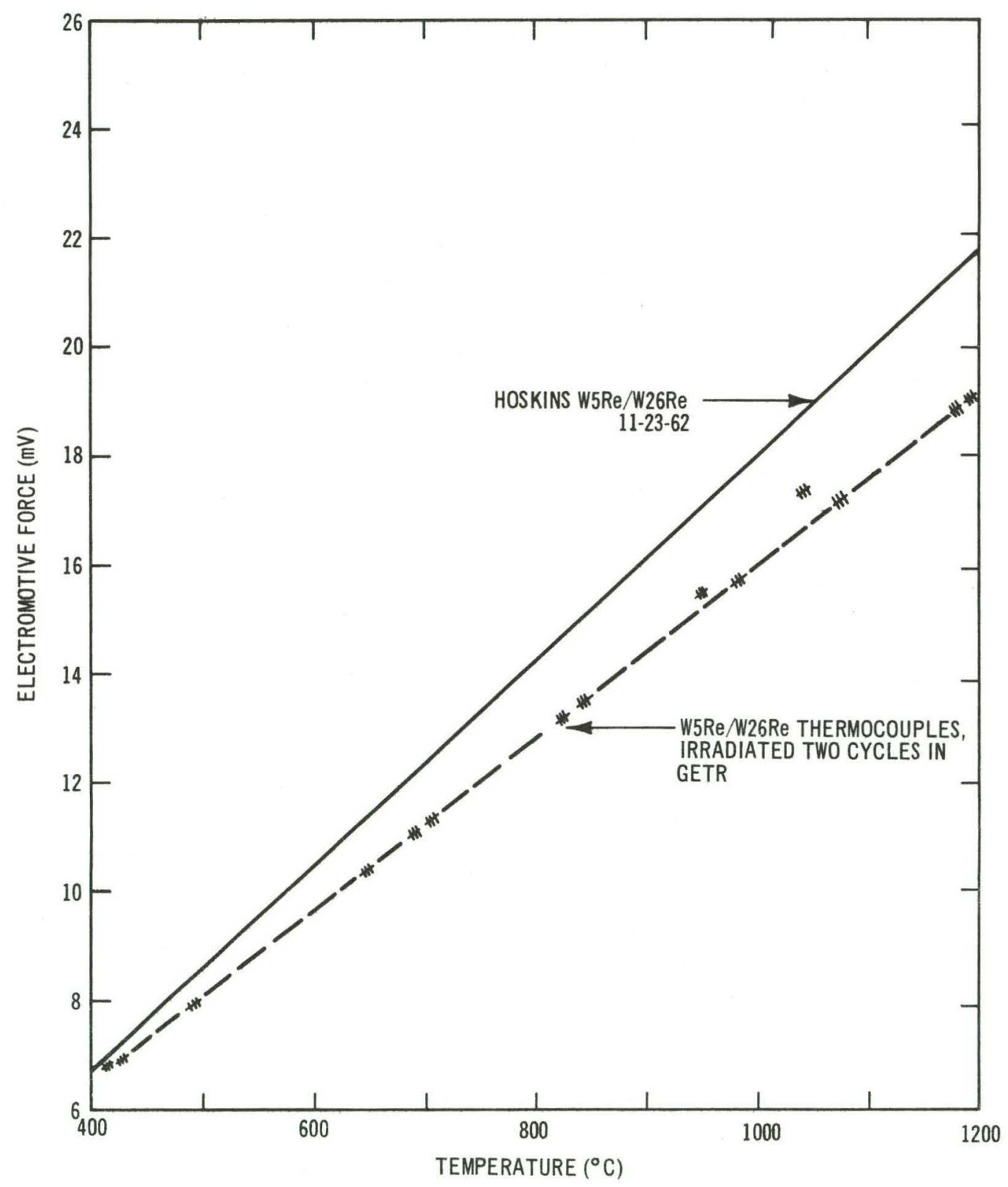

FIGURE 5-1. CALIBRATION DATA OF IRRADIATED W5Re/W26Re THERMOCOUPLES 
described $^{(7)}$ in which a central void was allowed to form prior to melting. Calculations of $\int_{\mathrm{Ts}}^{\mathrm{Tm}} \mathrm{kd} \theta *$ were made using the microstructural markers of grain growth and melting as shown in Figure 5-2. Several interpreations of the microstructure defining the melt radius have been suggested and are noted in Figure 5-2. $(9,10)$ Considering Zone $\mathrm{B}$ to be the preferred melting diameter, ${ }^{(9)}$ the value of

\section{$\int_{\mathrm{Ts}}^{*} \mathrm{Tm} \theta$ refers to the integral conductivity}

of fuel between the fuel surface temperature (Ts) and fuel melting temperature (Tm).

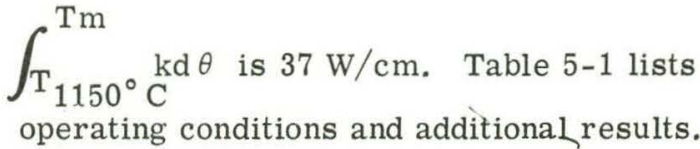

Figure 5-3 shows a comparison of the results of this experiment with those of other workers. Comparing the values of the integral at $2750^{\circ} \mathrm{C}^{(11)}$ (melting point of the fuel), the Baily, et al. $(12,13)$ data are in good agreement with this work.

\section{Additional capsules, E1J-1 and} $\mathrm{E} 1 \mathrm{~J}-5$, containing fuel with $\mathrm{O} / \mathrm{M}$ ratios of 1.94 and 1.97 respectively have been irradiated under similar conditions and are awaiting examination.

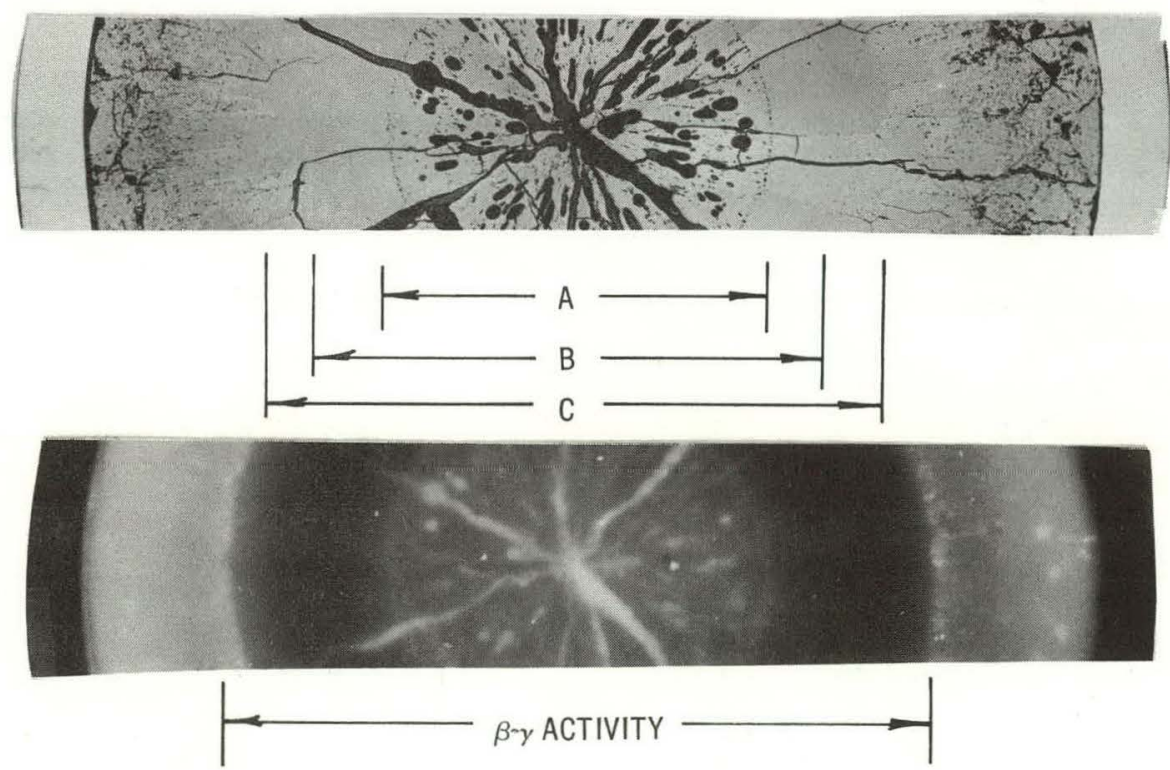

THE THREE ZONES DESIGNATED A, B, C CORRESPOND TO OUTER RADIUS OF POROUS FUEL, THE INITIATION OF PORES WITHIN DENSE GRAINS, AND THE ORIGIN OF COLUMNAR GRAINS RESPECTIVELY. CALCULATIONS ARE BASED UPON ZONE B REPRESENTING THE RADIUS OF MELTING. 
TABLE 5-1

E1J-7, FUEL PARAMETERS, OPERATING CONDITIONS AND RESULTS

Fuel

Composition, $\mathrm{PuO}_{2}$

Theoretical Density

$\mathrm{O} / \mathrm{M}$

Fuel-Cladding Gap
$24.64 \%$

$91.9 \%$

2. 000

$0.003 \mathrm{mil}$

Operating Conditions and Results

Linear Power

Temperature Cladding Inside Diameter

Fuel Surface Temperature

Gap Conductance

Psf $\left(\mathrm{r}_{\text {egg }}\right)$ *

Psf $\left(r_{\text {cgg }}\right)$

Psf $(r), \beta-\gamma$ activity

Psf $\left(\mathrm{r}_{\mathrm{m}}\right)$, Zone A

Psf $\left(r_{m}\right)$, Zone $B^{* *}$

Psf $\left(\mathrm{r}_{\mathrm{m}}\right)$, Zone $\mathrm{C}$

$\mathrm{T}_{\text {egg }}$

$\mathrm{T}_{\text {cgg }}$

Tm (Solidus)

$\int_{\mathrm{T}_{1150}{ }^{\circ} \mathrm{C}}^{\mathrm{T}} \mathrm{egg} \mathrm{d} \theta$

$\int_{\mathrm{T}_{1150^{\circ} \mathrm{C}}^{\mathrm{T}} \operatorname{cgg} \mathrm{kd} \theta}$

$\int_{\mathrm{T}_{1150}{ }^{\circ} \mathrm{C}}^{\mathrm{T}} \mathrm{T}-\gamma$ activity $k d \theta$

$\int_{\mathrm{Ts}}^{\mathrm{Tm}} \mathrm{kd} \theta$, Zone A

$\int_{\mathrm{Ts}}^{\mathrm{Tm}} \mathrm{kd} \theta$, Zone $\mathrm{B}^{* *}$

$\int_{\mathrm{Ts}}^{\mathrm{Tm}} \mathrm{kd} \theta$, Zone C
$24.0 \mathrm{~kW} / \mathrm{ft}$

$1214^{\circ} \mathrm{F}\left(655^{\circ} \mathrm{C}\right)$

$1150^{\circ} \mathrm{C} \pm 20^{\circ} \mathrm{C}\left(2102^{\circ} \mathrm{F} \_36^{\circ} \mathrm{F}\right)$

$1610 \div 70 \mathrm{Btu} / \mathrm{h}-\mathrm{ft}^{2}{ }^{2}{ }^{\circ} \mathrm{F}$

$0.185 \mathrm{mil}$

$0.315 \mathrm{mil}$

0.440

0.645

$0.590 * *$

0.525

$1715^{\circ} \mathrm{C}+35^{\circ} \mathrm{C}$

$2080^{\circ} \mathrm{C} \pm 30^{\circ} \mathrm{C}$

$2750^{\circ} \mathrm{C} \pm 25^{\circ} \mathrm{C}$

11. $6 \mathrm{~W} / \mathrm{cm}$

19. $8 \mathrm{~W} / \mathrm{cm}$

$27.6 \mathrm{~W} / \mathrm{cm}$

$40.5 \mathrm{~W} / \mathrm{cm}$

37. $0 * * \mathrm{~W} / \mathrm{cm}$

$32.9 \mathrm{~W} / \mathrm{cm}$

NOTES: *Psf - Power shape factor covering fuel geometry and neutron flux suppression. $\left(\mathrm{r}_{\text {egg }}\right)$ - Equiaxed grain growth radius.

$\left(\mathrm{r}_{\mathrm{cgg}}\right)$ - Columnar grain growth radius.

$\left(\mathrm{r}_{\mathrm{m}}\right)$ - Melting radius.

***Preferred boundary of melting. 


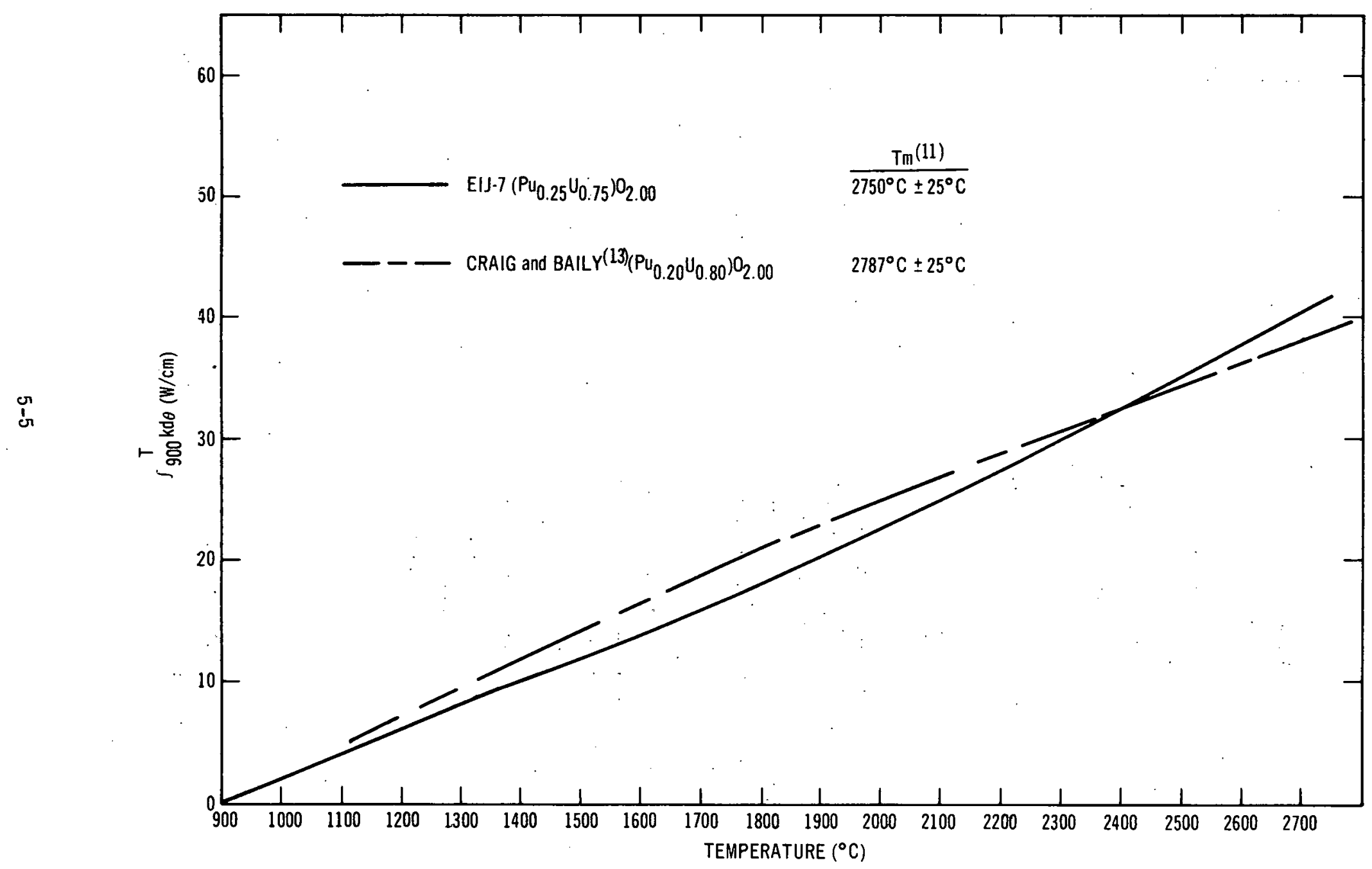




\subsection{HIGH BURNUP IRRADIATIONS}

\subsubsection{Capsule E2P/E2Q (Swelling under Axial Restraint in 15- and 10-mil Tubing)}

Capsules E2P and E2Q were removed from GETR after two additional cycles of irradiation at power levels estimated at $15 \mathrm{~kW} / \mathrm{ft}$ and at burnups of 8900 and 9400 $\mathrm{MWd} / \mathrm{Te}$, respectively. The pins were removed from their capsules for profilometry and gamma scanning and then reencapsulated and inserted in GETR for additional irradiation.

Profilometer traces of the two pins are shown in Figure 5-4. The diametral increases of the two pins are attributed to thermal expansion of the fuel closing the $1 \pm 0.5 \mathrm{mil}$ diametral gaps and then subsequent straining of the cladding. The average $\Delta D$ values for E2Q with 10 mil cladding exceed that of E2P with 15 mil tubing; significant ridging of the thin wall tubing was measured at pellet interfaces. It is not certain why the top ends of both pins showed the greatest diametral strain since the exposure and thermal profiles of the two pins were not the same; that is, E2P peak power was at the top of the pin while in E2Q it was at the bottom. This is manifest in the gamma scans of the two pins (Figure 5-5). The higher burnup of $E 2 Q$ in relation to E2P is also evident from Figure 5-5. The positions of the fuel pins will be reversed for the next irradiation period to obtain equivalent lifetime average power and burnup.

\subsubsection{Capsules E5C, E5D, E5E} (High Burnup Tests of Long Fuel Columns)

Capsules E5C, E5D and E5E were removed from GETR after 19 months of irradiation at linear powers of $19 \mathrm{~kW} / \mathrm{ft}$. Fuel burnup is approximately $130,000 \mathrm{MWd} / \mathrm{Te}$. These capsules contain 16-inch long columns of physically blended fuel and were designed to compare the performance of soilid pellets, annular pellets, and vi-pack powder in relatively long pins.

\section{4 PHYSICAL PROPERTY STUDIES}

\subsubsection{Mechanical Properties}

Analysis of the creep and plasticity data on stoichiometric $\mathrm{UO}_{2}$ has been completed. The steady state response of the material as a function of temperature, stress, grain size, and density can be described by the equation:

$$
\begin{aligned}
\dot{\epsilon} & =\mathrm{A} \sigma \exp (-90,000 / \mathrm{RT}) \\
& +\mathrm{B} \sigma^{4.5} \exp (-132,000 / \mathrm{RT})
\end{aligned}
$$

where,

$$
\begin{aligned}
& A=\frac{1}{\left(-9.02 \times 10^{-6}+1.03 \times 10^{-7} \mathrm{D}\right) \mathrm{G}^{2}} \\
& B=\frac{1}{-6.58 \times 10^{5}+7.27 \times 10^{3} \mathrm{D}}
\end{aligned}
$$

and where:

$$
\begin{aligned}
& \dot{\epsilon}=\text { steady state creep rate } \\
& \sigma=\text { applied stress in psi } \\
& \mathrm{R}=1.986 \text { calories } / \mathrm{mole}^{\circ} \mathrm{K} \\
& \mathrm{T}=\text { temperature }{ }^{\circ} \mathrm{K} \\
& \mathrm{D}=\% \text { theoretical density } \\
& \mathrm{G}=\text { grain size in microns }
\end{aligned}
$$

Comparison of the 90 experimental data points with creep rates calculated from this expression indicates that there is $90 \%$ confidence that the calculated behavior will be within $\pm 2 \circ \%$ of an experimental test. This level of confidence in the expression applies when variables are within the following ranges:

- Stress $\quad 1000$ to 16,000 psi 
LEGEND:

EP, 15 mil TUBING

WALL THICKNESS

- - - EQ, 10 mil TUBING,

WALL THICKNESS

I

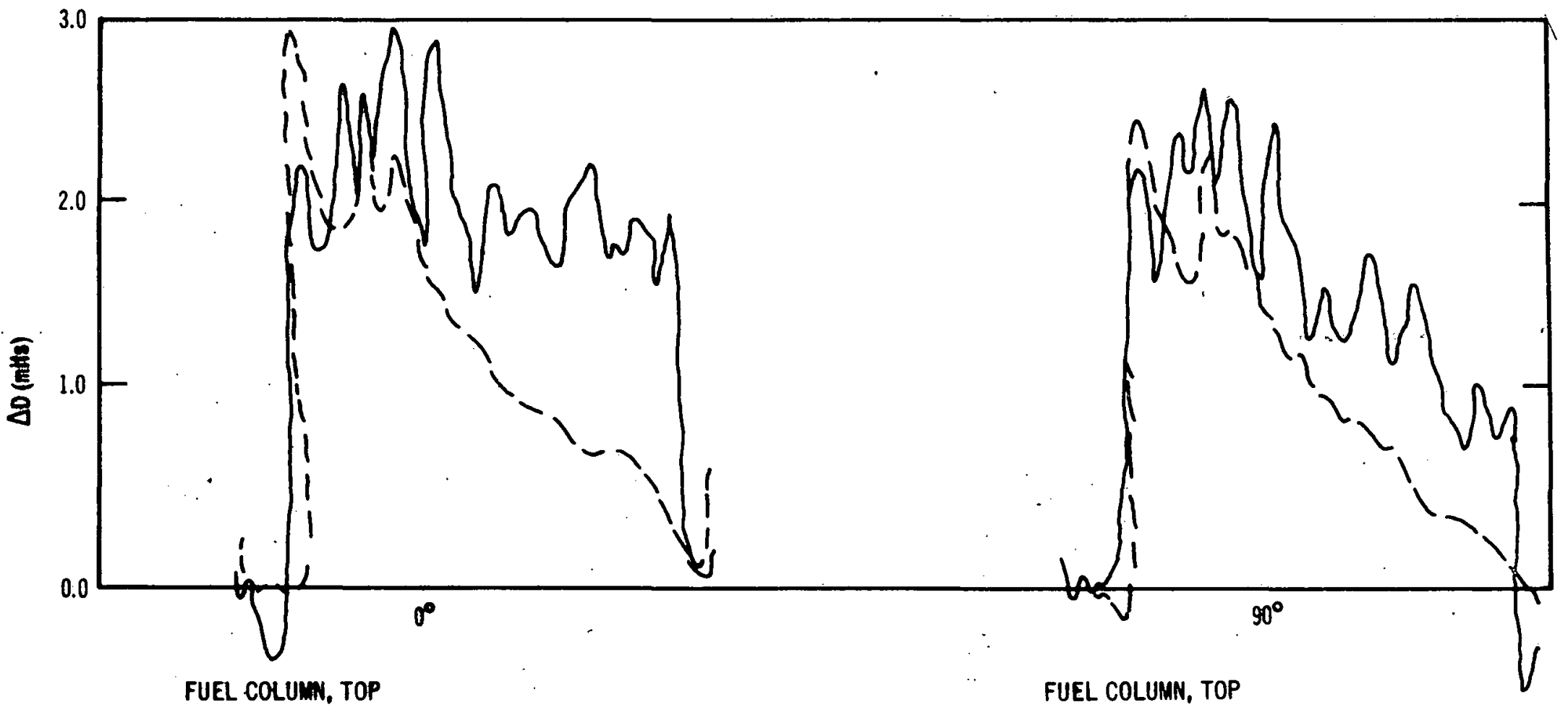

FIGURE 5-4. PROFULUETER TRACES OF PANS E2P AND EZO AT FIRST MTERIM EXAMINATION AT 


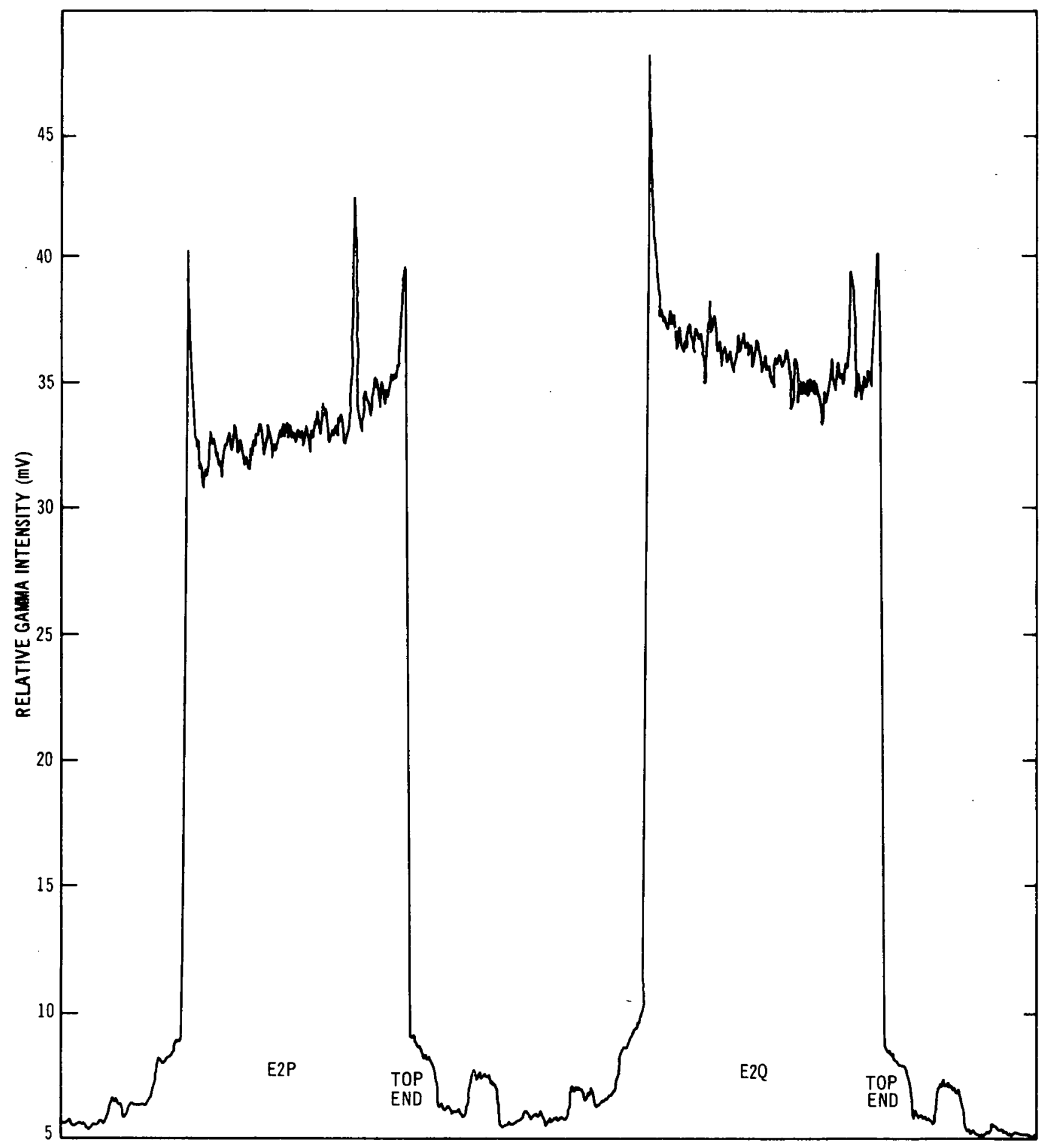

FIGURE 5-5. GAMMA SCAN OF CAPSULE E2P (8900 MWd/To) AND E20 (9400 MWd/T॰) 


\section{GEAP-10028}

- Temperature $1440^{\circ} \mathrm{C}$ to $1760^{\circ} \mathrm{C}$

- Density $90 \%$ to $98 \%$ theoretical

- Grain Size 4 to 30 microns

Figure 5-6 shows the relationship between experimental data and curves plotted from the derived expression.
Installation of the compression creep apparatus in a plutonium glovebox has been completed. A thorough checkout of the equipment remains to be done before testing begins on mixed. oxide samples. 


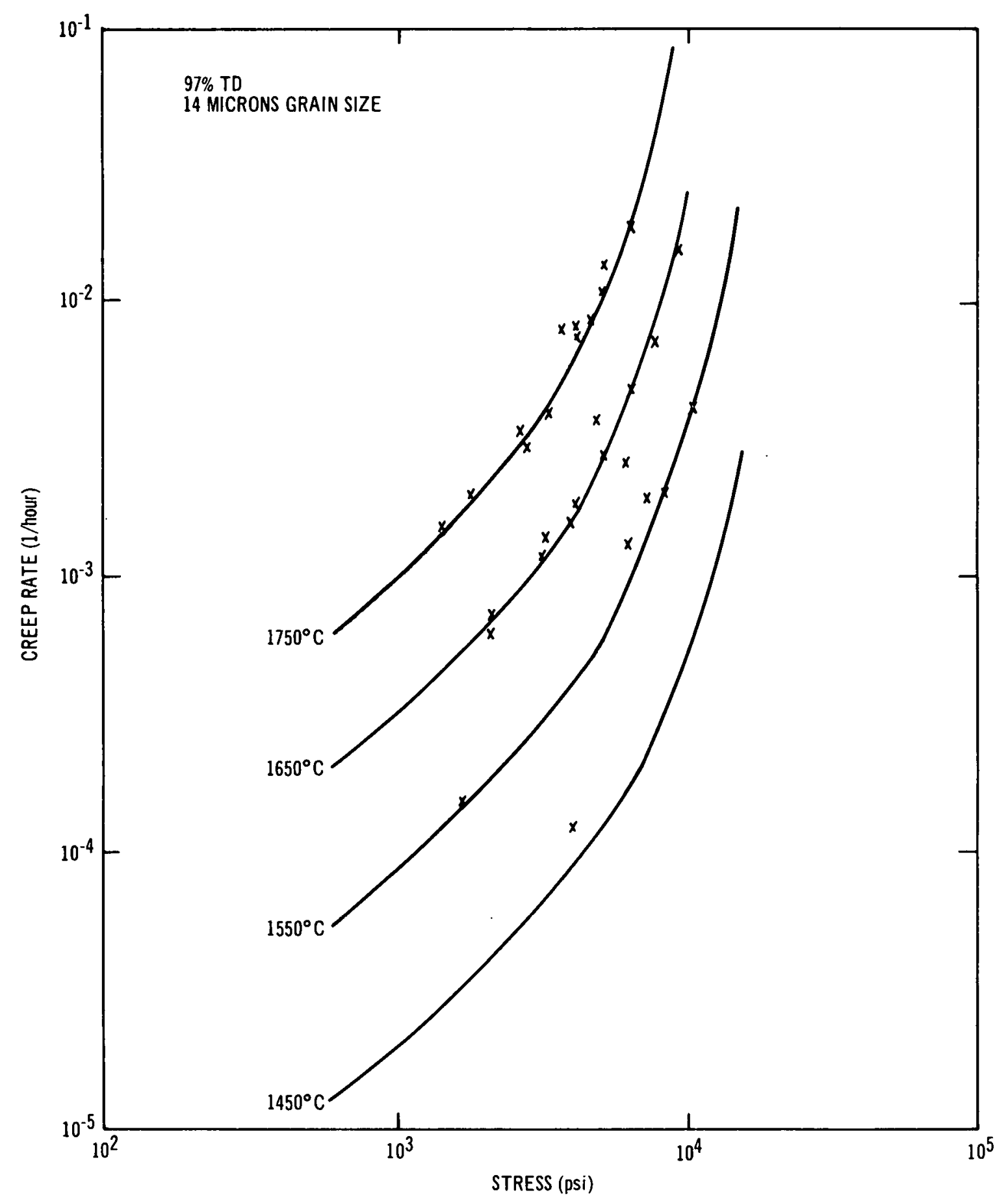

FIGURE 5-6. CREEP RATE VERSUS STRESS FOR STOICHIOMETRIC UO 


\section{SECTION VI}

\section{TASK F-INTEGRAL FAST FLUX IRRADIATIONS}

\section{1 GENERAL}

This task factors the more promising results of the basic fuel technology developments into the design, fabrication, and integral testing of fuel elements in fast fluxes. Important fuel performance characteristics, such as fission gas release, fuel-cladding interactions, and fuel thermal performance, are determined under conditions simulating, as closely as possible, those expected in a fast ceramic reactor. Testing of fuel pins in a fast flux, in principle, will permit testing of fuel bundles under fair approximation of prototypical conditions, although this has not as yet been possible in EBR-II.

The test parameters for Task $\mathrm{F}$ are selected by a combination of design analysis (which relies on basic properties data) and on the results of selected experiments (such as those in Task $\mathrm{E}$ and Task $\mathrm{L}$ ). In addition, the results of prior fast-flux irradiation tests are interpreted as quantitatively as possible to guide the selection of future tests. The selection of test parameters is also influenced and guided by the work under. Task $C$, which focuses on the preferred range for safety considerations of LMFBR designs. Demonstration of high fuel burnup $(50,000$ to $100,000 \mathrm{MWd} / \mathrm{Te})$ is required over a range of power levels ( 4 to $24 \mathrm{~kW} / \mathrm{ft}$ ). Fuel parameters that are under study in a fast environment include density, configuration, fabrication process history, stoichiometry, diametral gap, axial gap, and external . restraint. Fast flux tests are performed with both encapsulated and unencapsulated pins.

\section{2 MEDIUM POWER, LONG TERM IRRADIATIONS}

\subsubsection{Group 2 (Medium Power Scoping Irradiations)}

Post irradiation examination of the Group-2 capsules removed from EBR-II subassembly XG05 after calculated peak fuel burnups of $\sim 75,000 \mathrm{MWd} / \mathrm{Te}$ was completed. Table 6-1 describes the Group-2 fuel pin variables and current status. Results of the examination of these capsules were partially reported in previous quarterlies. $(1,14)$ Figures 6-1 through 6-6 are the gamma scans and profilometer traces of fuel pins F2H, F2R, and F2T. The gamma scans and profilometry traces of fuel pins F2C and F20 were presented in the 27 th quarterly report. ${ }^{(1)}$ The relationship between the fuel pin profilometer traces and the cold diameter of the fuel pellets within each fuel pin (except the failed pin F20) are shown in Figures 6-7 through 6-10. There was no apparent relationship between the diametral increase observed for pin F2T in which the fuel column was axially restrained and the diametral increases in unrestrained pins F2C, F2H, and F2R. A topical report is being prepared on the results of the examination of these fuel pins.

The four remaining Group-2 capsules (F2D, F2G, F2V, and F2X) were reinserted into the EBR-II on February 25, 1969 at the start of run 33 for irradiation toward a target burnup of $100,000 \mathrm{MWd} / \mathrm{Te}$. The fuel pins in these capsules can be the first mixed oxide fuel to reach a burnup of $100,000 \mathrm{MWd} / \mathrm{Te}$ in EBR-II. Peak calculated burnup on these 
TABLE 6-1

\section{SUMMARY OF GROUP 2 FUEL PIN TEST PARAMETERS}

\begin{tabular}{|c|c|c|c|c|c|c|}
\hline$\underline{\mathrm{PIN}}$ & $\begin{array}{l}\text { TYPE } \\
\text { FUEL }\end{array}$ & $\begin{array}{c}\text { SMEARED } \\
\text { DENSITY } \\
\text { (\% of Theoretical) } \\
\end{array}$ & $\underline{O} / \mathrm{M}$ & $\begin{array}{l}\text { CLADDING } \\
\text { TYPE } \\
\end{array}$ & $\begin{array}{c}\text { INITIAL } \\
\text { DIAMETRAL } \\
\text { GAP } \\
\text { (inches) } \\
\end{array}$ & $\begin{array}{c}\text { CALCULATED } \\
\text { BURNUP } \\
\text { (MWd/Te) } \\
\end{array}$ \\
\hline F2C & $\mathrm{SP} * *$ & 93.1 & 2.00 & Inc -800 & 0.0027 & 71,000 \\
\hline$\cdot \mathrm{F} 2 \mathrm{H}$ & SP & 94.9 & 1. 98 & $316 \mathrm{SS}$ & 0.0021 & 74,000 \\
\hline F2R & SP & 95.2 & 2.00 & $347 \mathrm{sS}$ & 0.0015 & 71,000 \\
\hline $\mathrm{F}^{2} \mathrm{~T}^{*}$ & SP & 94.6 & 2.00 & 347 SS & 0.0023 & 74,000 \\
\hline
\end{tabular}

STATUS: Post-irradiation examination complete. Report in progress.

$\begin{array}{llcc} & \text { F2F } & \text { SP } & 94.6 \\ \text { F2O } & \text { SP } & 94.0 \\ & \text { STATUS: } & \text { Both pins failed. } & \text { Report in progress. }\end{array}$

\begin{tabular}{|c|c|c|c|c|c|c|}
\hline F2D & SP & 94.9 & 2.00 & $347 \mathrm{SS}$ & 0.0023 & 73,000 \\
\hline F2G & SP & 92.9 & 1. 98 & 347 SS & 0.0032 & 71,000 \\
\hline F $2 \mathrm{~V}$ & SP & 86.8 & 1.99 & 316 SS & 0.0034 & $.70,000$ \\
\hline F2X & $\mathrm{VP} * * *$ & 83.0 & 1.99 & 316 SS & ---- & 59,000 \\
\hline
\end{tabular}

STATUS: Reinserted into EBR-II for further irradiation.

* Fuel Column was axially restrained.

** SP $=$ solid pellet fuel.

*** VP = vibratory compacted powder fuel. 


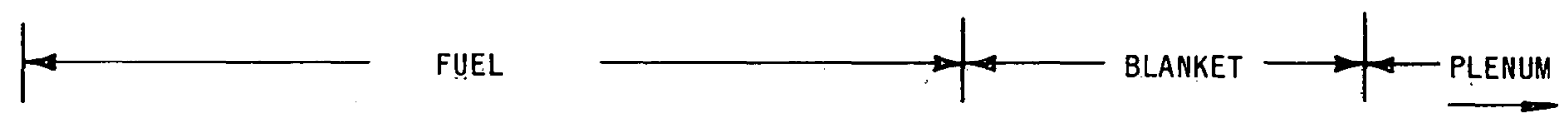

i

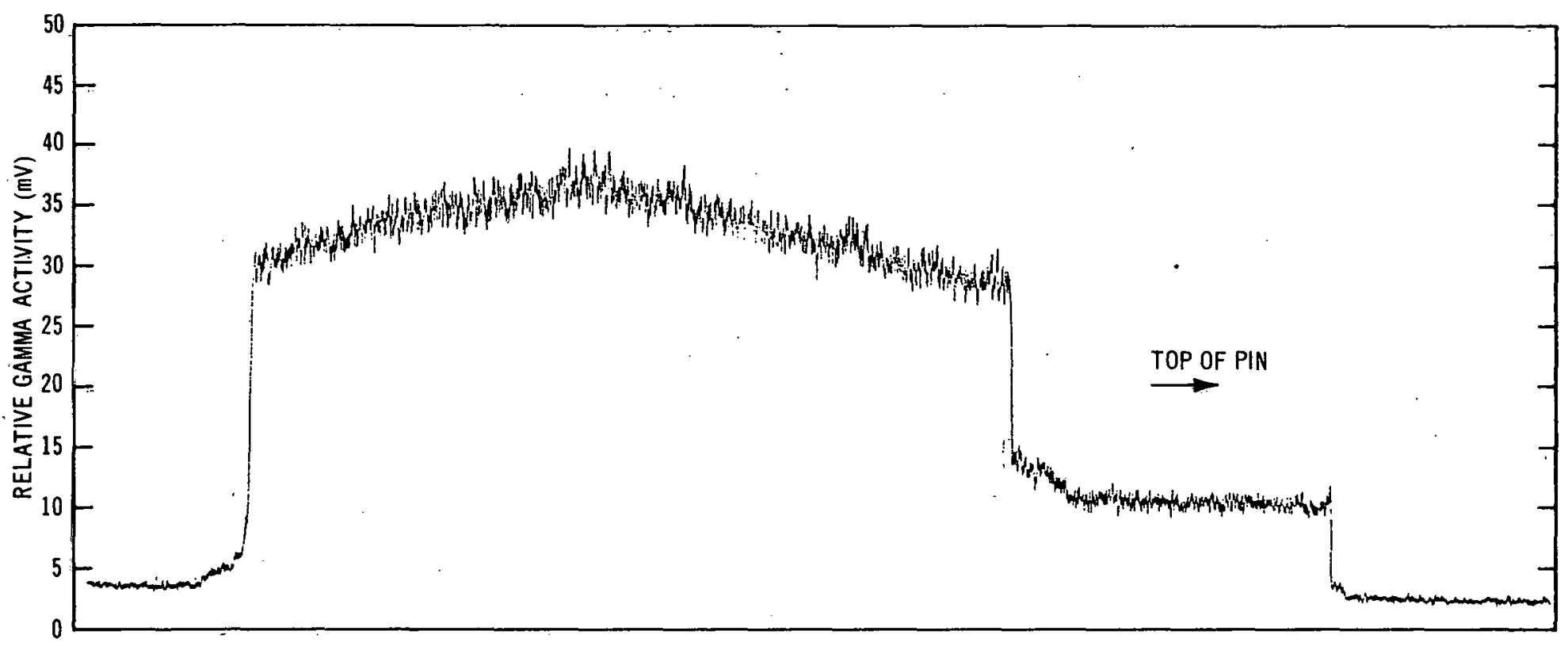

FIGURE 6 -1 GROSS GAMMA SCAN OF FUEL PIN FsH 


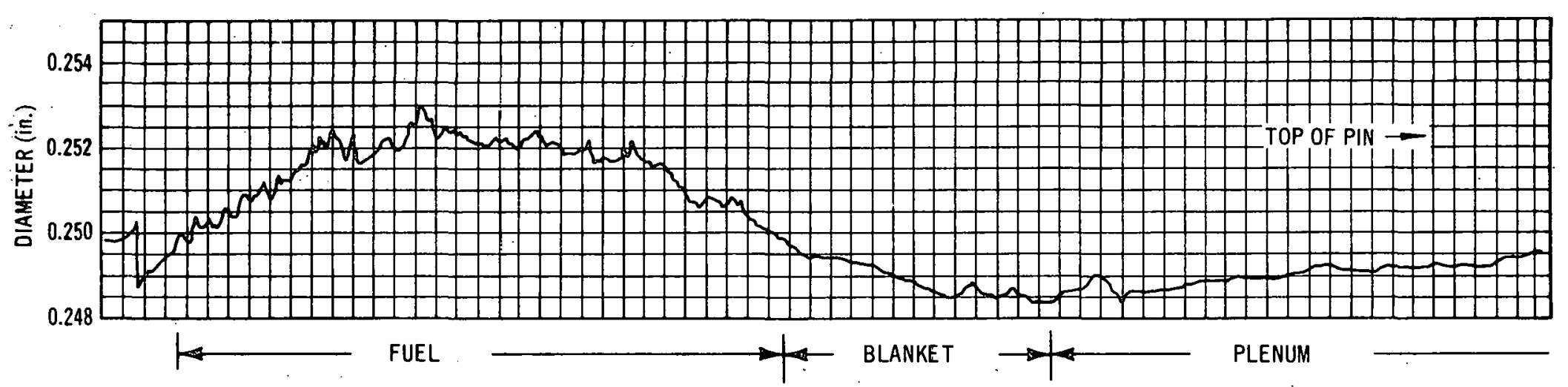

(a) $0^{\circ}$ ORIENTATION
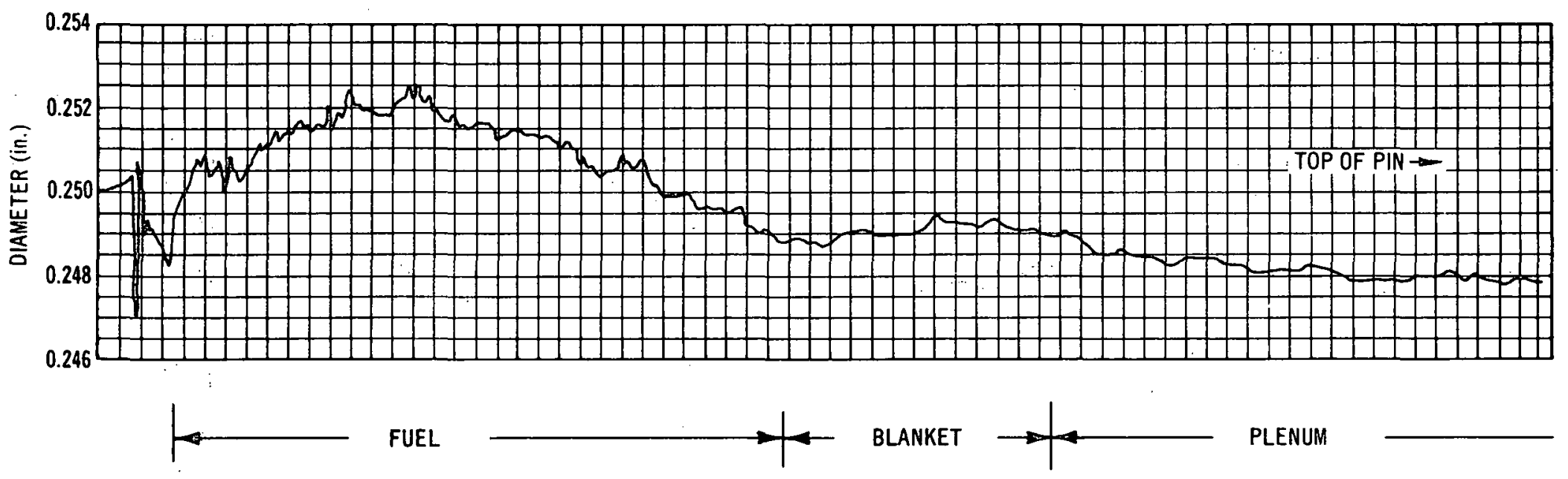

(b). $90^{\circ}$ ORIENTATION 


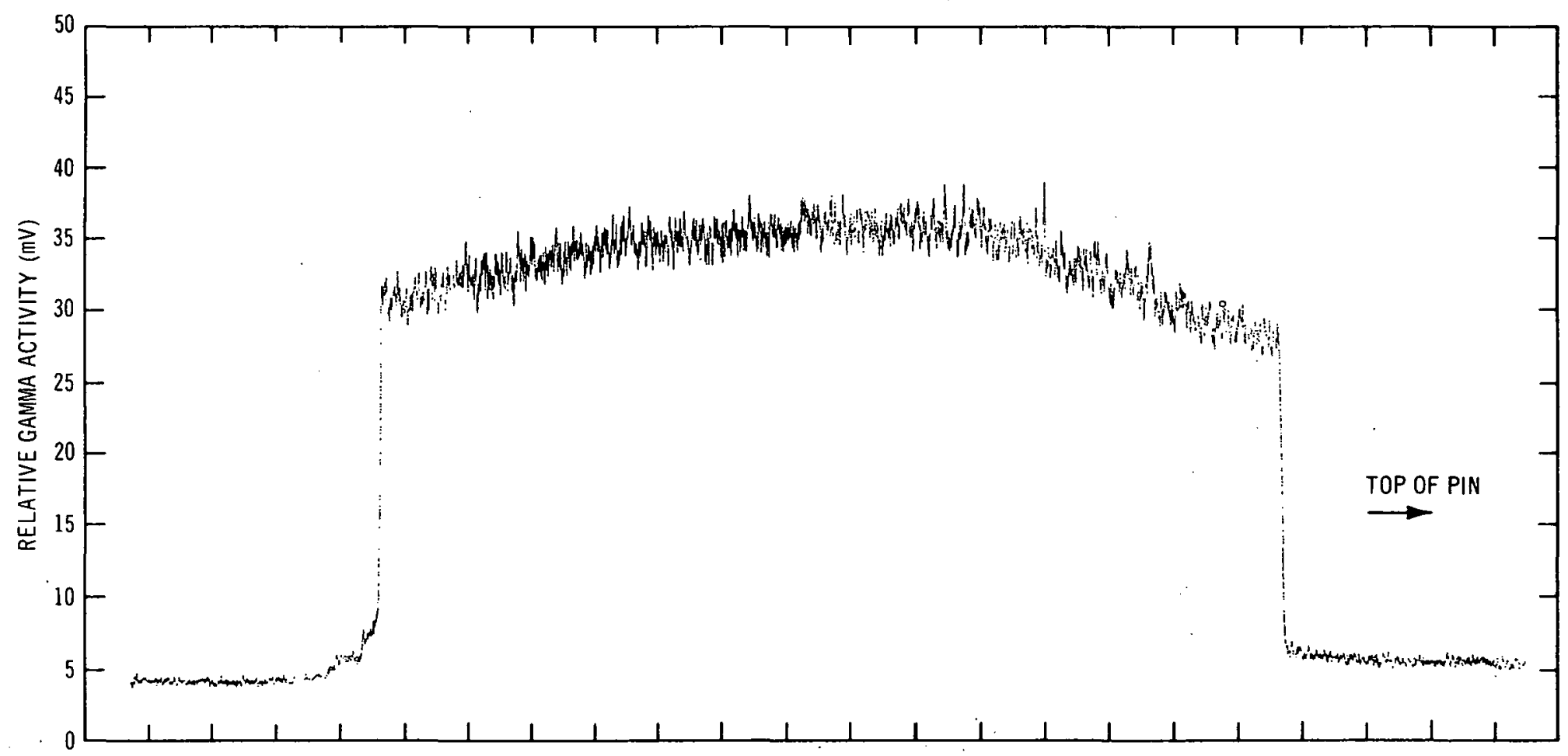




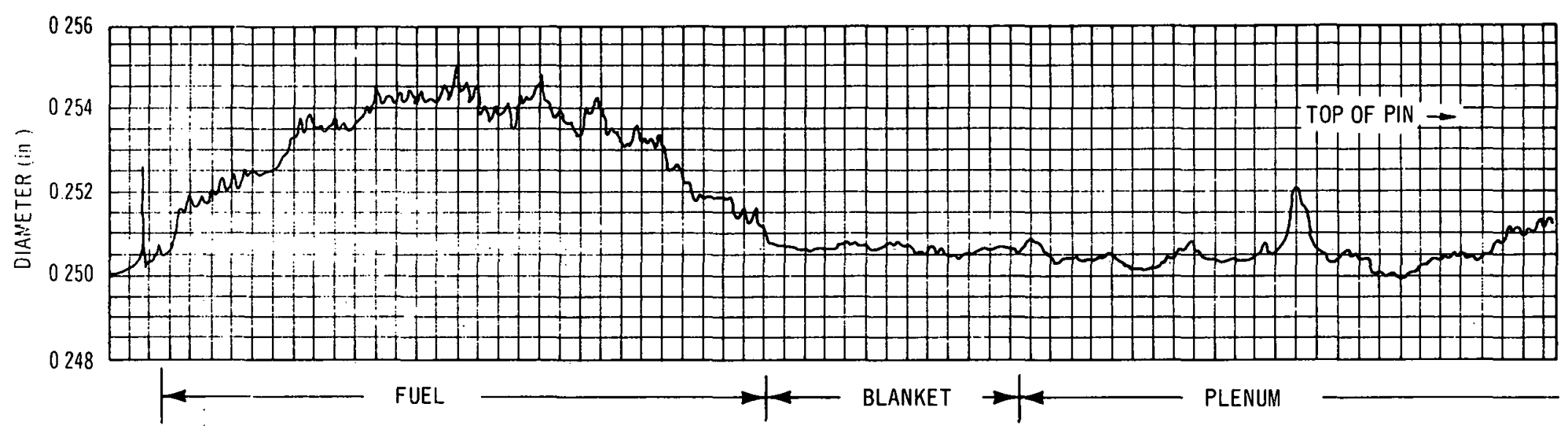

(a) $0^{\circ}$ ORIENTATION

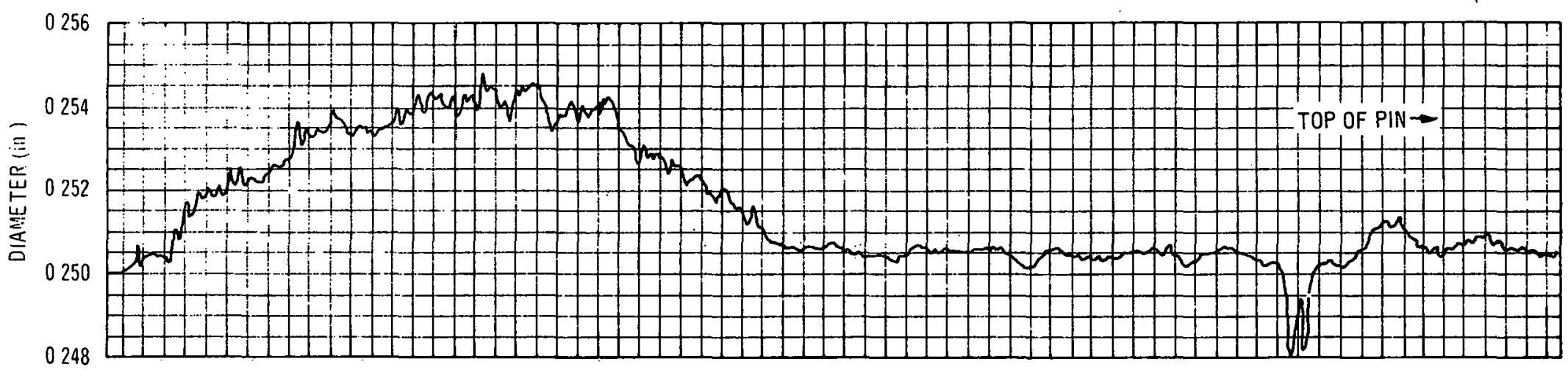




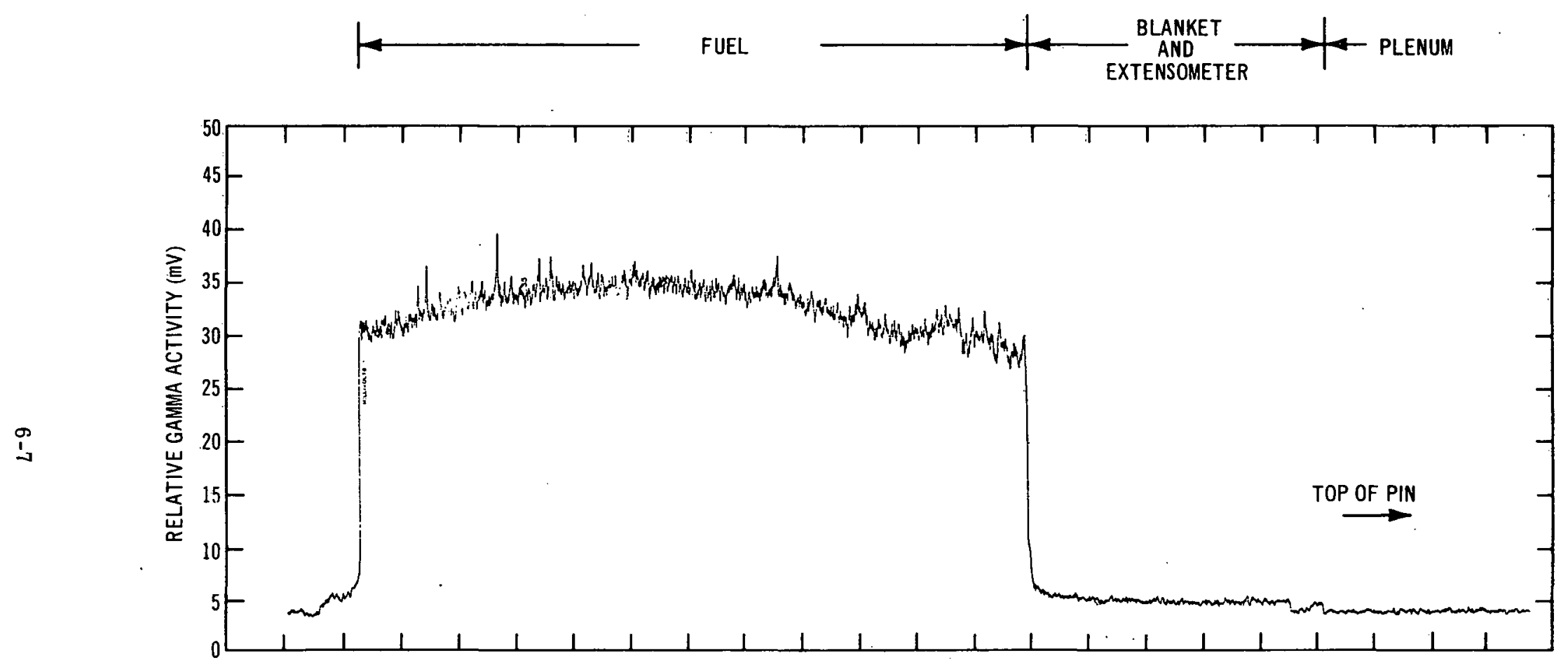




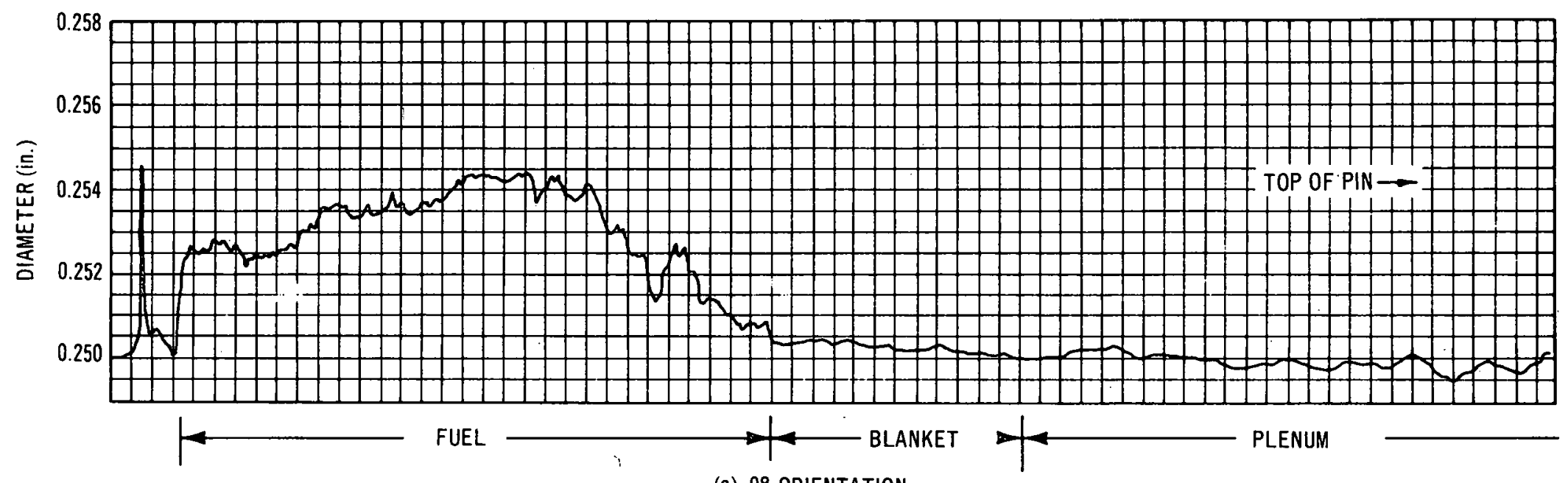

b.

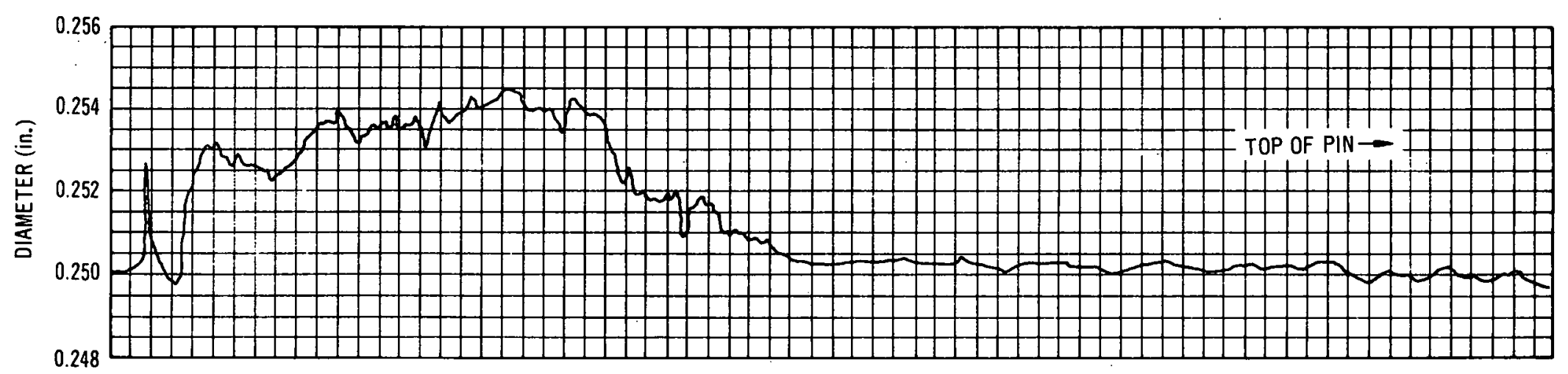

FUEL

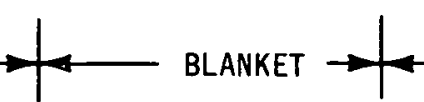

PLenum

(b) $90^{\circ}$ ORIENTATION

FIGURE 6-6. PROFHLMETER TRACES OF FUEL PIN F2T 

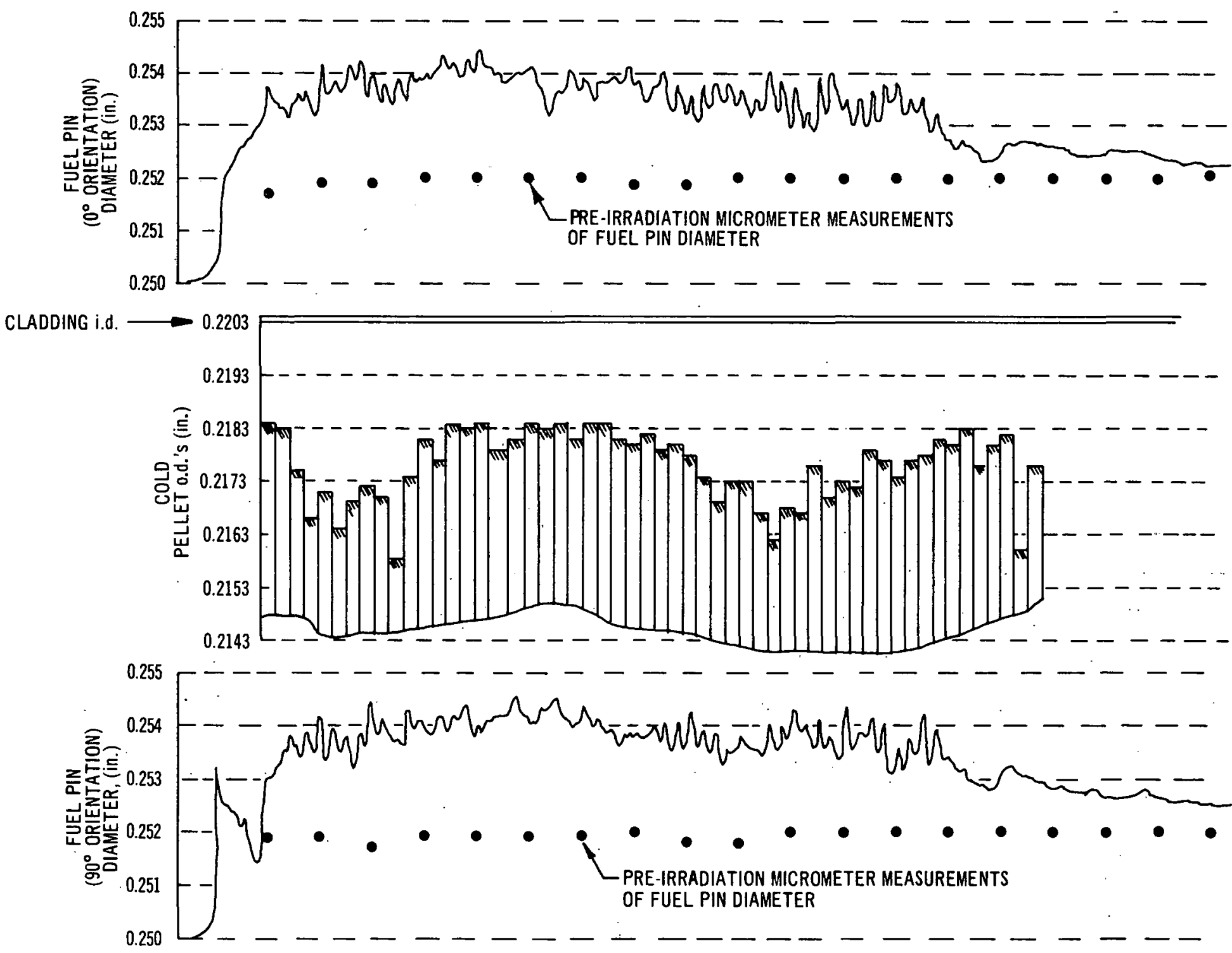

FIGURE 6-7. RELA TIONSHIP BETWEEN PELLET 0.D. AND THE FUEL PIN PROFILOMETER TRACES OF FUEL PIN F2C 

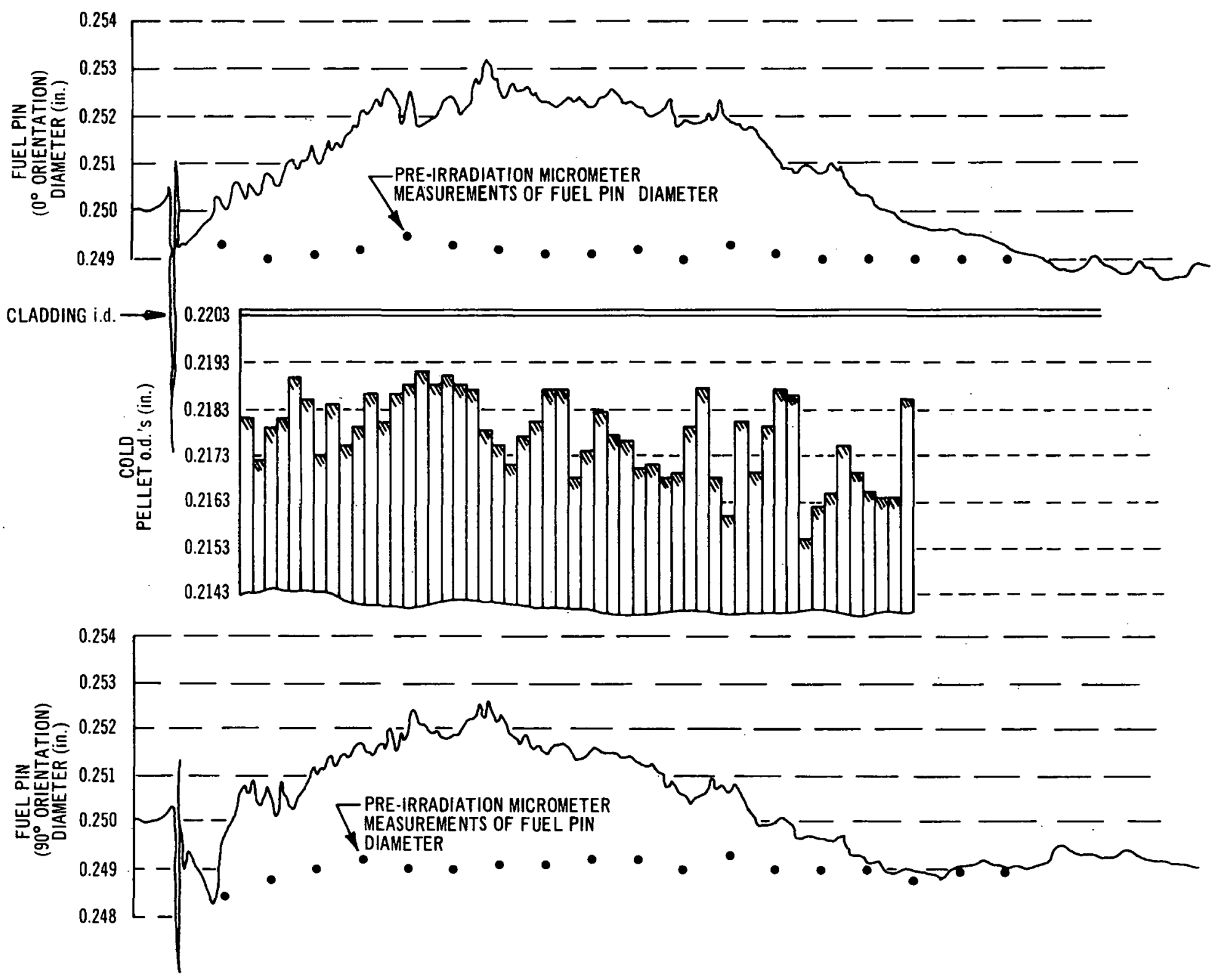

FIGURE 6-8. RELATIONSHIP BETWEEN PELLET O.D. AND THE FUEL PIN PROFILOMETER TRACES OF FUEL PIN F2H 


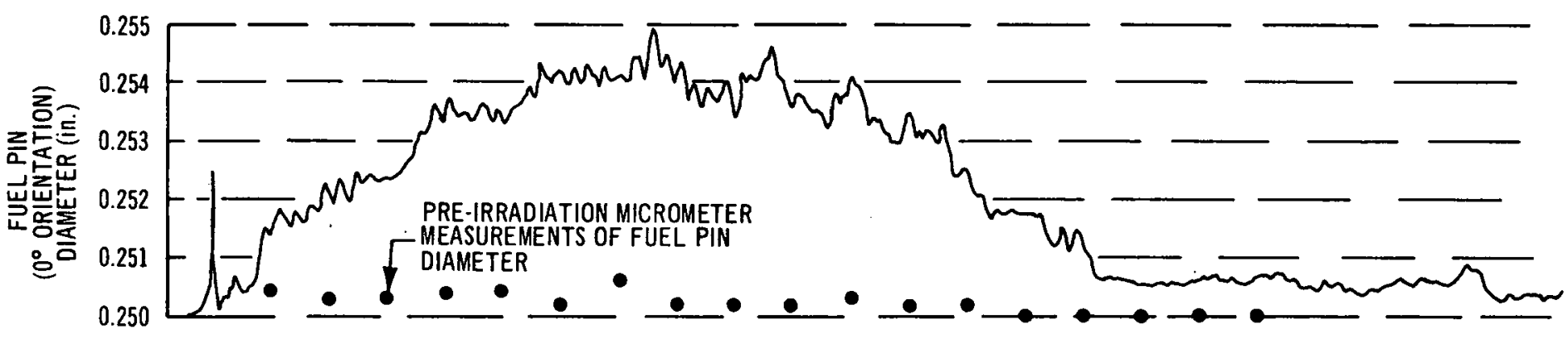

CLADDING i.d. $\rightarrow 0.2203$
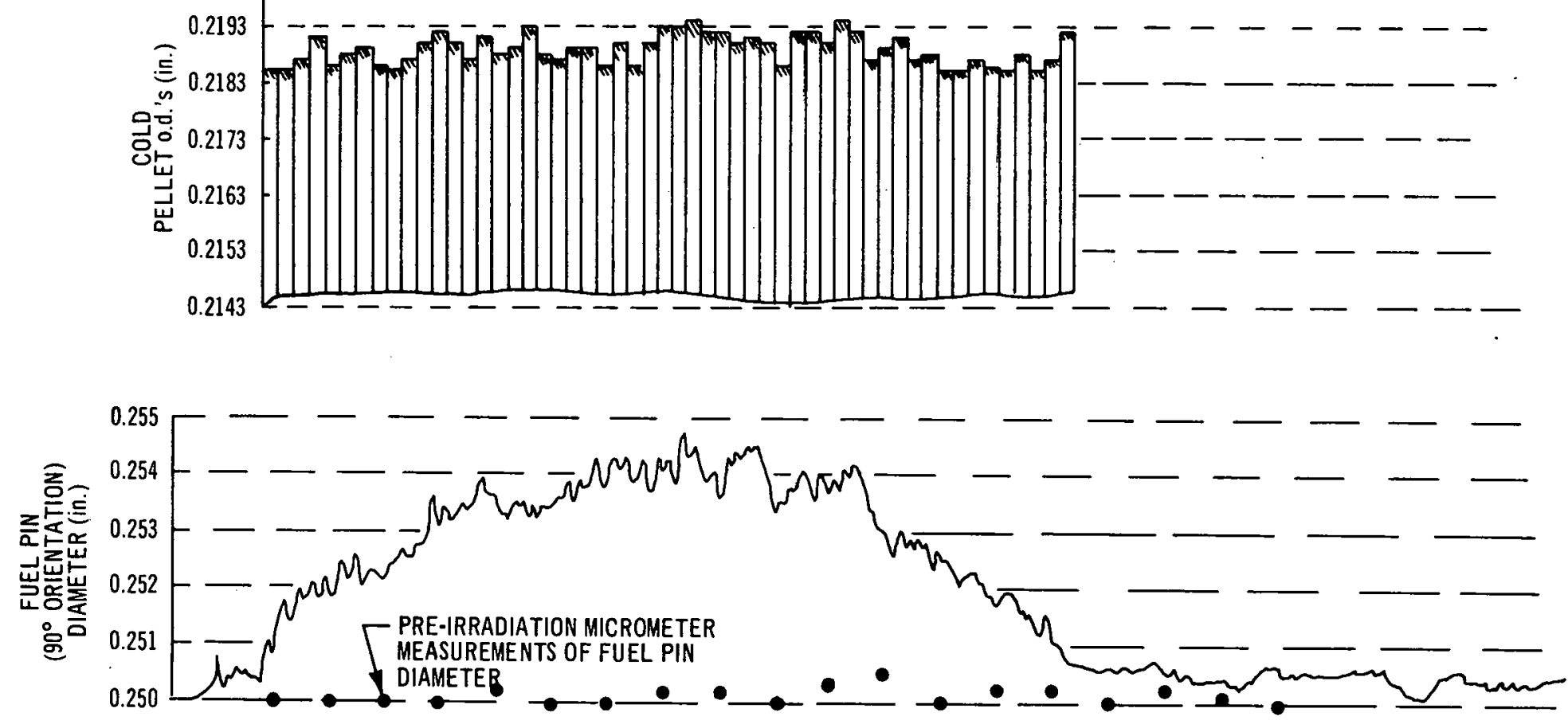

FIGURE 6-9. RELATIONSHIP BETWEEN PELLET O.D. AND THE FUEL PIN PROFILOMETER TRACES OF FUEL PIN FZH 


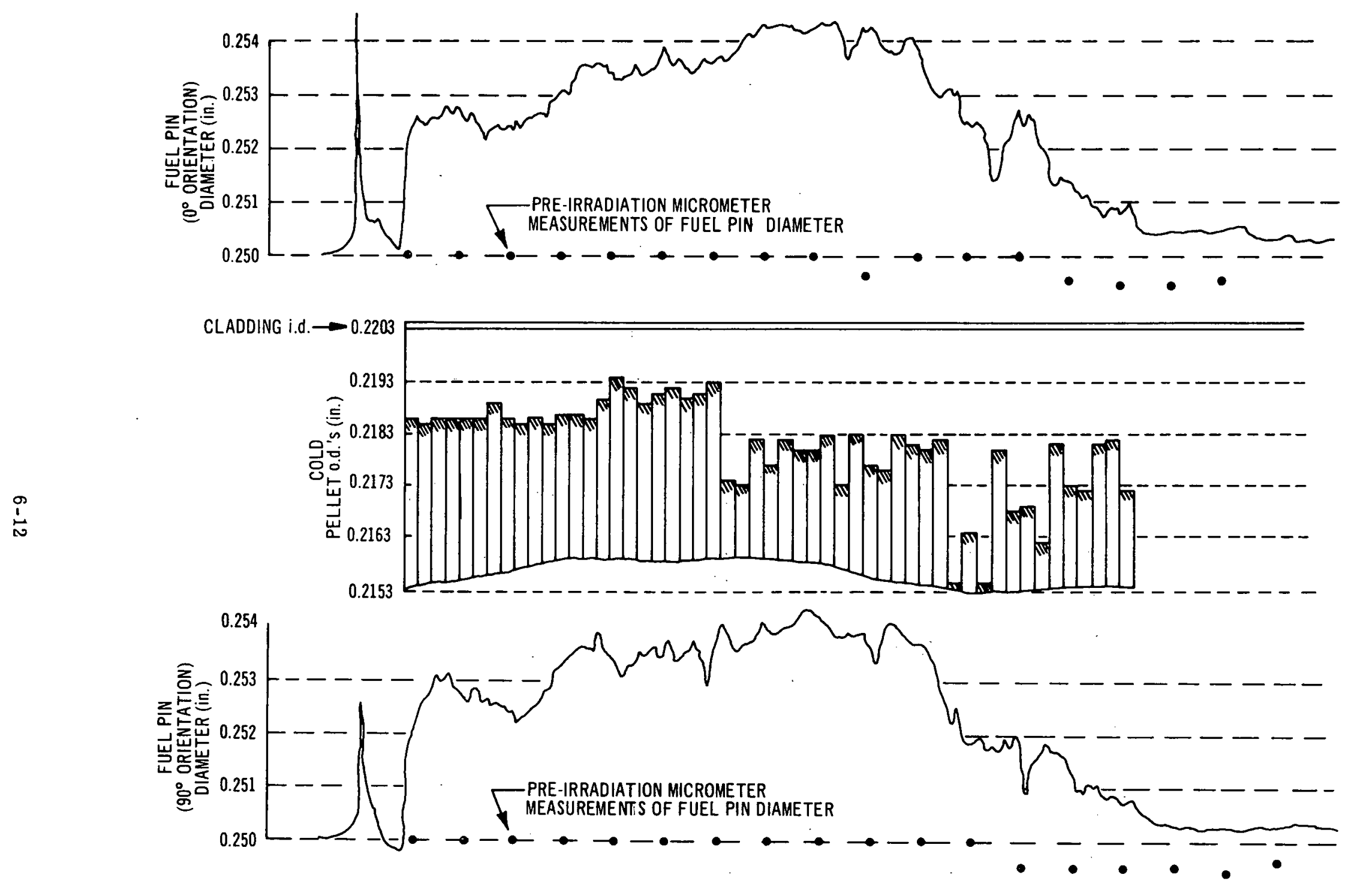

FIGURE 6-10. RELATIONSHIP BETWEEN PELLET O.D. AND THE FUEL PIN PROFILOMETER TRACES OF FUEL PIN F2T 
capsules was 74,700 MWd/Te as of April 15, 1969.

Metallographic examination of failed pin, F20, in the Group- 2 series was continued. A cross section of the fuel pin is shown in Figure 6-11. Extensive grain boundary attack of the hyperstoichiometric fuel was observed. Around the perimeter of the fuel and between the fuel and cladding, a rim of fuel-sodium reaction product with thicknesses of up to 20 mils was observed. This is approximately four times the thickness of the reaction layer observed in the failed F4F pin. (1) The differences in the thickness of the reaction layer are believed to be caused by the difference in stoichiometry of the fuel in each pin. Pin F20 contained fuel with an $\mathrm{O} / \mathrm{M}$ of 2.04 while the fuel in F4F was stoichiometric $(2.00 \mathrm{O} / \mathrm{M})$.

Approximately 0.001-inch of intergranular attack was observed on the o.d. and i.d. of the Type-347 stainless-steel cladding adjacent to regions of the cladding which showed evidence of having been overheated (see Figure 6-11). The temperature of these regions is believed to have been greater than $1650^{\circ} \mathrm{F}$ based on the cladding microstructure and the sigma phase observed. The high temperature appears to have prevented the formation of the fuelsodium reaction phase in this region.

The development of the fuel microstructure was distinctively off-center and oriented toward the over-heated cladding. This, along with the low gas release, as compared to pins F2C, F2H, F2R, and F2T which were irradiated in the same subassembly (60\% release contrasted to approximately $30 \%$ for pin F2O), implies that failure occurred early in the irradiation.

The origin of the cladding failure has not been located, but the longitudinal rupture in the cladding which extended the entire length of the fuel column was found to have occurred, for the most part, along the weld of the weldrawn tubing. (7) Whether the weld or heat-affected zone was the region of initial failure or whether the failure only propagated along the weld could not be determined from the metallographic examination.

\section{3 LOW POWER FUEL SWELLING IRRADIATIONS}

\subsubsection{Group 0 (Low Power Swelling of High Density Fuel)}

Capsule F0E was returned to Vallecitos from EBR-II after attaining a calculated peak fuel burnup of $\sim 40,000 \mathrm{MWd} / \mathrm{Te}$. The postirradiation examination was initiated. A list of the fuel pin parameters is given in Table $6-2$. The capsule was neutrographed, gamma scanned, and profilometer traces obtained of the capsule body. The neutrograph of the capsule is shown in Figure 6-12. Pellet interfaces are visible in the neutrograph. Chipped areas in the pellets could be seen suggesting that at the low fuel temperature, the fuel did not swell or plastically deform into the void present in these areas. Peak operating power of the $\mathrm{F} 0 \mathrm{E}$ pin was $6 \mathrm{~kW} / \mathrm{ft}$.

Measurements of the post-irradiation fuel length made from the neutrographs indicate an 0.096 inch $(\sim 0.7 \%)$ change in length.

The gamma scan of the capsule indicated no abnormal peaks or indications of fuel movement or fission product concentrations.

Profilometer traces of the capsule body are shown in Figure 6-13. A maximum diametral increase of 0.0005 inch was measured in the peak flux region.

Work is now in progress to remove the fuel pin from the capsule for destructive examination. 


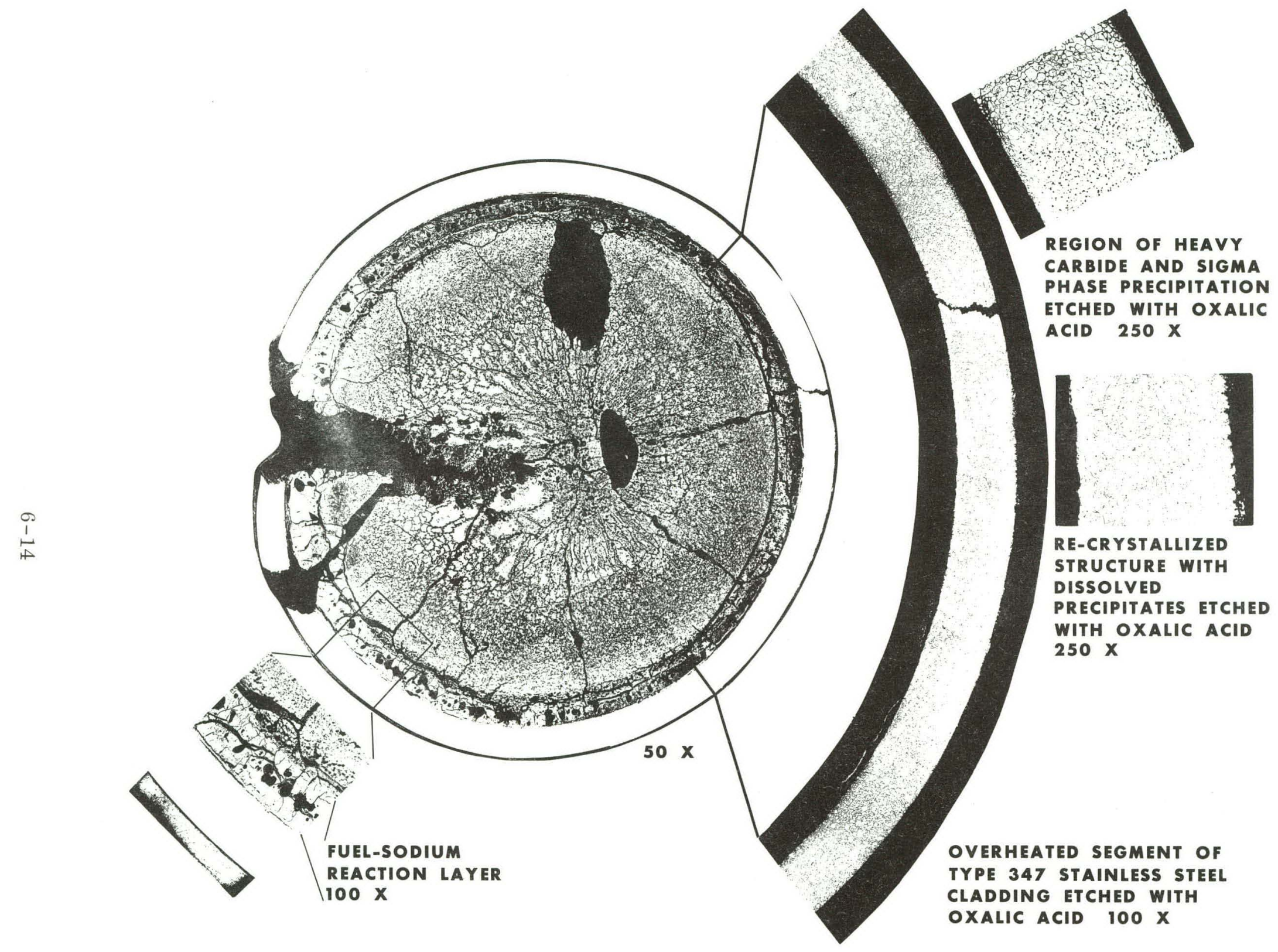

FIGURE 6-11. TRANSVERSE SECTION OF FUEL PIN TAKEN 1.3 INCHES FROM BOTTOM OF FUEL COLUMN 


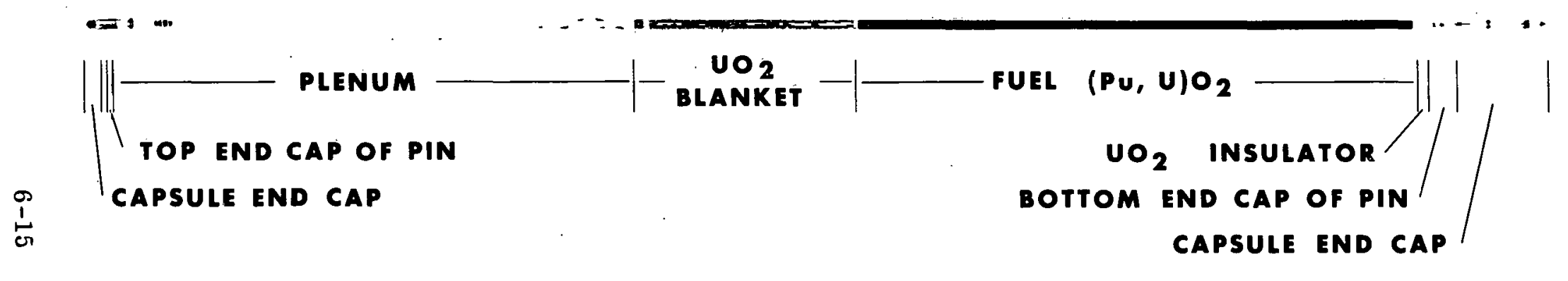

NEUTROGRAPh Of FUEL EXPOSED TO DELINEATE OXIDE fuel 


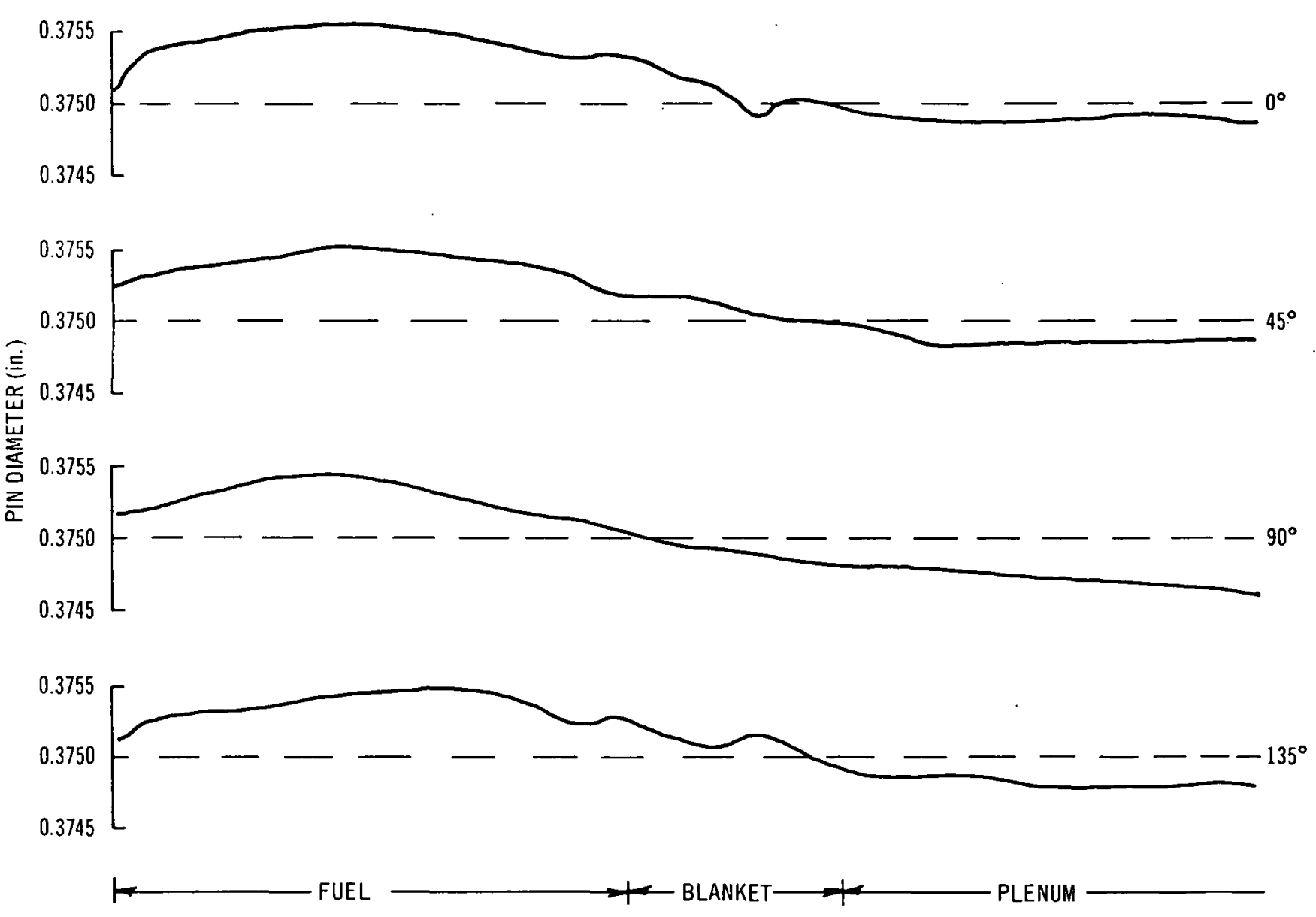


TABLE 6-2

\begin{tabular}{cl} 
CAPSULE FOE TEST PARAMETERS \\
\hline \\
Fuel Parameters & - \\
Fuel Type & solid pellet \\
Pu & $20 \%$ \\
U-235 & $93.7 \%$ \\
O/M & 1.999 \\
Length & 14.25 in. \\
Density & \\
$\quad$ Pellet & $96.5 \%$ theoretical \\
Smeared & $93.6 \%$ theoretical
\end{tabular}

Cladding Parameters

Material

$347 *$

Wall

Outside Diameter

0.015 in.

0.250 in.

Fuel-Cladding Gap

0.002 in.

*Stainless steel, annealed

Four capsules in the Group 0 series continue to be irradiated in EBR-II. Target burnup for two of these capsules (F0A and $\mathrm{FOC}$ ) is $60,000 \mathrm{MWd} / \mathrm{Te}$. The other two capsules (FOB and FOD) have a burnup goal of $100,000 \mathrm{MWd} / \mathrm{Te}$. Calculated peak burnup on these capsules as of April 15, 1969 was $51,000 \mathrm{MWd} / \mathrm{Te}$.

\subsubsection{Group 6 (Fuel-Cladding Interactions Under Accelerated Swelling)}

Irradiation of the four Group- 6 capsules in EBR-II subassembly XO10 continued. Calculated peak fuel burnup in these capsules as of April 15, 1969, was 53,500 MWd/Te.

\subsubsection{Group 8A (Effect of Fuel Density on Fuel Swelling Rate)}

The seven Group-8A capsules in EBR-II subassembly XO20 continued to be irradiated.
Calculated peak burnup on the capsules in subassembly XO19 was $35.600 \mathrm{MWd} / \mathrm{Te}$ on April 15, 1969; the nine capsules in subassembly XO20 reached a calculated peak burnup of $36,200 \mathrm{MWd} / \mathrm{Te}$.

\subsubsection{Groüp 8B (Effect of Void Deployment on Fuel-Cladding Interactions}

The nineteen Group-8B capsules continued to be irradiated in EBR-II subassembly XO36. These low power $(6-9 \mathrm{~kW} / \mathrm{ft})$ capsules reached a calculated peak burnup of 13,000 MWd/Te on April 15, 1969.

\subsection{HIGH POWER INTERMEDIATE BURNUP IRRADIATIONS}

\subsubsection{Group 3B (Density and Stoichiometry Effects)}

Calculated peak burnup of the fuel in these capsules was 45, $400 \mathrm{MWd} / \mathrm{Te}$ on April 15, 1969. These capsules are continuing to be irradiated in subassembly XO27.

An addendum to the hazards analysis for the Group 3B was prepared for submittal to the EBR-II project. The addendum was prepared in response to questions received from the EBR-II project concerning the request to continue the irradiation to 80,000 MWd/Te.

\subsubsection{Group 4 (Low Density Fuel Behavior at High Heat Ratings)}

An interim examination of the seven Group-4 capsules was completed at EBR-II. These capsules were removed from EBR-II subassembly XO39. Calculated peak burnup of the fuel was $57,000 \mathrm{MWd} / \mathrm{Te}$. The interim examination consisted of (a) visual examination, (b) neutron radiography, (c) welghing of all capsules, and (d) capsule diameter and length measurements. A list of the fuel fabrication parameters, power ratings, and 
percent dimensional changes is given in Table 6-3.

All fuel pins and capsules were observed to have maintained their integrity.

Length and weight changes in the capsules were found to be negligible.

Fuel length measurements taken from the neutron radiographs showed fuel length changes ranging from $0.07 \%$ to $3.10 \%$. Attempts were made to correlate the axial expansion of the fuel to an as-fabricated parameter or a function of several parameters. A correlation between the as-fabricated minimum diametral gap and axial expansion evolved and is shown in Figure 6-14. The significance of this result is that the fuel axial expansion for a constant burnup appears to be controlled by the minimum as-fabricated diametral gap. However, since the fuel pellets comprising the fuel column vary in diameter and there is an axial flux profile, the expansion should also be a function of the location along the fuel column of pellets with a minimum gap. Therefore, Figure 6-14 is not necessarily considered useful in quantitatively predicting axial expansion from the minimum diametral gap. Support to this hypothesis is supplied by the plot shown in Figure 6-15 which shows the axial expansion versus the minimum diametral gap in the top 1 inch of the fuel pins. As can be seen, the curve is quantitatively different, but the general trend still exists (i.e., increasing expansion with increasing diametral gap). The effect of diametral gap on diametral expansion of the fuel pins is indeterminate at this time since the fuel pin diameters could not be measured during the interim examination.

Capsule diameter measurements were made at EBR-II using a Bausch and Lomb DR-25B optical gauge with an accuracy of 0.0001 inch. Since this instrument is not capable of making continuous diametral measurements, measurements were taken at 1 -inch intervals over the fueled portion of the capsule and at 2-inch intervals along the plenum. The measurement data are listed in Table 6-4. Figure 6-15 illustrates the diametral expansion as a function of position along the capsule length for the solid pellet fueled capsules F4A, E, G, H, and J. Figure 6-16 shows a similar plot for the powder fueled capsules $F 4 \mathrm{~K}$ and $\mathrm{L}$. The percent diametral change plotted in Figures 6-16 and 6-17 were based on the dimensions obtained over the plenum region of the capsules since pre-irradiation profilometer measurements were not taken on the capsule bodies. * Comparison of the diameter measurements over the plenum region with the drawing dimensions showed that the plenum regions of all capsule bodies were within the $0.375 \pm 0.001$ inch allowable diameter. The capsule diametral expansions ranged from $0.295 \%$ to $0.390 \%$ for the solid pellet capsules and from $0.295 \%$ to $0.465 \%$ for the powder fueled capsules. It is of interest to note that the powder capsules represent both the minimum and maximum capsule expansions even though they ran at the lowest powers.

Based on the results of the interim examination a request was submitted to and approved by AEC/Reactor Development Technology (RDT) to reinsert all seven capsules into EBR-II for additional irradiation up to $80,000 \mathrm{MWd} / \mathrm{Te}$ burnup.

\subsection{ELEVATED CLADDING TEMPERATURE TESTS}

\subsubsection{Group 5 (Fuel Performance at Peak FCR Cladding Temperatures)}

Fabrication of the last three Group-5 fuel pins (F5Q, F5R, and F5S) was completed. Six additional Group-5 fuel pins were removed

\footnotetext{
* Profilometer traces are now obtained on all capsule bodies.
} 
TABLE 6-3

\section{GROUP F4 FUEL PIN PARAMETERS}

\begin{tabular}{|c|c|c|c|c|c|c|c|c|c|c|c|c|c|c|c|}
\hline$\underline{\text { Pin }}$ & $\underline{\mathrm{O} / \mathrm{M}}$ & $\frac{\mathrm{Pu}}{\underline{\mathrm{Pu}+\mathrm{U}}}$ & $\frac{U-235}{U}$ & $\frac{\mathrm{Pu}-239}{\mathrm{Pu}}$ & $\begin{array}{c}\text { Fuel } \\
\text { Diameter } \\
\text { (in.) } \\
\end{array}$ & $\begin{array}{c}\text { Fuel } \\
\text { Weight } \\
\text { (grams) }\end{array}$ & $\begin{array}{c}\begin{array}{c}\text { Fuel } \\
\text { Volume } \\
\text { (cc) }\end{array} \\
\end{array}$ & $\begin{array}{c}\text { Average } \\
\text { Fuel } \\
\text { Dénsity } \\
\text { (gm/cc) } \\
\end{array}$ & $\begin{array}{c}\text { Pre-Irradiation } \\
\text { Fuel Length } \\
\text { (in.) } \\
\end{array}$ & $\begin{array}{l}\text { Post-Irradiation } \\
\text { Fuel Length } \\
\text { (in.) } \\
\end{array}$ & $\begin{array}{c}\Delta \mathrm{L} \\
\text { (in.) }\end{array}$ & $\frac{\% \Delta \mathrm{L}}{\mathrm{L}}$ & $\begin{array}{c}\text { Gap } \\
\text { (mils) }\end{array}$ & $\begin{array}{c}\text { Peak Heat } \\
\text { Rating in XO39 } \\
\text { Subassembly } \\
(\mathrm{kW} / \mathrm{ft}) \\
\end{array}$ & $\begin{array}{c}\text { Fuel } \\
\text { Pin** } \\
\text { Cladding } \\
\text { Type } \\
\end{array}$ \\
\hline F4A & 2.000 & 0.20 & 0.9315 & 0.911 & 0.2169 & 84.38 & 8.62 & 9.79 & 14.23 & 14.45 & 0.22 & 1.55 & 2. $0-4.8$ & 16.88 & $304 \mathrm{SS}$ \\
\hline F4E & 1. 999 & 0.29 & 0.9315 & 0.911 & 0.2162 & 84.98 & 8.57 & 9.92 & 14.25 & 14.57 & 0.32 & 2.25 & $2.6-5.5$ & 16.62 & 316 SS \\
\hline F 4 G & 1.979 & 0.21 & 0.9315 & 0.911 & 0.2164 & 83.88 & 8.56 & 9.80 & 14.20 & 14.43 & 0.23 & 1.62 & $2.1-4.4$ & 16.62 & $316 \mathrm{SS}$ \\
\hline F4H & 1.981 & 0.20 & 0.9315 & 0.911 & 0.2167 & 84.61 & 8.56 & 9.88 & 14.17 & 14.42 & 0.25 & 1.77 & $2.3-4.2$ & 16.47 & $I-800$ \\
\hline F4J & 1.983 & 0.30 & 0.9315 & 0.911 & 0.2164 & 85.19 & 8.61 & 9.89 & 14.20 & 14.64 & 0.44 & 3.10 & $3.0-4.2$ & 16.72 & $316 \mathrm{SS}$ \\
\hline F $4 K^{*}$ & 1.997 & 0.20 & 0.9315 & 0.911 & 0.2200 & 83.12 & 8.85 & 9.39 & 14.21 & 14.37 & 0.16 & 1.13 & 0 & 16.17 & $316 \mathrm{SS}$ \\
\hline F4L* & 1.976 & 0.25 & 0.9315 & 0.911 & 0.2202 & 83.16 & 8.84 & 9.41 & 14.19 & 14.20 & 0.01 & 0.07 & 0 & 16.34 & $I-800$ \\
\hline
\end{tabular}

* Vi-Pack Powder Pins

** Capsule bodies are Type-304 stainless steel. 
O SOLID PELLETS

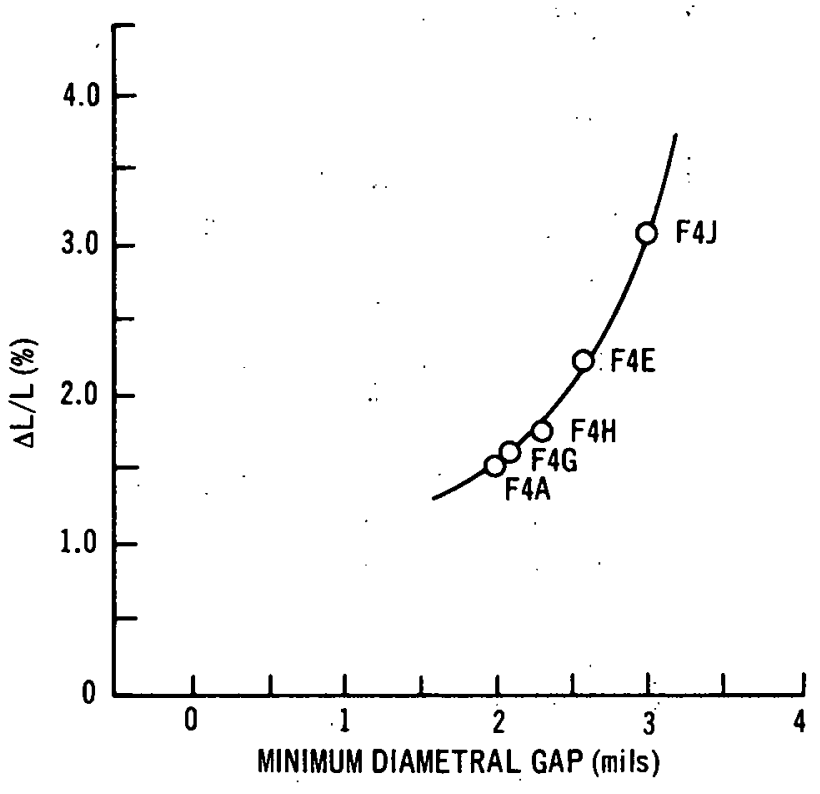

FIGURE 6-14. GROUP F4, FUEL AXIAL EXPANSION VERSUS THE MINIMUM A'S-FABRICATED DIAMETRAL GAP

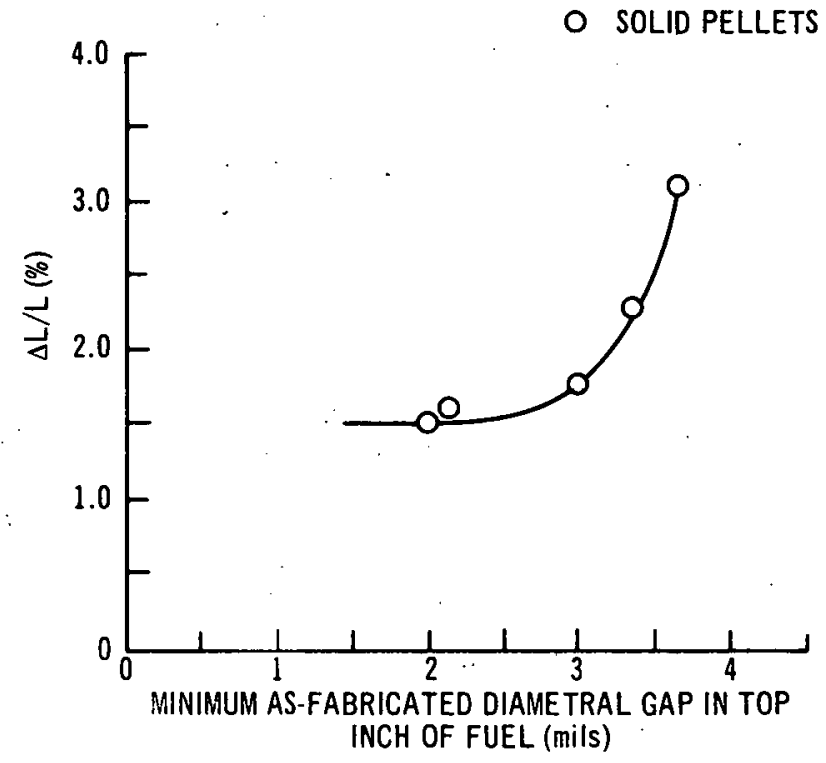

FIGURE 6-15. GROUP F4, FUEL AXIAL EXPANSION VERSUS THE MINIMUM AS-FABRICATED DIAMETRAL GAP IN TOP.INCH OF.FUEL COLUMN 
TABLE 6-4

DIAMETER MEASUREMENTS OF GE F-4 SERIES CAPSULES FROM X-039

\begin{tabular}{|c|c|c|c|c|c|c|c|c|c|c|c|c|c|c|}
\hline \multirow{2}{*}{$\begin{array}{l}\text { Distance from } \\
\text { Bottom of } \\
\text { Capsule (in.) } \\
\end{array}$} & \multicolumn{2}{|c|}{ Capsule F-4-H } & \multicolumn{2}{|c|}{ Capsule F-4-J } & \multicolumn{2}{|c|}{ Capsule F-4-E } & \multicolumn{2}{|c|}{ Capsule F-4-K } & \multicolumn{2}{|c|}{ Capsule F-4-L } & \multicolumn{2}{|c|}{ Capsule F-4-A } & \multicolumn{2}{|c|}{ Capsule F-4-G } \\
\hline & $\begin{array}{c}0 \\
\text { Degree } \\
\end{array}$ & $\begin{array}{c}90 \\
\text { Degree } \\
\end{array}$ & $\begin{array}{c}0 \\
\text { Degree } \\
\end{array}$ & $\begin{array}{c}90 \\
\text { Degree } \\
\end{array}$ & $\begin{array}{c}0 \\
\text { Degree } \\
\end{array}$ & $\begin{array}{c}90 \\
\text { Degree } \\
\end{array}$ & $\begin{array}{c}0 \\
\text { Degree } \\
\end{array}$ & $\begin{array}{c}90 \\
\text { Degree } \\
\end{array}$ & $\begin{array}{c}0 \\
\text { Degree } \\
\end{array}$ & $\begin{array}{c}90 \\
\text { Degree } \\
\end{array}$ & $\begin{array}{c}0 \\
\text { Degree } \\
\end{array}$ & $\begin{array}{c}90 \\
\text { Degree }\end{array}$ & $\begin{array}{c}0 \\
\text { Degree } \\
\end{array}$ & $\begin{array}{c}90 \\
\text { Degree }\end{array}$ \\
\hline 37 & 0.3753 & 0.3754 & 0.3754 & 0.3753 & 0.3754 & 0.3752 & 0.3755 & 0.3760 & 0.3757 . & 0.3753 & 0.3753 & 0.3755 & 0.3756 & 0.3756 \\
\hline 35 & 0.3755 & 0.3753 & 0.3754 & 0.3753 & 0.3756 & 0.3755 & 0.3755 & 0.3756 & 0.3754 & 0.3752 & 0.3752 & 0.3755 & 0.3756 & 0.3756 \\
\hline 33 & 0.3754 & 0.3754 & 0.3754 & 0.3753 & 0.3755 & 0.3755 & 0.3755 & 0.3757 & 0.3754 & 0.3753 & 0.3752 & 0.3753 & 0.3756 & 0.3755 \\
\hline 31 & 0.3754 & 0.3754 & 0.3754 & 0.3754 & 0.3755 & 0.3756 & 0.3756 & 0.3756 & 0.3751 & 0.3753 & 0.3753 & 0.3754 & 0.3755 & 0.3755 \\
\hline 29 & 0.3755 & 0.3755 & 0.3754 & 0.3754 & 0.3756 & 0.3755 & 0.3756 & 0.3755 & 0.3754 & 0.3754 & 0.3753 & 0.3754 & 0.3756 & 0.3756 \\
\hline 27 & 0.3755 & 0.3755 & 0.3754 & 0.3755 & 0.3755 & 0.3756 & 0.3756 & 0.3755 & 0.3754 & 0.3754 & 0.3755 & 0.3755 & 0.3755 & 0.3756 \\
\hline 25 & 0.3755 & 0.3756 & 0.3754 & 0.3755 & 0.3755 & 0.3758 & 0.3756 & 0.3756 & 0.3756 & 0.3754 & 0.3755 & 0.3756 & 0.3756 & 0.3756 \\
\hline 23 & 0.3756 & 0.3756 & 0.3754 & 0.3756 & 0.3755 & 0.3759 & 0.3759 & 0.3756 & 0.3754 & 0.3756 & 0.3757 & 0.3757 & 0. 3754 & 0. 3757 \\
\hline 21 & 0.3756 & 0.3757 & 0.3756 & 0.3756 & 0.3756 & 0.3759 & 0.3758 & 0.3757 & 0.3755 & 0.3755 & 0.3756 & 0.3759 & 0.3758 & 0.3757 \\
\hline 19 & 0.3758 & 0.3757 & 0.3756 & 0.3761 & 0.3756 & 0.3762 & 0. 3760 & 0.3758 & 0.3755 & 0.3756 & 0.3758 & 0.3758 & 0.3756 & 0.3757 \\
\hline 18 & 0.3758 & 0.. 3759 & 0.3758 & 0.3758 & 0.3757 & 0.3764 & 0. 3761 & 0.3758 & 0.3758 & 0.3758 & 0.3758 & 0.3759 & 0.3759 & 0.3759 \\
\hline 17 & 0.3760 & 0.3758 & 0.3758 & 0.3759 & 0.3759 & 0.3769 & 0.3753 & 0.3761 & 0.3759 & 0.3758 & 0. 3760 & 0.3759 & 0.3759 & 0. 3761 \\
\hline 16 & 0.3763 & 0.3761 & 0.3761 & 0.3761 & 0.3761 & 0.3769 & 0.3763 & 0.3761 & 0.3762 & 0.3758 & 0.3761 & 0.3760 & 0.3763 & 0.3760 \\
\hline 15 & 0.3763 & 0.3764 & 0.3764 & 0.3763 & 0.3763 & 0.3772 & 0.3764 & 0.3763 & 0.3769 & 0.3770 & 0.3766 & 0.3763 & 0.3763 & 0.3764 \\
\hline 14 & 0.3766 & 0.3766 & 0.3766 & 0.3767 & 0.3766 & 0.3771 & 0.3765 & 0.3766 & 0.3769 & 0.3771 & 0.3765 & 0.3766 & 0.3768 & 0.3767 \\
\hline 13 & 0.3768 & 0.3767 & 0.3766 & 0.3767 & 0.3767 & 0.3770 & 0.3767 & 0.3767 & 0.3772 & 0.3773 & 0. 3767 & 0.3766 & 0.3768 & 0. 3766 \\
\hline 12 & 0.3768 & 0.3768 & 0.3767 & 0.3769 & 0.3766 & 0.3769 & 0.3768 & 0.3767 & 0.3769 & 0.3770 & 0.3768 & 0.3766 & 0.3768 & 0.3766 \\
\hline 11 & 0.3770 & 0.3768 & 0.3767 & 0.3768 & 0.3768 & 0.3768 & 0.3768 & 0. 3767 & 0.3772 & 0.3771 & 0.3768 & 0.3767 & 0.3768 & 0.3767 \\
\hline 10 & 0.3767 & 0.3768 & 0.3767 & 0.3771 & 0.3767 & 0.3768 & 0.3766 & 0.3767 & 0.3770 & 0.3770 & 0.3768 & 0.3767 & 0.3768 & 0.3767 \\
\hline 9 & 0.3766 & 0.3767 & 0.3767 & 0.3767 & 0.3768 & 0.3768 & 0.3765 & 0.3765 & 0.3769 & 0.3769 & 0. 3764 & 0.3766 & 0.3768 & 0.3766 \\
\hline 8 & 0.3765 & 0.3766 & 0.3765 & 0.3766 & 0.3766 & 0.3767 & 0.3763 & 0. 3764 & 0.3766 & 0.3767 & 0.3763 & 0.3764 & 0.3767 & 0.3763 \\
\hline 7 & 0.3761 & 0.3765 & 0.3765 & 0.3768 & 0.3764 & 0.3763 & 0.3760 & 0.3760 & 0.3767 & 0.3767 & 0.3762 & 0.3763 & 0.3763 & 0.3763 \\
\hline 6 & 0.3760 & 0.3760 & 0.3761 & 0.3762 & 0.3762 & 0.3759 & 0.3760 & 0.3759 & 0.3765 & 0.3766 & 0. 3759 & 0.3761 & 0.3761 & 0.3761 \\
\hline 5 & 0.3759 & 0.3760 & 0.3758 & 0.3761 & 0.3758 & 0.3758 & 0. 3758 & 0.3757 & 0.3764 & 0.3765 & 0.3758 & 0.3760 & 0.3759 & 0.3761 \\
\hline 4 & 0.3756 & 0.3758 & 0.3754 & 0.3759 & 0.3757 & 0.3756 & 0.3757 & 0.3757 & 0.3762 & 0.3763 & 0.3755 & 0.3758 & 0.3756 & 0.3759 \\
\hline 3 & 0.3754 & 0.3756 & 0.3755 & 0.3756 & 0.3756 & 0.3755 & 0.3756 & 0.3758 & 0. 3761 & 0.3760 & 0.3754 & 0.3758 & 0.3756 & 0.3756 \\
\hline
\end{tabular}




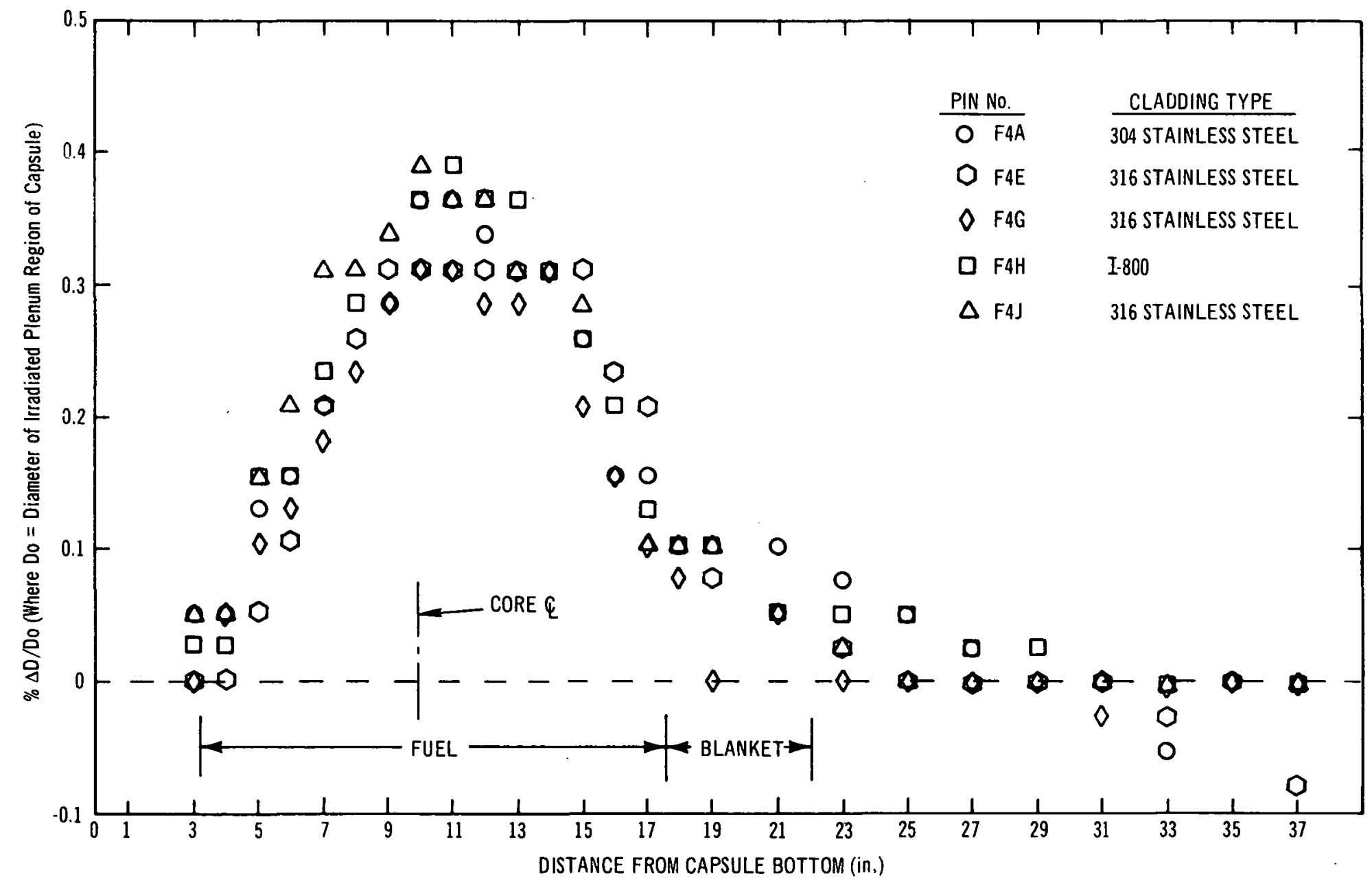




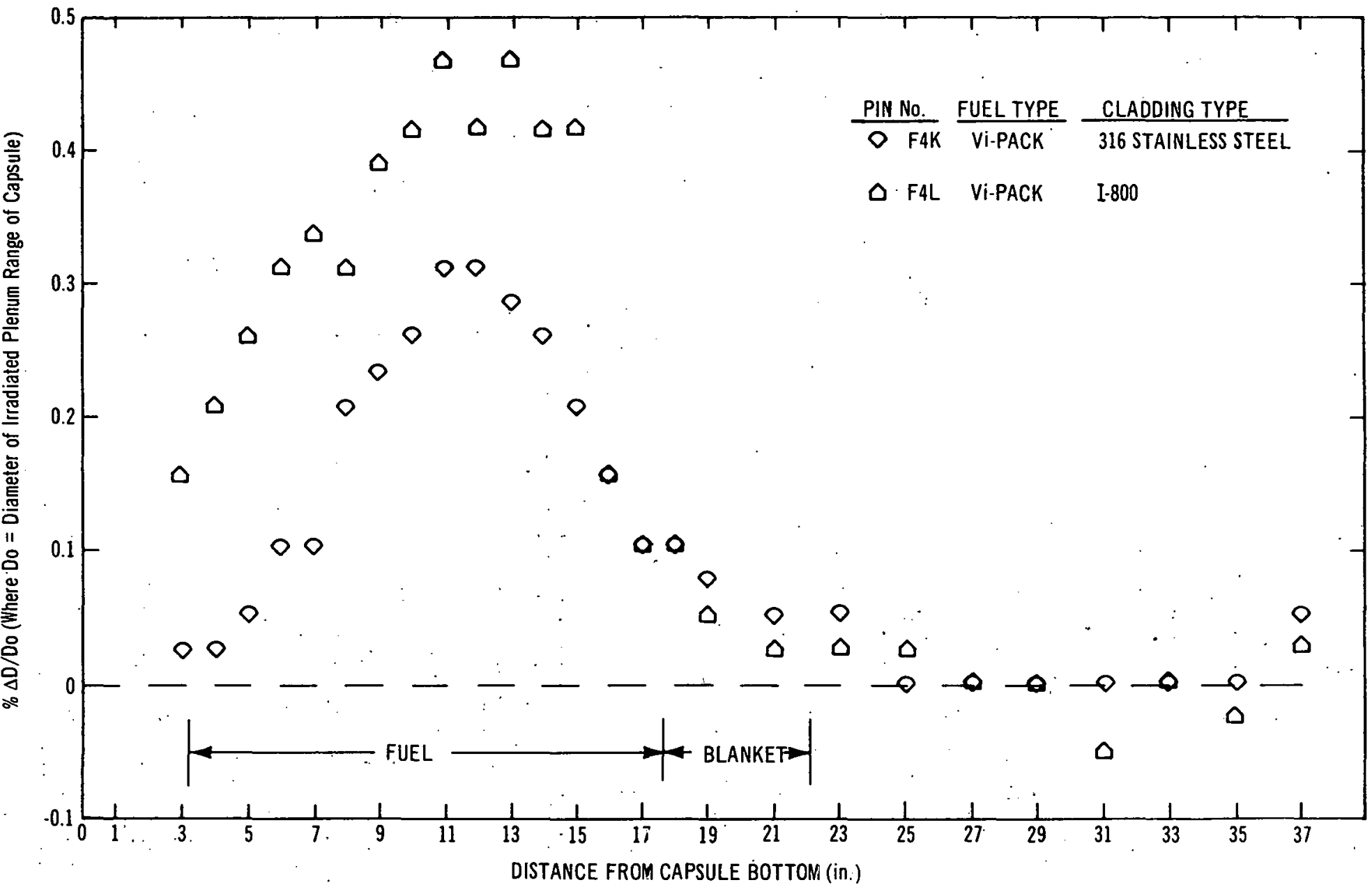

FIGURE 6-17. CAPSULE DIAMETRAL EXPANSION AS A FUNCTION OF POSITION ALONG THE CAPSULE (Powder-Fueled Pins F4K and F4L) 
from their capsules following detection of insufficient weld penetration. ${ }^{*}$ The fuel pin cladding showed no deleterious effects following reaction of the capsule sodium bond with an ethylene glycol-n butyl ether solution. All nine fuel pins were encapsulated and shipped to the EBR-II site for preinsertion inspection.

The Group-5 hazards analysis was completed and submitted to the EBR-II project for approval.

\subsubsection{Group 10B (Cladding Performance at Peak Cladding Temperatures)}

Preparation of powder for the 19 Group-10B fuel pins was completed and fuel fabrication initiated. Fabrication of capsule and fuel pin hardware continued.

\section{6 UNENCAPSULATED FUEL PIN IRRADIATIONS}

\subsubsection{Group 3A (Unencapsulated Fuel Pin Irradiations to Evaluate Fuel-Cladding . and Cladding Coolant Interactions)}

Irradiation of the sixteen 0.290 -inchdiameter Group-3A fuel pins continued. These are the highest burnup unencapsulated mixed oxide fuel pins under irradiation in the EBR-II as part of the FCR P.A. 10 program. Calculated peak burnup on these capsules on April 30, 1969 was $23,300 \mathrm{MWd} / \mathrm{Te}$.

\subsubsection{Group 9A (High Power, High Burnup, Unencapsulated Fuel Pin Irradiations)}

The thirty-seven Group-9A fuel pins were inserted into the EBR-II at the beginning of run 33. This is the first subassembly of

\footnotetext{
*These capsules were fabricated and inspected approximately 1 year ago. Improvements in nondestructive test procedures and in criteria for welds resulted in rejection when the capsules were reinspected.
}

0.250-inch-diameter unencapsulated fuel pins to be irradiated in the EBR-II under the FCR P.A. 10 program. Calculated peak burnup on the fuel in these pins as of April 15, 1969 was $4600 \mathrm{MWd} / \mathrm{Te}$.

\subsubsection{Group 9B (Medium Power, High Burnup, Unencapsulated Fuel Pin Irradiations)}

Fabrication of the Group-9B fuel pins was completed. All 37 pins were shipped to the EBR-II site for pre-irradiation inspection.

The hazards analysis for the Group-9B irradiation was completed and submitted to the EBR-II project for approval.

\subsubsection{Group 9C (High Power, High Burnup, Unencapsulated Fuel Pin Irradiations)}

An addendum to the Group-9C data package was prepared and submitted to the EBR-II project. The addendum provided answers to comments on the data package made by the EBR-II project.

Approval for insertion of the fuel pins was granted and they were loaded into EBR-II subassembly XO56. The subassembly was inserted into the EBR-II on April 3, 1969. Target burnup for these 0.250 -inch-diameter fuel pins is $100,000 \mathrm{MWd} / \mathrm{Te}$.

\subsubsection{Group 9D (Medium Power, High Burnup, Unencapsulated Fuel Pin $\underline{\text { Irradiations) }}$}

The 37 Group-9D pins were shipped to the EBR-II site for pre-irradiation inspection. The data package and an addendum to the data package were submitted to the EBR-II project. Approval for insertion of the pins into the EBR-II was granted and the pins were loaded into EBR-II subassembly XO58. The 37 pins in this subassembly were the first EBR-II samples incorporating Xe tagging. Clearances between the 37 rod 
bundle and the hexagonal shroud can were measured during the assembly of the subassembly. The subassembly was loaded into the EBR-II at the beginning of run 34. Target burnup for these pins is $100,000 \mathrm{MWd} / \mathrm{Te}$.

\subsection{PRE-IRRADIATION TRANSIENT TESTS}

\subsubsection{Group 7 (Effect of Irradiation, Density, and Axial Restraint)}

Two Group-7 capsules, F7C and F7D, were removed from the EBR-II on April 4, 1969. Calculated peak burnup on the fuel in these two capsules was $59,800 \mathrm{MWd} / \mathrm{Te}$.

These capsules will be returned to Vallecitos and re-encapsulated for transient irradiation in TREAT under Task $C$.

Irradiation of four additional Group-7 capsules was initiated. The capsules were inserted in the F.BR-II in subassembly XO50 on April 3, 1969. Target burnup for these capsules is $50,000 \mathrm{MWd} / \mathrm{Te}$.

\section{8 HOMOGENEITY OF MIXED OX.IDE FUELS}

Plutonium homogeneity checks were run on unirradiated mixed oxide samples (prepared by the direct and reverse strike process for coprecipitation*) using alpha autoradiographs and the microprobe. The results indicated minor variations among the three samples examined. Based on these results a series of five samples prepared by each method were selected for examination to determine plutonium homogeneity using autoradiography and microprobe techniques. Examination of these samples is under way.

The anomaly found between microprobe analysis and chemical analysis of the plutonium concentration in irradiated mixed oxide

\footnotetext{
* In the direct strike ammonium hydroxide is added to the nitrate solution. The nitrate solution is added to the ammonium hydroxide in a reverse strike.
}

fuel was resolved. Chemical analysis showed appreciable plutonium concentration gradients (increases in plutonium concentration of 2 to $4 \%$ near the fuel centerline in initial 20 wt $\%$ fuel) while no plutonium gradient was detected by the microprobe. A check sample was run at ANL on an irradiated sample from pin F2Z. Results from the ANL microprobe analysis were found to agree with the chemical analysis. As a result, the Vallecitos method for plutonium was reviewed. An error was found in the procedure and corrected. Samples previously examined were rerun and the increase in plutonium concentration at the center of irradiated mixed oxide was found to agree with chemical analysis.

\subsection{MEASUREMENT OF THE AXIAL LOCATION OF THE FLUX PEAK IN THE EBR-II CORE}

Measurements of the axial distribution of the integrated neutron flux in Row 4 of the EBR-II core were performed. The basis of this effort was the radioactivity produced by neutron bombardment of the stainless-steel capsule bodies containing the Group-2 FCR fuel pins, which were irradiated in the EBR-II core. The gamma activity distribution measured along the length of the capsule body was used to determine the relative integrated neutron flux along the axis of the core.

During the course of the post-irradiation examination of the Group-2 encapsulated fuel pin specimens, the capsule bodies were sectioned and the fuel pin removed. The position of the capsule bodies with respect to the EBR-II core was established by using the top of the " $T$ " bar grid support for the capsules as a reference point. The " $T$ " bar grid is located 3 inches below the bottom of the fuel. The capsule bodies $(0.375$-inch o.d. by 0.335 inch i.d.) were Type-304 stainless steel from the same heat.

After the removal of the fuel pins, the relative gamma activity along each capsule 
body was measured using a precision gamma scanning apparatus. The gamma activity scan was made along the length of the irradiated tube by drawing the tube past a narrow slit in the 3-foot-thick shielding wall of a hot cell. All gamma energies above $0.5 \mathrm{MeV}$ were counted by the system. The reproducibility of the system, checked by rescanning the same tube, was $\pm 1 \%$ when the recorder was set to produce a maximum reading greater than one half of full scale on the charts. A spectral scan of the gamma activity of the irradiated stainless steel indicated that Co-58 (0.81 MeV) and Mn-54 (0.835 MeV) were the primary activation products present. Based on the Watts fission spectrum, the threshold energies for these $n, p$ reactions are $2.9 \mathrm{MeV}$ (Ni-58 to $\mathrm{Co}-58$ ) and $3.0 \mathrm{MeV}$ (Fe-54 to Mn-54).* Therefore the gamma activity in the capsule bodies corresponds to the distribution of the relative integrated flux for neutrons greater than $\sim 3 \mathrm{MeV}$.

Four capsule bodies from subassembly XG05 were scanned under identical conditions. The results from each tube were normalized to obtain the relative axial distribution of the gamma activity. The normalized activity distribution between the four capsule bodies was in agreement within $\pm 2 \%$. The average of the normalized curves is shown in Figure 6-18. This curve also represents the relative exposure to neutrons above $\sim 3 \mathrm{MeV}$ along the length of the in-core section of subassembly $\mathrm{XG05}$. Note that the measured gamma activity is not symmetrical about the core centerline.

The peak gamma activity occurs below the core centerline 6 inches above the bottom of the fuel.

The normalized curve of the gamma scan for subassembly XG06 is shown in Figure 6-19. This curve is also asymmetrical with respect to the core centerline and the peak occurs 6 inches above the bottom of the fuel.

$\overline{\text { *ASTM.Specification } \cdot E 261-65 T}$
A comparison of the two curves shows local differences up to $10 \%$ between them. Both subassemblies were in comparable core locations, Row 4, position 2, but in different sectors of the core.

The relative gamma activity was also measured along each fuel pin irradiated in the subassemblies using the same precision gamma scanning apparatus. All gamma energies above $0.5 \mathrm{MeV}$ were counted by the system. A spectral scan of the gamma activity of the irradiated fuel pin indicated that $\mathrm{Cs}-137$ (0.66 MeV), Zr-95 (0.72 MeV), Zr-95 (0.72 MeV), Nb-95 (0.77 MeV), and La-140 (1.6 MeV) are the primary sources of activity. $\mathrm{Ru}-103$ and the main activation products of the cladding, Co-58 and Mn-54, were also observed.

As a first approximation the gamma activity of the fission products in the fuel is proportional to the local burnup and fission rate; therefore, the gamma activity can be used to obtain the relative axial power distribution. On this basis the normalized gamma activity can be used to obtain the relative axial power distribution. On this basis the normalized gamma activity distribution of low power pins $F 2 P, W$ and $Y$ with peak powers ranging from 10 to $14 \mathrm{~kW} / \mathrm{ft}$, were averaged to obtain the relative axial distribution of power in the core for subassembly XG06 shown in Figure 6-18. These pins were selected to minimize any effect on the axial redistribution of fission products, or fuel, or both, because of low central temperatures in the fuel.

The fission product gamma activity distributions from three pins, F2C, $\mathrm{H}$, and $\mathrm{T}$ were averaged and are plotted in Figure 6-19. These fuel pins operated at peak powers from 16.5 to $17.3 \mathrm{~kW} / \mathrm{ft}$ in subassembly XG05 and exhibited some indications of fission product axial redistribution. However, the curve obtained from the average is in general agreement with the fuel in S/A XG06: the measured fission product gamma activity 


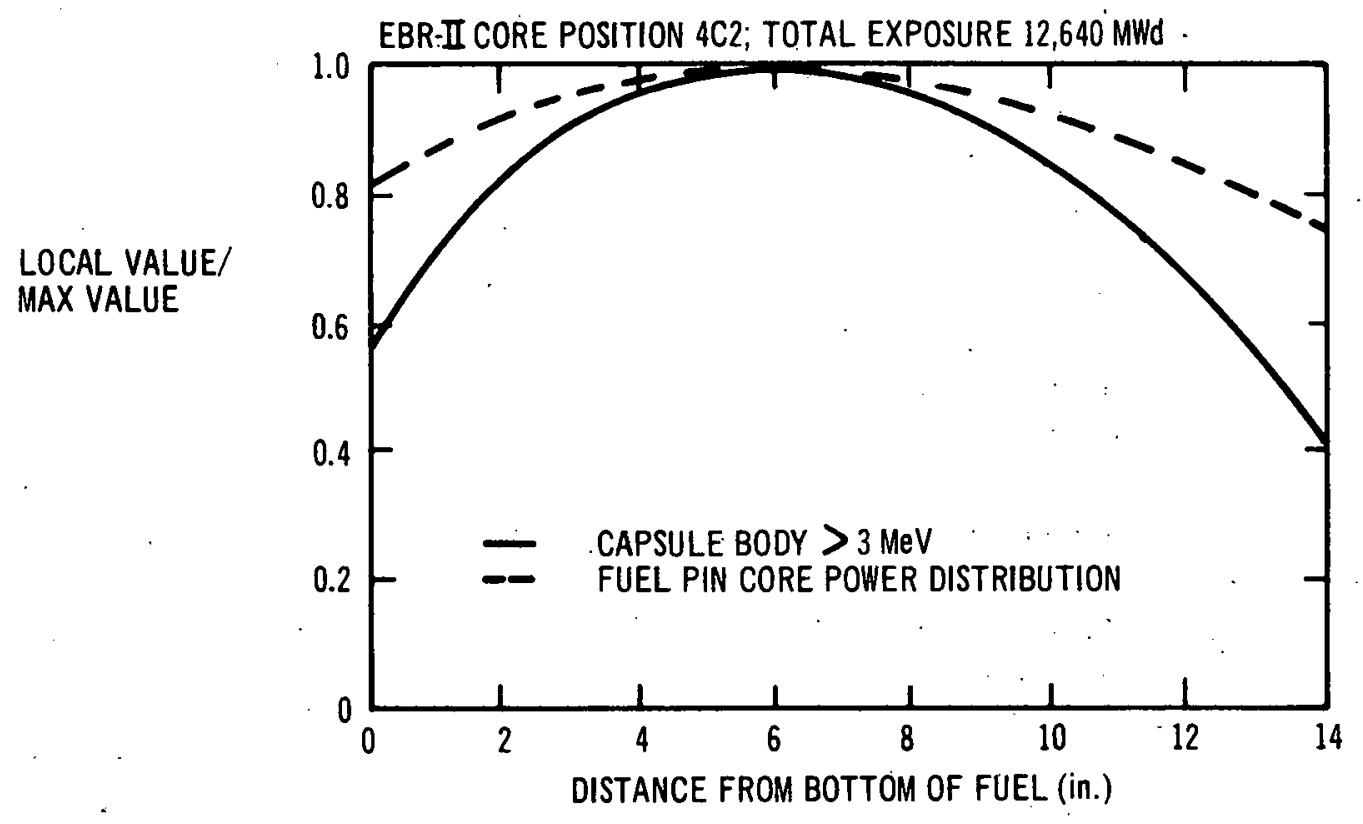

FIGURE 6-18. NORMALIZED AXIAL DISTRIBUTION OF GAMMA ACTIVITY FOR SUBASSEMBLY XGO5

LOCAL VALUE/ MAX VALUE

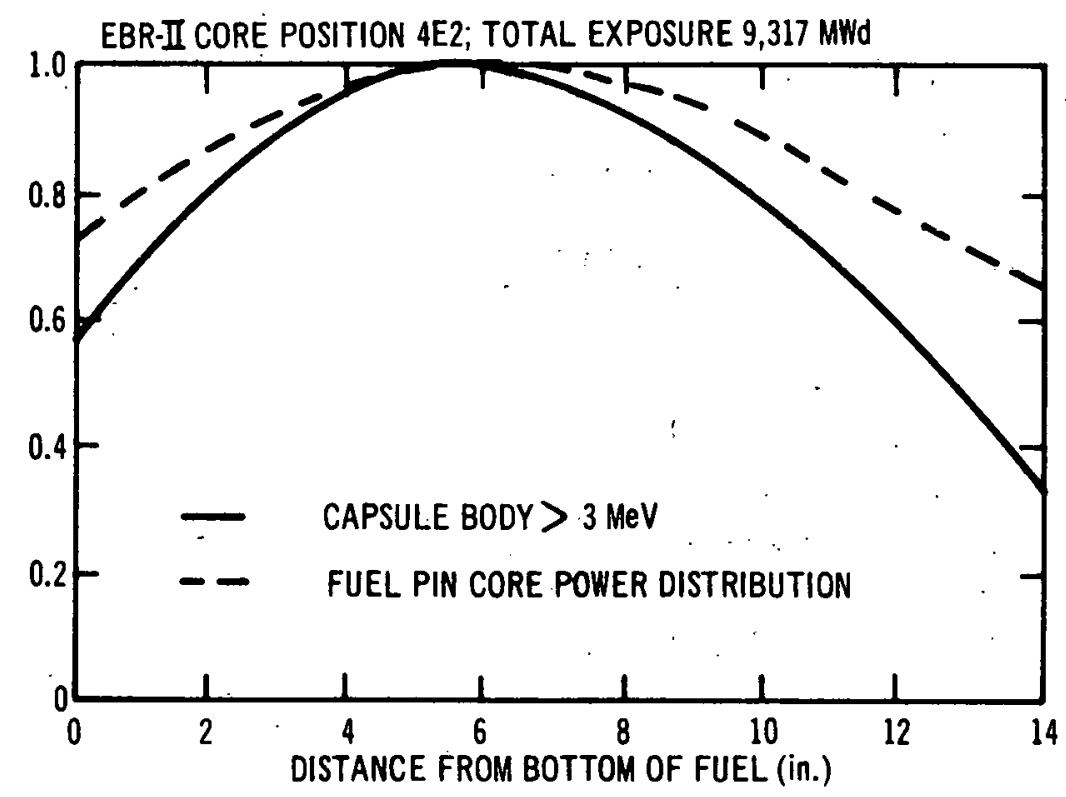

EKCURE 6-19. NORMALIZED AXIAL DISTRIBUTION OF GAMMA ACTIVITY FOR SUBASSEMBLLY XCOS 
in the fuel is not symmetrical about the core centerline. Its peak occurs below the core centerline 6 inches above the bottom of the fuel which agrees with the location of the peak of neutron flux $>3 \mathrm{MeV}$.

The geometric center of the EBR-II core changed during the residence time of the Group-2 subassemblies in the reactor. This was the result of changes made in the basic core size. The initial core height was 14.2 inches. A driver fuel pin design change. resulted in a shorter core $\mathbf{1 3 . 5}$ inches high. This change occurred over about a 6 -month period by replacing the expended driver fuel subassemblies with new subassemblies containing 13.5-inch fuel pins. The geometric core midplane location ranged from the initial 7.1 inches to finally 6.75 inches above the bottom of the fuel. Additional irradiation history of the two subassemblies is presented below:

- Subassembly No.

XG05 XG06

- EBR-II Position 4C2 $4 \mathrm{E} 2$

- Date Installed $9-3-65 \quad 9-3-65$

- Date Removed $3-6-68 \quad 2-20-67$

- Total Exposure (MWd) 12,640 9, 317

Discussions with ANL/EBR-II staff concerning the location of the peak flux in the EBR-II revealed that the nuclear center of the core is expected to be below the core midplane. The following reasons were given:
- The lower blanket is closer to the core than the upper blanket and is therefore a more effective reflector.

- Fuel containing control and shim rods enter the core from the bottom which results in greater reactivity in the lower half of the core.

The following conclusions can be drawn based on the gamma activity distribution above $0.5 \mathrm{MeV}$ (primarily Co-58 and Mn-54 activity).

- The location of maximum flux does not coincide with the geometric mid-core of EBR-II. Gamma scan measurements indicate that it is about 6 inches above the bottom of the fuel rather than 6.75 to 7.1 inches.

- The neutron spectra softens away from the peak region. This phenomenon can be seen by comparing the normalized plot of gamma activity for capsule bodies and for fuel pins.

- The axial distribution of the neutron exposure should be determined for each subassembly individually. There are detectable differences in the relative neutron exposure between subassemblies in supposedly comparable core positions.

- These effects are critical to making quantitative plots of fuel and clad swelling and to comparisons between different experiments. 
TASK G-CORE NEUTRONICS, THERMAL

\author{
HYDRAULICS AND SAFETY ANALYSIS
}

\subsection{GENERAL}

The purpose of Task $G$ is to provide guidance for effective planning and coordination of the experimental programs within P. A. 10, and to contribute to the basic analytical and design tools for the sodiumcooled fast breeder program. This requires integration of results of several disciplines, including core neutronics, thermal hydraulics, and safety and economic aralysis. To accomplish this, improved analytical methods and computer programs are being developed and used in analytical studies of fast reactor neutronics, safety characteristics, and both analytical and experimental thermal hydraulics. These studies, together with a continual evaluation and surveillance of the results of experimental programs, form a basis for establishing current design and safety criteria. These criteria, in turn, define the range of reactor characteristics and test parameters upon which the experimental programs must focus.

During 1969, methods development and parametric analyses were focused primarily on the areas of: (1) nuclear data and updating of group constants, with emphasis on processing of data for use in neutronics computations, (2) nuclear core analyses, including the evaluation of approximations. used in neutronics computations, (3) transient and safety analysis, including accident studies and improvement of FORE II and sodium voiding models, and (4) thermal-hydraulic and fuel analysis, including fuel swelling model development and coolant mixing studies.

\subsection{NUCLEAR DATA AND GROUP CONSTANTS}

\subsubsection{Cross Section Files}

Single level Breit-Wigner statistical parameters for $\mathrm{Pu}-239$ source resonances have been derived from the following high resolution, experimental data: (a) the ORNL-RPI alpha value, ${ }^{(15)}$ (b) fission cross sections of C. D. James, (16) Shunk, et al., (17) (Petrel bomb data), and Y. V. Ryabov, S. Donssik, et al, (18) and (c) Uttley's total cross section values. (19) This analysis indicates a consistency between the ORNL-RPI alpha values and the independent fission and total cross section measurements. A set of statistically "best" $s$-wave resonance parameters were derived from these data and the subsequent total and fission cross sections and alpha values computed.

$$
\text { The derived values of }\left\langle\Gamma_{\mathrm{f}}\right\rangle_{\mathrm{J}=1}^{\ell=0} \text { are }
$$

listed in Table 7-1 for a number of energies. The $\left\langle\Gamma_{n}\right\rangle_{J=0,1}^{\ell=0}$ vary as Uttley's total

cross section. Other parameters were taken to be

$$
\left\langle\Gamma_{\mathrm{f}}\right\rangle_{\mathrm{J}=0}^{\ell=0}=1500 \mathrm{MeV},\left\langle\Gamma_{\gamma}\right\rangle_{\mathrm{J}=0,1}^{\ell=0}=41.6 \mathrm{MeV}
$$

and $\mathrm{D}=8.78$ and $3.12 \mathrm{eV}$ for $\mathrm{J}=0$ and 1 , respectively. The principal difference between these parameters and those in the ENDF/B data file ${ }^{(20)}$ are that

$\left\langle\Gamma_{n}\right\rangle_{J=0,1}^{l=0} \quad$ values vary with neutron energy 
and the energy variation of $\left\langle\Gamma_{f}\right\rangle_{J=1}^{l=0}$ departs

from that predicted by Hill-Wheeler theory. ${ }^{(21)}$

In Figure 7-1, measured fission cross sections are shown together with values calculated from the newly derived parameters. Figure 7-2 shows the computed alpha values along with the preliminary ORNL-RPI and U. K. ${ }^{(22)}$ experimental results. Good agreement is seen between the computed values and both the James and Shunk fission cross sections and the ORNL-RPI alpha measurements. Agreement with Uttley's total cross section is exact since the reduced neutron width was taken to be directly proportional to the measured data.

The computation of the average $\left\langle\Gamma_{f}\right\rangle_{J=1}$ value was repeated omitting the Russian values altogether. The results did not show much change, and gave exceptional agreement with a recent evaluation of $\sigma_{f}$ made by James and Patrick. (23) Additional recent experimental results are now available and are being studied. It is believed that these measurements will change the results of this analysis very little and that the resonance parameters in Table 7-1 form a good basis for fast reactor computation.

In addition to the analysis described above, other recent nuclear cross section

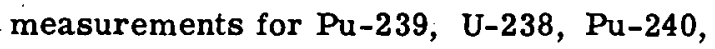
$\mathrm{Pu}-241,0, \mathrm{Na}, \mathrm{Fe}, \mathrm{Ni}$, and $\mathrm{Cr}$ are being studied to arrive at more accurate evaluated data for use in the ENDF/B format. The early evaluation is being concentrated on the fuel isotopes, with $\sigma(\mathrm{n}, \mathrm{f})$ of Pu-239 and $\mathrm{Pu}-241$, and $\sigma(\mathrm{n}, \gamma)$ of $\mathrm{U}-238$ and Pu-240 of particular interest. For the lighter materials, the high energy fine variations in $\sigma$ (elastic) and $\sigma(n, \gamma)$ are of most interest. The new ENDF/B data for $\mathrm{Fe}, \mathrm{Cr}$, and $\mathrm{Ni}$, evaluated through NNCSC, may make it unnecessary to perform these evaluations in depth. In arriving at evaluated data, consideration will be given to the effects that changes have on the comparison of calculated and measured quantities for ZPR-III, Assembly 48.

\subsubsection{Working Committee Activities}

These specifications are being determined jointly with B. Toppel of Argonne National Laboratory (ANL), and P. Michael of Brookhaven National Laboratory. They will be presented at the next meeting of the ad hoc committee on April 23 and 24, in Knoxville, Tennessee.

\subsubsection{Multi-Group Cross Section Averaging}

Fundamental mode calculations were made in cooperation with Pacific Northwest Laboratory (PNL) and ANL to compare the ENDRUN and ETOX results. (a PNL code similar to ENDRUN) with the more detailed GAFGAR and $\mathrm{MC}^{2}$ calculations. ZEBRA Assembly 6A was used for the model. Table 7-2 lists results of the four calculations for $\mathrm{k}_{\mathrm{eff}}$, the Doppler effect, the sodium coefficient, and a number of fission and capture ratios. The comparison shows good agreement between the GAFGAR-MC ${ }^{2}$ results for the specific composition and the cross section adjusting approaches of ENDRUN and ETOX. ETOX results are generally slightly closer to the $\mathrm{MC}^{2}$ results than are ENDRUN values, possibly because the algorithms in ETOX are more similar to those used in $\mathrm{MC}^{2}$.

The approximate running times listed in Table 7-2 point out the advantages of the rapid adjusting procedure. Comparisons of central worth calculations indicated poorer agreement, particularly for light materials. Poorer agreement in the sodium coefficient may also be found for larger reactors where the coefficient is closer to zero. 


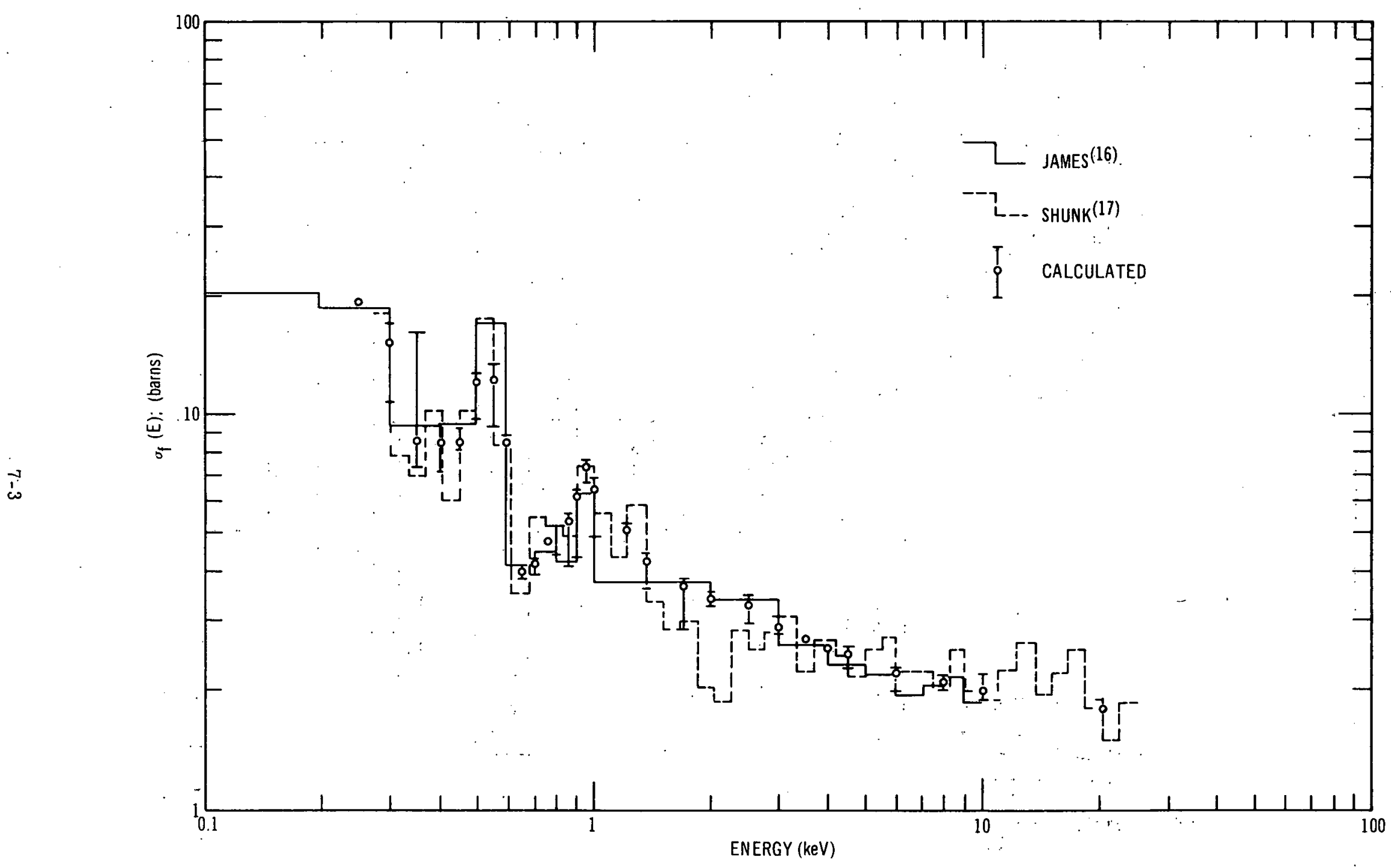




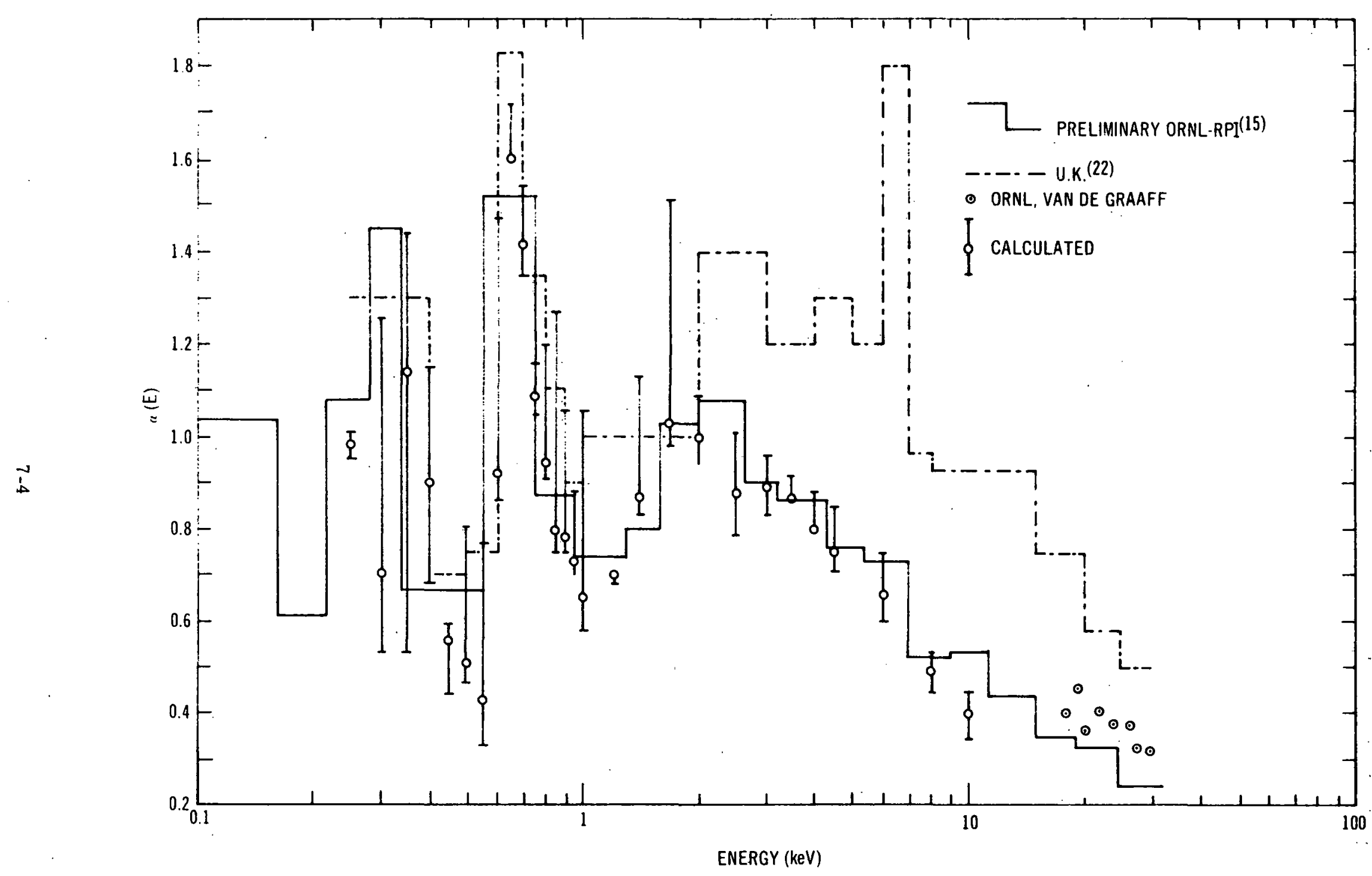


TABLE 7-1

\begin{tabular}{l} 
VALLUES OF $\left\langle\Gamma_{\mathrm{f}}\right\rangle_{\mathrm{J}=1}^{\ell=0} \frac{\text { DERIVED FROM TOTAL AND }}{\text { FISSION CROSS SECTION AND ALPHA MEASUREMENTS }}$ \\
\hline
\end{tabular}

\begin{tabular}{|c|c|c|c|c|}
\hline $\mathrm{E}(\mathrm{eV})$ & $\sum_{\mathrm{J}=1}^{l=0}$ & $E(\mathrm{eV})$ & $\begin{array}{l}\ell=0 \\
J=1\end{array}$ & $(\mathrm{eV})$ \\
\hline 300 & 0.072 & 1000 & 0.076 & \\
\hline 350 & 0.026 & 1200 & 0.065 & \\
\hline 400 & 0.044 & 1400 & 0.039 & 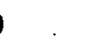 \\
\hline 450 & 0.118 & 1700 & 0.025 & \\
\hline 500 & 0.129 & 2000 & 0.026 & \\
\hline 550 & 0.182 & 2500 & 0.033 & \\
\hline 600 & 0.036 & 3000 & 0.031 & \\
\hline 650 & 0.010 & 3500 & 0.032 & \\
\hline 700 & 0.014 & 4000 & 0.038 & \\
\hline 750 & 0.027 & 4500 & 0.045 & \\
\hline 800 & 0.037 & 6000 & 0.054 & \\
\hline 850 & 0.052 & & & \\
\hline 900 & 0.052 & & & \\
\hline 950 & 0.056 & & & \\
\hline
\end{tabular}

A number of corrections and accuracy checks have been made to the ENDRUN code. The code will now perform complete calculations where partial runs for materials had been previously necessary. The materials which were involved in partial runs for the analysis described above, are now being recomputed. The accuracy of the resolved resonance calculations for $\mathrm{U}-238$ as a function of input options was determined and a rule of thumb established. The self-overlap correction for unresolved resonance calculations was checked out and indicated an increase in the Doppler coefficient. ENDRUN results which previously were questioned have been carefully checked and found to be correct.

\subsection{CORE ANALYSIS}

\subsubsection{Two-Dimensional Methods}

The new code DOT2DB, which incorporates the diffusion theory subroutines of the BNWL code $2 \mathrm{DB},(24,25)$ into the twodimensional transport theory code DOT, ${ }^{(26)}$ has been successfully run for both small and large problems. Both the transport and diffusion theory options have been checked out, including the convergence acceleration procedures. One of the test cases was an $(r, z)$ diffusion representation of EBR- $I I$ in 10 groups, providing a reference calculation of this reactor in support of other P. A. 10 activities. 
TABLE 7-2

FUNDAMENTAL MODE CALCUKATIONS FOR ZEBRA ASSEMBLY 6A

\begin{tabular}{|c|c|c|c|c|}
\hline & $\mathrm{MC}^{2}$ & GAFGAR & $1 \mathrm{DX}$ (ETOX) & FCC (ENDRUN) \\
\hline & - & & (26 Groups) & (29 Groups) \\
\hline $\mathbf{k}_{\text {eff }}$ & 0.9828 & 0.9850 & 0.9838 & 0.9792 \\
\hline$\delta \mathrm{k}_{\mathrm{eff}}$ for $\delta \mathrm{T}^{\mathrm{U}-238}\left(1100 \rightarrow 300^{\circ} \mathrm{K}\right)$ & 0.0084 & 0.0080 & 0.0075 & 0.0071 \\
\hline$\delta \mathrm{k}_{\text {eff }}$ for $\delta \mathrm{N}^{\mathrm{Na}}=+0.001$ & 0.0069 & 0.0066 & 0.0069 & 0.0067 \\
\hline$\sigma_{\mathrm{f}}^{\mathrm{U}-235} / \sigma_{\mathrm{f}}^{\mathrm{Pu}-239}$ & 1.0875 & 1.0730 & 1.0796 & 1. 1087 \\
\hline$\sigma_{\mathrm{f}}^{\mathrm{U}-238} / \sigma_{\mathrm{f}}^{\mathrm{Pu}-239}$ & 0.0399 & 0.0371 & 0.0397 & 0.0398 \\
\hline$\sigma_{c}^{\mathrm{U}-238} / \sigma_{\mathrm{f}}^{\mathrm{Pu}-239}$ & 0.1585 & 0.1601 & 0.1562 & 0.1563 \\
\hline$\sigma_{\mathrm{c}}^{\mathrm{Pu}-239} / \sigma_{\mathrm{f}}^{\mathrm{Pu}-239}$ & 0.2128 & 0.2147 & 0.2118 & 0.2107 \\
\hline$\sigma_{\mathrm{f}}^{\mathrm{Pu}-240} / \sigma_{\mathrm{f}}^{\mathrm{Pu}-239}$ & 0.2672 & 0.2656 & 0.2673 & 0.2675 \\
\hline$\sigma_{c}^{\mathrm{Pu}-240 / \sigma_{\mathrm{f}}} \mathrm{Pu-239}$ & 0.2382 & 0.2347 & 0.2357 & 0.2460 \\
\hline$\sigma_{\mathrm{c}}^{\mathrm{B}-10} / \sigma_{\mathrm{f}}^{\mathrm{Pu}-239}$ & 1.4359 & 1.4477 & 1.4186 & 1.4685 \\
\hline Running Time (min) & $\sim 20$ & $\sim 10$ & $\sim 1.2$ & $\sim 0.8$ \\
\hline
\end{tabular}

Emphasis is now being placed on increasing the code calculational efficiency by refining the programming of the main transport and diffusion flux calculation subroutines. In addition, a revised version of $2 \mathrm{DB}{ }^{(27)}$ has been received which contains a diffusion subroutine for a triangular mesh. Consideration is being given to incorporating this subroutine into DOT2DB. A subroutine for computing effective delayed neutron fractions by region and by isotope has been written for BISYN and checked out. Built-in values of delayed neutron fractions by decay group and by isotope are used together with an input spectrum of delayed neutrons to give $\beta_{\text {eff }}$.

FORTRAN IV versions of the machine language file control subroutines (read, write, etc.) have been programmed and tested in BISYN. This new version of BISYN is all FORTRAN IV and conversion to a Univac 1108 computer will be tested. The cost of a typical problem on the GE 635 increased by a factor of 3 using the all FORTRAN IV version. The expanded version of BISYN, which allows more regions and downscatter groups, has been programmed and tested through the flux solutions. 


\subsubsection{Anisotropic Scattering}

An investigation of neutron anisotropic scattering effects in FCR calculations is under way. In particular, the magnitude of the error introduced through the treatment of anisotropic scattering by a transport cross section is of interest. Twenty-four group cross sections, with anisotropic scattering represented by a Legendre series through $P_{3}$, are being used in our version of the code ANISN ${ }^{(28)}$ for the analysis. The transport cross section $\sigma_{t r}$, being used in the analysis is defined for group $\mathrm{g}$ as $\left(\sigma_{\mathrm{tr}}\right)_{\mathrm{g}}=\left(\sigma_{\mathrm{t}}\right)_{\mathrm{g}}-\sum_{\mathrm{g}^{\prime}}\left(\sigma_{\mathrm{s}_{1}}\right)_{\mathrm{g} \rightarrow \mathrm{g}^{\prime}}$ where $\left(\sigma_{\mathrm{s}_{1}}\right)_{\mathrm{g} \rightarrow \mathrm{g}^{\prime}}$ is the $\mathrm{P}_{1}$ anisotropic scattering matrix (without the $2_{\ell+1}$ factor).

The preliminary results (for spherical bare FCR models of different sizes) are given in Table 7-3. Conclusions which can be drawn from these results follow:

- Anisotropic scattering is important. The $\mathrm{P}_{\mathrm{o}}$ results are very poor.

- Treatment of anisotropic scattering through the linear $\left(P_{1}\right)$ term is sufficient in all cases.

- Treatment of anisotropic scattering through use of a transport cross section is quite good, particularly for large reactors.

- $\mathrm{S}_{4}$ transport thery is sufficient for large reactors, but $S_{6}$ is needed for small reactors.

- Errors due to approximate treatment of anisotropic scattering effects are not as important as the error in using diffusion theory in place of transport theory.

\subsubsection{Fuel Cycle Methods}

The principal routines for the fuel cycle code FUMBLE have been coded and are presently being checked out. These routines include:

- The burnup search iteration scheme to satisfy the specifications for reactivity, rated power, peak power, fuel exposure, and refueling interval.

- The reactor reload routines which may include fuel shuffling from stored fuel repositories (with or without a holdup period), recycle of discharged and reprocessed fuel, and makeup sources of fissile and fertile fuel.

- The output preparation and fuel cycle cost computations.

\subsection{TRANSIENT AND SAFETY ANALYSIS}

\subsubsection{Accident Analysis}

The first version of the FREADM code has been assembled and successfully run through the steady state initialization calculation. Calculations with one axial fuel node were performed to test the heat transfer time step control. The method used and results were reported in an ANS (American Nuclear Society) paper. A summary of test case parameters is given in Table 7-4. The estimated computational cost ratio (with control to without control) versus the ratio of heat transfer to kinetics time step for a full sized problem is shown in Figure 7-3. The points shown are estimates based on the one node calculations.

Calculation of reactivity effects due to sodium voiding was done using the 
TABLE 7-3

$k_{\text {eff }}$ OF BARE CORE CALCULATIONS

\begin{tabular}{|c|c|c|c|c|}
\hline & $\mathbf{P}_{0}$ & $P_{1}$ & $\mathrm{P}_{3}$ & $\sigma_{\operatorname{tr}}$ \\
\hline \multicolumn{5}{|l|}{$B^{2}=4 \times 10^{-3}$} \\
\hline Diffusion & $1.08247^{\circ}$ & 1.00338 & - & 1. 00439 \\
\hline $\mathrm{S}_{4}$ & 1.08808 & 1.01110 & - & 1.01438 \\
\hline$s_{6}$ & - & 1.00984 & 1.01179 & - \\
\hline$S_{8}$ & - & 1.00953 & - & - \\
\hline$s_{16}$ & - & 1.00929 & - & - \\
\hline \multicolumn{5}{|l|}{$B^{2}=2.0 \times 10^{-3}$} \\
\hline Diffusion & 1.06431 & 1. 01201 & - & 1. 01285 \\
\hline \multicolumn{5}{|l|}{$\mathrm{B}^{2}=1 \times 10^{-3}$} \\
\hline Diffusion & 1. 04825 & 1. 01941 & - & 1.01996 \\
\hline $\mathrm{S}_{4}$ & - & 1.02018 & - & - \\
\hline$s_{6}$ & - & 1. 02004 & 1. 02028 & - \\
\hline$s_{16}$ & - & 1.02001 & - & - \\
\hline
\end{tabular}

BISYN code. Results indicate that a simple formulation will be adequate for use in the FREADM code.

The sodium voiding and coolant flow subroutine which has been modified to include consideration of radial blankets has been debugged and will now be incorporated into FREADM.

\subsubsection{Numerical Methods}

Experience with numerical models presently available for determining the solution of transient temperatures in a reactor coolant channel has shown that inaccuracies can result in many of the situations encountered in transient conductive-convective heat transfer analysis. This study was initiated to determine the specific shortcoming of present methods and to develop a new, more rigorous model.
Typically, in a reactor core heat transfer analysis, the length of a coolant channel is divided into several axial sections, so the axial power profile is approximately constant in each section. It is then desirable to describe the convective heat transport in terms of the inlet, average, and outlet coolant temperatures of the axial section. The transient convective problem requires special consideration because of the transport effects involved. That is, coolant enters the axial section at a given temperature and time, transfers heat by conduction from the fuel pin, and exits from the section at another temperature and time. The analysis has shown that consideration of the transient time of the coolant through the axial section is of key importance in the correct analysis of the convective heat transfer.

To demonstrate what is needed in the way of a convective finite difference model, the equation for the average, or nodal, 
TABLE 7-4

SUMMARY OF TEST CASE PARAMETERS

Series 1 - Step Reactivity Insertion, No Feedback

\begin{tabular}{|c|c|c|c|c|c|}
\hline Case & $\$$ & $\mathrm{Tmax}^{\circ} \mathrm{F}$ & NKS & NNK/NHT & \multirow{9}{*}{$\begin{array}{l}\mathrm{E} 1=2.0 \\
\mathrm{E} 2=50.0 \\
\mathrm{E} 3=0.1\end{array}$} \\
\hline 1 & 0.50 & 50 & 1 & 1 & \\
\hline 2 & 0.50 & 50 & 10 & 5 & \\
\hline 3 & 0.50 & 100 & 100 & 10 & \\
\hline 4 & 0.50 & 200 & 100 & 20 & \\
\hline 5 & 1.20 & 50 & 1 & 1 & \\
\hline 6 & 1.20 & 50 & 10 & $51 / 21$ & \\
\hline 7 & 1.20 & 100 & 100 & $101 / 27$ & \\
\hline 8 & 1.20 & 200 & 100 & $101 / 15$ & \\
\hline
\end{tabular}

Series 2 - Step Reactivity Insertion, $\mathrm{T} \mathrm{dk} / \mathrm{dT}=-0.006$

\begin{tabular}{rrrrr} 
Case & $\$$ & NKS & NNK/NHT & \\
\hline 1 & 0.1 & 1 & 1 & 10 \\
2 & 0.1 & 10 & 1 & $\mathrm{E} 1=2.0$ \\
3 & 0.5 & 1 & 5 & $\mathrm{E} 2=50.0$ \\
4 & 0.5 & 10 & 1 & $\mathrm{E} 3=0.1$ \\
5 & 1.2 & 1 & 10 &
\end{tabular}

Series 3 - Ramp Reactivity Insertion of $1.20 \$, \mathrm{~T} d \mathrm{~d} / \mathrm{dT}=-0.006$

$\left.\begin{array}{crrrr}\text { Case } & \$ / \mathrm{sec} & \operatorname{Tmax}^{\circ} \mathrm{F} & \mathrm{NKS} & \mathrm{NNK} / \mathrm{NHT} \\ \hline 1 & 1 & 50 & 1 & 1 \\ 2 & 1 & 50 & 10 & \\ 4 & 1 & 10,000 & 100 & 100 \\ 5 & 10 & 50 & 1 & 1 \\ 6 & 10 & 50 & 10 & 100\end{array}\right\} \begin{array}{r}\mathrm{E} 2=50.0 \\ \mathrm{E} 3=\mathbf{0}\end{array}$

E1 = Maximum allowable fractional power increase over a kinetics time step

E2 = Maximum allowable nodal fuel temperature increase $\left({ }^{\circ} \mathrm{F}\right)$

E3 = Maximum allowable reactivity change (\$)

$T \max =$ Minimum temperature change between heat transfer calculations

NKS = Maximum number of kinetics steps per heat transfer step

NNK/NHT = Average ratio of kinetics steps per heat transfer step 


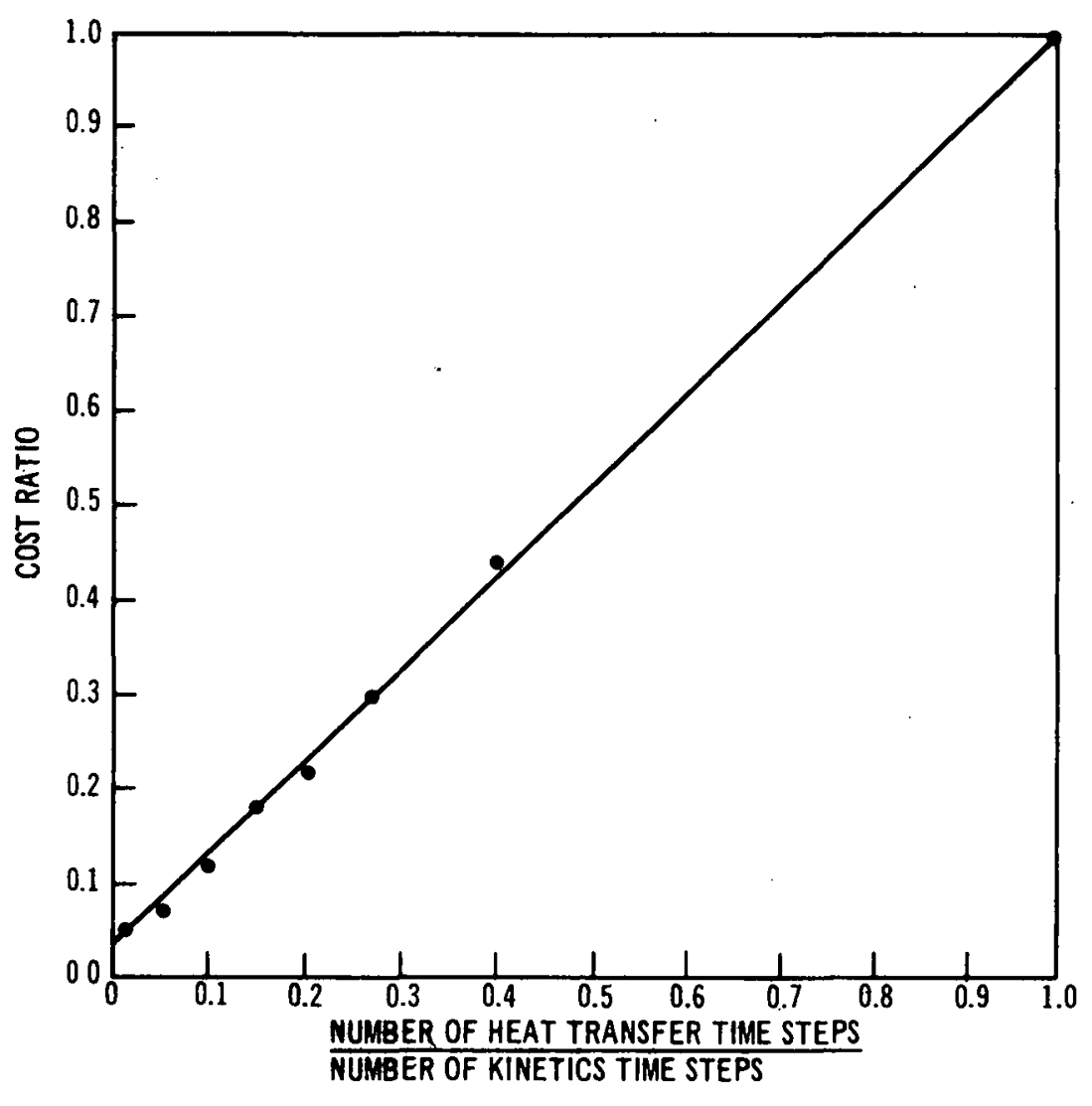

EIGURE 7-3. EFFECTIVENESS OF FREADM TIME STEP CONTROL

coolant temperature is written for an axial section:

$$
\begin{aligned}
\rho \mathrm{cA} \frac{\delta \mathrm{T}_{\mathrm{c}}}{\delta \mathrm{t}} & =\frac{1}{\mathrm{R}_{\mathrm{wc}}}\left[\mathrm{T}_{\mathrm{w}}-\mathrm{T}_{\mathrm{c}}\right] \\
& -\rho \mathrm{cAu} \frac{\mathrm{T}_{\mathrm{L}}-\mathrm{T}_{\text {in }}}{\mathrm{L}}
\end{aligned}
$$

where:

$$
\begin{aligned}
& T_{\mathrm{c}}=\begin{array}{l}
\text { average coolant temperature } \\
\text { of the section }
\end{array} \\
& \mathrm{T}_{\mathrm{in}}=\begin{array}{l}
\text { inlet coolant temperature to } \\
\text { the section }
\end{array} \\
& \mathrm{T}_{\mathrm{L}}=\begin{array}{l}
\text { outlet coolant temperature of } \\
\text { the section }
\end{array} \\
& \mathrm{T}_{\mathrm{w}}=\text { average cladding temperature } \\
& \rho \mathrm{cA}=
\end{aligned}
$$

$$
\begin{aligned}
R_{w c}= & \text { thermal resistance between clad- } \\
& \text { ding and coolant } \\
t \quad= & \text { time }
\end{aligned}
$$

The problem to date has been the use of a valid model for the coolant outlet temperature, $T_{L}$. The analysis has shown that the value for $\mathrm{T}_{\mathrm{L}}$ is strongly dependent on the relative size of the time increment $\tau$, and the transit time of the coolant through the node $\lambda$.

$$
\lambda=\frac{\mathrm{L}}{\mathrm{u}} .
$$

In order to understand the transient response of the coolant and the transport delay effects involved, the complete axial coolant temperature profile was determined as a function of position, $z$, and time, $t$, for a simplified set of boundary conditions.

The physical model used was simply an axial section of coolant channel with a 
specified heat input to the coolant. The geometry is shown in Figure 7-4. By selecting the simplification of a specified heat input, the delay time associated with conducting heat to or from the fuel is ignored, but the model is useful in permitting isolation and specific examination of the coolant transport effects. After the solution is found, the heat input can be reassociated with the heat transfer from the fuel pin so that finite difference equations can be formulated.

Initially, it is desirable to find the response of the chosen system to either a step change in coolant flow or a step change in inlet temperature. With the elimination of the time lag between coolant and fuel, it can be shown that a decrease in flow gives an equivalent response to an increase in heat input, and thus all of the major types of perturbations to the coolant temperature can be covered by flow decrease or inlet temperature change.

From these results, the coolant temperature for a step reduction in flow and for a step increase in inlet temperature are shown in Figures 7-5 and 7-6. By examining Figures $7-5$ and 7-6, the transport effects mentioned previously become evident. For the step decrease in flow (or step increase in heat input), the new axial temperature profile in the channel does not fully establish itself until $t \geq \lambda$. The effect at the outlet is felt gradually. During the transient, $0 \leq \mathrm{t} \leq \lambda$, the temperature for $\mathrm{z}>\mathrm{u}_{\mathrm{F}} \mathrm{t}$ maintains its original gradient, the profile being displaced upward, and for $\mathrm{z}<\mathrm{u}_{\mathrm{F}} \mathrm{t}$ the new profile is fully established. For the step change in inlet temperaturc, the perturbation propagates up the channel at velocity $u_{F}$ and is not seen at the outlet until $t=\lambda$.

From these results, the following finite difference model for the coolant outlet temperature was developed:
For $\tau<\lambda$ :

$$
\begin{aligned}
T_{L}^{j+1}= & T_{L}^{j}+\tau_{j+1}\left[\frac{1}{\rho c A R w c}\left(T_{w}^{j}-T_{c}^{j}\right)\right. \\
& \left.-2 \frac{\left(T_{L}^{j}-T_{c}^{j}\right)}{\lambda_{j+1}}\right]+\frac{\beta}{1+\beta}\left(T_{L}^{j}-T_{L}^{j-1}\right)
\end{aligned}
$$

where:

$$
\begin{aligned}
& \Delta_{c}=2 \tau_{j+1} / \lambda_{j+1} \\
& \beta=\left\{\begin{array}{cc}
0 & \Delta_{c}<1 \\
\left(\Delta_{c}-1\right) / 2 & \Delta_{c}>1
\end{array}\right. \\
& \tau_{j+1}=t_{j+1}-t_{j}=\text { time increment } \\
& \lambda_{j+1}=\mathrm{L} / \mathrm{u}_{\mathrm{j}+1} \\
& \mathrm{j}=\text { time step index } \\
& \text { For } \tau>\lambda \text { : } \\
& T_{L}^{j+1}=T_{i n}^{j}+\dot{T}_{i n}^{j+1}\left(\tau_{j+1}-\lambda_{j+1}\right) \\
& +\frac{\lambda_{j+1}}{\rho c A R w c}\left(T_{w}^{j}-T_{c}^{j}\right)
\end{aligned}
$$

where: ,

$$
\dot{T}_{\text {in }}^{j+1}=\frac{T_{\text {in }}^{j+1}-T_{i n}^{j}}{\tau_{j+1}}
$$

To verify the new equations, a computational model was set up which had the capability of calculating a transient by the recommended method (designated method 1) and also by two other methods which are presently in use (designated methods 2 and 3 ). The model consisted of one axial section with the coolant coupled by conduction to one fuel node. The three models differed only in their method of calculating the coolant outlet temperature. 

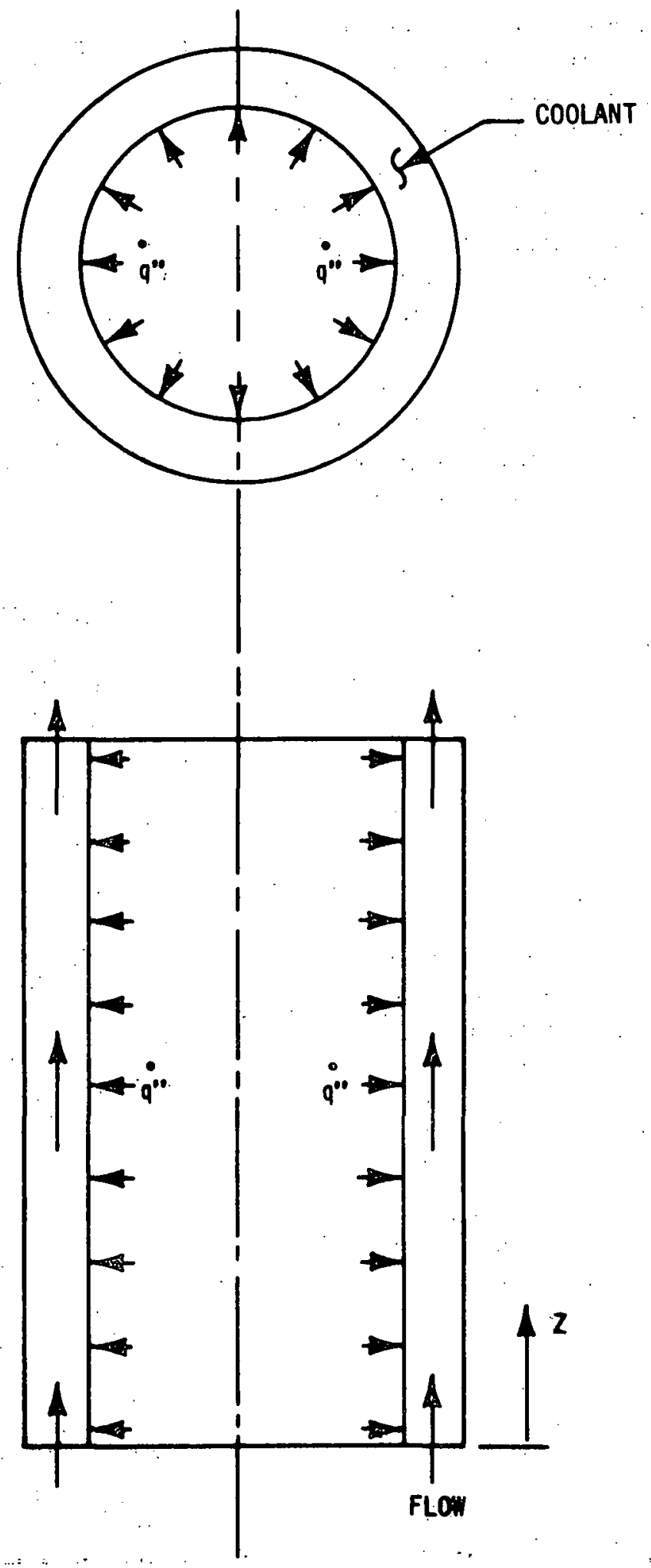

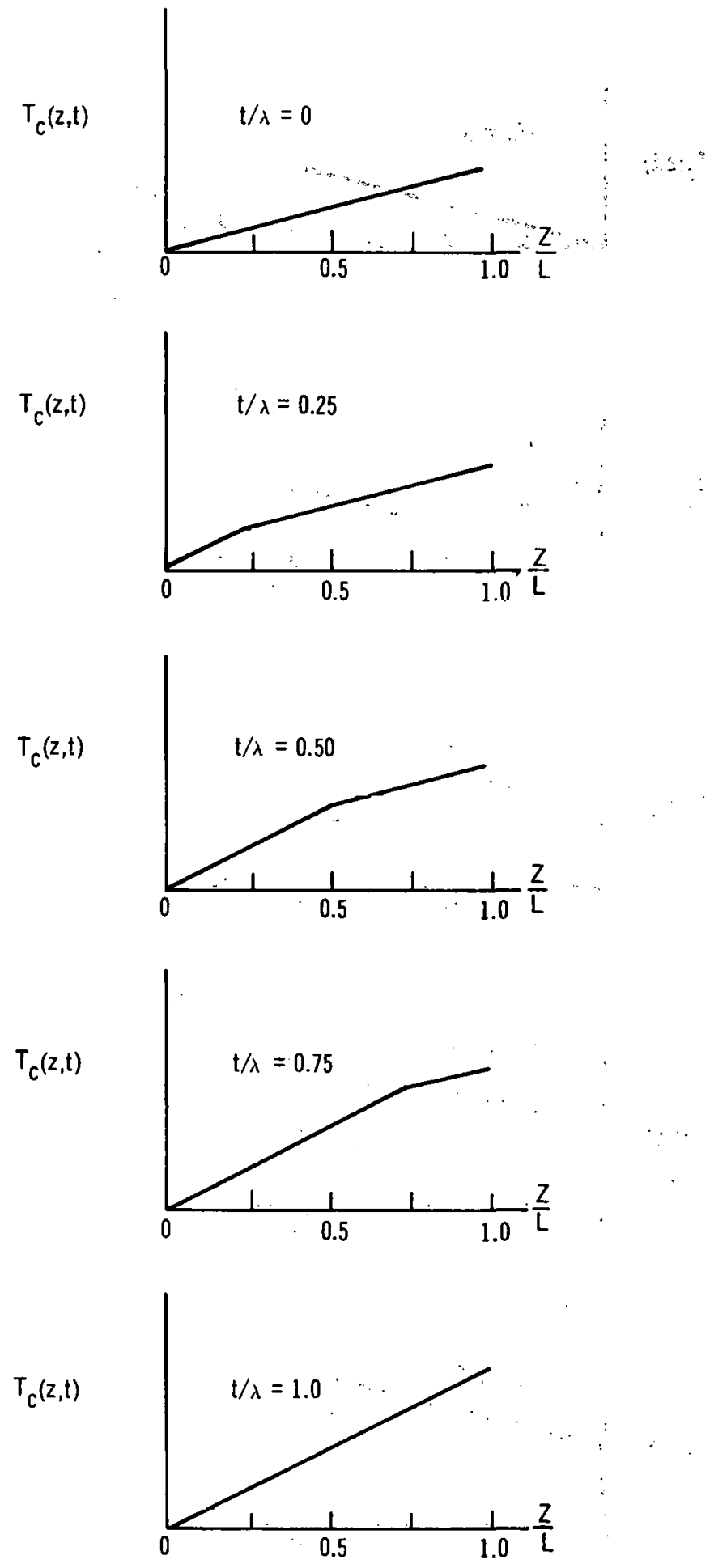

FIGURE 7:5. STEP DECREASE IN FLOW AT CONSTANT POWER 

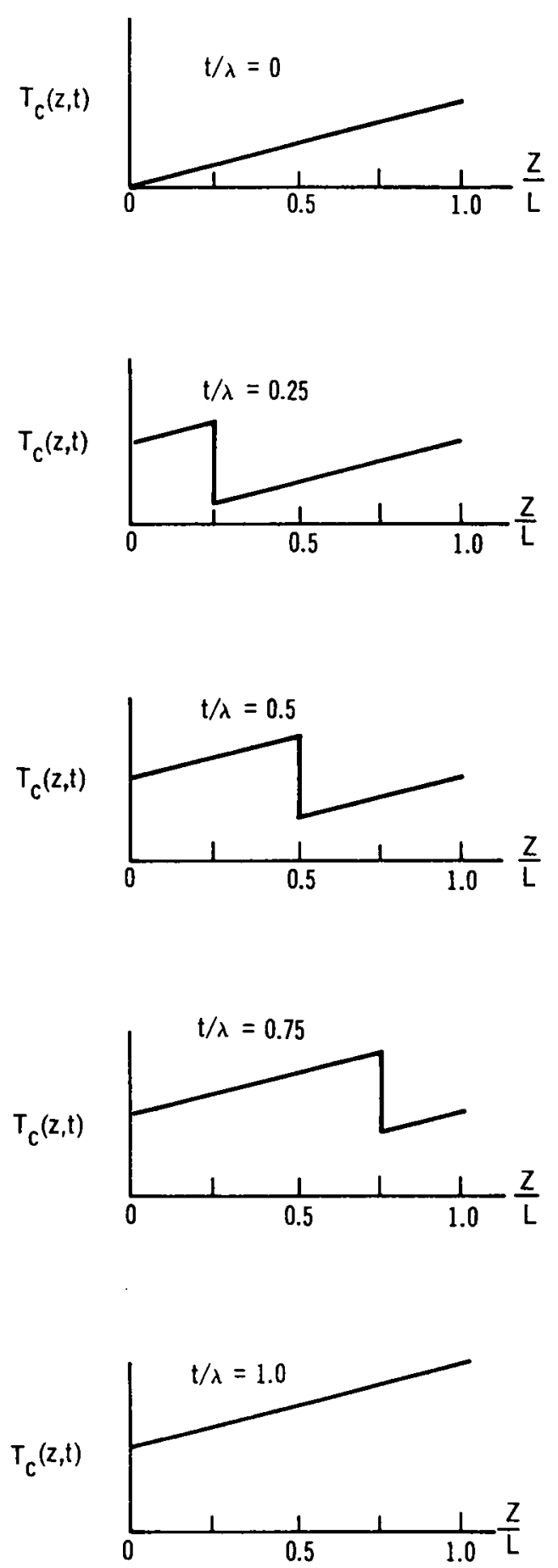

FIGURE 7-6. STEP INCREASE TO COOLANT INLET TEMPERATURE 
Figure 7-7 shows the coolant response to a $50 \%$ step flow loss. It can be seen that overall the new model predicts the best results. Method 2 underpredicts the outlet temperature and thus gives too large a change in the average coolant temperature. Method 3 overpredicts the outlet temperature for $\tau<\lambda$, but comes into line for $\tau>\lambda$. It can also be seen that Method 1 does overshoot the temperature by about $10 \%$ but corrects itself. It was found that this problem could be eliminated with a more refined nodal structure in the fuel pin.

On the other hand, when a $95 \%$ flow loss accident, resulting in very low flow and a large value of $\lambda$, was run, Method 2 yielded better results than Method 3. However, Method 1 was still superior to either of the other two. See Figure 7-8.

A complete summary of the work can be found in the conference proceedings on "The Effective Use of Computers in the Nuclear Industry," a joint ANS-ORNL-UTC conference, April 21 through 23, 1969, in Knoxville, Tennessee.

\subsection{FUEL ANALYSIS AND THERMAL HYDRAULICS}

\subsubsection{VELVET Temperature Calculations}

Using the recently revised VELVET code, an extensive set of temperature distributions and thermal results has been generated for unsupported, internal fuel rods. Emphasis is placed on results and conclusions pertinent to current fuel bundle thermal designs. Examples of these are the effects of pitch-to-diameter ratio on average and local heat transfer performance and the adequacy of slug flow analyses.

The analysis separates the basic repeating unit of a fuel bundle into two parts: (a) fuel pin and (b) gas gap, cladding and coolant channel. A Fourier series rep resentation of temperatures is used for the fuel; the fuel surface heat flux is specified as a boundary condition, and the corresponding temperature distribution is calculated. The gap, cladding and coolant associated with one-twelfth a pin $\left(30^{\circ} \mathrm{seg}-\right.$ ment) are simulated in a nodal model. The eddy diffusivities for heat transfer are determined from the momentum diffusivities by Dwyer's correlation. Matching of the fuel and nodal model partial solutions is done at the fuel surface. The computer analysis is iterated between the two simulations until the fuel surface heat flux and temperature distributions are matched. The model retains temperature-dependent material properties and includes a turbulent velocity profile in the coolant.

The variations of the average Nusselt numbers and convective heat transfer coefficients with bundle pitch-to-diameter ratios $(\mathrm{P} / \mathrm{D})$ are significant. This is shown in Figure 7-9 where the average Nusselt numbers are plotted as a function of Peclet number and $P / D$. The lower the $P / D$, the poorer are the thermal characteristics of the bundle. The reduction in heat transfer is particularly severe for $P / D$ values of 1.1 or below.

For each $\mathrm{P} / \mathrm{D}$, the Nusselt numbers have the "dog-leg" variation' with Peclet number characteristic of essentially all liquid metal flows. At low Peclet numbers, the Nusselt numbers are constant. This is the regime of negligible thermal diffusion (i.e., $\epsilon_{\mathrm{H}} / \alpha \simeq 0$ ), although the flow is fully turbulent. Not shown in Figure 7-9 is the relatively sudden drop in Nusselt number when the flow becomes laminar. This occurs in the 10 to 40 range of Peclet number.

At higher Peclet numbers, the Nusselt numbers vary approximately as $\mathrm{Pe}^{0.8}$. This rise in Nusselt number is the result of the increasing importance of turbulent diffusion 


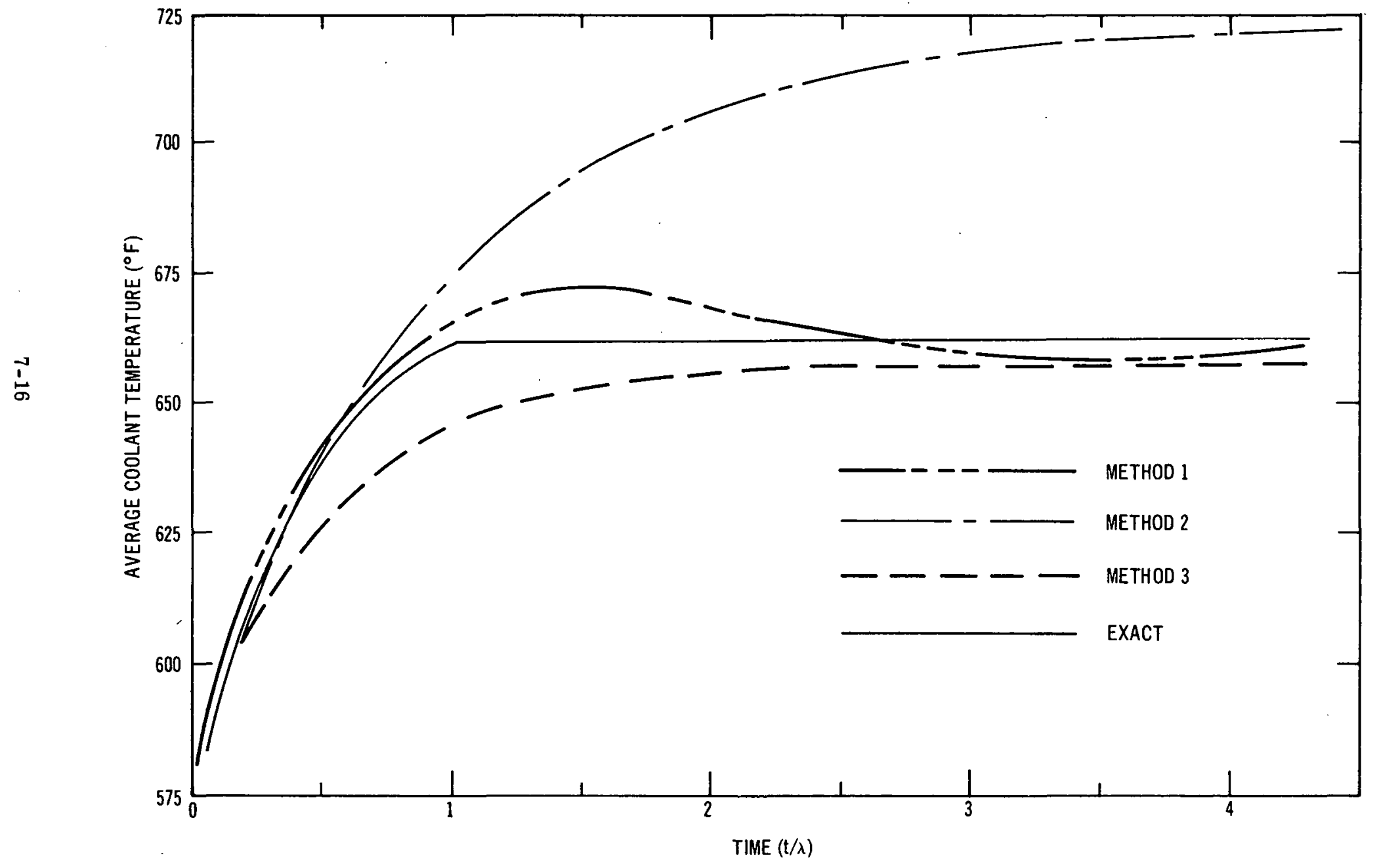




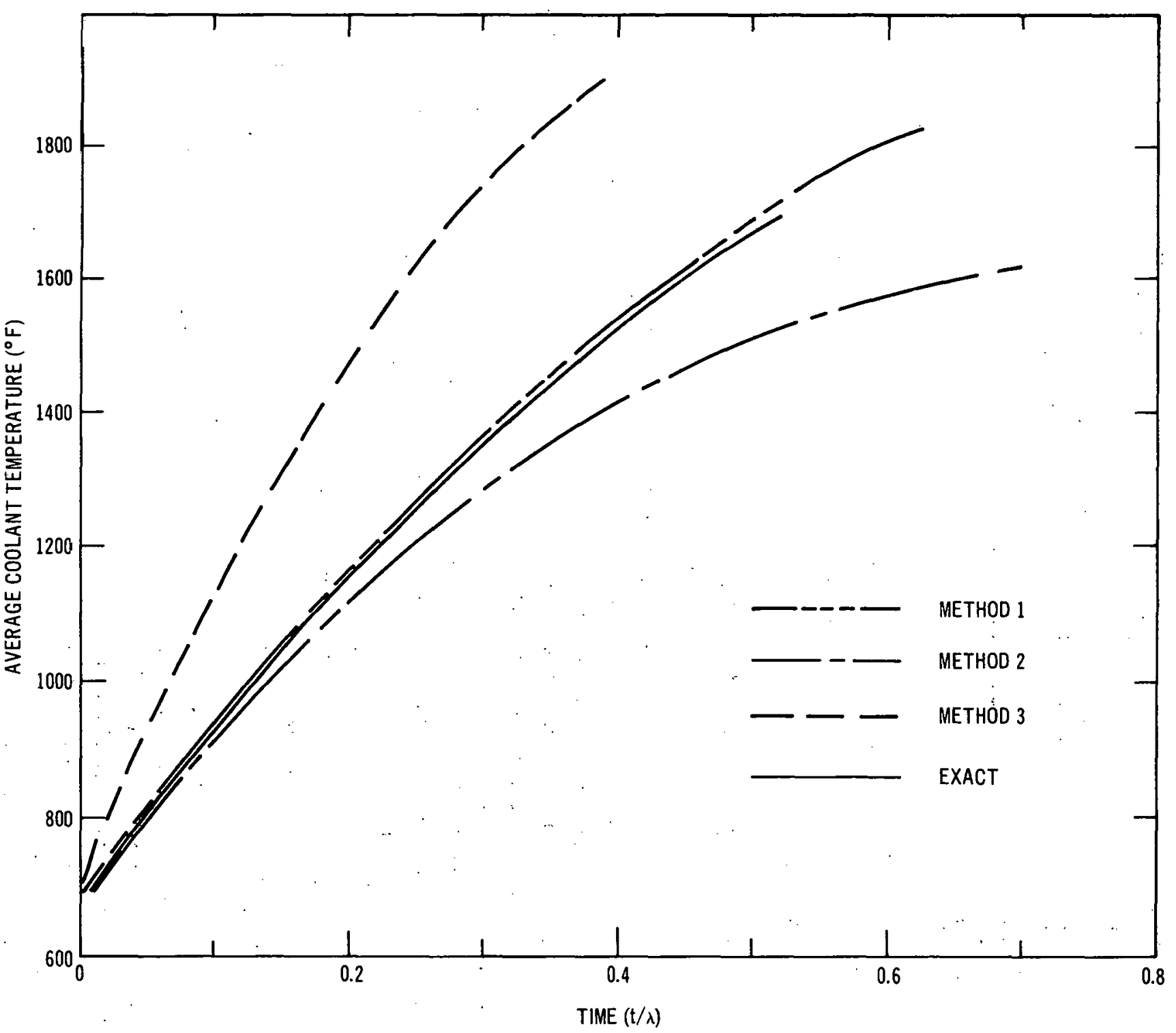


GEAP-10028

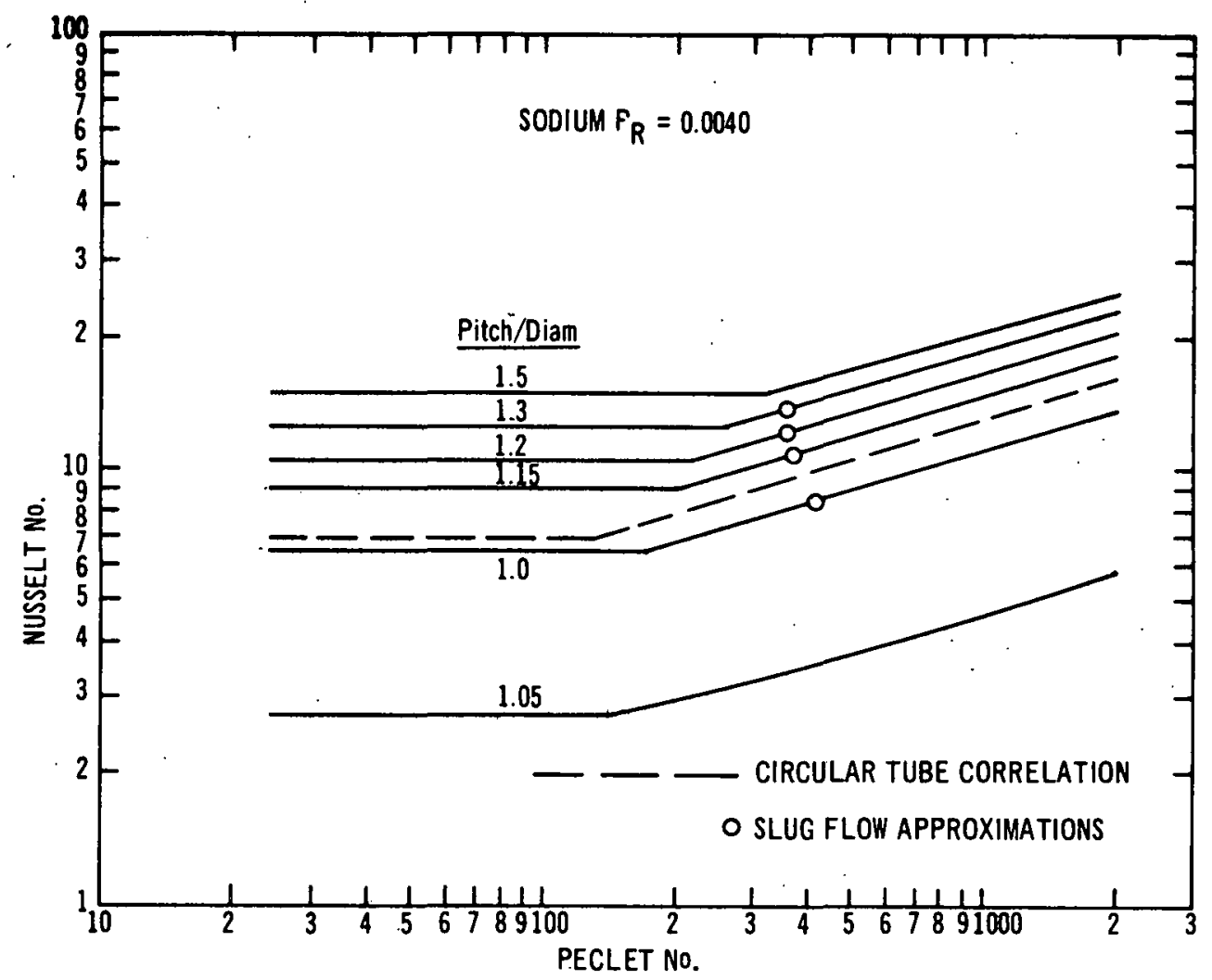

FICURE 7-2 NUSSELT NUMBER VARIATION

as the Reynolds number (or Peclet number) is increased. For comparison, the NusseltPeclet correlation for sodium flow in a circular tube is also plotted in Figure 7-9. It is seen to fall between the 1.1 and $1.15 \mathrm{P} / \mathrm{D}$ rod bundle results and is very similar in shape to the bundle correlations.

Slug flow analyses have been performed for a number of pitch-to-diameter ratios. Slug flow implies the use of two simplifying but incorrect assumptions: (a) uniform velocity everywhere in the channel and (b) negligible turbulent diffusivity. These two assumptions tend to be counterbalancing, and the results of liquid metal slug flow analyses are often. reasonable approximations. It will be noted that slug flow does not permit a Reynolds number dependence.

In Figure 7-9, the slug flow results are plotted at the Reynolds number at which the Nusselt number matches that of the complete VELVET solution. The slug flow results correspond to Peclet number in the range of 350 to 450 . Slug flow results are conservative for higher Peclet numbers but somewhat optimistic (up to 20-30\% higher) for lower Peclet numbers. Slug flow cladding temperature distributions do not differ significantly from those predicted by the complete analysis for $\mathrm{P} / \mathrm{D}$ greater than 1.1 .

The temperature distributions on the. outside surface of the cladding are summarized in Figures 7-10 and 7-11. These distributions have the general form

$$
\mathrm{T}_{\mathrm{wo}}(\phi)=\overline{\mathrm{T}}_{\mathrm{wo}}+\mathrm{A}_{\mathrm{wo}} \cos (6 \phi)
$$

with second order contributions from the higher harmonics $\cos (6 \mathrm{n} \phi)$.

The cladding temperature variation is a function of the pitch-to-diameter ratio and the Peclet number. The variation also increases linearly with heat flux. The plots 


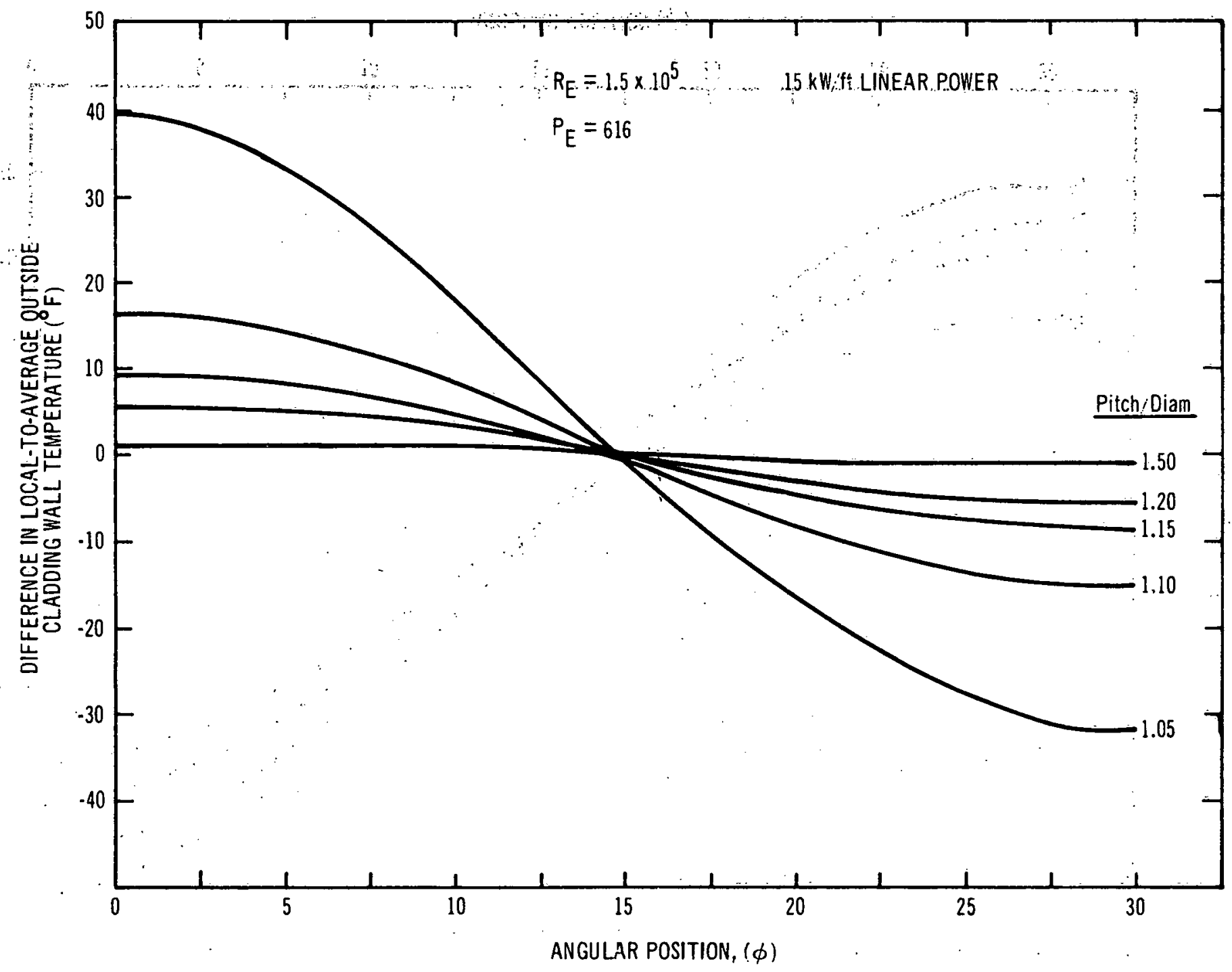




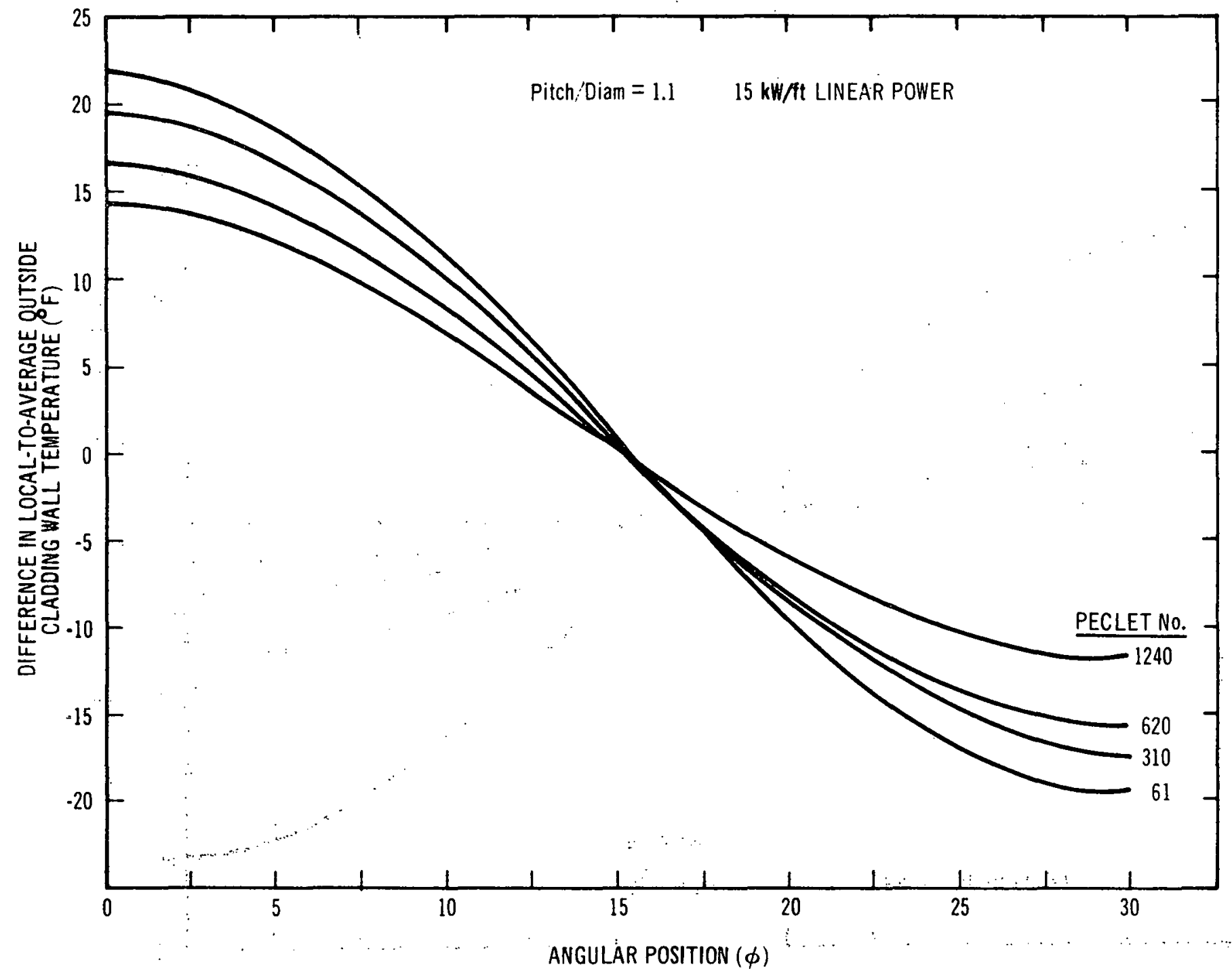


are for an average heat flux of $0.8 \times 10^{6}$ $\mathrm{Btu} / \mathrm{h}-\mathrm{ft}^{2}$ which, for the 0.25 -inch-diameter pins considered, corresponds to $15 \mathrm{~kW} / \mathrm{ft}$ linear power. For P/D greater than 1.2, the cladding temperatures do not show significant circumferential variations.

The circumferential variations of the cladding-to-coolant heat flux exhibit the same type of dependence on P/D and Peclet number as the cladding temperature variations. However, the heat flux is not well approximated by a simple cosine function for $P / D$ less than 1.1. For $P / D$ greater than approximately 1.3 , the heat flux can be assumed to be circumferentially constant for all Peclet numbers.

The fuel-to-cladding conductance was found to have a negligible effect on circumferential temperature distributions for bundles with $P / D$ of 1.05 or greater. It is concluded that no significant thermal variations occur in the cladding and coolant because of fuel swelling prior to the time the swollen fuel begins to strain the cladding.

The results of this two-region study are in good agreement with the published singleregion (coolant only) analyses of Dwyer ${ }^{(29)}$ and Borishanski, et al. , ${ }^{(30)}$ for liquid metal flow parallel to closely packed rod bundles. Although a different heat flux boundary condition (i.e., circumferentially uniform) is assumed in the previous studies to simplify the problem by analyzing only the coolant region, this appears to be of little importance. The average heat transfer results of the present study fall between those of the cited references except at low P/D or Peclet numbers. This is consistent with the fact that the uniform heat flux solutions give lower limits for Nusselt numbers. For P/D greater than 1.15, the surface heat flux variation has no significant thermal effect. It is only at low $P / D$ and Peclet numbers that the heat flux variation is of importance.
A comparison of the cladding circumferential temperature distributions calculated in this study was made with the analytic predictions of Dwyer for uniform surface heat flux. Although the heat flux distributions are different for the two analyses, the surface temperature distributions are quite similar. In addition, both studies show that the temperature variations are not significantly affected by a ten-fold increase in flow rate in the turbulent range. Apparently the bundle pitch-to-diameter ratio and the linear power generation rate are the only significant parameters determining circumferential temperature variations, at least for pitch-todiameter ratios greater than 1.05 .

\subsubsection{Fuel Swelling}

\subsubsection{Model Development}

An addition was made to the model to predict the expansion of fuel operating at low power. The case was examined, for which a central void would not be expected. Assumptions for this case based upon observed fuel morphology of low power fuel were:

(a) The intergranular bubbles remain a fixed distance apart.

(b) The bubbles continue to grow until contact is made with neighboring bubbles at which time additional gas which is generated is released.

The results of these assumptions on the volumetric expansion of low-power fuel. when incorporated in the fuel swelling computer code is shown in subsection 7.5.2.4.

\subsubsection{Physical Property Studies}

\subsection{Clad Swelling Data Correlation}

Analysis of the available data on swelling of Types 304 and 316 stainless steels has 
yielded an empirical equation believed suitable for determining the amount of fuel pin swelling which may be attributed to swelling of the cladding over the range of data taken. All available data for 304 and 316 stainless steels were included subject to the stipulations that the samples were irradiated within the core region of the reactor and that swelling determination was by the immersion density technique. The reasons for excluding data from the blanket region are that fluences are more uncertain and the neutron spectrum changes greatly from point to point. Furthermore, at the relatively low fluences prevailing in the blanket, the amount of swelling observed appears to be higher than would be predicted by either of the equations to be described below. Swelling determinations by transmission electron microscopy were considered generally unreliable and were excluded.

The data used in the analysis will be tabulated in a forthcoming topical report. All but two of the samples were annealed Type-304 material and all but one received their irradiation in EBR-II, the exception being one sample irradiated in DFR. Data were fit to an empirically derived equation of the form

$\frac{-\Delta \rho}{\rho}=A F^{n} \exp \left[C_{1}\left(\frac{1}{T}\right)+C_{2}\left(\frac{1}{T}\right)^{2}\right]$

where:

$$
\begin{aligned}
& \frac{\Delta \rho}{\rho} \sim \frac{\text { change in density }}{\text { original density }}(\%) \\
& \mathrm{F} \sim \text { fluence }\left(10^{22} \mathrm{n} / \mathrm{cm}^{2} \mathrm{E}>0.1 \mathrm{MeV}\right) \\
& \mathrm{T} \sim \text { irradiation temperature }\left({ }^{\circ} \mathrm{K}\right)
\end{aligned}
$$$$
\mathrm{A}, \mathrm{n}, \mathrm{C}_{1}, \mathrm{C}_{2} \sim \text { constants determined by }
$$
least squares fit of data.

The equation was linearized by taking the natural logarithm of both sides yielding

$\ln \left(\frac{-\Delta \rho}{\rho}\right)=\ln A+n \ln F+C_{1}\left(\frac{1}{T}\right)+C_{2}\left(\frac{1}{T}\right)^{2}$
The result of a least squares fit of the data to Equation (7-2) depends strongly on which parameter is chosen as the dependent (random) variable. With $\ln \left(\frac{-\Delta \rho}{\rho}\right)$ as the dependent variable, Equation $(7-1)$ is found to be

$$
\begin{gathered}
\frac{\Delta \rho}{\rho}=-7.8 \times 10^{-5} \mathrm{~F}^{1.59} \exp \\
{\left[\frac{15510}{\mathrm{~T}}-\left(\frac{2660}{\mathrm{~T}}\right)^{2}\right]}
\end{gathered}
$$

There is, perhaps, more reason to take ln $F$ as the dependent variable. While the density change of a specimen can be measured with great accuracy for the density changes considered here, there is evidence of a high degree of uncertainty in the fluence values assigned to some specimens (this point will be discussed below). If the greatest amount of uncertainty is associated with the fluence estimates, there is reason to take it as the random variable. On this basis, Equation $(7-1)$ is found to be

$$
\begin{aligned}
\frac{\Delta \rho}{\rho}= & -5.8 \times 10^{-5} \mathrm{~F}^{2.35} \exp \\
& {\left[\frac{15820}{\mathrm{~T}}-\left(\frac{2760}{\mathrm{~T}}\right)^{2}\right] }
\end{aligned}
$$

The effect of temperature on the data correlation of swelling is indicated in Figures 7-12 and 7-13. The temperature effect is seen to be a parabola on semi- $\log$ coordinates which peaks in the vicinity of $600^{\circ}$ to $650^{\circ} \mathrm{C}$. In these figures, data points derived from samples cut from a single piece of metal are connected in order by straight lines. Although some of the data sub groupings as indicated by the interconnected data points fit the equation very well, there is, however, fairly high divergence of the data from the curve generated by the equation.

The indicated effect of fluence on swelling is more strikingly influenced by the choice of dependent variable. The least squares analysis yields exponents on the fluence term of 1.59 


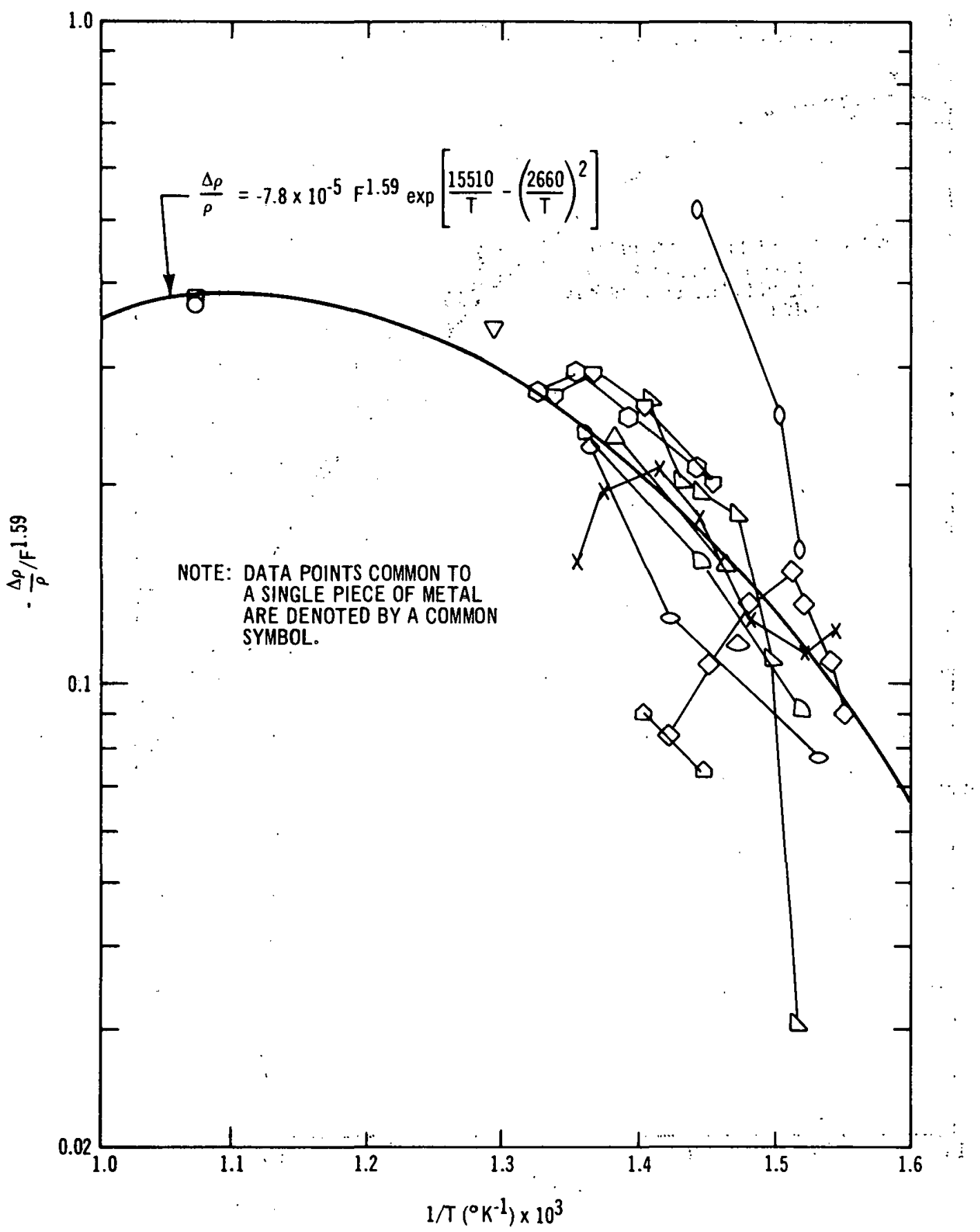

FIGURE 7-12. CLAD SWELLING NORMALIZED AGAINST FLUENCE EFFECT VERSUS RECIPROCAL TEMPERATURE. EQUATION FIT TO DATA ASSUMING In $\left(-\frac{\Delta p}{\rho}\right)$ DEPENDENT. VARIABLE 


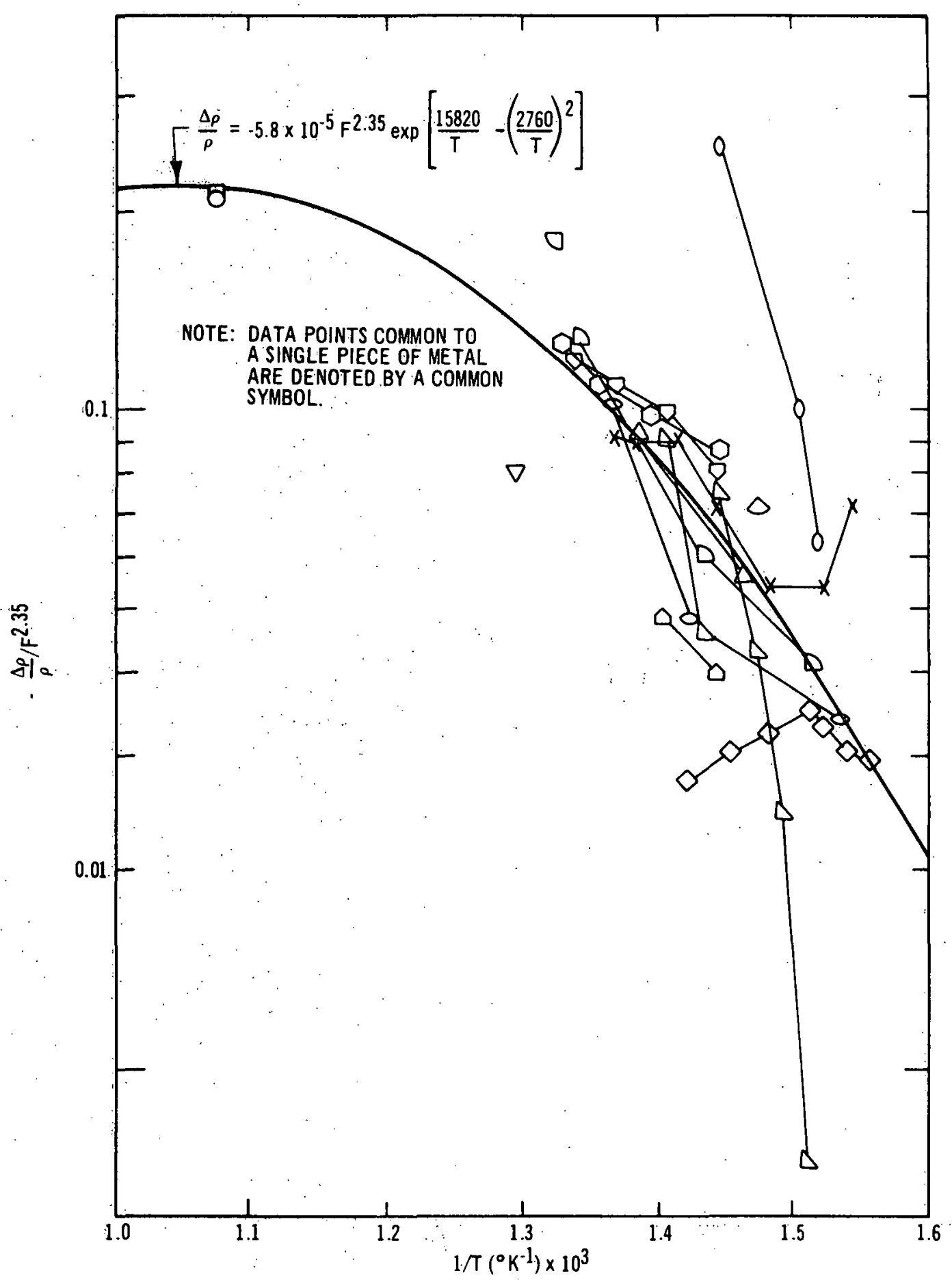

FIGURE 7-13. CLAD SWELLING NORMALIZED AGAINST FLUENCE EFFECT VERSUS RECIPROCAL TEMPERATURE. EQUATIION FIT TO DATA ASSUMING IIF DEPENDENT VARIABLE 
and 2.35 for the choice of $\ln \left(\frac{-\Delta \rho}{\rho}\right)$ and $\ln F$ respectively. The effect of fluence on swelling is indicated in Figures 7-14 and 7-15 for the two exponents 1.59 and 2.35 respectively.

An equation, being between the two extremes represented by Equations (7-3) and (7-4) was obtained by forcing the exponent on fluence to equal 2 . This result is obtained by taking $\ln \left(\frac{-\Delta \rho}{\rho} / F^{2}\right)$ to be the dependent variable. This equation, which is presently being used in the F2 fuel pin swelling data correlation, is given by:

$$
\begin{aligned}
\frac{\Delta \rho}{\rho}= & -6.7 \times 10^{-5} \mathrm{~F}^{2} \exp \\
& {\left[\frac{15670}{\mathrm{~T}}-\left(\frac{2710}{\mathrm{~T}}\right)^{2}\right] }
\end{aligned}
$$

The application of the equation to the analysis of $\mathrm{F} 2$ pin data will be reported in the next quarterly.

Several explanations may be advanced for the lack of a better correlation. The most obvious possibility is that the phenomenon is inadequately described by Equation (7-1). Other possible reasons are noted below:

There appears to be a large uncertainty in the fluence numbers reported. The greatest problem is locating the point of peak fluence relative to the specimens. Moving the peak fluence axially by as little as 1 inch can have a significant effect on how the data correlates. In some cases, there is an uncertainty in the shape of the fluence-axial position curve.

- The stated temperatures of the irradiations are subject to large errors.

It must be emphasized that the validity of extrapolating any of these equations beyond the range of data which was used is very questionable. Similarly, it is restated that . these equations are applicable only for Types 304 or 316 stainless steel. These data, with only one exception, were from EBR-II, and to estimate the amount of swelling which would be observed in another reactor requires one to make assumptions concerning the effect of the flux spectrum. Such extrapolations should only be made after an appropriate physical model has been evolved for purposes of data correlation. Work is now in progress to develop such a model within Task $L$.

\subsection{Fuel Grain Size Determination}

Work has been initiated on the determination and uncertainty of the fuel grain size as a function of temperature and burnup.

\subsubsection{Correlation with Experimental Data}

The statistical data correlation method described in the last quarterly has been applied to eight Task F pins.

The raw swelling data are the profilometer traces taken along the pin length at $0^{\circ}, 45^{\circ}, 90^{\circ}, 135^{\circ}$ circumferential positions during the post-irradiation examination. A Task L study evaluating the uncertainties of these measurements has been completed and were applied in this analysis. The arithmetic average of the traces, assumed representative of the pin, is smoothed to eliminate noise on the order of less than a pellet length and then reduced to point values assigned to pre-irradiation pellet locations. Correspondence between pre $z$ and post-irradiation pellet locations is checked. The information removed during smoothing is preserved as a local-to-pellet average factor for future analysis.

The pellet density, diameter, length and cladding dimensions are recorded during fabrication with small uncertainty. The burnup, linear power, cladding temperature, and cladding fluence profiles are estimated 


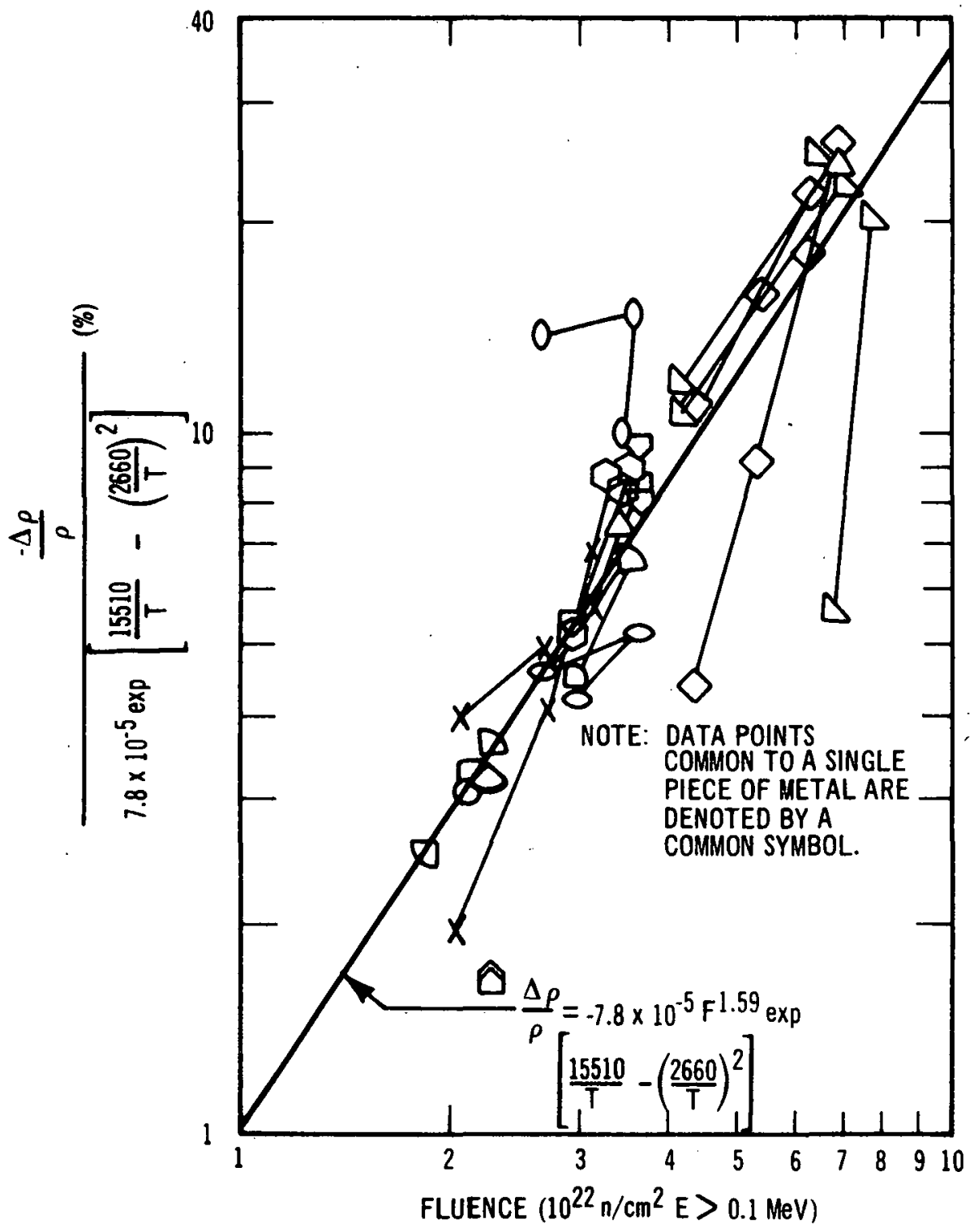

FIGURE 7-14. CLAD SWELLING NORMALIZED AGAINST TEMPERATURE EFFECT VERSUS FLUENCE. EQUATION FIT TO DATA ASSUMING In $\left(-\frac{\Delta \rho}{\rho}\right)$ DEPENDENT VARIABLE 


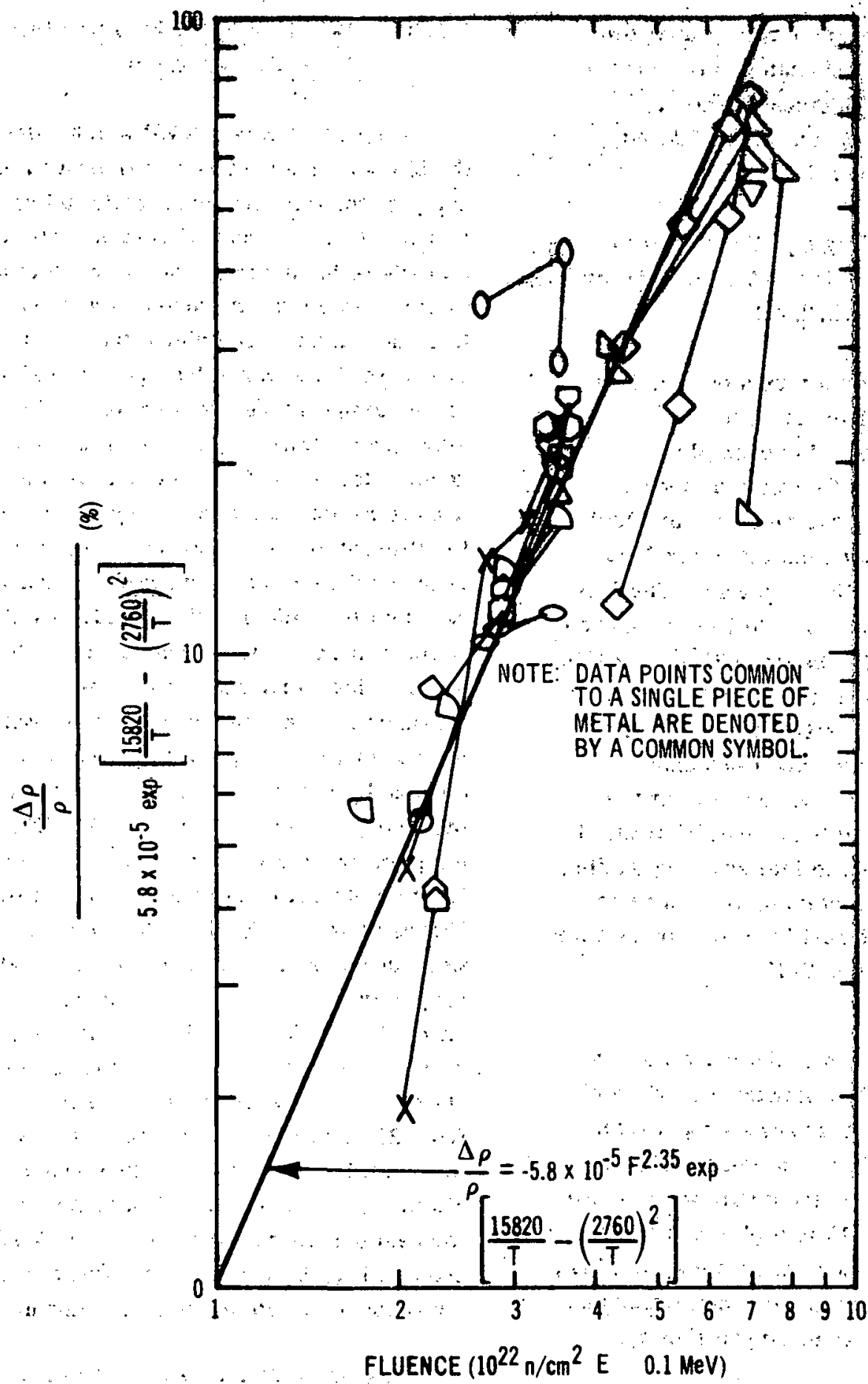


from EBR-II coolant temperature and power measurements, gamma scan traces, chemical analyses, and cross section microstructure examination, and then reduced to point values noted in Figure 7-16.

The clad swelling equations used in this analysis are based upon the correlation noted in subsection 7.5.2.2.1.

Several functional forms of variables involved in fuel swelling are noted in Figure 7-17. The $\Delta D$, for example, may be linear with burnup following an incubation period. Fission gas retention and fuel plasticity effects may combine to produce a peak in $\Delta \bar{D}$ versus linear power. The fuel density functional form should have a marked variation for densities between $85 \%$ and $100 \%$. At least four variables are expected to affect cladding restraint: position along the pin, material, temperature, and thickness. Greater swelling at the bottom than at the top has been observed in several F2 pins. If the cladding response to fuel swelling loading is basically creep, material, temperature, and thickness, functional form will be similar to that shown in Figure 7-17.

Functional forms of the variables are tested systematically following a statistical pattern. Figure 7-18 shows a progression yielding a fair 0.81 correlation coefficient with fair confidence in the coefficients of the equation. Figure 7-19 is a plot of the final correlation (based upon data from eight pins), plus the clad swelling and thermal expansion effects, against the reduced profilometer trace of pin F2T.

The analysis of a few F2 pins will continue until reasonable confidence has been . established that the individual contributions of the driving mechanisms are being adequately separated from the total $\Delta \mathrm{D}$ observed.

\subsubsection{Development of Fuel Swelling Computer Program}

The subroutine TEMP which calculates the temperature profile was improved to compute the temperature profile in low power fuel which has no central void as well as in fuel where the average volumetric temperature is at a maximum. An analysis was made using this subroutine to determine the effect of changes in several input variables upon the calculated center temperature and void size. The temperature profile was calculated on the basis of a density dependent fuel conductivity where three density regions were considered which correspond to different grain structures in the fuel. There is theoretical and experimental evidence to suggest that the radius of the boundaries of these regions increase with burnup. The effect of varying these critical temperatures was investigated. A minimum temperature of $2130^{\circ} \mathrm{C}$ for columnar grain growth and $1750^{\circ} \mathrm{C}$ for equiaxed grain growth was assumed for fuel originally $90 \%$ dense early in life. The center temperature and void size was calculated as a function of linear power and is shown in Figures 7-20 and 7-21. These temperatures were then assumed to be $1700^{\circ} \mathrm{C}$ and $1265^{\circ} \mathrm{C}$ respectively, which is not unreasonable to expect late in fuel life time. The center temperature and void size for this case are also shown. An increase in the central void radius from 21 to 28 mils results at peak power for the lower grain growth temperature assumptions. Similarly, an increase in linear power required for center melting from a value of $17 \mathrm{~kW} / \mathrm{ft}$ to one of $19.8 \mathrm{~kW} / \mathrm{ft}$ would correspond to these lower grain growth temperature assumptions. ....

Figure 7-22 shows a model of the fuel microstructure used in the computer code. The local temperature and temperature gradient is determined for 50 equally spaced radial positions after which the maximum stable intragranular and intergranular bubble size is computed by methods 


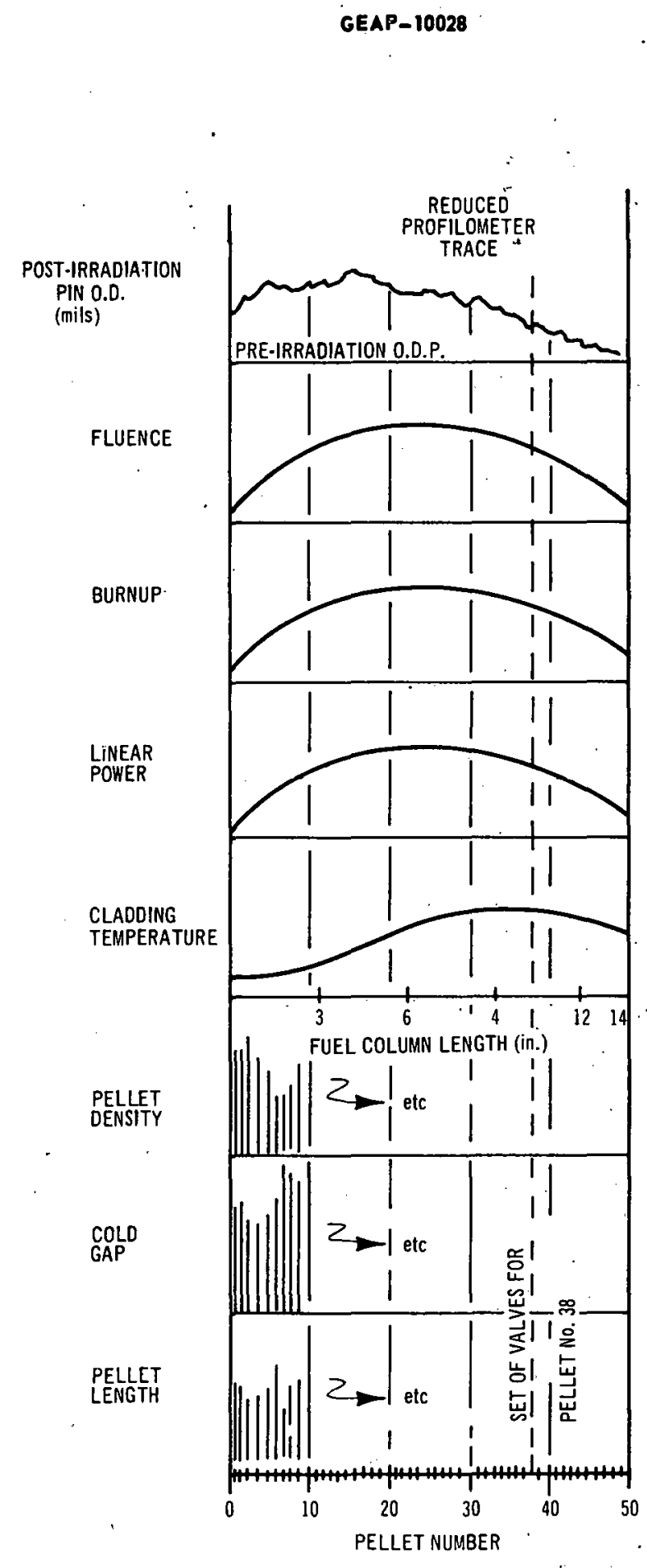

FIGURE 7-16. CORRELATION DATA BANK 
A. CLADDING SWELLING

B. THERMAL EXPAMSION INTERFERENCE

C. FUEL SWELLING

1. BURNUP

2. FUEL TEMPERATURE (LINEAR POWER)

3. FUEL DENSITY

4. CLADDING RESTRAINT

- THICKNESS

- TEMPERATURE

- axial position
(B-B)

$\frac{Q}{Q_{0}} e^{\left(-\frac{Q}{Q_{0}}\right)}$

$\operatorname{ASIN}\left[\frac{\rho}{\rho_{T D}}\left(\frac{d}{\mathrm{ID}}\right)^{2}\right]$

$$
e^{\frac{Q}{R T}}
$$

$2.7-\mathrm{e}^{\left(\frac{\mathrm{L}}{\mathrm{L}_{0}}\right)}$
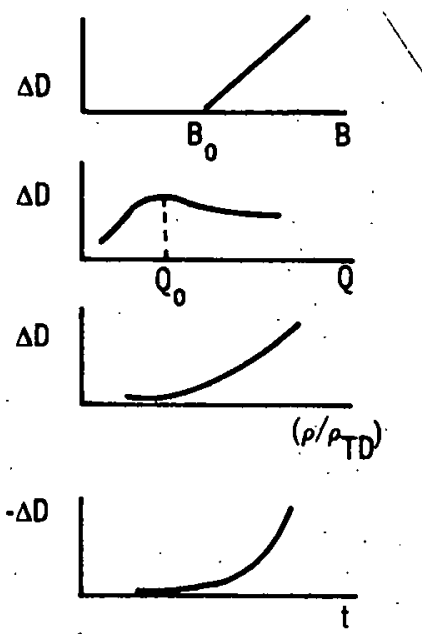

$-\Delta D$

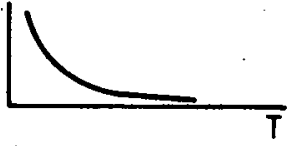

$-\Delta D$

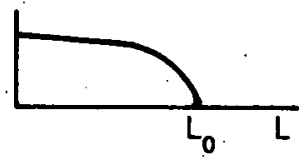

FIGURE 7-17. FUEL PIN DIAMETRAL DEFORMATION

discussed by Barnes and Nelson ${ }^{(31)}$ and

Nichols. ${ }^{(32)}$ The bubble size was determined assuming growth under constraint imposed by surface tension; viscous forces, and hydrostatic pressure until the limiting size is reached. When the intragranular bubbles reach their limiting size they migrate to grain boundaries. The bubbles then migrate to the central void where the gases are eventually released from the fuel.

Parametric studies were run to determine the local gaseous swelling as a function of radial position, linear power, and burnup. Figure 7-23 shows the log of the gaseous swelling for three power levels at burnups between 20,000 and 100,000 MWd/Te. As the power level and burnup increase, the predicted location of the unreleased gases move farther from the fuel center.

It is recognized that the model does not predict the exact pore distribution that has been deter mined by the visual counting of pores in fuel cross sections after fast flux irradiation. This discrepancy may be due to incorrect choice of constants to specify the physical properties of the fuel or errors inherent in visual counting techniques.

Figure 7-24 shows the predicted total volumetric fuel swelling as a function of - the activation energy for creep which defines fuel plasticity. Assuming an activation energy at $90,000 \mathrm{cal} / \mathrm{mole}$ which should be typical of that for stoichiometric $\mathrm{UO}_{2}$, the predicted total volumetric expansion for a 0.22-inch-diameter pellet operating at $8 \mathrm{~kW} / \mathrm{ft}$ with a surface temperature of $825^{\circ} \mathrm{C}$. was $4 \%$. If an activation energy for creep is assumed which is typical of that for hyperstoichiometric $\mathrm{UO}_{2}$, namely $60 \mathrm{kcal} / \mathrm{mole}$, the total volumetric swelling predicted is more than twice that for stoichiometric fuel. A different pore morphology is also predicted for the two cases. The more plastic fuel with the lower activation energy is predicted to contain only gas bubbles at grain 
boundaries in roughly the outer $10 \%$ of the fuel radius. The stoichiometric fuel on the other hand is predicted to contain both bubbles within the grain as well as at grain boundaries. According to the model, intragranular bubbles must reach a critical size before they are released to the grain boundary and it requres a higher burnup in stoichiometric fuel because of greater viscous restraint.

Figure 7-25 shows the predicted total volumetric expansion for a stoichiometric fuel in a fast flux operating at a power of $6 \mathrm{~kW} / \mathrm{ft}$ (without center void) and a higher power of $10 \mathrm{~kW} / \mathrm{ft}$ (with central void) as well as that expected from solid fission products as a function of burnup. Although local gaseous swelling may reach $10 \%$, the integrated gaseous swelling is predicted to contribute less than $1-1 / 2 \%$ of the total volumetric expansion for all power levels above $6 \mathrm{~kW} / \mathrm{ft}$ and burnup below $100,000 \mathrm{MWd} / \mathrm{Te}$. 


\begin{tabular}{|c|c|c|c|c|c|}
\hline & $\begin{array}{l}\% \frac{\Delta D}{D}=f_{1} \text { (CL } \\
+f \text { (BURNUP) }\end{array}$ & $\begin{array}{l}\text { YELLLNG) }+h \text { (THERM } \\
+f \text { (LWEAR POWER) }\end{array}$ & $\begin{array}{l}\text { PAMSTON WTERFEREMC } \\
+ \text { + (FUEL DEMSTYY) }\end{array}$ & +1 (CLADDHG RESTRAHT) & $\begin{array}{l}\text { CORRELATION } \\
\text { COEFFICIEMT } \\
\end{array}$ \\
\hline 1. & $\begin{array}{l}A_{1} B \\
(1.0)\end{array}$ & & & & 0690. \\
\hline 2. & $\begin{array}{l}A_{1} B \\
(1.0)\end{array}$ & $A_{2} \frac{Q}{9} e^{-\left(\frac{Q}{9}\right)}$ & & & 0.691 \\
\hline 3. & $\begin{array}{c}A_{0}+A_{1} B \\
(1.0) \quad(1.0)\end{array}$ & $A_{2} \frac{Q}{9} e^{-\left(\frac{l}{9}\right)}$ & & & 0.722 \\
\hline 4. & $A_{0}+A_{1} B$ & $A_{2} \frac{Q}{9} e^{-\left(\frac{Q}{9}\right)}$ & $A_{3} \operatorname{asin}\left(\frac{P_{S}}{P_{T D}}\right)$ & & NOT COMPLETE \\
\hline 5. & $\begin{array}{l}A_{0}+A_{1} B \\
(0.9)=(1.0)\end{array}$ & 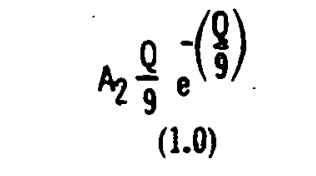 & $\underset{(1.0)}{A_{3}}\left(\frac{P_{s}}{\rho_{T D}}\right)$ & $\underset{(0.5)}{A_{4}\left[2 . e^{l / L}\right]}$ & 0.801 \\
\hline 6. & $\begin{array}{l}A_{0}+A_{1} B \\
(0.9)(1.0)\end{array}$ & $\mathrm{A}_{2} \frac{\mathrm{O}}{(1.0)} \mathrm{e}^{-\left(\frac{\mathrm{l}}{\mathrm{g}}\right)}$ & ${ }_{(1.0)}^{A_{3} \sin }\left(\frac{\rho_{S}}{\rho_{T D}}\right)$ & $A_{4}\left[\begin{array}{c}{\left[2.7-\mathrm{e}^{l / L} \mathrm{~L}\right]} \\
(0.8)\end{array}\right.$ & 0.808 \\
\hline & DENCE LEV & OF & & $\begin{array}{c}+A_{5} i^{4} e^{R T} \\
(0.8)\end{array}$ & \\
\hline
\end{tabular}




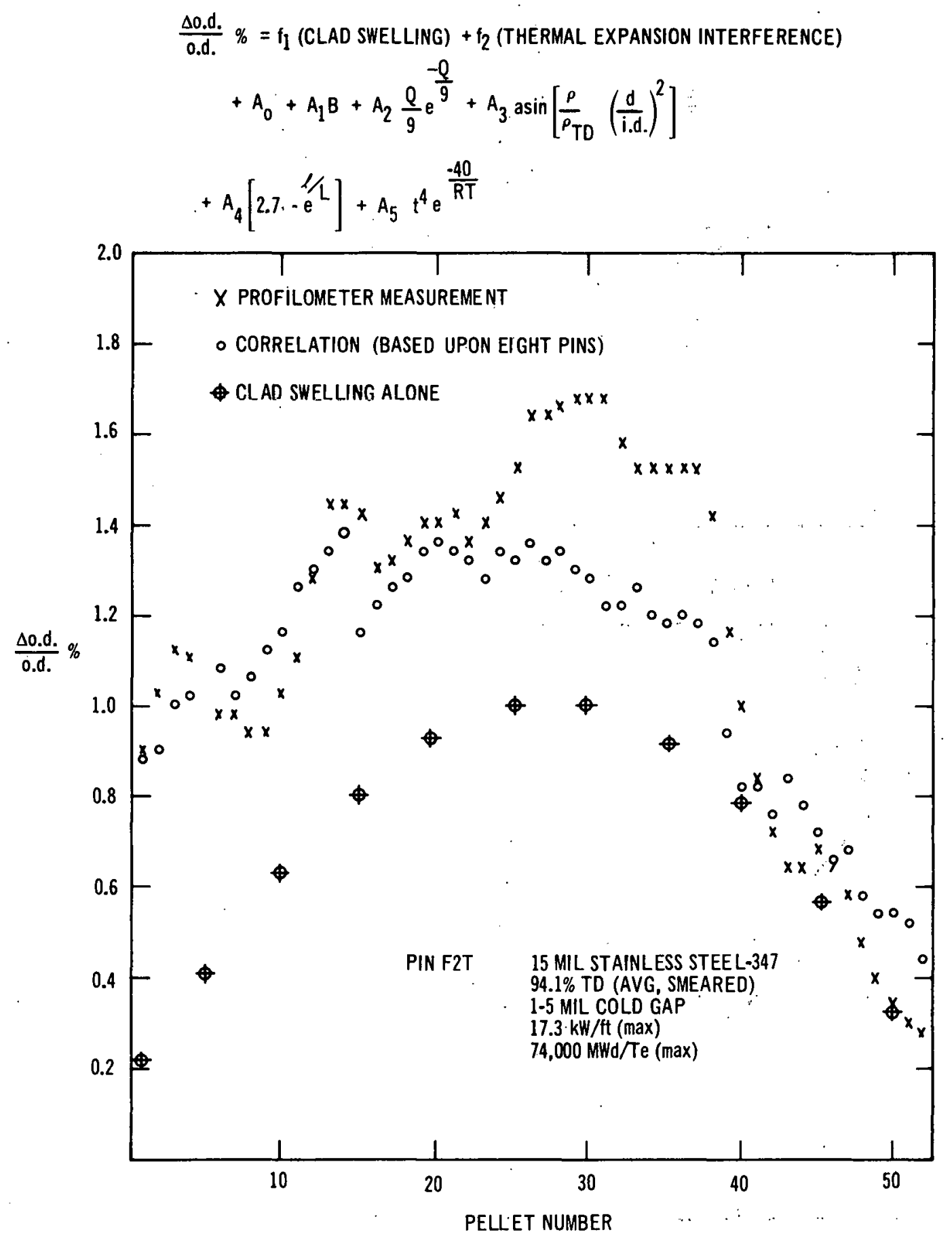

FIGURE 7-19. FINAL CORRELATION COMPARED WITH F2T DATA 


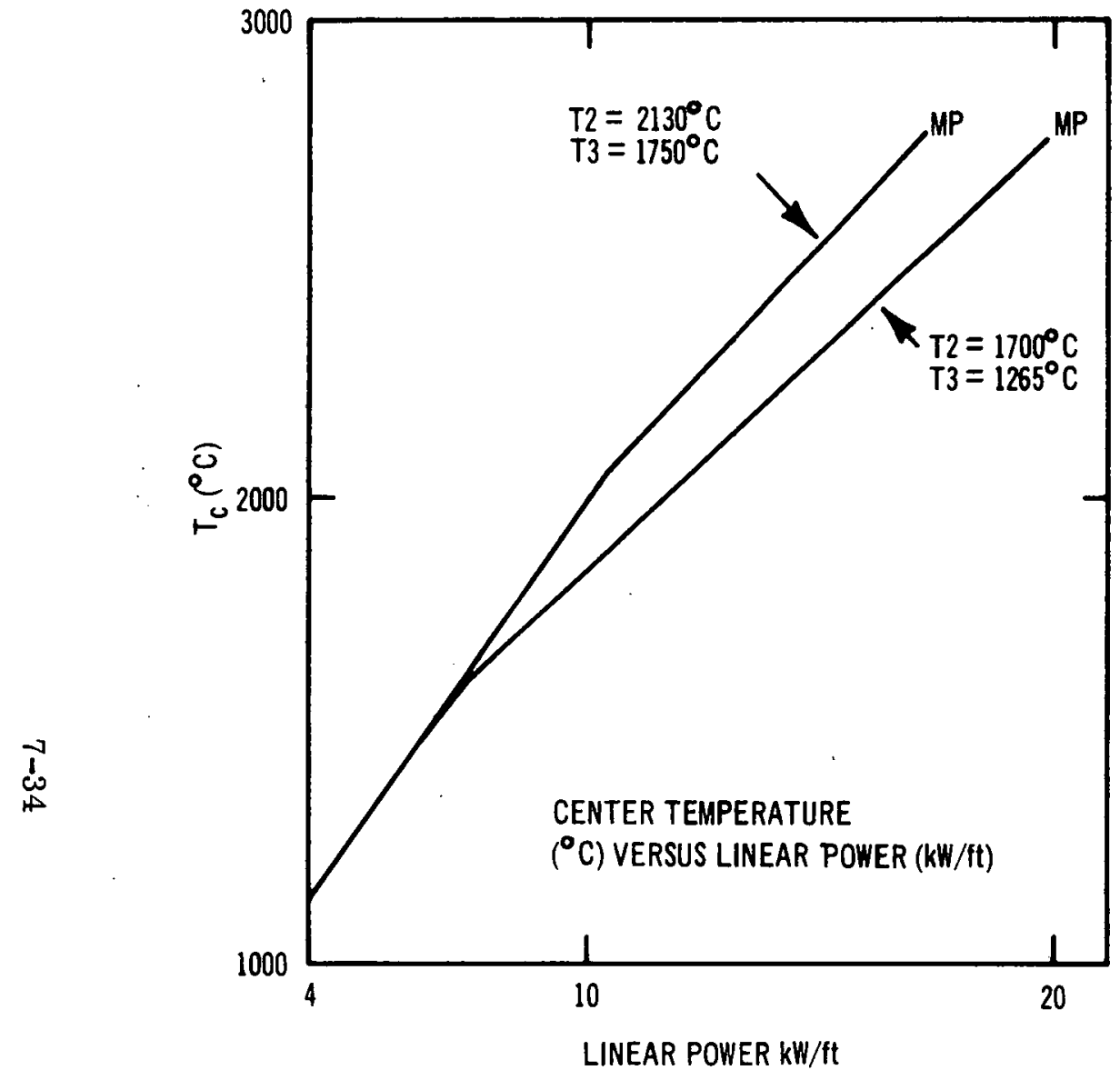

FIGURE 7-20. CHANGE IN CENTER TEMPERATURE WITH CHANGE IN TEMPERATURE, DEFINING THREE FUEL DENSTTY REGIONS.

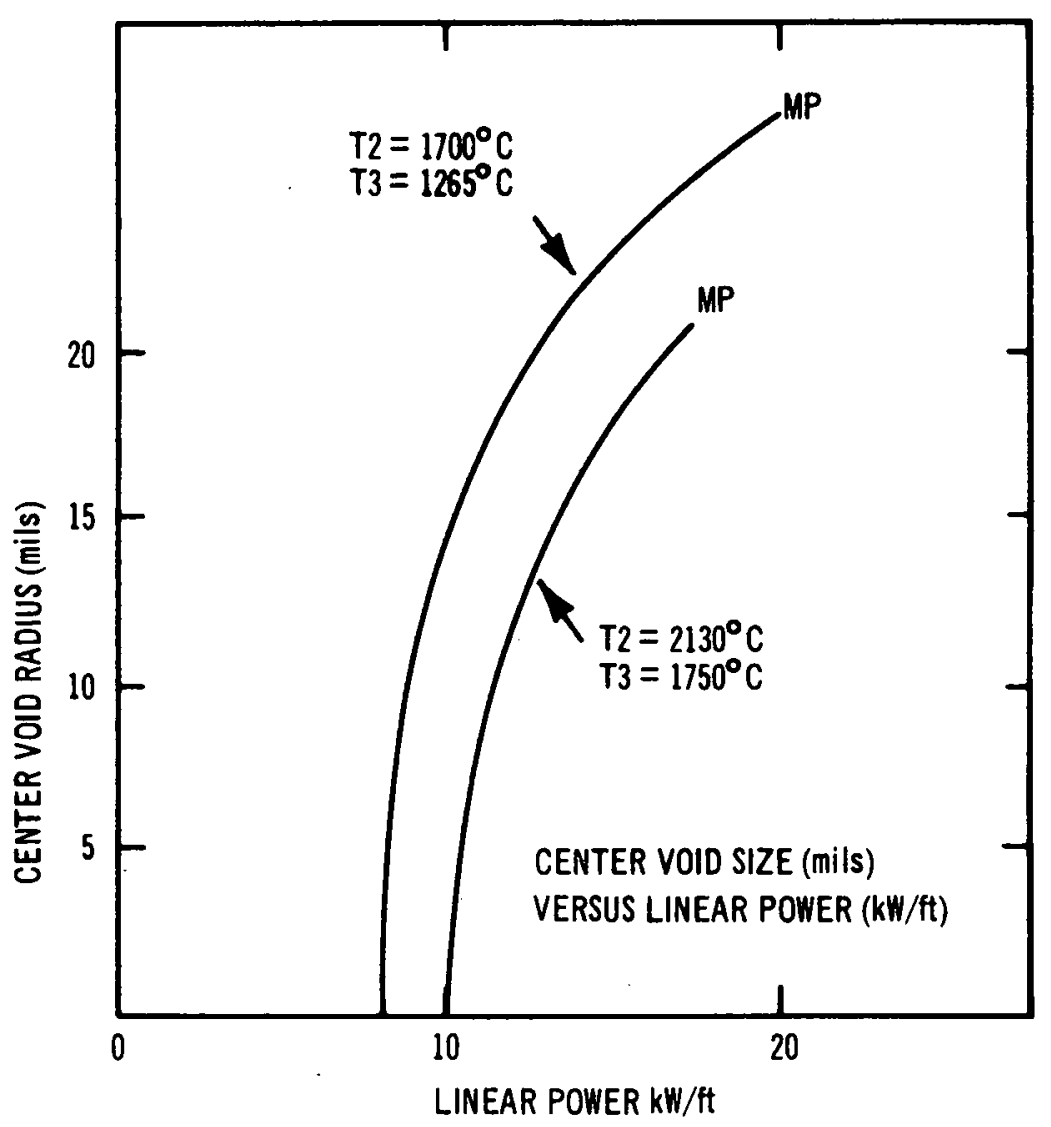

NOTE: INITIAL FUEL DENSITY ASSUMED WAS 90\% AND FINAL DENSITY OF COLUMNAR REGION WAS $99 \%$.

FIGURE 7-21. CHANGE IN CENTRAL VOID RADIUS WITH CHANGE IN TEMPERATURE, DEFWING THREE DENATY REGHONS 


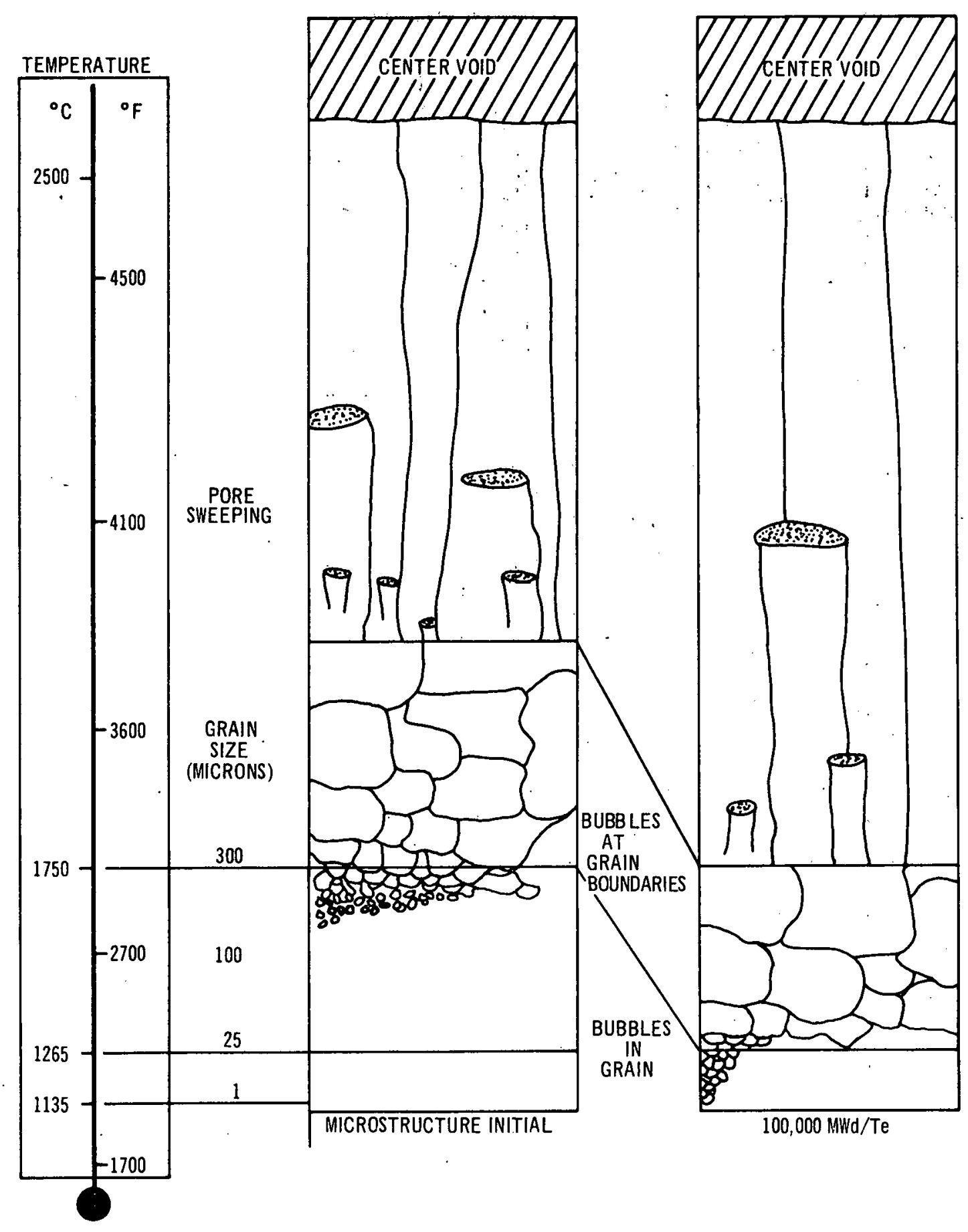

FIGURE 7-22. REPRESENTATION OF FUEL MICROSTRUCTURE FOR A PIN AT $16 \mathrm{~kW} / \mathrm{ft}$ AT A LOW AND HIGH BURNUP 

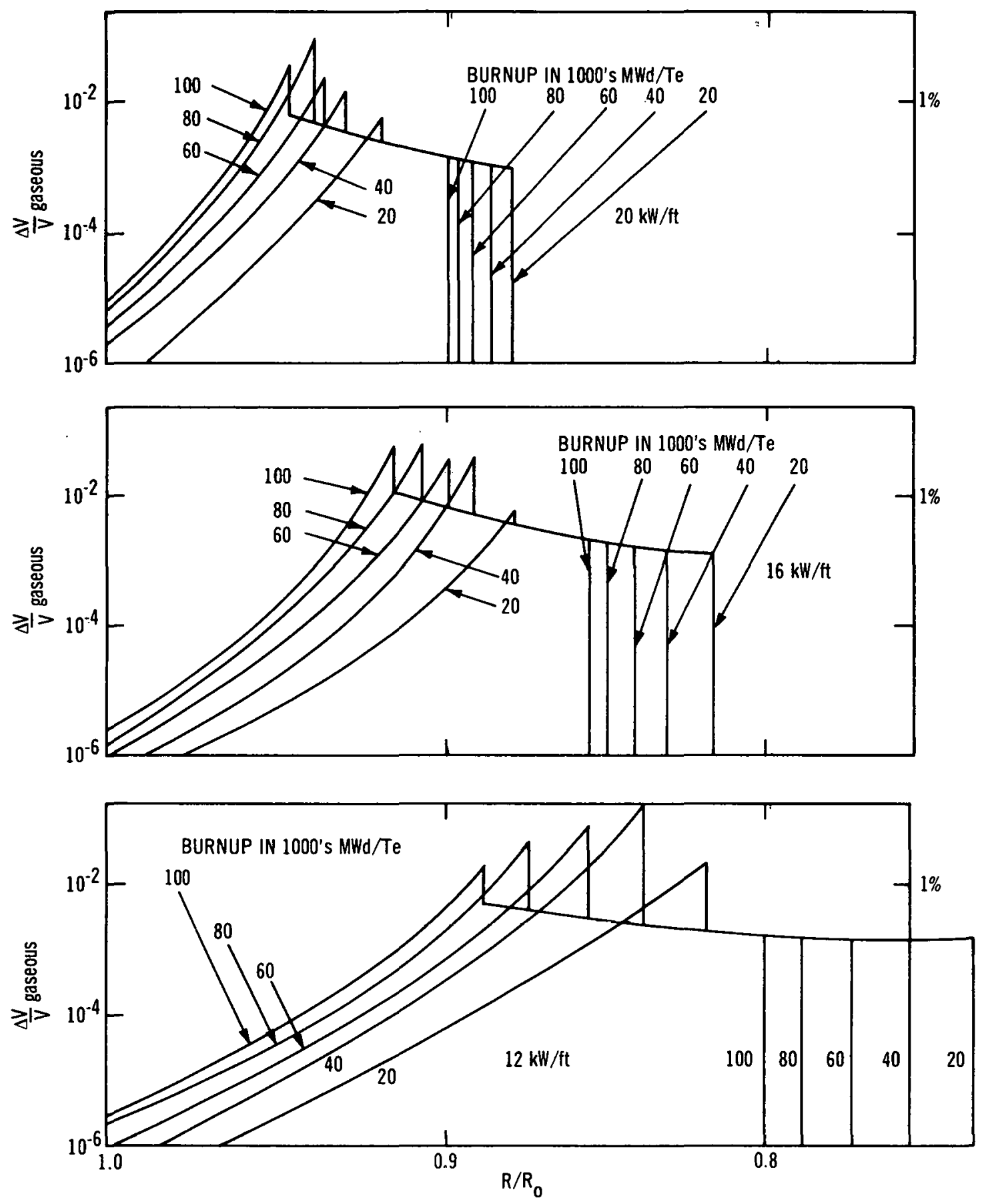

NOTE: FUEL RADIUS $\left(R_{0}\right)$ ASSUMED WAS 0.11 inches.

FIGURE 7-23. PREDICTED MAGNITUDE AND LOCATION OF GASEOUS FUEL SWELLING AS A FUNCTION OF LINEAR POWER LEVEL. 


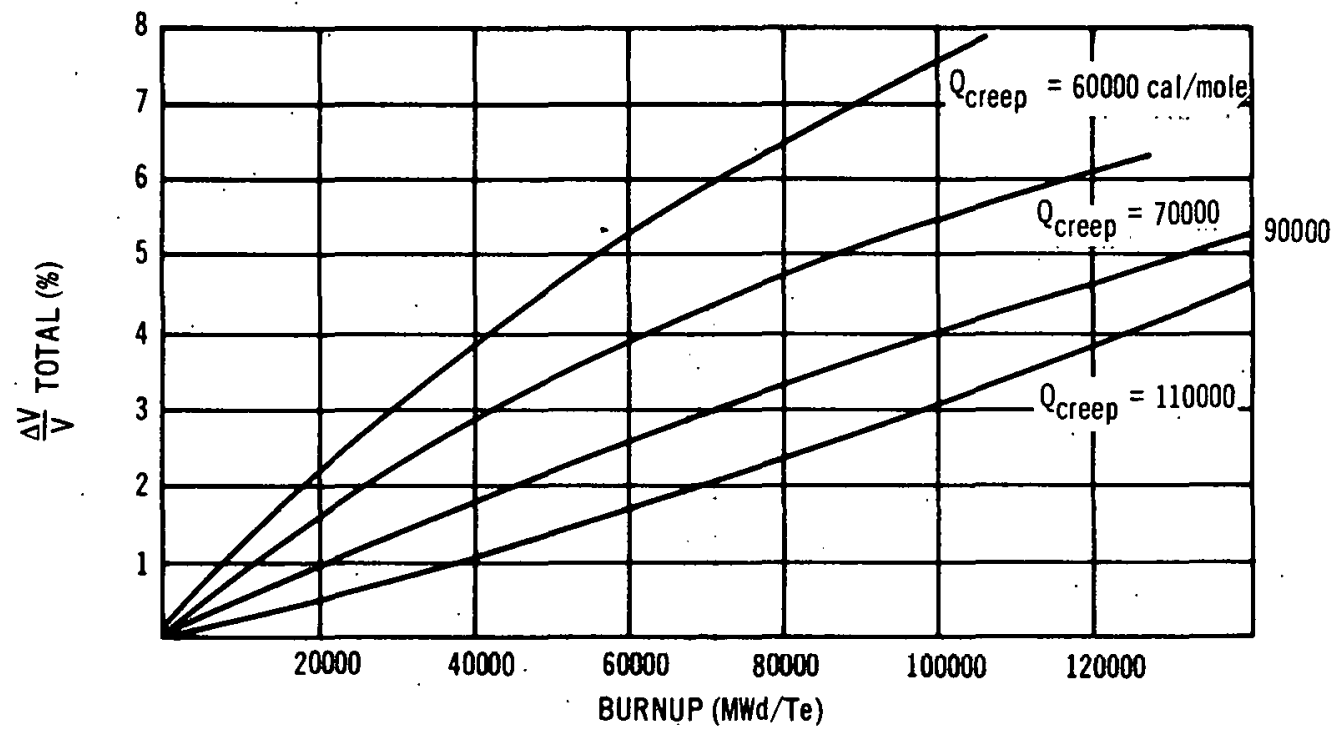

NOTE: THE ACTIVATION ENERGY FOR CREEP OF STOICHIOMETRIC FUEL IS $\sim 90,000 \mathrm{cal} / \mathrm{mole}$. A MORE PLASTIC FUEL WITH AN ACTIVATION ENERGY FOR CREEP OF $60,000 \mathrm{cal} / \mathrm{mole}$ (TYPICAL OF HYPERSTOICHIOMETRIC FUEL) IS PREDICTED TO SWELL NEARLY TWICE AS MUCH AS STOICHIOMETRIC FUEL (NEGLECTING ANY EFFECT OF CLADDING CONSTRAINT).

FIGURE 7-24. EFFECT OF FUEL PLASTICITY ON THE PREDICTED TOTAL FUEL SWELLING OF A PIN OPERATING AT $8 \mathrm{~kW} / \mathrm{ft}$

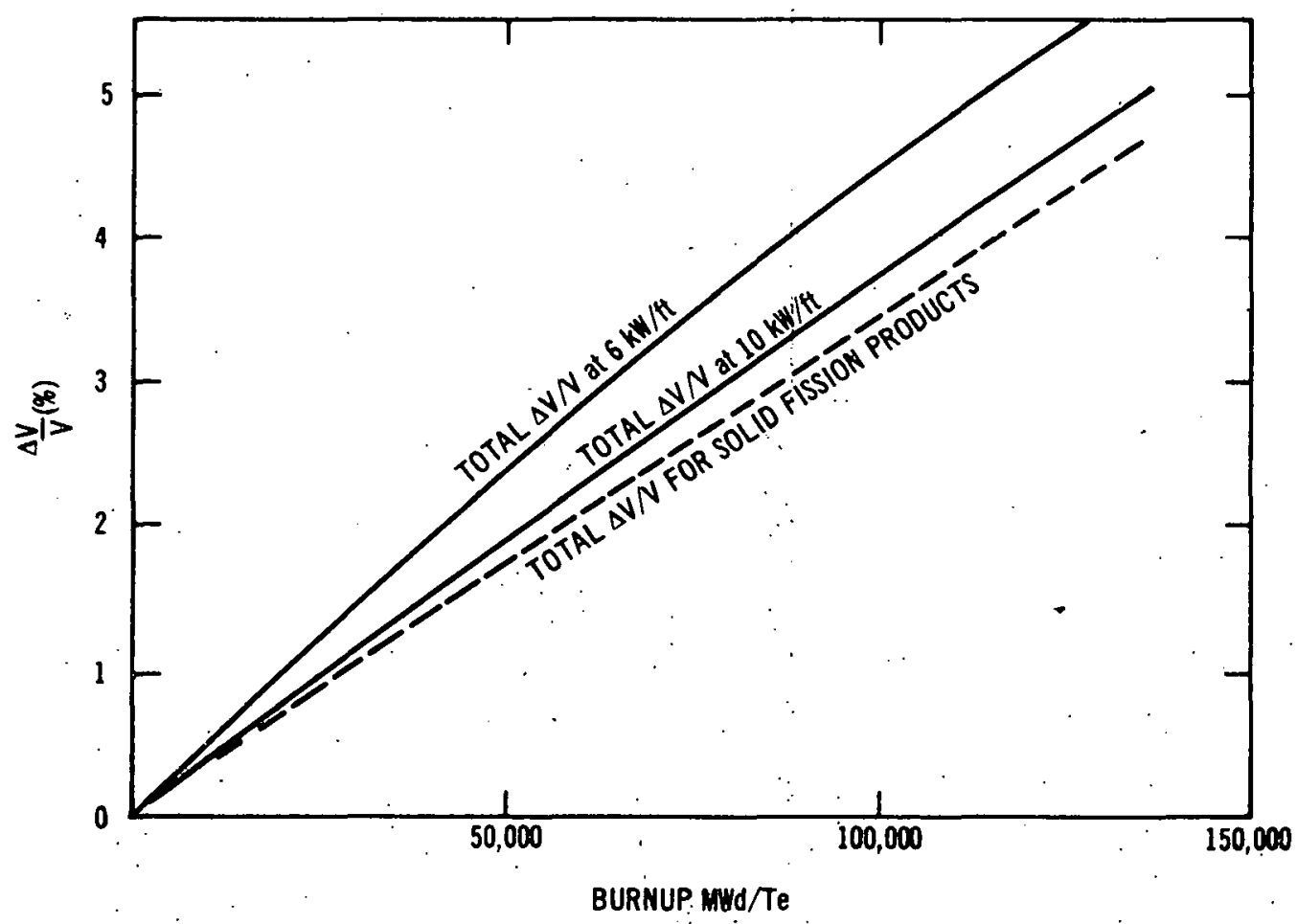

FIGURE 7-25. COMPARISON OF. TOTAL PREDICTED SWELLING FROM GASEOUS AND SOLID FISSION PRODUCTS TO THAT PREDHCTED FOR SOLID FISSON PRODUCTS ALONE: (No. Crodit Tatom feer intitiol fuol Porosity in this Case) 


\section{SECTION VIII}

\section{TASK L-CLADDING DEVELOPMENT}

\subsection{GENERAL}

The technical and economic feasibility of ceramic-fueled fast reactors depends on the attainment of high levels of performance of the fuel system, especially the survival of the cladding at temperatures and specific powers of practical interest. The present status of testing and analysis of potential cladding material with regard to alloys and environmental variables indicates good prospects that adequate initial performance of cladding for fast reactor fuel elements can be obtained by using carefully specified materials within the range of compositions of commercial processing methods. No material, however, has yet been tested under fully typical conditions. Data are not yet available to establish optimum compositions or structures, although some tentative trends have been suggested. This lack of test experience to support the rational selection of preferred cladding specifications is regarded as a major remaining obstacle to the attainment of the reliable operation of an LMFBR fuel system.

The general objectives of the cladding development program for the next 4 years are to contribute to the attainment of the desired levels of fast reactor fuel element performance which, in turn, are required by the desired fuel-cycle economics. These objectives of specific activities are:

a. Determine the performance characteristics-including mechanical properties, fracture characteristics, radiation damage, and struc-' tural stability-of the most likely cladding material candidates under test conditions simulating LMFBR environmental parameters. The candidate materials are within the range of compositions and structures which can be produced by present commercial processes.

b. Obtain data and perform systematic data analysis of the response of candidate alloys to test environments which simulate reactor applications, on which to base selection of a preferred alloy for near-term LMFBR applications.

c. Determine the in-depth material behaviou required to establish performance limitations (such as allowable stress levels, creep rates, maximum strains, local temperatures), on selected alloys, based on initial fast-flux test results, and recommend preferred material specifications and design limits for LMFBR use.

\subsection{MATERIALS IRRADIATION PERFORMANCE}

\subsubsection{Series L-2, L-6, and L-15-EBR-II Materials Capsules}

The series L-2 (four capsules), L-6 and L-15 materials capsules are at EBR-II in various stages of their scheduled irradiations. The L-2 (four capsules) were reinserted into a new Mark A-19 subassembly (S/A) designated XO50 for further irradiation in a Row 4 core position. Irradiation of this new S/A began in January and is scheduled to continue until late 1969 when the target fluences $\left(7.6 \times 10^{22}\right)$ for these capsules will be reạched. As of April 15, the L-2 (four capsules) have accumulated $5.0 \times 10^{22} \mathrm{n} / \mathrm{cm}^{2 *}$ total fluence.

\footnotetext{
* Unless otherwise noted, all reported fluences are based on EBR-II physics predictions.
} 
The L-6 materials capsules were discharged from a Row 2 core position in January, 1969 , after accumulating $5.0 \times 10^{22} \mathrm{n} / \mathrm{cm}^{2}$ total fluence, removed from S/A XO18, and inserted into a new Mark B-7 S/A designated X018A. S/A XO18A is scheduled for irradiation in a Row 4 core position which will amount to only $1 \times 10^{22} \mathrm{n} / \mathrm{cm}^{2}$ additional total fluence. Further irradiation in Row 2 is planned for the L- 6 capsules to acquire the target total fluence of $1.3 \times 10^{23} \mathrm{n} / \mathrm{cm}^{2}$ in a reasonable time period.

The L-15 materials capsules previously irradiated in S/A XO39 to $1.4 \times 10^{22} \mathrm{n} / \mathrm{cm}^{2}$ total fluence are still waiting reinsertion into another Mark A-19 S/A for further irradiation. Target fluence for the L-15 is $3 \times 10^{22} \mathrm{n} / \mathrm{cm}^{2}$.

\subsubsection{Series L-10 EBR-II Materials Capsules}

The purpose of the L-10 capsules irradiation experiment was to expose specimens of LMFBR clad candidate alloys to fast neutron flux and, subsequently, to evaluate the effect of the irradiation on material properties. All five austenitic alloys - Types 304, 316, 321, 347 , and Incoloy-800, currently being considered for LMFBR clad were included as both tubular and flat sheet tensile specimens. A high purity $14 \mathrm{Cr}-14 \mathrm{Ni}-\mathrm{Fe}$ alloy was also included as sheet tensile specimens to establish the effect of specific structural and chemical modifications on neutron radiation damage in austenitic alloys.
The post-irradiation evaluation program for the series L-10 materials capsules will consist of the following:

- An investigation of the irradiation performance of the capsules.

- An evaluation of the mechanical and physical properties of the materials specimens.

\subsubsection{Capsule Description}

The L-10 capsules were designed for insertion in an EBR-II Mark B-19 core subassembly (ANL drawing EB-1-38928D). The contents of each capsule, Figure 8-1 included seven test sections and a sodium reservoir attached coaxially by umbilical tubing. Each capsule was identified by a code designation, Table 8-1, and only one tubular test material was used per capsule. The test sections consisted of a 0.250 -inch o.d. $\times 0.220$-inch i.d. $\times 3.4$-inch long tube fitted on both ends with open end plugs.

Four test sections, two on each end of the capsule insert, contained only tungsten rod for gamma heating. The remaining three test sections (located in the core region) contained two tensile specimens, tungsten holders for gamma heating, and a fusible metal thermometer capsule called a sentinel. Two flux wires of iron and nickel were strung axially along the external surface of each test section to monitor neutron flux.

TABLE 8-1

L-10 TUBULAR TEST MATERIALS

\begin{tabular}{|c|c|}
\hline $\begin{array}{c}\text { Capsule } \\
\text { Designation }\end{array}$ & Material \\
\hline $\begin{array}{l}\mathbf{A} \\
\mathbf{B} \\
\mathbf{C} \\
\mathbf{D} \\
\mathbf{E} \\
\mathbf{F} \\
\mathbf{G} \\
\mathbf{H} \\
\mathbf{I} \\
\mathbf{J}\end{array}$ & $\begin{array}{l}\text { Incoloy-800 } \\
\text { Incoloy-800 } \\
\text { Incoloy-800 } \\
316 \text { SS } \\
316 \text { SS } \\
316 \text { SS } \\
304 \text { SS } \\
304 \text { SS } \\
347 \text { SS } \\
321 \text { SS }\end{array}$ \\
\hline
\end{tabular}

\begin{tabular}{l} 
Heat Treatment \\
\hline As received \\
As received \\
$2200^{\circ} \mathrm{F}-24 \mathrm{~h}$ \\
As received \\
As received \\
$2200^{\circ} \mathrm{F}-24 \mathrm{~h}$ \\
As received \\
As received \\
As received \\
As received
\end{tabular}

In-Core Stress

Level (psi) at

Temperature

12,000

12,000

12,000

13,000

13,000

13,000

8,000

8,000

12,000

10,000 


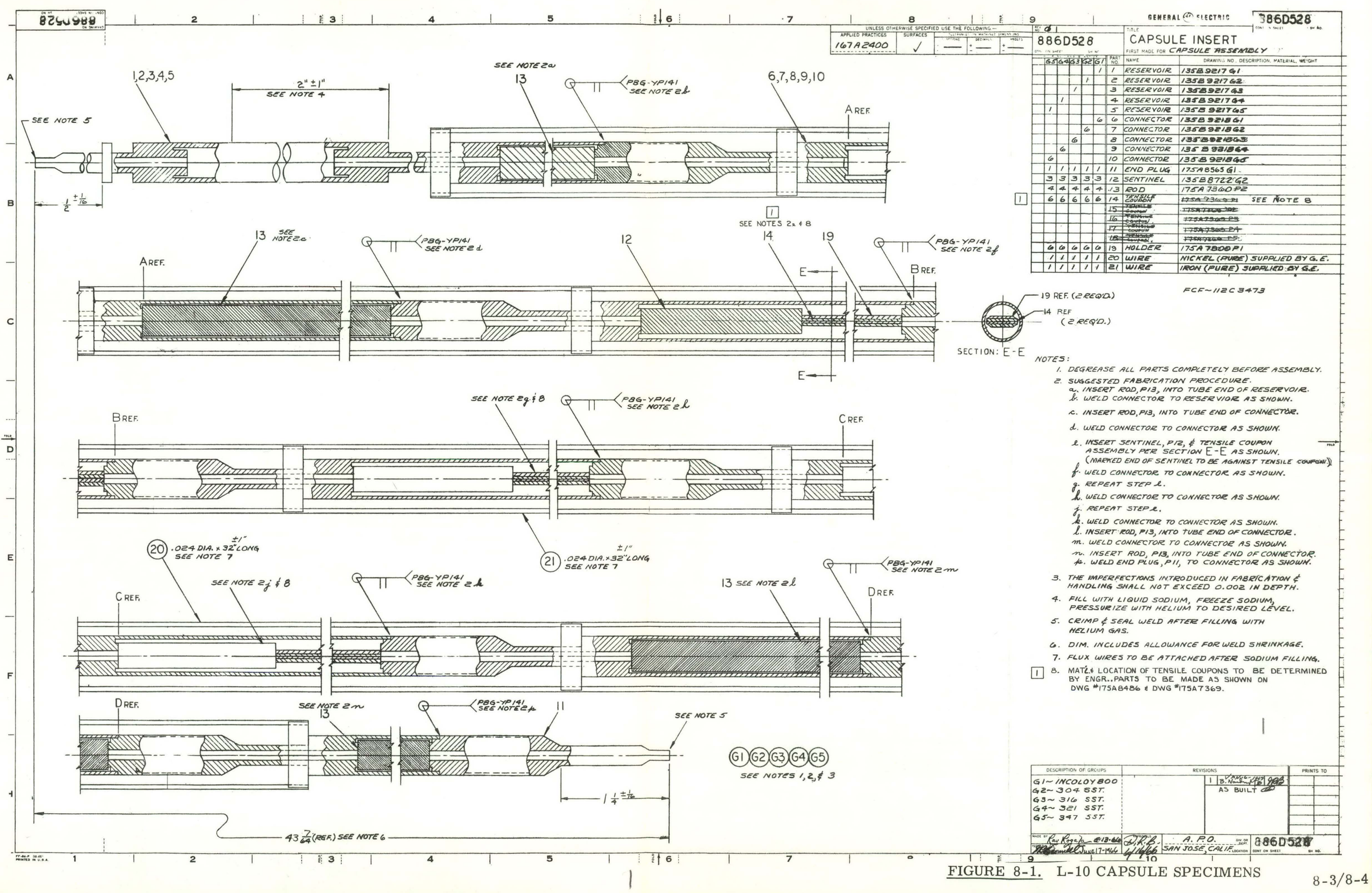




\subsubsection{Irradiation History}

The L-10 capsules were irradiated in the EBR-II subassembly designated XO16. This subassembly was irradiated in Row 4 from April, 1967, to September, 1968. The XO16 subassembly has received 7, $894 \mathrm{MWd}$ of EBR-II exposure which is equivalent to about $2.8 \times 10^{22} \mathrm{n} / \mathrm{cm}^{2} *$ total fluence in the peak core position. The total exposure time for XO16 was approximately 175 effective full power days $(\sim 4,200$ hours).

Since thermocouples were not available to monitor the temperature, heat transfer calculations were used to define the peak irradiation temperature for each section. The analysis used resulted in calculated temperatures ranging from $1260^{\circ} \mathrm{F}$, for test sections 1 and 7 , to $1420^{\circ} \mathrm{F}$ for test sections 2 and 6 . Temperature of test sections 3,4 , and 5 was calculated to be $1430^{\circ} \mathrm{F}$.

\subsubsection{Post-Irradiation Examination}

The first phase of the L-10 capsules examination consisted primarily of nondestructive examination of the capsules and test sections, and capsule disassembly. The steps taken and the observations made are presented in the following paragraphs:

The capsules were first identified and visually examined. All of the capsules were straight and clean. The total package of 10 capsules were photographed as shown in Figure 8-2. The outside spiral wires were removed. No residual sodium was observed on the capsule surfaces.

Gross gamma-scans were taken of the entire length of capsules A and C. Capsule C was situated closest to the core center during

* Total fluence based on EBR-II physics predictions.

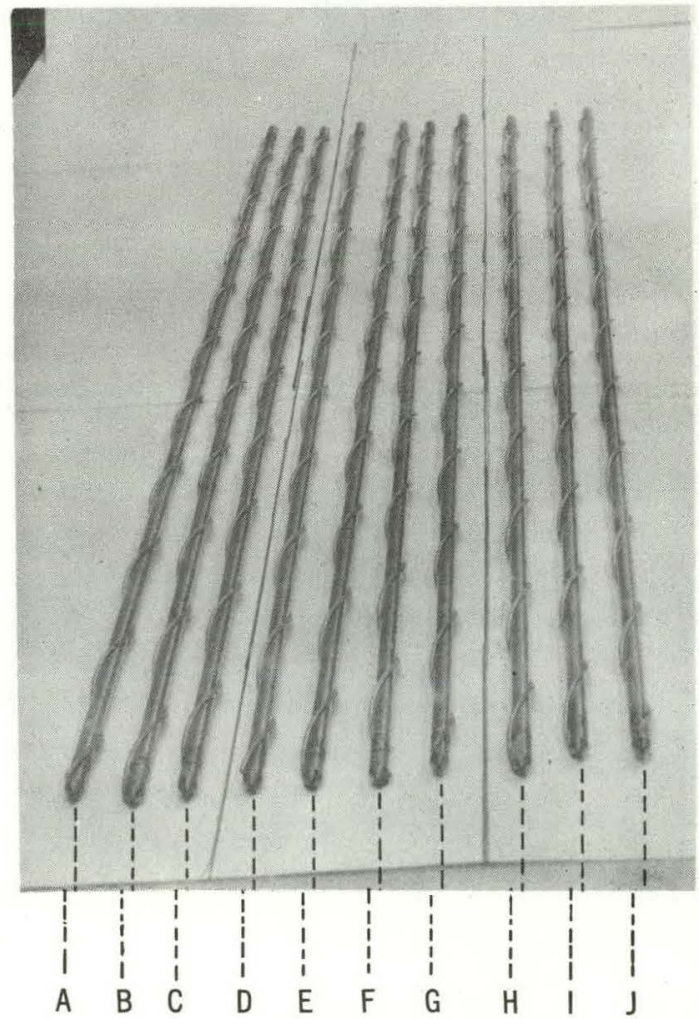

FIGURE 8-2. THE L-10 CAPSULES PHOTOGRAPHED THROUGH HOT CELL WINDOW 
irradiation, while capsule A was farthest away from the core center. The peak gross gamma activity was greater for capsule $\mathrm{C}$ than capsule A, indicating a 15\% flux drop across the subassembly. The capsule tubes from $\mathrm{A}$ and $\mathrm{C}$ were also gamma-scanred independently without the test section inserts. For these scans, only $\mathrm{Mn}^{54}$ was monitored by setting the gamma energy window at 0.84 to $0.90 \mathrm{MeV} . \mathrm{Mn}^{54}$ originates from the $\mathrm{Fe}^{54}$ (n, p) $\mathrm{Mn}^{54}$ reaction which as a threshold above $3 \mathrm{MeV}$ and, therefore, is a good detector for fast neutron flux. The difference in the $\mathrm{Mn}^{54}$ scans for capsule tubes $\mathrm{A}$ and $\mathrm{C}$ was $2.4 \%$ less than observed on the gross scans, which indicated a lesser drop in fast flux across the subassembly than that measured by the gross scans on the intact capsules.

High resolution gamma-scans, Figure $8-3$, were taken of the core section of capsule $\mathrm{C}$ to measure any movement of the tantalum markers used in the low melting alloy sentinels, Figure 8-4. In all cases, the tantalum balls had moved, indicating that the highest melting temperature, $1185^{\circ} \mathrm{F}\left(640^{\circ} \mathrm{C}\right)$ for $\mathrm{Al}-\mathrm{Ni}$ eutectic, was attained, or exceeded.

Following the gamma-scans, micrometer measurements were taken on capsule tubes $\mathrm{A}$ and $\mathrm{C}$. No change in diameters were observed axially along either tube indicating very little, if any, clad swelling in L-10 capsule tubes.

The inserts containing the test sections were then removed from all capsule tubes. The inserts were stuck in three (B, D, and J) of the ten capsules, and these capsule tubes had to be sectioned in several places to remove the inserts. The inserts were not stuck due to sodium deposit but rather due to swelling of the tubular test sections.

All of the tubular test sections were separated and diameter measurements taken on 22 of the 40 blanket sections. In only one section, B-6, was a diameter increase (0. 059 inch) observed. This large an increase for a blanket section remains unexplained.

Sodium was observed in the bottom of seven capsule tubes, indicating that the test sections inside had failed due to internal pressure. The three Incoloy- 800 capsules (A, B and C) did not contain sodium. Since all of the L-10 test sections were designed to operate at stresses to $80 \%$ of the 10,000 hour rupture strength, these failures indicated that the test sections were operating above the design temperature of $1200^{\circ} \mathrm{F}$, causing higher hoop stresses to occur in the weaker tubing specimens.

All 30 core tubular test sections were profiled to determine the degree of swelling in the test sections. The results, Table 8-2, show that the core test sections in capsules B, D, F, G, I, and J had swelled measurably due to the internal pressure. No swelling was observed in test sections from capsules $\mathrm{A}, \mathrm{C}, \mathrm{E}$, and $\mathrm{H}$, and it is assumed that these test sections leaked early in the irradiation, resulting in stresses too low for creep to occur. Apparently all core test sections from capsule B (Incoloy-800) swelling $>20 \%$, indicated extreme plasticity in these test sections. The significance of the swelling shown in Table 8-2 is not readily apparent since the time period during which the swelling occurred is not known. The capsule B results suggest that most of the swelling occurred very rapidly in a burst-type fashion.

Had the swelling occurred over a longer time period, the irradiation embrittlement commonly observed in post-irradiation testing would certainly have reduced the creep swelling in all of these alloys. Therefore, the conclusion is drawn that capsule B swelled early in life.

The thirty core sections were opened by removing one end plug and the sodium removed. The tensile specimens were removed along with the temperature sentinels for further examination. 


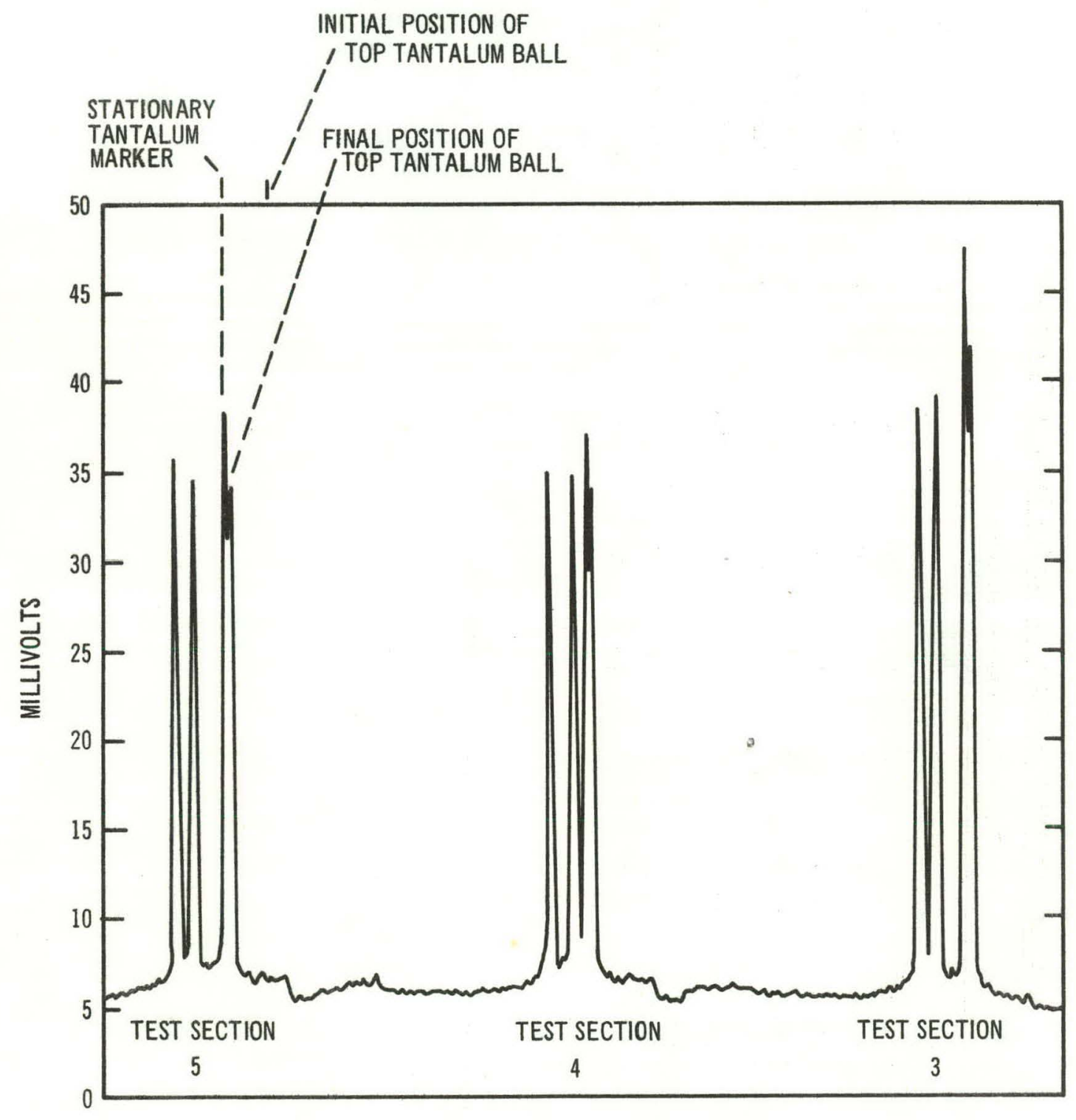

FIGURE 8-3. HIGH RESOLUTION GAMMA SCAN OF CAPSULE L 10-C SENTINELS 
TABLE 8-2

TUBULAR TEST SECTION SWELLING IN L-10 CAPSULES

\begin{tabular}{|c|c|c|c|c|c|c|c|c|c|}
\hline \multirow{2}{*}{\multicolumn{2}{|c|}{ Alloy }} & \multirow{2}{*}{$\begin{array}{l}\text { Capsule } \\
\text { Identity } \\
\end{array}$} & \multicolumn{7}{|c|}{ Percent Increase In Diameter (\%) } \\
\hline & & & 1 & 2 & 3 & 4 & 5 & 6 & 7 \\
\hline T'ype-304 & $A R$ & $\mathrm{G}$ & N. M. (1) & N.M. & 1.2 & 5.6 & 8.0 & 0 & 0 \\
\hline Type- 304 & AR & $\mathrm{H}$ & 0 & N.M. & 0 & 0 & 0 & 0 & 0 \\
\hline Type-316 & AR & $\mathrm{D}$ & N. M. & N. M. & 0.4 & 8.9 & 7.3 & 0 & 0 \\
\hline Type-316 & AR & $\mathrm{E}$ & N.M. & N.M. & 0 & 0 & 0 & 0 & 0 \\
\hline Type-316 & $\mathrm{SA}$ & $\mathrm{F}$ & N. M. & N. M. & 0.8 & 5.2 & 2.4 & 0 & 0 \\
\hline Type-321 & $\mathrm{AR}$ & J & N. M. & N. M. & 0 & 4.4 & 1.2 & N.M. & 0 \\
\hline Type- 347 & AR & I & N.M. & N.M. & 0 & 2.8 & 1.6 & 0 & 0 \\
\hline Inc -800 & $\mathrm{AR}$ & A & 0 & N. M. & 0 & 0 & 0 & N. M. & N. M \\
\hline Inc -800 & $\mathrm{AR}$ & B & 0 & 0.8 & 24 & $\mathrm{D}^{(2)}$ & 26 & 24 & 0 \\
\hline Inc- 800 & $\mathrm{SA}$ & $\mathrm{C}$ & N. M. & 0 & 0 & 0 & 0 & 0 & 0 \\
\hline
\end{tabular}

Comments
Failed
Leak resulting in low stress
Failed
Leak resulting in low stress
Failed
Failed
Failed
Leak resulting in low stress
Very rapid swelling
Leak resulting in low stress

(1) N.M. refers to not measured.

(2) D refers to excessive damage on disassembly of capsule due to excessive swelling.

(3) AR refers to as-received.

(4) SA refers to solution annealed. 


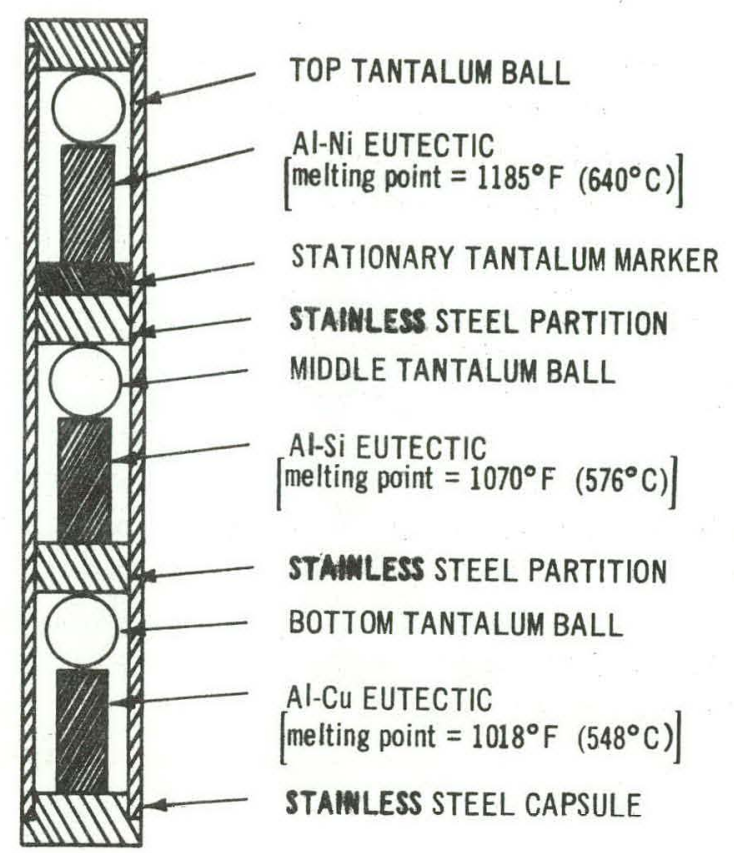

\section{FIGURE 8-4. DESCRIPTION OF L-10 TEMPERATURE SENTINELS}

\subsubsection{Series L-14 Materials Capsules in EBR-II}

A description of the L-14 series capsules has been presented earlier. (33) These capsules were irradiated in (S/A) XO25 which received 8, 399 MWd of EBR-II exposure, or approximately $3.1 \times 10^{22} \mathrm{n} / \mathrm{cm}^{2}$ total fluence in the peak core position. The total exposure time for XO25 was 187 EFPD ( 4500 hours).

The L-14 capsules have been received at Vallecitos and are scheduled for examination in late April.

\subsubsection{Clad Swelling}

The available data on swelling of 300 series stainless steels have been analyzed under joint Task G-Task L sponsorship in an attempt to obtain an empirical relationship between the quantities affecting the phenomenon. Data for 304 and 316 samples irradiated within the core region were fit to an equation of the form

$-\frac{\Delta \rho}{\rho}=A F^{n} \exp \left[C_{1}\left(\frac{1}{T}\right)+C_{2}\left(\frac{1}{T}\right)^{2}\right]$

where: $\frac{\Delta \rho}{\rho}$ is per cent change in density

$$
\begin{aligned}
& \mathrm{F} \quad \text { is fluence }\left(10^{22} \mathrm{n} / \mathrm{cm}^{2}, \mathrm{E}>0.1 \mathrm{MeV}\right) \\
& \mathrm{T} \quad \text { is temperature }\left({ }^{\circ} \mathrm{K}\right) \\
& \mathrm{A}, \mathrm{n}, \mathrm{C}_{1}, \mathrm{C}_{2} \text { are constants }
\end{aligned}
$$

A least squares fit of the data led to two equations :

$-\frac{\Delta \rho}{\rho}=7.8 \times 10^{-5} \mathrm{~F}^{1.59} \exp \left[\frac{15510}{\mathrm{~T}}-\left(\frac{2660}{\mathrm{~T}}\right)^{2}\right]$

when $\frac{\Delta \rho}{\rho}$ was considered to be the dependent (random) variable, and

$-\frac{\Delta \rho}{\rho}=5.8 \times 10^{-5} \mathrm{~F}^{2.35} \exp \left[\frac{15820}{\mathrm{~T}}-\left(\frac{2760}{\mathrm{~T}}\right)^{2}\right]$

when $\mathrm{F}$ was considered to be the dependent (random) variable. 
The best estimate of the exponent on fluence would seem to be somewhere between the values of 1.59 and 2.35 found by the two techniques. The equations fit the data for samples irradiated within the core region moderately well, but do not appear to account for swelling of samples irradiated in the blanket where fluences are lower than those considered in the analysis.

More details of the analyses are contained in the Task G portion of this Quarterly.

\section{3 MATERIALS MANAGEMENT AND SPECIFICATION PROGRAM}

The prime function of the materials management program is the complete quality characterization of current and prospective FCR cladding material. This characterization, as outlined in detail in an earlier document, ${ }^{(14)}$ includes the documentation of (a) chemistry, (b) structure, (c) dimensions, (d) surface condition, and (e) mechanical properties. Associated with the latter two categories is the evaluation of the effect of surface defects or other local irregularities that contribute to clad-wall thinning on the general mechanical properties of the tubing. The ultimate objective of this work is the establishment of a realistic, yet custom, specification for the procurement of nuclear grade austenitic stainless steel tubing.

To provide input data for this evaluation program, and at the same time provide cladding material for current irradiation programs, identical orders for tubing were placed with four commercial tube vendors. The tubing order orders called for the production of 1000 feet of annealed Type $304 \mathrm{H}$ and 2000 feet of annealed Type $316 \mathrm{H}$, to specifications somewhat more rigid than normal. In addition to this material (all of which was 0.250-inch diameter, 0.015inch wall), mill quantities of all five candidate cladding alloys-Types 304, 316, 321, 347, and Incoloy-800-were made available for this study. This material was produced by a single vendor and included $30 \%$ cold-worked material (316 and Incoloy-800) as well as tubing with wall thicknesses of $0.010,0.012$, and $0.015-$ inch. This material, all 0.250-inch in diameter, was produced to normal heat exchanger tubing specifications and was procured before the four-vendor order, principally to provide seamless cladding and test material for P.A. 10 experimental programs.

\subsubsection{Tubing Quality Control}

The bulk of characterization work on tubing of the five materials discussed in the previous section has been completed and was reported in earlier documents. $(14,1)$ The detailed surface inspection data collected in this evaluation is currently being utilized in the defect study program.

\subsubsection{Vendor Assessment}

The assessment of relative tube vendor capability for producing consistently high quality material is utilizing representative quantities of Types $304 \mathrm{H}$ and $316 \mathrm{H}$ tubing produced by Superior Tube Company, Handy \& Harman Tube Company, Trent Tube Company, and Matthey Bishop, Incorporated. Most of the microstructural characterization of each tubing lot and the non-destructive testing program which includes diametral measurements and ultrasonic inspection is completed. Results of the microstructural examinations are shown in Figures 8-5 and 8-6. Each lot of material is displayed in three modes: (a) a $100 \mathrm{X}$ photomicrograph of a transverse cross-sectional surface of a tube segment (etched) to provide the standard format for ASTM grain size determination, (b) a 250X magnification of the same cross-section to provide a clearer indication of the general microstructure of the alloys, and (c) a 100X photomicrograph of the surface of a longitudinal cross-section 


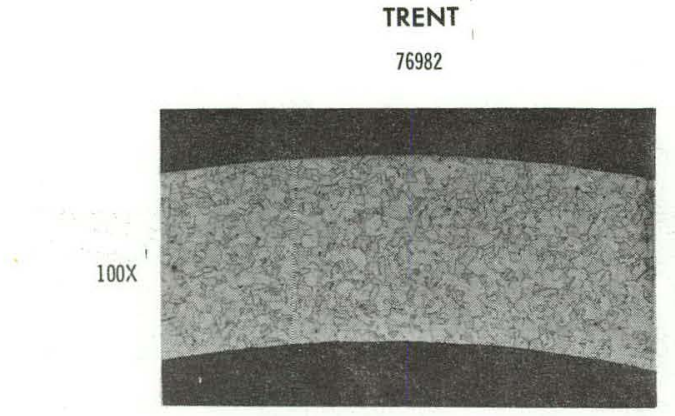

68AP0 0755

ASTM 7-1/2

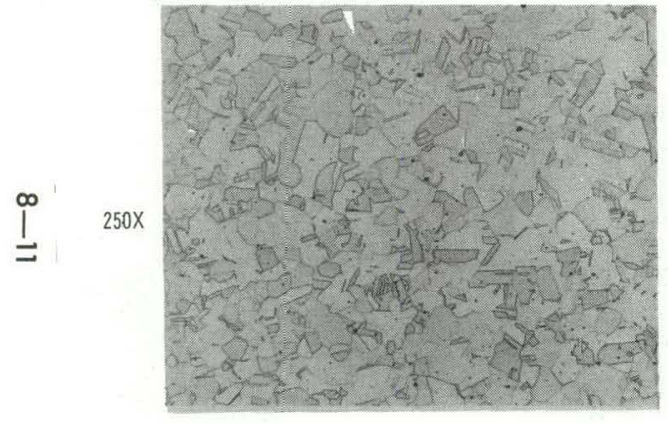

68AP0 0755

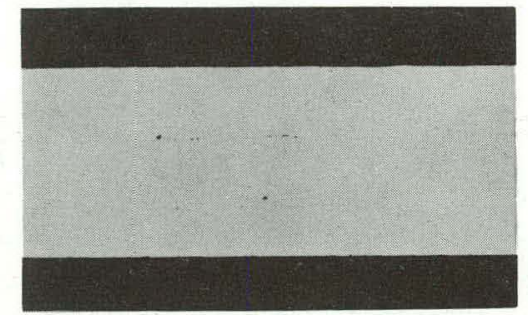

68AP0 0756
HANDY \& HARMAN

03575

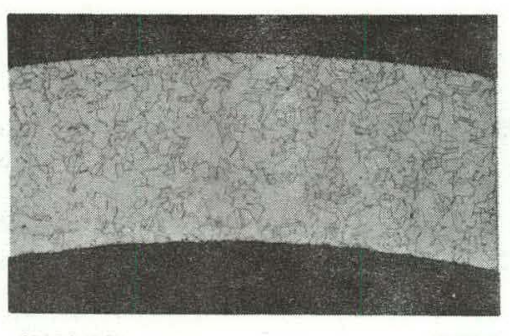

68APO 0835

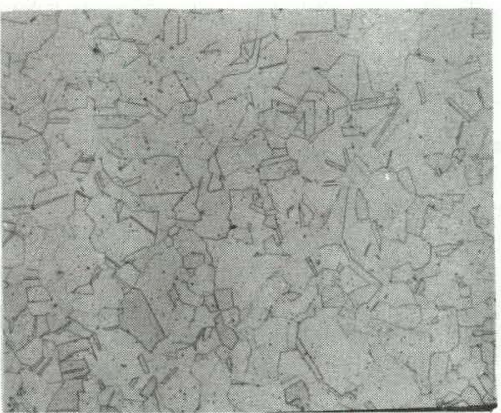

68AP0 0835

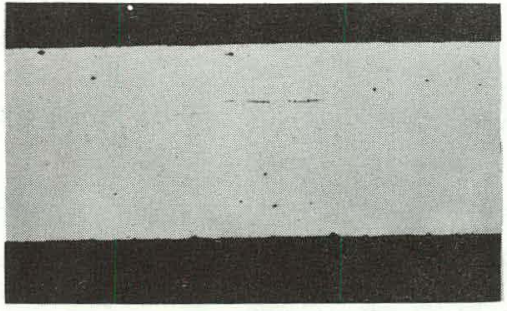

68AP0 0838

C-2 THIN SERIES

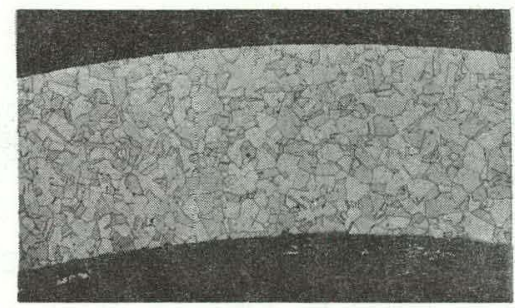

68AP0 0912

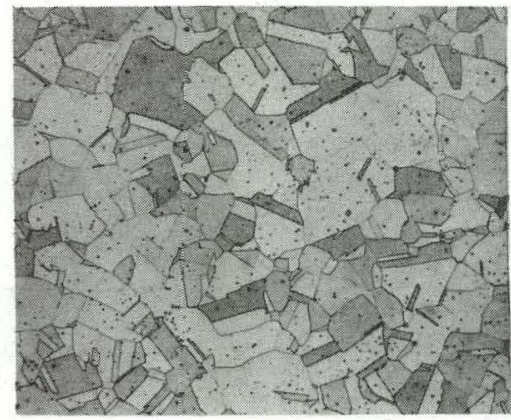

68AP0 0912

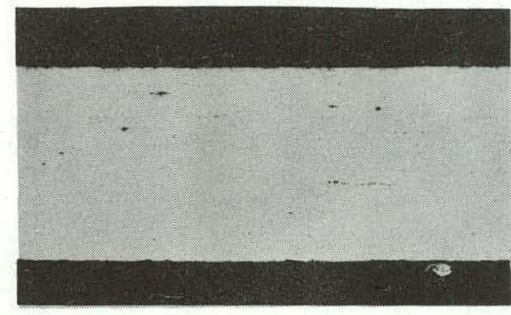

68AP0 0913

ASTM 6
SUPERIOR

20184

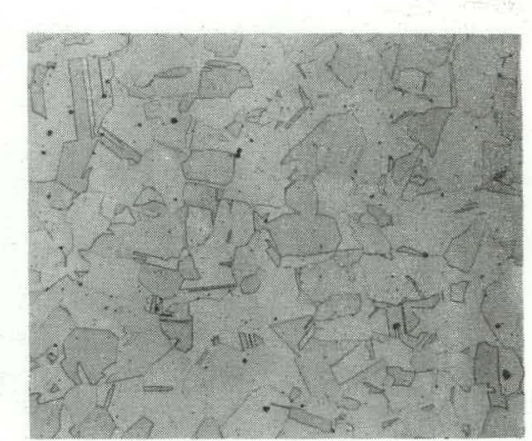

68AP0 0971

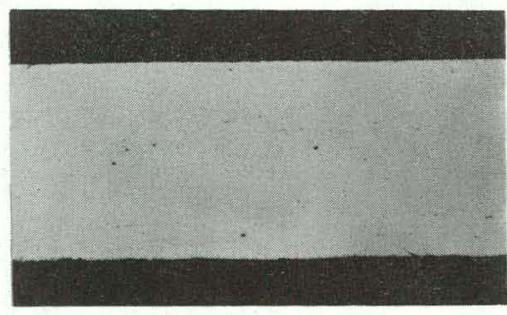

68AP0 0972 

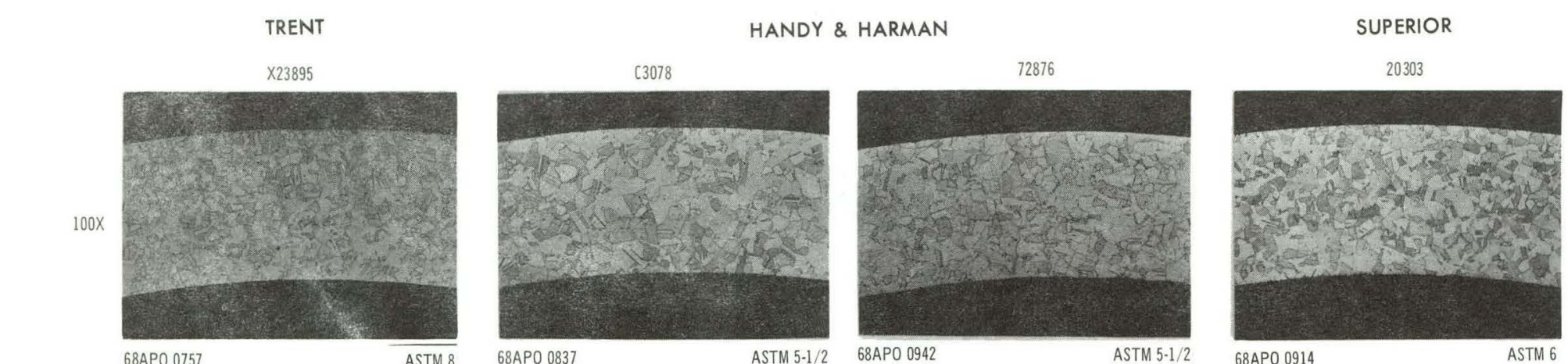

MATTHEY BISHOP

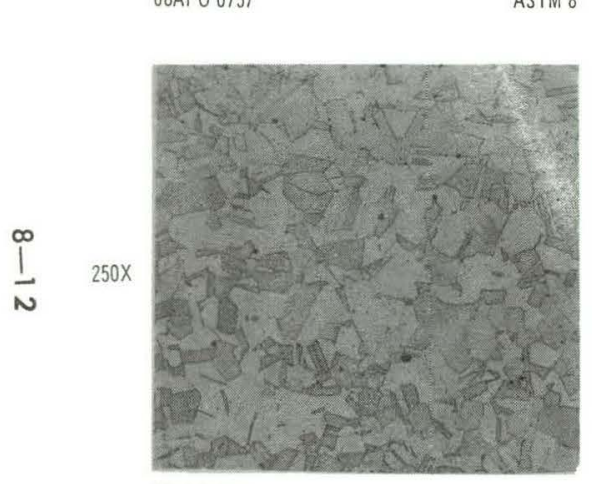

68AP0 0757
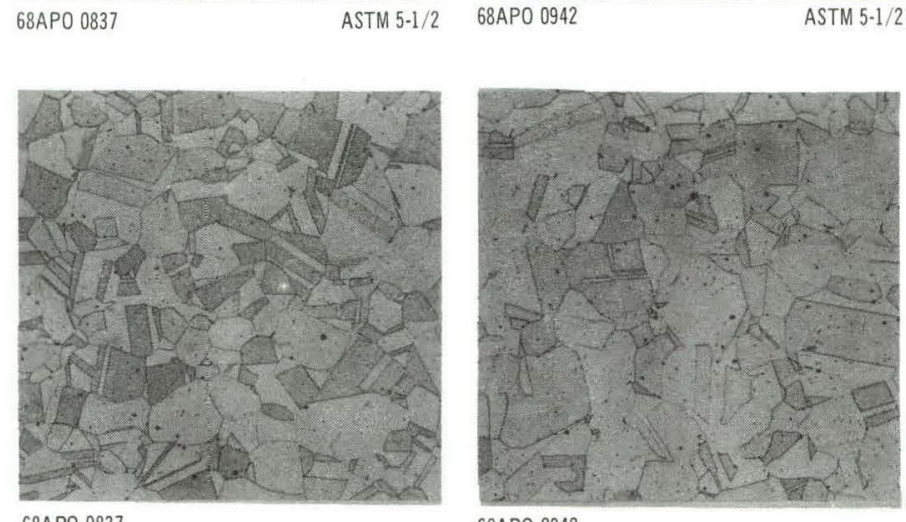

68AP0 0837

68APO 0942

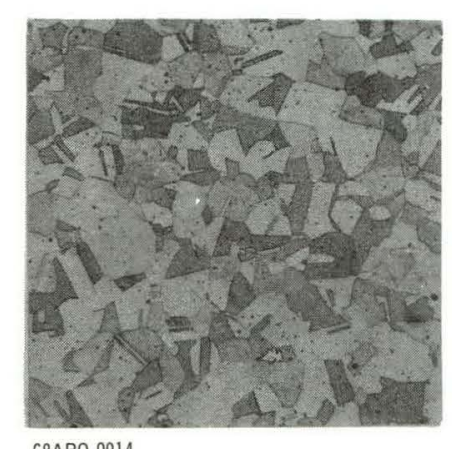

68AP0 0914
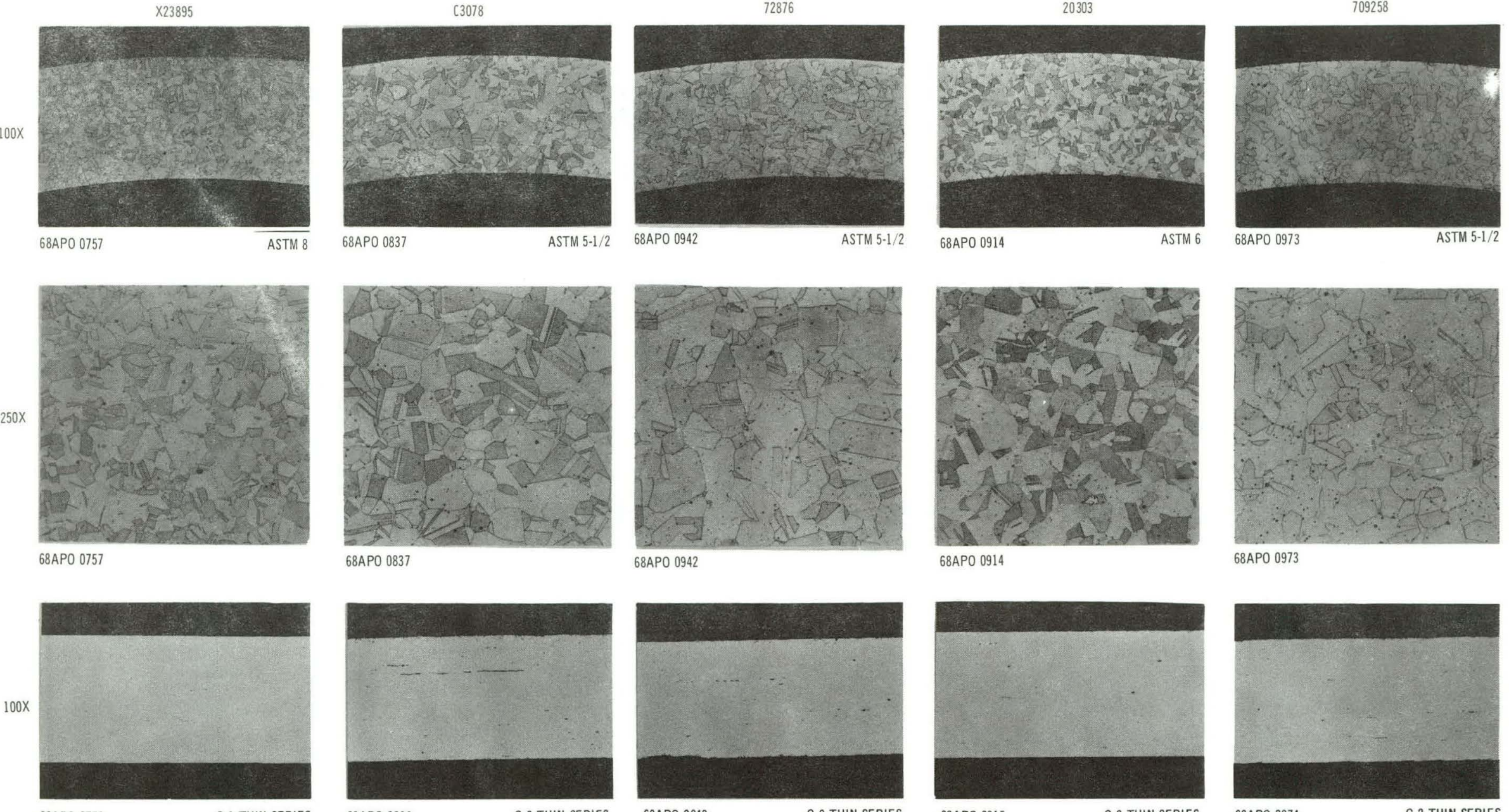

68APO 0758

C-1 THIN SERIES

68AP0 0836

C-3 THIN SERIES

68APO 0943
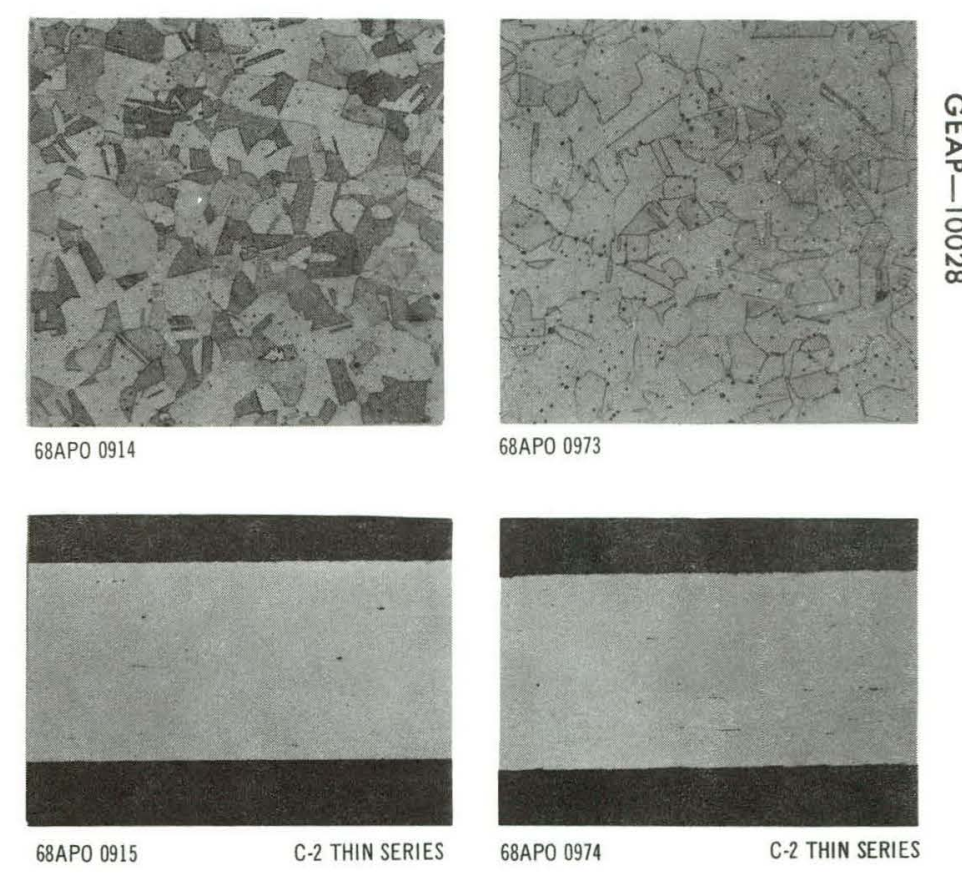

FIGURE 8-6. COMPARATIVE METALLOGRAPHY ON TYPE-316H STAINLESS STEEL: ASSESSMENT-OF-VENDOR TUBING 
(unetched) to illustrate the type, size and distribution of inclusions. The results show that the microstructures of all lots are comparable, the only distinguishing feature being grain size. In all cases, however, the grain sizes fell within the range allowed by specification (ASTM 5-8, incl.).

Dimensional measurements and ultrasonic inspection are being performed on 40 randomly-selected tube sections from each lot. Measurements include complete o.d. and i.d. surveys performed by air gaging and wall thickness and eccentricity measurements performed by ultrasonic resonance techniques. Defect surveys were performed by ultrasonic pulse-echo techniques utilizing a defect standard (reject level) measuring 0.0015 -inch deep by 0.25 -inch long.

The results of the dimensional and ultrasonic surveys completed to date are summarized in Table 8-3. The diametral measurements represent the average mean diameter of a given quantity of tube sections (generally 40, except where noted otherwise).

The number of tube sections shown to be out of specification is based on the following dimensional tolerances:

$$
\begin{aligned}
& \text { O.D. : } 0.250 \pm 0.001 \text { inch (all lots) } \\
& \begin{array}{l}
\text { I.D. : } 0.220 \pm 0.001 \text { inch (all lots } \\
\text { except Trent) }
\end{array} \\
& \text { I.D. on Trent Tubing: } 0.220 \pm 0.0015 \\
& \text { inch }
\end{aligned}
$$

Characterization of the nine material heats shown in Table 8-3 is continuing with the assessment of chemistry, wall thickness, eccentricity, surface condition, and mechanical properties. The latter will be based on room and elevated temperature burst, tensile and stress-rupture testing.

\subsubsection{Tube Defect Study}

The objective of this work is to provide an empirical basis for the establishment of acceptable wall thickness variations and allowable defect sizes.

The defect evaluation of short-term burst and long-term creep rupture properties will be made on artificially and naturallydefected Type 316 tubing.

The assessment of the effect of defect size and orientation on the $1300^{\circ} \mathrm{F}$ burst strength was reported earlier. ${ }^{(1)}$ This earlier work showed that the hoop strength of 15-mil wall tubing containing defects as deep as 2.7 mils was only $8 \%$ lower than that of identical undefected tubing tested under the same conditions.

The defect study is continuing with the evaluation of long-term stress-rupture properties of defected tubing. This program is utilizing specimens selected from the wellcharacterized material as well as artificially defected tubes.

\subsubsection{Test Technique Development}

\subsubsection{Biaxial Creep Facility}

The biaxial creep facility was designed and fabricated to provide RHO with facilities to creep test irradiated tubing materials at elevated temperature. The objective of these tests is to provide creep rate data on highly irradiated tubular specimens. The creep tests are performed by monitoring the diameter increase of pre-pressurized pin specimens as a function of time at a constant temperature. Since the specimens contain only gas, the tube behaves as though under a constant hoop stress during the test. The diameter measurements are made at room temperature which means the specimens are thermally cycled for each measurement. Therefore, three specimens are required to define one creep curve for a given temperature and stress level. One specimen is required for periodic diameter measurements, usually 5 to 7 measurements per test. 
TABLE 8-3

DIMENSIONAL AND ULTRASONIC ASSESSMENT OF TUBING COMPARISON OF VENDORS

Type $304 \mathrm{H}$

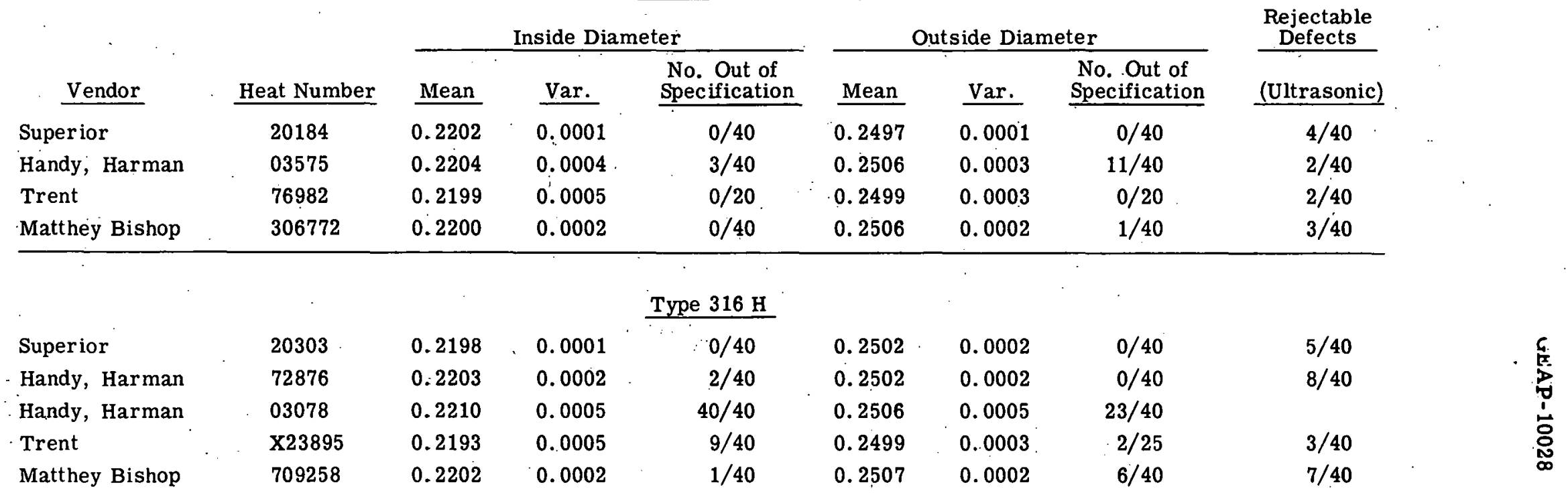


A second specimen is taken out less often for diameter measurements, say 2 or 3 times, to check the effects of interrupting the creep test, i.e., thermal cycling. The third specimen is not removed during the test and provides a final check on the effects of interrupting the creep test. The diametral measurements are taken using a micrometer or dial gage instrument having an accuracy of \pm 0.0001 inch.

Four $1300^{\circ} \mathrm{F}$ control tests as shown in Table 8-4 have been initiated to provide data on unirradiated capsule tubes similar to the initial irradiated tubes from Task $F$ and Task L EBR-II irradiation capsules, which will be tested later. All of the tests were terminated since sufficient data were obtained before rupture. The results are shown in Table 8-5.

The analysis of these data is based on the assumption that the diameter increase due to the internal pressure is uniform throughout the specimen. Also, the resultant creep curve from these specimens is continuous. Under constant stress conditions, the slope of the creep curve should continually decrease to a minimum constant value defined as the steady-state creep rate. The creep curves, as defined by the data in Table 8-5 are shown in Figure 8-7. The relative positions of the curves are as expected, but the 11, 300 psi curve is in error as will be shown by later analysis of these data. The 11,300 psi curve based on extrapolation from the other curves is shown to illustrate where this curve should be.

To better define the strain-time curves, the data points are plotted on log scales in Figure 8-7. The best fit curve was drawn through each set of data. The curves were extrapolated on both ends to provide the necessary strain-time points for further

TABLE 8-4

$1300^{\circ} \mathrm{F}$ CONTROL TESTS FOR CAPSULE TUBES

\begin{tabular}{|c|c|c|c|c|}
\hline $\begin{array}{l}\text { Specimen } \\
\text { Number }\end{array}$ & $\begin{array}{c}\text { Initial } \\
\text { Room } \\
\text { Temperature } \\
\text { Pressure } \\
\text { (psi) }\end{array}$ & $\begin{array}{l}\text { Initial } \\
1300^{\circ} \mathrm{F} \\
\frac{11)}{\text { Pressure }} \\
\text { (psi) }\end{array}$ & $\begin{array}{c}\begin{array}{c}\text { Initial } \\
1300^{\circ} \mathrm{F}\end{array} \\
\text { Hoop Stress } \\
\text { (psi) }\end{array}$ & $\begin{array}{c}\begin{array}{c}\text { Predicted } \\
\text { Rupture } \\
\text { Time }\end{array} \\
\text { (hrs) }\end{array}$ \\
\hline $\begin{array}{l}1 \\
2 \\
3\end{array}$ & $\begin{array}{l}660 \\
660 \\
660\end{array}$ & $\begin{array}{l}2,090 \\
2,090 \\
2,090\end{array}$ & $\begin{array}{l}18,500 \\
18,500 \\
18,500\end{array}$ & $\begin{array}{l}<100 \\
<100 \\
<100\end{array}$ \\
\hline $\begin{array}{l}4 \\
5 \\
6\end{array}$ & $\begin{array}{l}490 \\
490 \\
490\end{array}$ & $\begin{array}{l}1,550 \\
1,550 \\
1,550\end{array}$ & $\begin{array}{l}13,800 \\
13,800 \\
13,800\end{array}$ & $\begin{array}{l}<500 \\
<500 \\
<500\end{array}$ \\
\hline $\begin{array}{l}7 \\
8 \\
9\end{array}$ & $\begin{array}{l}400 \\
400 \\
400\end{array}$ & $\begin{array}{l}1,270 \\
1,270 \\
1,270\end{array}$ & $\begin{array}{l}11,300 \\
11,300 \\
11,300\end{array}$ & $\begin{array}{l}<1,000 \\
<1,000 \\
<1,000\end{array}$ \\
\hline $\begin{array}{l}10 \\
11 \\
12\end{array}$ & $\begin{array}{l}330 \\
330 \\
330\end{array}$ & $\begin{array}{l}1,050 \\
1,050 \\
1,050\end{array}$ & $\begin{array}{l}9,300 \\
9,300 \\
9,300\end{array}$ & $\begin{array}{l}<3,000 \\
<3,000 \\
<3,000\end{array}$ \\
\hline
\end{tabular}

1. Calculated from $\frac{P V}{T}=n R=$ constant or $\mathrm{P}_{1300^{\circ} \mathrm{F}}=3.17 \mathrm{P}_{\mathrm{R} . \mathrm{T} \text {. }}$.

2. Calculated based on hoop stress $=\frac{\mathrm{PD}}{2 \mathrm{t}}$

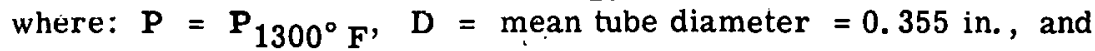
$t .=$ wall thickness $=0.020 \mathrm{in}$. hoop stress $=8.88, \mathrm{P}_{1.300^{\circ} \mathrm{F}}$ : 


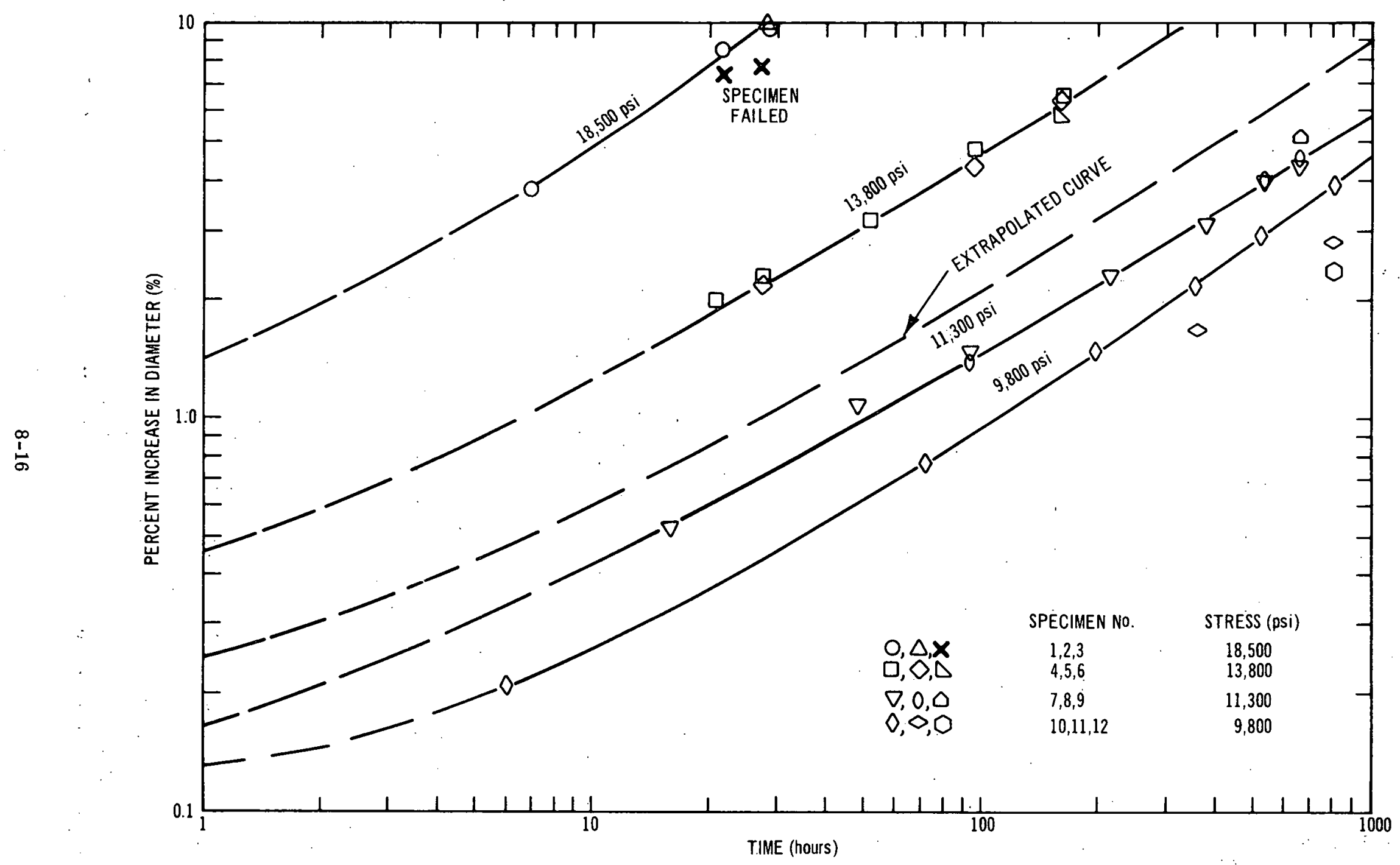

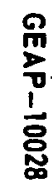

FIGURE 8-7. $1300^{\circ} \mathrm{F}$ CREEP CURVES FOR TYPE.304 CAPSULE TUBES 
TABLE 8-5

DIAMETER INCREASE OF $1300^{\circ} \mathrm{F}$ CONTROL TEST SPECIMENS

\begin{tabular}{|c|c|c|c|c|c|c|}
\hline \multirow[b]{2}{*}{ Time (hrs) } & \multicolumn{3}{|c|}{ Diameter Increase (mils)* } & \multicolumn{3}{|c|}{$\Delta \mathrm{D} / \mathrm{D}_{\mathrm{O}}(\%)$} \\
\hline & No. 1 & No. 2 & $\underline{\text { No. } 3}$ & No. 1 & No. 2 & No. 3 \\
\hline $\begin{array}{r}0 \\
7 \\
22 \\
29\end{array}$ & $\begin{array}{c}0 \\
14.1 \\
32.0 \\
36.1\end{array}$ & $\begin{array}{c}0 \\
- \\
27.3 \\
28.0\end{array}$ & $\begin{array}{c}0 \\
- \\
- \\
36.4\end{array}$ & $\begin{array}{c}0 \\
3.8 \\
8.5 \\
9.6\end{array}$ & $\begin{array}{c}0 \\
- \\
7.3 \\
7.5\end{array}$ & $\begin{array}{c}0 \\
- \\
- \\
9.7\end{array}$ \\
\hline : & No. 4 & No. 5 & No. 6 & No. 4 & No. 5 & No. 6 \\
\hline $\begin{array}{r}0 \\
21 \\
28 \\
53 \\
98 \\
164\end{array}$ & $\begin{array}{c}0 \\
7.6 \\
8.8 \\
12.1 \\
17.9 \\
24.6\end{array}$ & $\begin{array}{c}0 \\
- \\
8.3 \\
- \\
16.3 \\
24.2\end{array}$ & $\begin{array}{c}0 \\
- \\
- \\
- \\
- \\
23.4\end{array}$ & $\begin{array}{c}0 \\
2.0 \\
2.3 \\
3.2 \\
: 4.8 \\
6.6\end{array}$ & $\begin{array}{c}0 \\
- \\
2.2 \\
- \\
4.3 \\
6.5\end{array}$ & $\begin{array}{c}0 \\
- \\
- \\
- \\
6.2\end{array}$ \\
\hline & No. 7 & No. 8 & No. 9 & No. 7 & No. 8 & No. 9 \\
\hline $\begin{array}{r}0 \\
16 \\
25 \\
49 \\
95 \\
218 \\
384 \\
552 \\
672\end{array}$ & $\begin{array}{c}0 \\
2.0 \\
? * * \\
4.0 \\
5.7 \\
8.8 \\
11.7 \\
15.1 \\
16.8\end{array}$ & $\begin{array}{c}0 \\
- \\
? * * \\
5.4 \\
- \\
- \\
14.9 \\
17.3\end{array}$ & $\begin{array}{c}0 \\
- \\
- \\
- \\
- \\
- \\
19.1\end{array}$ & $\begin{array}{l}0 \\
0.53 \\
? \\
1.1 \\
1.5 \\
2.3 \\
3.1 \\
4.0 \\
4.4\end{array}$ & $\begin{array}{c}0 \\
7 \\
- \\
1.4 \\
- \\
- \\
4.0 \\
4.6\end{array}$ & $\begin{array}{c}0 \\
- \\
- \\
- \\
- \\
- \\
- \\
-\quad 5.1\end{array}$ \\
\hline & No. 10 & No. 11 & No. 12 & No. 10 & No. 11 & No. 12 \\
\hline $\begin{array}{r}0 \\
6 \\
72 \\
199 \\
365 \\
534 \\
820\end{array}$ & $\begin{array}{r}0 \\
0.8 \\
2.9 \\
5.6 \\
8.4 \\
10.8 \\
14.6\end{array}$ & $\begin{array}{c}0 \\
- \\
- \\
- \\
6.4 \\
- \\
10.4\end{array}$ & $\begin{array}{c}0 \\
- \\
- \\
- \\
- \\
- \\
9.1\end{array}$ & $\begin{array}{c}0 \\
0.21 \\
0.77 \\
1.5 \\
2.2 \\
2.9 \\
3.9\end{array}$ & $\begin{array}{c}0 \\
- \\
- \\
- \\
1.7 \\
-\overline{2} \\
2.8\end{array}$ & $\begin{array}{c}\ddots 0 \\
\vdots \\
- \\
- \\
- \\
- \\
2.4\end{array}$ \\
\hline
\end{tabular}

* Where no values are given specimens were not removed from test. ** Specimens were removed but not measured.

evaluation. From the curves in Figure 8-7, the time required to reach a given strain as a function of stress are obtained. These constant strain curves are plotted on linear stress-log time axes as shown in Figure 8-8. Again the assumption is made that the curves are smooth and continuous. The data points from the 11,300 psi curves do not lie on any of the curves defined by the other stress levels. On this basis, the 11,300 psi curve shown in Figure 8-7 is not a valid curve for this stress and temperature if the original assumptions are correct.
The extrapolated curve for this stress level was obtained from the curves in Figure 8-8 and illustrates how $1300^{\circ} \mathrm{F}$ creep curves for other stress levels may be obtained. The final curves for use in design studies are isochronal stress-strain curves. These curves are shown in Figure $8-9$ for $1,3,10,100$, and 1000 hours. The points plotted were taken from the curves as defined in Figure 8-8 and are not actual data points from the creep tests.

The curves presented in Figures 8-7, 8-8, and 8-9 are not intended for use as 


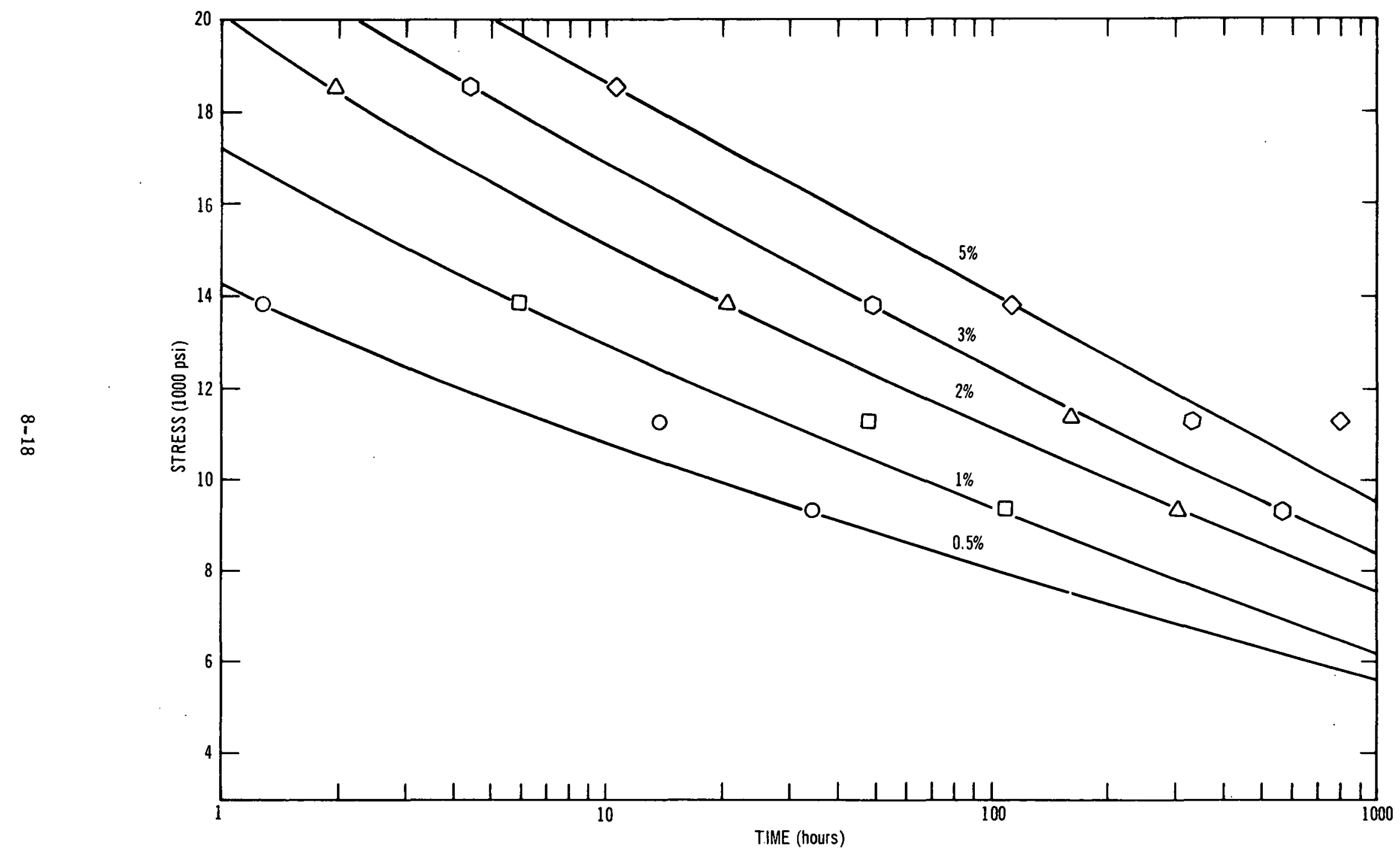




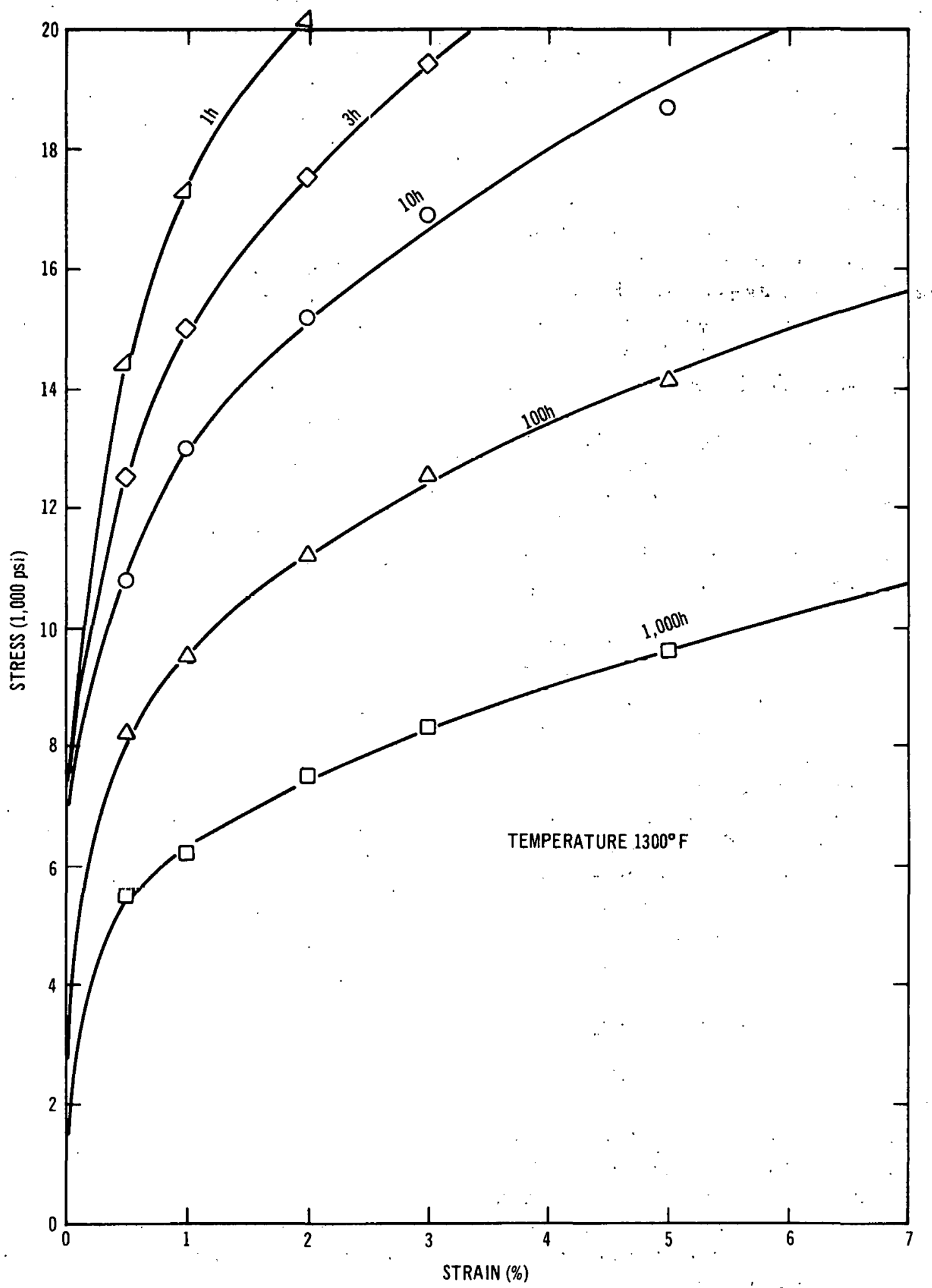

FIGURE 8-9. ISOCHRONAL BIAXIAL STRESS-STRAIN CURVES FOR TYPE-304 CAPSULE TUBES 
design data, but rather to illustrate the analysis used in evaluation of data from the biaxial creep program. These figures also illustrate the region where strain measurements are required to better define the curves which are used for extrapolation. It is intended to define each creep curve as shown in Figure 8-7 by at least five different data points spread out over the strain range of 0.2 to $5 \%$. Extrapolation to lower and higher strain levels can then be done with reasonable assurance that the extrapolation is valid.

The effect of thermal cycling was not well defined by these initial tests. At the higher stress levels ( $>13,000 \mathrm{psi}$ ), no effect on the creep rate was observed for as many as five cycles. At $11,300 \mathrm{psi}$, no difference in creep rate was observed for tests cycled four and eight times; but both cycled tests exhibited lower creep rates than the uncycled tests which is unexpected. The lowest stress tests $(9,300 \mathrm{psi})$ do show a general trend for increased creep rate (larger diameter change) with increasing temperature cycles during the test. This phenomenon has been observed in cyclic temperature tests ${ }^{(34)}$ of this type before, and further control tests are necessary before any quantitative evaluation of this trend can be made. In the present analysis of biaxial data, this trend was neglected.

\subsubsection{Clad Deformation Studies}

In the past, considerable effort has been expended in developing methods of measuring and analyzing local deformations and, in some instances, hypothesizing the types of clad loading mechanisms that might be acting. This work has continued with the establishment of a preliminary framework from which to analyze the combinations of loading mechanisms (deformation modes) which might lead to failure. Conditions and events that produce deformation and/or stress in fuel cladding have been described and discussed in a preliminary manner; relations for predicting the effects of such mechanisms on cladding have been gathered and made available, and those areas needing additional analysis have been identified (Table 8-6).

A method of determining the critical deformation mode (failure mode) was demonstrated by calculation of the increments of strain obtained on startup. In this demonstration, using estimated values from Table 8-6, the maximum effective local strain calculated on startup was approximately $1 \%$ and occurred on the inside clad surface at the pellet-pellet interface when a wire space contact load was next to the interface. Considered in this example were the effects of thermal expansion, thermal loading from radial and circumferential gradients, rod bowing, pellet thermal distortion, and the discontinuity produced by a large pellet next to a small one. By superimposing similar results of subsequent periods of steady and transient operation, it would be possible to predict the location and amount of maximum strain at any time. A simplified flow chart of the types of calculation steps required for analysis is shown in Figure 8-10. Because of the need to consider many variables, such as temperature level, transient rates and fluence level as a function of space and time, it is readily apparent that it will be necessary to make use of computer methods.

Necessary for predicting imminent failure in such a process is the establishment of a failure criterion. It was proposed that the criterion be based on strain level, which appears more appropriate than stress due to the predominance of secondary stresses, particularly in vented fuel. Such a criterion might be related to a "Damage Index" of the form : 


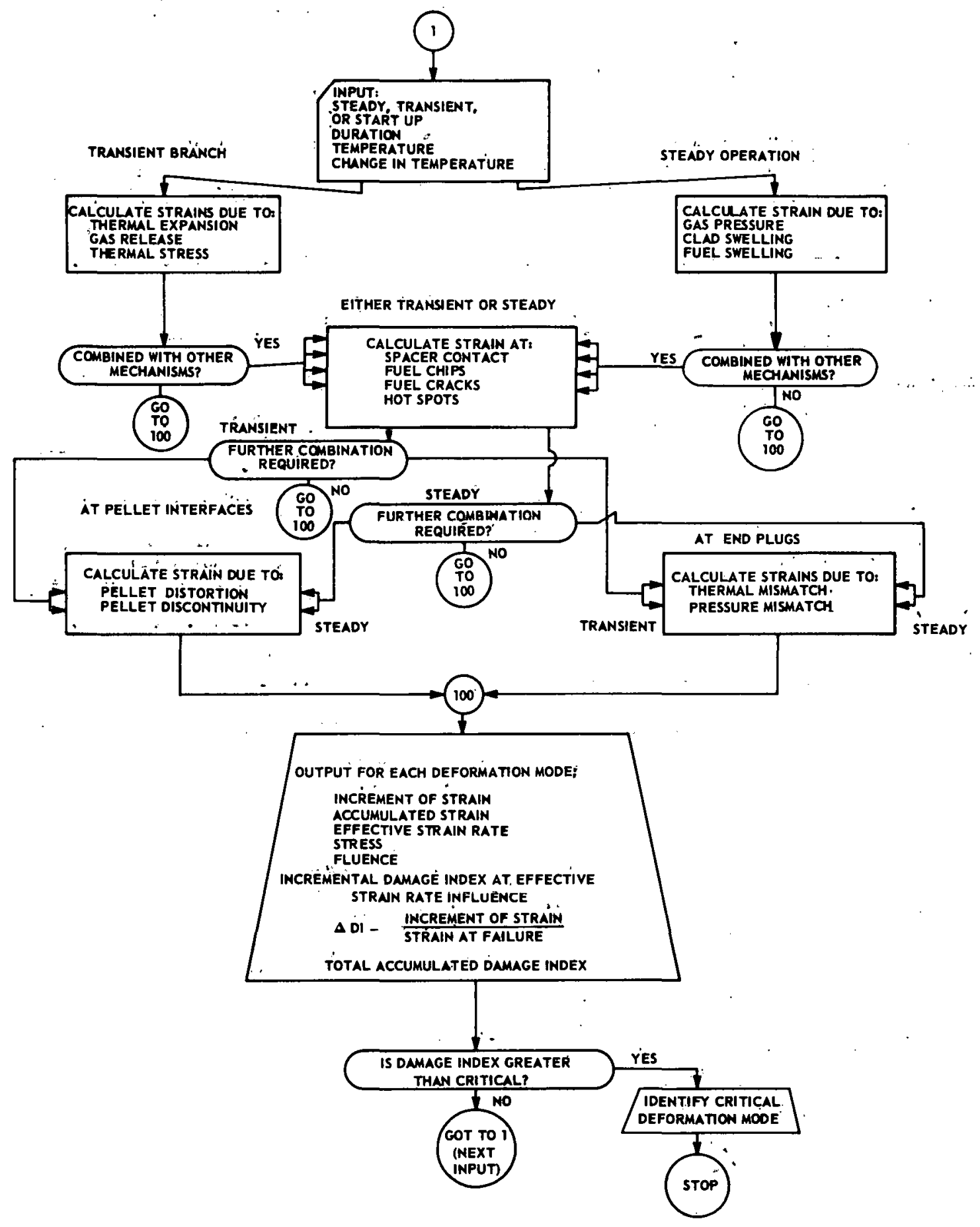

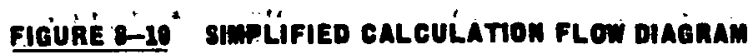




$$
\text { Damage Index }=\sum_{i} \frac{\epsilon_{i}}{\epsilon_{i t}}
$$

where: $\epsilon_{i}=$ strain during event $i$

$$
\epsilon_{i t}=\text { total strain under conditions } i \text {. }
$$

As shown in Figure 8-10 the increment of strain would be calculated for each reactor event, under each deformation mode (combination of loading mechanisms), compared to the ductility under these specific conditions (temperature, fluence, strain rate, etc.), and the Damage Index determined. The details of the preliminary work described above is necessarily brief. Because of the scope and importance of the subject, a topical report will be issued covering this work in detail. 


\section{TABLE 8-6}

GEAP-10028

\section{: SUMMARY}

LOADING MECHANISM

ASSUMPTIONS

Thermal Expansion

The only effect of interference cons idered is on start-up.
subsequent fluctuations estimated at $0.1 \%$ strain per 108 change in power level have been neglected. Any interfer-
ence calculated is assumed to be accomodated only by clad

Radial Temperature Assumed significant only on start-up unless stre levels are high enough to cause $g$.
cycle. Wail bending in character.

EVATION Neglected except on start-up. Niembrane in nature with the
maximum load compress ive at the peak temperature location.
circumferential bending assuned negligible. Menbrane in
character.

circumferer Neglected except on start-up. Assumed $\Delta T=100^{\circ} \circ$ across rod
and deflectcion prevented by spacers. Beam bending but
membrane in character. AT to be determined No estimates.

Local Hot Spots $\begin{array}{ll}\text { End plug - Thermal } & \begin{array}{l}\text { Neglected under normal operation. Problems appear at outlet } \\ \text { on scram and at both ents on fuel insmatch } \\ \text { and membrane in character. }\end{array}\end{array}$ End Plug - Pressure Results based on elastic expansion of pin due to gas pressure
Mismatch

Pellet Discontinuity The largest pellet is placed next to the smallest. Deforma-

Pellet Distortion

The thermal distortion is assumed to produce a ridge with corresponding therement is hoop stress and longitudinal Dending stresses. Occurs on start-up only. Walues based
on data from Fre test fuel capsule with $1 / 2$ mil ridge
height and lower limit calculation on logitudinal bending The 'analytic and experimental capablitities have not been
developed to the state that estimates of deformation can
be made.

fuel Cracks

Spacer contact

Assuming a spacer load (W) of 4 pounds from thermal bow, produced deformation considered negligible.

Fuel Chtp No Estimates

Fission Gas Pressure The pressure for vented design has arbitrarily been set at 350 psi. Both pressures are assumed
to exist during entire 11 fe except at start-up. $\sigma_{0}=\frac{P R}{t}$
$\sigma_{2}=\frac{1}{2} \frac{P R}{t}$

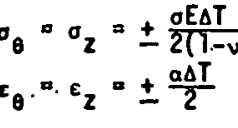

$\sigma_{\theta}=\sigma_{z}=\frac{a \varepsilon S T}{2}$ $\varepsilon_{\theta}=\varepsilon_{z}=\frac{a \Delta T}{2}$ $\sigma_{\theta}=\sigma_{z}=\alpha E S T$ $2= \pm \sqrt{\left(\frac{3}{1-w^{2}} \frac{\partial E}{R}\right.}$ $\sigma_{\theta}=\left(1 \pm \sqrt{\frac{3}{1-v^{2}}}\right) \frac{\delta E}{\mathrm{~B}}$ 8 =aRST $\sigma_{2}= \pm \sqrt{\frac{3}{1-v^{2}}} \frac{E}{R}$ $\sigma_{0}= \pm \sqrt{\frac{3}{1-v^{2}}} \frac{E}{R}$ $\sigma_{2}= \pm \sqrt{\frac{3}{1-v}} \frac{\delta \varepsilon}{R}$ $\sigma_{\theta}= \pm \sqrt{\frac{3}{1-v^{2}}} \frac{\delta E}{R}$

Fuel Swelling Does not include clad swelling. Strain rates obtalined from
experimental data on .in growth assuming $50 \%$ to be caused

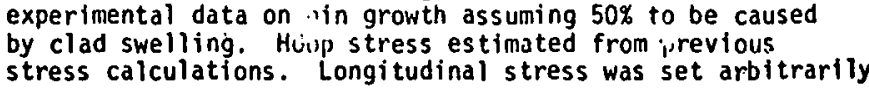

Vibration

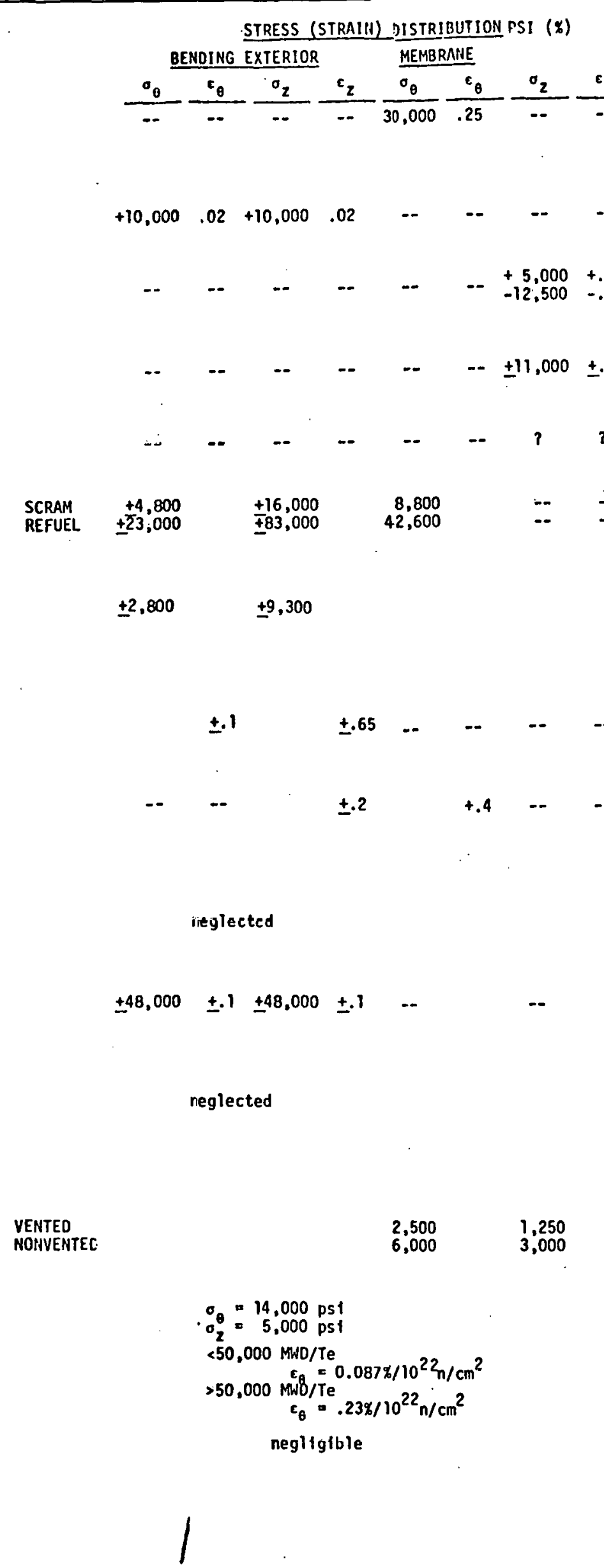

EUTURE ACTIVITY NECESSARY

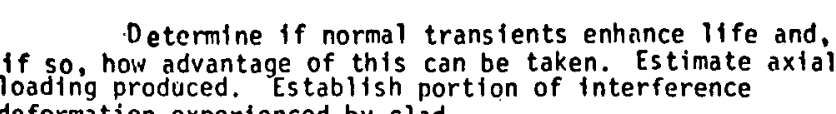

Analysis considered satisfactory.

Analysis considered satisfactory with continued thermal-
hydraulic analysts.

Better estimates of temperature distributions needed
including extension to third dimenston.

Thermal analysis is required to estimate the temperature
gradients possible.

Close scrutiny is required to establish if there is a
necessity to 11 mit temperature difference or number of

Introduce effect of creep expansion mismatch and produce
relations in terms of strain.

Analysis considered satisfactory.

Estimate axial loading, experimental work is
to better characterize deformation at ridges

Entend earlier work concerning stress distribu prugraul.

Values of strain introduced under creep condittons should be establish realistic spacer loads.
esterning

Estimate the stratn distribution and establish an experimental

Creep rates versus stress are needed under reactor conditiof effects of clad swelling and fuel swelling. Ana-
lytic studies should increase understanding.

Analytic atudies underway. Exper1mentally,
clad swelling and gas pressure effects shou clad swelling and gas pressure effects should
be separated to obtain rates as a function of temperature and power.

The possibi11ty of vibration should be carefully monitored with future design changes, particularly if it is found
necessary to provide a "loose" assembly to accomodate pin 


\section{REFERENCES}

1. "Sodium-Cooled Reactors, Fast Ceramic Reactor Development Program, TwentySeventh Quarterly Report, May - July 1968," August 1968, (GEAP-5677).

2. Pechurova, N. I., Ippolitova, E. A., and Kovba, L. M. , "Investigation of the Hydrolytic Processes of Normal Uranates of Alkali Elements," U. S. Atomic Energy Commission, November 1964, (ANL-TRANS-33), p. 110.

3. Skirvin, S. C., "Users Manual for the THTD Computer Program," Nuclear Materials and Propulsion Operation, Nuclear Technology Department, General Electric Company, Cincinnati, Ohio, 1966 (G. E. RGOFPD647).

4. "Sodium-Cooled Reactors, Fast Ceramic Reactor Development Program, TwentySixth Quarterly Report, February April 1968," May 1968, (GEAP-5631).

5. Thomas, G. R., and Field, J. H., "Destructive Examination of an AxiallyRestrained Pelleted Mixed-Oxide Specimen that Failed During Transient Overpower Conditions," November 1968, (Trans. Am. Nuc. Soc. 11), p. 697.

6. Fox, J. N., Lawler, B. E., and Butz, H. R., "FORE-II A Computational Program for the Analysis of Steady-State and Transient Reactor Performance," September 1966, (GEAP-5273).

7. "Sodium Cooled Reactors, Fast Ceramic Reactor Development Program, TwentyNinth Quarterly Report, November January 1969," February 1969, (GEAP-5753).
8. Novak, P. E., and Asamoto, R. R., "An In-Pile Evaluation of W - Re Thermocouple Systems for Use to $4700^{\circ} \mathrm{F}$ in SEFOR Fuel," October 1968, (GEAP-5468).

9. Robertson, J. A. L., et al., "Temperature Distribution in $\mathrm{UO}_{2}$ Fuel Elements," Journal of Nuclear Materials, 7, 225, (December 1962).

10. Lyons, M. F., et al., "New Evidence to Delineate the $\mathrm{UO}_{2}$ Molten Boundary," ANS Transactions 8-2, pp. 376-379, (December 1965).

11. Aitken, E. A., and Evans, S. K., "A Thermodynamic Data Program Involving Plutonia and Urania at High Temperatures,". October 1968, (GEAP-5672).

12. Baily, W. E., et al., "Thermal Conductivity of Uranium-Plutonium Oxide Fuels," AIME Nuclear Symposium, October 1967.

13. Craig, C. N., and Baily, W. E., "In-Pile Comparison of Effective Thermal Conductivity of $\left(\mathrm{PuO}_{2}-\mathrm{UO}_{2}\right)$ Mixed Oxides," . January 1968, (GEAP-5556).

14. "Sodium-Cooled Reactors, Fast Ceramic Reactor Development Program, TwentyEighth Quarterly Report, August October 1968," November 1968, (GEAP-5700).

15. Gwin, R., et al., "Measurements of the Neutron Fission and Absorption Cross Sections of $\mathrm{Pu}-239$ Over the Energy Region 0.01 to $\mathrm{eV}$ to $30 \mathrm{keV}, " \mathrm{NPD}$ Annual, May 15, 1968.

16. James, C. D., TRDWP/P30 (1965)A Preliminary Report. 


\section{REFERENCES (Continued)}

17. Shunk, E. R., Brown, W. K., and La Bauve, R., "Fission Cross Sections From Petrel," Section on Pu-239, December 1966, (LA-3586).

18. Ryabov, Y. V., et al., "Measurement of the Radiative Capture and Fission Cross Section Ratios for U-235 and Pu-239 in the Resonance-Neutron Energy Region," Atomnaya Energiya, 24, 4, (1968).

19. Uttley, C. A., $\operatorname{EANDC}(\mathrm{UK})-35, \underline{L}$, 1964 and EANDC(UK)-40, L, (1964).

20. Greebler, P., Aline, P., Hutchins, B. A., "Evaluation and Compilation of $\mathrm{Pu}-239$ Cross Section Data for the ENDF/B Files," December 1966, (GEAP-5272).

21. Hill, D. L., Wheeler, J. A., "Physics Review," 89, 1102, (1953).

22. Schomberg, M. G. , Sowerby, M. G., Evans, F. W., "A New Method of Measuring Alpha (E) for. Pu-239," Paper SM-101/41, IAEA Symposium on Fast Reactor, Physics and Related Safety Problems, Karlsruhe, Germany, November 1967.

23. James, G. D., Patrick, B. A., "Evaluation of the $\mathrm{Pu}-239$ Fission Cross Section in the Energy Range $1 \mathrm{keV}$ to $100 \mathrm{keV}$," October 1968, [AERE-M-2065 (amended) ]

24. Little, W. W., Jr., and Hardie, R. W., "2DB, A Two-Dimensional Diffusion Burnup Code for Fast Reactor Analysis," January 1968, (BNWL-640).

25. Little, W. W., Jr., and Hardie, R. W., "2DB Users Manual," July 1968, (BNWL-831).
26. Mynatt, F. R., "A Users Manual for DOT, A Two-Dimensional Discrete Ordinates Transport Code with Anisotropic Scattering," K-1694 (to be published).

27. Little, W. W. , Jr., and Hardie, R. W., "2DB Users Manual," February 1969, (BNWL-831, Rev. 1).

28. Engle, W. W., Jr., "A Users Manual for ANISN, A One Dimensional Discrete Ordinates Transport Code with Anisotropic Scattering," March 1967, (K-1693).

29. Dwyer, O. E., "Analytical Study of Heat Transfer to Liquid Metals Flowing In-line Through Closely Packed.Rod.Bundles," Nuclear science \& Eng., $25: 343$ (1966).

30. Borishanski, V. M., Gotovski, M. A., and Firsova, E. V., "Heat Exchange When a Liquid Flow Longitudinally Through a Bundle of Rods Arranged in a Triangular Lattice," Atomnaya Energiya $22: 318$ (1966).

31. Barnes, R. S., Nelson, R. S., "Theories of Swelling and Gas Retention in Reactor Materials," June 1965, (AERE-4952).

32. Nichols, F. A., "Behavior of Gaseous Fission Products in Oxide Fuel," October 1966, (WAPD-TM-570).

33. 'Sodium-Cooled Reactor, .Fast Ceramic Reactor Development Program, Twentieth Quarterly Report, August - October 1966," (GEAP-5292).

34. Taft, L. H., and Broom, T., "Exploratory Tests on Effects of Temperature and Load Cycling on Creep Resistance and Microstructure of Two Austenitic Steels," Joint International Conference on Creep, Inst. of Mech. Engr., 3-77-3-81, 1963. 


\section{APPENDIX}

\section{PRIOR REPORTS}

Prior progress reports to the Commission under this contract include:

Monthly Progress Letters, Number 1-94, from July 1959 through October 1968.

\begin{tabular}{|c|c|}
\hline AP-3888 & $\begin{array}{l}\text { FCR Development Program - } \\
\text { First Quarterly Report, } \\
\text { October-December } 1961 .\end{array}$ \\
\hline EAP-3957 & $\begin{array}{l}\text { FCR Development Program - } \\
\text { Second Quarterly Report, } \\
\text { January-March } 1962 \text {. }\end{array}$ \\
\hline EAP-3981 & $\begin{array}{l}\text { FCR Development Program - } \\
\text { Third Quarterly Report, } \\
\text { April-June } 1962 \text {. }\end{array}$ \\
\hline EAP-4080 & $\begin{array}{l}\text { FCR Development Program - } \\
\text { Fourth Quarterly Reporl, } \\
\text { July September } 1962 \text {. }\end{array}$ \\
\hline ;EA P-4158 & $\begin{array}{l}\text { FCR Development Program - } \\
\text { Fifth Quarterly Report, } \\
\text { October-December } 1962 .\end{array}$ \\
\hline EAP-4214 & $\begin{array}{l}\text { FCR Development Program - } \\
\text { Sixth Quarterly Report, } \\
\text { January-March } 1963 .\end{array}$ \\
\hline EAP-4300 & $\begin{array}{l}\text { FCR Development Program - } \\
\text { Seventh Quarterly Report, } \\
\text { April-June 1963. }\end{array}$ \\
\hline-4382 & $\begin{array}{l}\text { FCR Development Program - } \\
\text { Eighth Quarterly Report, } \\
\text { July-September } 1963 \text {. }\end{array}$ \\
\hline 80 & $\begin{array}{l}\text { FCR Development Program - } \\
\text { Ninth Quarterly Report, } \\
\text { October-December } 1963 \text {. }\end{array}$ \\
\hline 4601 & $\begin{array}{l}\text { FCR Development Program - } \\
\text { Tenth Quarterly Report, } \\
\text { January-March } 1964 \text {. }\end{array}$ \\
\hline-4640 & $\begin{array}{l}\text { FCR Development Program - } \\
\text { Eleventh Quarterly Report, } \\
\text { April-June } 1964 \text {. }\end{array}$ \\
\hline GEAP-4723 & $\begin{array}{l}\text { FCR Development Program - } \\
\text { Twelfth Quarterly Report, } \\
\text { July September } 1964 \text {. }\end{array}$ \\
\hline GEAP-4795 & $\begin{array}{l}\text { FCR Development Program - } \\
\text { Thirteenth Quarterly Report, } \\
\text { October } 1964 \text {-January } 1965 \text {. }\end{array}$ \\
\hline GEA & n - \\
\hline
\end{tabular}

GEAP-4931 FCR Development Program Fifteenth Quarterly Report, May-July 1965.

GEAP-4982 FCR Development Program Sixteenth Quarterly Report, August-October 1965.

GEAP-5098 FCR Development Program Seventeenth Quarterly Report, November 1965-January 1966.

GEAP-5158 FCR Development Program Eighteenth Quarterly Report, February-April 1966.

GEAP-5198 FCR Development Program Nineteenth Quarterly Report, May-July 1966.

GEAP-5292 FCR Development Program Twentieth Quarterly Report, August-October 1966.

GEAP-5433 FCR Development Program Twenty-First Quarterly Report, November 1966-January 1967.

GEAP-5491 FCR Development Program Twenty-Second Quarterly Report, February-April 1967.

GEAP-5522 FCR Development Program Twenty-Third Quarterly Report, May-July 1967.

GEAP-5541 FCR Development Program Twenty-Fourth Quarterly Report, August-October 1967.

GEAP-5584 FCR Development ProgramTwenty-Fifth Quarterly Report November 1967-January 1968.

GEAP-5631 FCR Development ProgramTwenty-Sixth Quarterly Report February-April 1968.

GEAP-5677 FCR Development Program Twenty-Seventh Quarterly Report May-July 1968.

GEAP-5700 FCR Developmènt Program Twenty-Eighth Quarterly Report August-October 1968

GEAP-5753 FCR Development ProgramTwenty-Ninth Quarterly Report, November 1968 -January 1969.

Supplementary Program Letters, Nos. 1-11 from October 1962 through April 1964.

Reports from G. D. Collins and W. J. Ozeroff on assignment to CEA - France. 
In addition, the following topical reports have been issued:

$\begin{aligned} & \text { GEAP-3287 } \text { Fast Oxide Breeder - Reactor } \\ & \text { Physics, Part I - Parametric } \\ & \text { Study of } 300 \text { MWe Reactor Core; } \\ & \text { P. Greebler, P. Aline, and } \\ & \text { J. Sueoka (November 10, 1959). }\end{aligned}$

GEAP-3347 Fast Oxide Breeder - Stress Considerations in Fuel Rod Design; K. M. Horst (March 28, 1960).

GEA P-3486 Fast Oxide Breeder Project Fuel Fabrication

Part I - Plutonium-Uranium Dioxide Preparation and Pelletized Fuel Fabrication; J. M. Cleveland and W. C. Cavanaugh;

Part II - Fabrication of PlutoniumUranium Dioxide Specimens by Swaging; M. E. Snyder and W. C. Cowden (August 15, 1960).

GEAP-3487 Fast Oxide Breeder - Preliminary Sintering Studies of PlutoniumUranium Dioxide Pellets; J. M. Cleveland and W.. C. Cavanaugh. (August 15, 1960).

GEAP-3646. Calculation of Doppler Coefficient and Other. Safety Parameters for a Large Fast: Oxide Reactor; P. Greebler; B. A. Hütchins; and J. R. Sueoka (March 9, 1961).

GEAP-3721 Core Design Study for a $500 \mathrm{MWe}$ Fast Oxide Reactor; K. M... Horst, B. A. Hutchins; F. J. Leitz, and B. Wolfe (December 28,: 1961).

GEA P-3824 Fabrication: Cost Estimate for $\mathrm{UO}_{2}$ and Mixed $\mathrm{PuO}_{2}-\mathrm{UO}_{2}$ Füel; G. . D. Collins (January 24, 1962):

GEAP-3833 The Post-Irradiation Examination of a $\mathrm{PuO}_{2}-\mathrm{UO}_{2}$ Fast Reactor Fuel; J. M. Gerhart (November 1961).

GEAP-3856 Experimental Fast Oxide Reactor; K. P. Cohen, M. J. McNelly, and B. Wolfe (November 27, 1961).

GEAP-3876 Plutonium Fuel Processing and Fabrication for Fast Ceramic Reactors; H. W. Alter, G. D. Collins, and E. L. Zebroski (February 1, 1962).

GEAP-3880 Comparative Study of PuC-UC and $\mathrm{PuO}_{2}-\mathrm{UO}_{2}$ as Fast Reactor Fuel Part I - Technical Considerations; K. M. Horst and B. A. Hutchins (February 15, 1962).

Part II - Economic Considerations; G. D. Collins (November 15, 1962).

GEAP-3885 Experimental Fast Ceramic Reactor Design, Status Report as of October 31, 1961; Edited by K. M. Horst (April 24, 1962).
GEAP-3923 Resonance Integral Calculations for Evaluation of Doppler Coefficients - The RAPTURE Code; J. H. Ferziger, P. Greebler, $M$. D. Kelley, and J. Walton (June 12, 1962).

GEA P-4028 A Fuel Reprocessing Plant for Fast Ceramic Reactors; H. W. Alter (February 1, 1962).

GEAP-4058 Analytical Studies of Transient Effects in Fast Reactor Fuels; R. B. Osborn and D. B. Sherer (August 1962).

GEAP-4090 FORE - A Computational Program for the Analysis of Fast Reactor Excursions; P. Greebler and D. B. Sherer (October 1962).

GEAP-4092 Doppler Calculations for Large Fast Ceramic Reactors, Effects of Improved Methods and Recent Cross Section Information; $\mathbf{P}$. Greebler and E. Goldman (December 1962).

GEAP-4130 Experimental Studies of Transient Effects. in. Fast Reactor Füls. Series I, $\mathrm{UO}_{2}$ Irradiations; -J:. $\mathrm{H}$. Field (November 15, 1962).

GEAP-4226 Conceptual Mechanical Design of 565 MWe Fast Ceramic Reactor; A. G. Silvester (April 1963).

GEAP-4271 Measurement of Oxygen-to-Metal Ratio in Solid Solutions of $\mathrm{UO}_{2}$ and $\mathrm{PuO}_{2} ; \mathrm{W}$.. L. Lyon: (May $31,2,1963)$ :

GEAP-4283 Experimental:Studies: of:Sodium Logging in:FCR:Fuels; G: L. O'Neill, P:: E. Novak," M:: L: Johnson, and W. E. Baily (September 1963).

GEAP-4350 Fast Reactor Meltdown Excursions - Analysis and Computer Program FARM I; B. C. Luci, D. R. Riley, and N. F. Friedman (December 5 , 1963).

GEAP-4410 Calculations of Doppler and Sodium Reactivity Effects; P. Greebler (November 1963).

GEAP-4414 Reactor Safety and Fuel Cycle Economics, K. P. Cohen (November 1963).

GEAP-4418 Liquid Metal Fast Breeder Reactor Design Study, $1000 \mathrm{MWe} \mathrm{PuO}_{2}-\mathrm{UO}_{2}$ Fueled Plant, Vols. I and II; M. J. McNelly, et al. (January 1964).

GEAP-4420 Influence of Doppler Effect on Meltdown Accident; N. F. Friedman (December 1963). 
GEAP-4466 Experimental Studies of Plutonium and Fission Product Redistribution in Fast Reactor Fuels; T. Lauritzen, et al., (July 1966).

GEAP-4471 Calculated Nuclear Parameters and Their Uncertainties in a 1000 MWe FCR; P. Greebler, et al., (October 1966).

GEAP-4472 User Requirements for Cross Sections in the Energy Range from $100 \mathrm{eV}$ to $100 \mathrm{keV}$; $P$. Greebler and B. A. Hutchins (1966).

GEAP -4580 FLUZ - A Computer Code for Analyzing the Reactor Response to Small Reactivity Oscillations; P. Greebler, B: A. Hutchins, and M. D. Kelley (March 22, 1965).

GEAP-4630 The Effects of Resonance Overlap on the Doppler Coefficient in a Fast Ceramic Reactor, Computer Codes RAVE and DOPIE;

B. A. Hutchins (August 1964).

GEAP-4675 Some Electrical Properties of the Plutonium-Uranium Mixed Oxide System; W. E. Baily (July 1966).

GEAP-4770 A Technical and Economic Evaluation of Vented Fuel for SodiumCooled Fast Ceramic Reactors; G. L. O'Neill, J. Duffy, J. C. Gilbertson, F. W. Knight, and D. B. Sherer (May 1965).

GEAP-4787 An Analysis of Fast Reactor Transient Response and Safety in Selected Accidents; W. Meinhardt, Jr. (August 1966).

GEAP-4804 Experimental Studies of Transient Effects in Fast Reactor Fuels, Series II; J. E. Hanson, J. H. Field, and S. A. Rabin (June 1965).

GEAP-4819 Experimental Studies of Transient Effects in Fast Reactor Fuels, Series III, Pre-Irradiated Mixed Oxide $\left(\mathrm{PuO}_{2}-\mathrm{UO}_{2}\right)$ Irradiations, Interim Report, Steady State Irradiations; J. E. Hanson and S. A. Rabin (September 1965).

GEAP-4822 Studies of Alternate Core Design Concepts for Fast Sodium Cooled Reactors; C. L. Cowan, (November 1966).

GEAP-4870 Some Design and Irradiation Experience with Capsules for Long Ceramic Fuel Elements; F. W. Knight (July 1966).
GEAP-4877 Diffusion of Plutonium and Uranium in Oxide Fuel at $2400^{\circ} \mathrm{C}$; $J$. Davies and P. Növak (Aứgust 1966).

GEAP-4878 The Solid-Liquid Phase Diagram for $\mathrm{UO}_{2}-\mathrm{PuO}_{2}$ System; W. L. Lyon afld W. ${ }^{\mathrm{E}}$ : Baily (May 1966).

GEAP-4897 Irradiation Behavior of Hyperand Hypo-Stoichiometric PlutoniaUrania Fuel at $70,000 \mathrm{MWd} / \mathrm{T}$; E. L. Zebroski, W. E. Baily, and D. P. Hines (March 1965).

GEAP-4922 BISYN - A Two Dimensional Synthesis Program; M. D. Kelley (December 1966).

GEAP-4939 Safety and Economic Characteristics of a 1000 MWe Fast Sodium Cooled Reactor Design; K. P. Cohen and G. L. O'Neill, (April 1967).

GEAP-5272 Evaluation and Computation of Pu-239 Cross Section Data for the ENDF/B Files; P. Greebler, $\mathrm{P}$. Aline, B. Hutchins (January 1967).

GEAP-5273 FORE II, A Computational Program for the Analysis of SteadyState and Transient Reactor Performance; B. E. Lawler, et al., (September 1967).

GEAP-5340 Neutron Spectrum Measurements in a Fast Plutonium Assembly ZPR-III Assembly 48; P. S. Brown and A. Weitzberg (April 1967).

GEAP-5494 RAPFU-A Computer Code; P. Greebler, C. Cowan (November 1967).

GEAP-5411 Turbulent Velocity Distribution in a Rod Bundle; D. J. Bender, D. M. Switick, J. H. Field (January 1968).

GEAP-4879 Thermal Conductivity of Uranium and Uranium Plutonium Oxides; T. E. Lannin (January 1968).

GEAP-5570 Short Term Fast Flux (EBR-II) Irradiation of $\mathrm{PuO}_{2}-\mathrm{UO}_{2}$ Fuel Pins; S. A. Rabin, W. W. Kendall, W. E. Baily (February 1968).

GEAP-4469 Experimental Studies of Transient Effects in Fast Reactor Fuels, Series III, Pre-Irradiated Mixed Oxide ( $\mathrm{PuO} 2-\mathrm{UO}_{2}$ ), Irradiations Final Report, Transient Irradiations; J. E. Hanson, J. H. Field (February 1968). 
GEAP-5344 Electron Microanalysis of Radioactive Materials I, Preliminary Experiments and Plans for a Shielded Facility: H. Rosenbaum, et al, (February 1968).

GEAP-5744 Analytical Procedures and Applications of Fluence Determinations from EBR-II' Flux Wires; A. Withop, B. A. Hutchins, G. C. Martin, (March 1968).

GEAP-5271 Implications of Recent Fast Critical Experiments on Basis Fast Reactor Design;

P. Greebler, (March 1968).

GEAP-5493 The Effect of Density on the Thermal Conductivity of Uranium Dioxide; R. Asamoto, (February 1968).
GEAP-5556 In-Pile Comparison of Effective Thermal Conductivity $\left(\mathrm{Pu}-\mathrm{UO}_{2}\right)$ Mixed Oxides; C. N. Craig, W. E. Bailv (March 1968).

GEAP-5635 Significance of Neutron Data Uncertainties to Fast Reactor Economics and Power Plant Design; B. A. Hutchins, et al. , (June 1968).

GEAP-5683 Thermodynamic Analysis of Possible Chemical Interactions in the System: $\mathrm{UO}_{2}-\mathrm{PuO}_{2}$ Fuel-Sodium-Stainless Steel; Aitken, E. A., (July 1968).

GEAP-5583 The Role of Fission Products in the Swelling of Irradiated $\mathrm{UO}_{2}-(\mathrm{U}, \mathrm{Pu}) \mathrm{O}_{2}$ Fuel; Anselin, F., (January 1969). 


\section{CONTRIBUTORS}

\section{TASK B-Defected Fuel Behavior}

G. D. Collins

J. T. Cochran

F. D. Coffman

M. D. Dermer

R. E. Murata

P. E. Novak

H. C. Pfefferlen

D. E. Plumlee

D. L. Brown

R. H. Eymann

J. Haggarty

R. H. Jones

\section{TASK C-Safety Experimentation}

J. H. Field

F. J. Lamphere

T. Hikido

G. L. Stimmell

G. Thomas

F. Aquino

D. Freeman

R. H. Eymann

\section{TASK E-Fuel Properties and}

Performance Evaluation

R. R. Asamoto

P. E. Bohaboy

R. N. Duncan

D. A. Cantley

G. F. Melde

K. J. Perry

B. F. Rubin

\section{TASK F-Integral Fast Flux Irradiations}
A. L. Barzin
W. Kimball
P. E. Bohaboy
H. Rosenbaum

D. A. Cantley

C. N. Craig

R. N. Duncan

G. R. Hull

L. S. Lee

R. C. Nelson

F. H. Scott

E. Aitken

K. Evans

TASK G-Core Neutronics, Thermal Hydraulics and Safety Analysis
W. Meinhardt
P. Greebler
J. Field
B. Hutchins
R. Stuart
M. Kelley
P. Magee
L. Price
D. Bullington
R. Protsik
D. Bender
J. Turner
S. Oldberg
R. Seymour
D. Hines
R. Evatt
F. Acquino
C. Hillsman
R. Thompson
P. Vaughan
S. Weber
H. Kleijn
S. Crick
J. Stephen
C. Cowan
J. Cox
D. Freeman
J. Telles

TASK L-Cladding Development
J. J. Albanses
T. A. Lauritzen
C. F. Barrett
A. Montes
L. Brown
R. P. Rhoades
H. J. Busboom
H. Saethre
F. A. Comprelli
W. K. Wagner
R. Erwin
A. Withop
R. H. Eymann
U. E. Wolff
J. P. Ferguson
D. L. Zimmerman
D. H. Frisby 


\section{DISTRIBUTION LIST}

Copies

Director, Contracts Division U. S. Atomic Energy Commission San Francisco Operations Office 2111 Bancroft Hay

Berkeley, California 94704

Chief, California Patent Group U. S. Atomic Energy Commission San Francisco Operations Office P. 0. Box 808

Livermore, California 94551

Division of Reactor Development and Technology

U.S. Atomic Energy Commission

Washington, D. C. 20545

Attn: Asst. Director for Reactor Engineering

Division of Reactor Development and Technology

U.S. Atomic Energy Commission

Washington, D. C. 20545

Attn: M. J. Whitman Asst. Director for Program Analys is

Division of Reactor Development and Technology

U.S. Atomic Energy Commission

Washington, D. C. 20545

Attn: A. Giambusso

Asst. Director for Project Mgmt (Attn: R. Sweek, G. Wensch, J. Morabito)

Division of Reactor Development and Technology

U.S. Atomic Energy Commission

Washington, D. C. 20545

Attn: J. A. Lieberman Asst. Director for Nuclear Safety

Division of Reactor Development and Technology

U.S. Atomic Energy Commission

Washington, D. C. 20545

Attn: J. W. Crawford Asst. Director for Plant Engineering

Division of Reactor Development and Technology

U.S. Atomic Energy Commission

Washington, D. C. 20545

Attn: R. H. Steel Division of Naval Reactors

Division of Reactor Development and Technology

U.S. Atomic Energy Commission

Washington, D. C. 20545

Attn: E. E. Sinclair

Asst. Director for Reactor Tech. (Attn: J.M.Simmons/I.Zartman)
RDT Site office

Copies

U.S. Ntomic Energy Commission

c/o General Electric Company

310 DeGuigne Drive

Sunnyvale, California

Attn: J.V. Levy

LMFBR Program Office

Argonne National Laboratory

9800 South Cass Avenue

Argonne, Illinois 60439

Attn: A. Amorosi, Director

LMFBR Program 0ffice

Argonne National Laboratory

9800 South Cass Avenue

Argonne, Illinois 60439

Attn: L. R. Kelman

Atomics International

P. 0. Box 309

Canoga Park, Cal.jifornia 91304

Attn: S. Golan

Director

Liquid Metals Information Center

P. 0. Box 309

Canoga Park, California 91305

The Babcock \& Wilcox Company

Atomic Energy Division

Lynchburg, Virginia 24501

Attn. M. W. Croft

Mr. L. W. Fromm, Manager

1000 MWle LMFBR Follow-On Study Project

Building 208

Argonne National Laboratory

9800 South Cass Avenue

Argonne, Illinois 60439

Mr. C. A. Anderson, Project Mgr

1000 MWe LMFBR Follow-On Study

Westinghouse Electric Corporation

Advanced Reactors Division

Waltz Mill Site

P. 0. Box 158

Madison, Pennsylvania 15663

FFTF Project

P. 0. Box 220

Richland, Washington 99352

Attn: Configuration \& Data Management

W. P. Staker, Project Manager

1000 MWe LMFBR Follow-On Study

Combustion Engineering, Inc.

P. 0. Box 500

Windsor, Connecticut 06095

RDT Senior Site Representative

U.S. Atomic Energy Commission

P. 0. Box 2325

San Diego, California 92112 
RDT Senior Site Representative Canoga Park Area Office P. 0. Box 591 Canoga Park, California 91305

RDT Senior Site Representative U.S. Atomic Energy Commission Argonne National Laboratory 9800 South Cass Nvenue Argonne, Illinois 60439

RDT Site Office U.S. Ntomic Energy Commission Atomic Power Development

Associates, Inc.

1911 First Street

Detroit, Michigan 48226

RDT Senior Site Representative 0ak Ridge llational Laboratory P. 0. Box X

Oak. Ridge, Tennessee 37830

RDT Senior Site Representative U.S. Atomic Energy Commission P. 0. Box 550

Richland, Washington 99352

RDT Site Representative

U.S. Atomic Energy Commission

Post Office Box 2108

Idaho Falls, Idaho 83401

RDT Site Representative

U.S. Atomic Energy Commission

United Nuclear Cornoration

Grasslands Road

Elmsford, New York 10523

Attn: M. Nanack

RDT Site Representative

U.S. Atomic Energy Commission

United Nuclear Corporation

Grasslands Road

Elmsford, New York 10523

Attn: A. Strasser

Argonne National Laboratory 9800 South Cass Avenue

Argonne, Illinois 60439

Attn: J. H. Kittel

Argonne National Laboratory 9800 South Cass Avenue Argonne, Illinois 60439

Attn: R. C. Vogel

Pacific Nlorthwest Laboratory P. 0. Box 999

Richland, Washington 99352

Attn: E. A. Eschbach

Pacific Northwest Laboratory P. 0. Lox 999

Richland, Washington 99352

Attn: E. A. Evans
University of California

Lawrence Radiation Laboratory

P. 0. Box 808

Livermore, California 94551

Attn: A. Rothman

1

Los Alamos Scientific Laboratory

P. 0. Box 1663

Los Alamos, Nlew Mexico 87544

Attn: R. D. Baker

1

Los Alamos Scientific Laboratory

P. 0. Box 1663

Los Alamos, New Mexico 87544

Attn: D. B. Hall

Los Alamos Scientific Laboratory P. 0. Box 1663

Los Alamos, New Mexico 87544

Attn: W. R. Wykoff

Los Alamos Scientific Laboratory P. 0. Box 1663

1

Los Alamos, New Mexico 87544

Attn: Reports Librarian

Westinghouse Electric Corporation Bettis Atomic Power Laboratory P. 0. Box 79

West Mifflin, Pennsylvania

Attn: E. J. Kreh

Oak Ridge National Laboratory

P. 0. Box X

1

Oak Ridge, Tennessee 37830

Attn: J. E. Cunningham

Brookhaven National Laboratory

Upton, New York 11973

Attn: 0. E. Dwyer

1

Battelle Memorial Institute

Columbus Laboratories

505 King Avenue

Columbus, Ohio 43201

Attn: D. Keller

Atomics International

P. 0. Box 309

Canoga Park, California 91304

Attn: H. Pearlman

Atomics International

P. 0. Box 309

Canoga Park, California 91304

Attn: FBR Project Manager

(R. J. Beeley)

1

Dow Chemical Company

Rock Flats Division

P. 0. Box 888

Golden, Colorado 80401

Attn: R. D. Forest

Scientific Representative

U.S. Atomic Energy Commission American Embassy

APO San Francisco 96503

1

1

1

1

1 


\section{DISTRIBUTION LIST (Continued)}

Copies

U.S. AEC Scientific Representative United States Embassy

Paris, France

APO New York 09777

Senior U.S. AEC Representative

U.S. Mission to the European

Communities

United States Embassy

Brussels, Belgium

Division of Technical Information Extension

U.S. Atomic Energy Commission

P. 0. Box 62

Oak Ridge, Tennessee 37831

Dr. John C. Hoodhouse

1 Guest Lane

Wilmington, Delaware 19809

Poiver Reactor Development Corp.

1911 First Street

Detroit, Michigan 48226

Attn: W. J. McCarthy

irgonne National Laboratory

Idaho Division

P. 0. Box 1096

Idaho Falls, Idaho 83401

Attn: F. A. Thalgott

Detroit Edison Company

1911 First Street

Detroit, Hichigan 48226

Attn: A. S. Griswold

Atomic Power Developuent Associates

1911 First Street

Detroit, Michigan .48226

Attn: A. A. Shoudy

Combustion Engineering, Inc.

Nuclear Division

Prospect Hill Road

Windsor, Connecticut 06095

Attn: W. P. Chernock
1

The Babcock \& bilcox Company

Atomic Energy Uivision

Lynchburg, Virginia 24501

Attn: H. S. Carringer

1

General Atomic

P. 0. Box 603

San Diego, California 92112

Attn: D. B. Coburn

The Cabcock \& Wilcox Company

Alliance Research Center

Alliance, Ohio 44601

Attn: D. Koch

Hestinghouse Electric Corporation Advance Reactors Division

P. 0. Box 217

Cheswick, Pennsylvania 15024

Attn: H. E. Ray

Nuclear llaterials \& Equipment Corp. I

Plutonium Laboratory

Leechburg, Pennsylvania 15656

Attn: William J. Ross

U. S. AEC Scientific Representative 1 United States Embassy

London, England ..

S. F. Stachura

Villa Plein Ciel

Quartier Roussier

Aix-en-Provence

13 - France

S. Visner

Nuclear Uivision

Combustion Engineering, Inc.

P. 0. Box 500

- Windsor, Connecticut 06095

1

The Babcock \& Wilcox Company

Atomic Enerny Division

Lynchburg, Virginia 24501

nttn: S. II. Esleeck 